
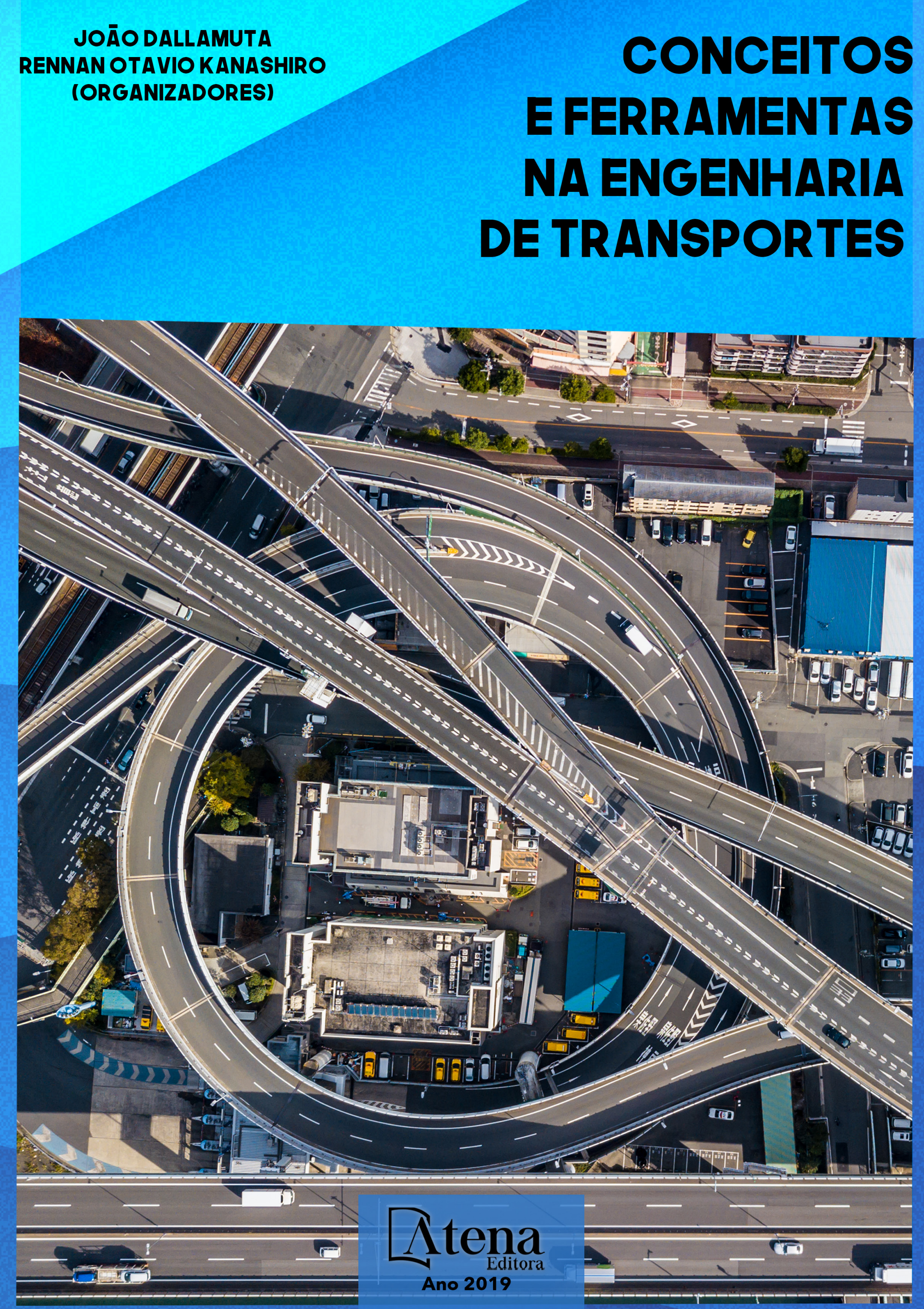
João Dallamuta

Rennan Otavio Kanashiro

(Organizadores)

\title{
Conceitos e Ferramentas na Engenharia de Transportes
}

\author{
Atena Editora \\ 2019
}




\author{
2019 by Atena Editora \\ Copyright (C) Atena Editora \\ Copyright do Texto @ 2019 Os Autores \\ Copyright da Edição (c) 2019 Atena Editora \\ Editora Executiva: Prof ${ }^{\mathrm{a}}$ Dr $^{\mathrm{a}}$ Antonella Carvalho de Oliveira \\ Diagramação: Rafael Sandrini Filho \\ Edição de Arte: Lorena Prestes \\ Revisão: Os Autores
}

O conteúdo dos artigos e seus dados em sua forma, correção e confiabilidade são de responsabilidade exclusiva dos autores. Permitido o download da obra e o compartilhamento desde que sejam atribuídos créditos aos autores, mas sem a possibilidade de alterá-la de nenhuma forma ou utilizá-la para fins comerciais.

\title{
Conselho Editorial
}

\section{Ciências Humanas e Sociais Aplicadas}

Prof. Dr. Álvaro Augusto de Borba Barreto - Universidade Federal de Pelotas

Prof. Dr. Antonio Carlos Frasson - Universidade Tecnológica Federal do Paraná

Prof. Dr. Antonio Isidro-Filho - Universidade de Brasília

Prof. Dr. Constantino Ribeiro de Oliveira Junior - Universidade Estadual de Ponta Grossa

Prof ${ }^{a}{ }^{a}{ }^{a}$ Cristina Gaio - Universidade de Lisboa

Prof. Dr. Deyvison de Lima Oliveira - Universidade Federal de Rondônia

Prof. Dr. Gilmei Fleck - Universidade Estadual do Oeste do Paraná

Prof $^{a} \mathrm{Dr}^{\mathrm{a}}$ Ivone Goulart Lopes - Istituto Internazionele delle Figlie de Maria Ausiliatrice

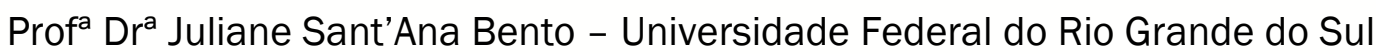

Prof. Dr. Julio Candido de Meirelles Junior - Universidade Federal Fluminense

Prof $^{a}$ Dr $^{a}$ Lina Maria Gonçalves - Universidade Federal do Tocantins

Prof $^{a}$ Dr $^{a}$ Natiéli Piovesan - Instituto Federal do Rio Grande do Norte

Prof $^{a}$ Dr $^{\text {a }}$ Paola Andressa Scortegagna - Universidade Estadual de Ponta Grossa

Prof. Dr. Urandi João Rodrigues Junior - Universidade Federal do Oeste do Pará

Prof $^{\mathrm{a}}$ Dr $^{\mathrm{a}}$ Vanessa Bordin Viera - Universidade Federal de Campina Grande

Prof. Dr. Willian Douglas Guilherme - Universidade Federal do Tocantins

\section{Ciências Agrárias e Multidisciplinar}

Prof. Dr. Alan Mario Zuffo - Universidade Federal de Mato Grosso do Sul

Prof. Dr. Alexandre Igor Azevedo Pereira - Instituto Federal Goiano

Prof ${ }^{a}$ Dr$^{a}$ Daiane Garabeli Trojan - Universidade Norte do Paraná

Prof. Dr. Darllan Collins da Cunha e Silva - Universidade Estadual Paulista

Prof. Dr. Fábio Steiner - Universidade Estadual de Mato Grosso do Sul

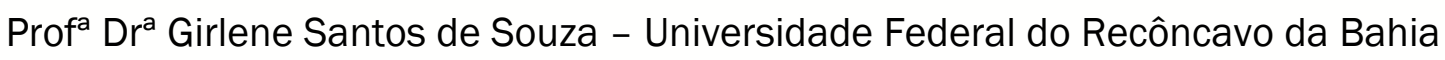

Prof. Dr. Jorge González Aguilera - Universidade Federal de Mato Grosso do Sul

Prof. Dr. Ronilson Freitas de Souza - Universidade do Estado do Pará

Prof. Dr. Valdemar Antonio Paffaro Junior - Universidade Federal de Alfenas 


\section{Ciências Biológicas e da Saúde}

Prof. Dr. Gianfábio Pimentel Franco - Universidade Federal de Santa Maria

Prof. Dr. Benedito Rodrigues da Silva Neto - Universidade Federal de Goiás

Prof. ${ }^{a}$ Dr. ${ }^{a}$ Elane Schwinden Prudêncio - Universidade Federal de Santa Catarina

Prof. Dr. José Max Barbosa de Oliveira Junior - Universidade Federal do Oeste do Pará

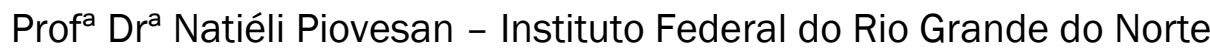

Prof $^{a}$ Dr $^{\text {a }}$ Raissa Rachel Salustriano da Silva Matos - Universidade Federal do Maranhão

Prof $^{\mathrm{a}} \mathrm{Dr}^{\mathrm{a}}$ Vanessa Lima Gonçalves - Universidade Estadual de Ponta Grossa

Prof $^{a}$ Dr $^{a}$ Vanessa Bordin Viera - Universidade Federal de Campina Grande

\section{Ciências Exatas e da Terra e Engenharias}

Prof. Dr. Adélio Alcino Sampaio Castro Machado - Universidade do Porto

Prof. Dr. Eloi Rufato Junior - Universidade Tecnológica Federal do Paraná

Prof. Dr. Fabrício Menezes Ramos - Instituto Federal do Pará

Prof $^{a}$ Dr $^{a}$ Natiéli Piovesan - Instituto Federal do Rio Grande do Norte

Prof. Dr. Takeshy Tachizawa - Faculdade de Campo Limpo Paulista

\section{Conselho Técnico Científico}

Prof. Msc. Abrãao Carvalho Nogueira - Universidade Federal do Espírito Santo

Prof. ${ }^{a}$ Dr ${ }^{a}$ Andreza Lopes - Instituto de Pesquisa e Desenvolvimento Acadêmico

Prof. Msc. Carlos Antônio dos Santos - Universidade Federal Rural do Rio de Janeiro

Prof. ${ }^{a}$ Msc. Jaqueline Oliveira Rezende - Universidade Federal de Uberlândia

Prof. Msc. Leonardo Tullio - Universidade Estadual de Ponta Grossa

Prof. Dr. Welleson Feitosa Gazel - Universidade Paulista

Prof. Msc. André Flávio Gonçalves Silva - Universidade Federal do Maranhão

Prof. ${ }^{a}$ Msc. Renata Luciane Polsaque Young Blood - UniSecal

Prof. Msc. Daniel da Silva Miranda - Universidade Federal do Pará

\begin{tabular}{|c|}
\hline $\begin{array}{c}\text { Dados Internacionais de Catalogação na Publicação (CIP) } \\
\text { (eDOC BRASIL, Belo Horizonte/MG) }\end{array}$ \\
\hline C744 $\begin{array}{c}\text { Conceitos e ferramentas na engenharia de transportes [recurso } \\
\text { eletrônico] / Organizadores João Dallamuta, Rennan Otavio } \\
\text { Kanashiro. - Ponta Grossa, PR: Atena Editora, } 2019 .\end{array}$ \\
Formato: PDF \\
Requisitos de sistema: Adobe Acrobat Reader \\
Modo de acesso: World Wide Web \\
Inclui bibliografia \\
ISBN 978-85-7247-352-1 \\
DOI 10.22533/at.ed.521192405 \\
1. Engenharia de transportes - Pesquisa - Brasil. I. Dallamuta, \\
João. II. Kanashiro, Otavio. \\
Elaborado por Maurício Amormino Júnior - CRB6/2422 629.04 \\
Ptena Editora \\
Ponta Grossa - Paraná - Brasil \\
contato@atenaeditora.com.br
\end{tabular}




\section{APRESENTAÇÃO}

Esta obra é composta por pesquisas realizadas por professores, alunos de graduação e pós-graduaçãocujas linhas de pesquisa procura modelar e propor soluções para problemas práticos de transporte, sobretudo no cenário brasileiro

Os desafios da engenharia de transporte envolvem aspectos técnicos inerentes ao oficio de engenheiro, mas sobretudo humanos, uma vez que envolve diretamente questões ligadas a segurança. Segundo a Organização Mundial de Saúde (OMS) o Brasil ocupa oquinto lugar entre os países recordistas em mortes no trânsito, atrás somente da Índia, China, Estados Unidos e Rússia. Considerando que dentre estas nações, apenas a Rússia apresenta população inferior a brasileiratemos um trânsito violento tanto em indicadores absolutos quando proporcionais.

Outros aspectos importantes no cenário de engenharia aplicada a problemas de trânsito é a eficiência. Temos uma matriz de transporte basicamente rodoviária e um ambiente regulatório e político complexo para mudar este cenário, via de regra nossos pesquisadores modelam e otimizam em cima de condições de contorno que não são nem de longe as melhores, como no dito popular, tiram leite de pedra. Ganhos de eficiência mesmo que pequenos, no Brasil são importantes, haja vista o cenário custoso (em valores monetários, tempo e riscos) que temos no Brasil.

E por fim, destacamos a importância da sustentabilidade. Há pouco mais de 40 anos atrás demos uma resposta a um problema, que na época era econômico e não de sustentabilidade, com o Proálcool. Atualmente novos desafios de sustentabilidade irão gerar impacto na engenharia de transporte. O biodiesel, veículos híbridos, elétricos e novas exigências legais de construção de vias tanto urbanas quando intermunicipais, devem provocar mudanças nos paradigmas atuais.

Esta obra reunimos aspectos demodelagem, otimização e estudos problemas práticos. Também são abordadas pesquisas nascom resultados áreas de construção e urbanismo. Todos os trabalhos com discussões de resultados e contribuições genuínas em suas áreas de conhecimento.

Boa leitura.

João Dallamuta

Rennan Otavio Kanashiro 


\section{SUMÁRIO}

CAPÍTULO 1 .1

USO DE MODELAGEM DINÂMICA DE SISTEMAS CONECTADA A UM SIG PARA A GERÊNCIA DE PAVIMENTOS URBANOS

José Leomar Fernandes Júnior

Simone Becker Lopes

DOI 10.22533/at.ed.5211924051

CAPÍTULO 2 15

MODELOS DE CONTROLE SEMAFÓRICO PARA OTIMIZAÇÃO DE FLUXO DE TRÁFEGO EM VIAS URBANAS

Ana Caroline Meireles Soares

João Viana da Fonseca Neto

Patrícia Helena Moraes Rêgo

DOI 10.22533/at.ed.5211924052

CAPÍTULO 3 26

MODELAGEM DE UMA REDE LOGISTICA REVERSA PARA COLETA E TRANSPORTE DE RESÍDUOS SÓLIDOS URBANOS

Adelaida Pallavicini Fonseca

Milton Jonás Monteiro

José Antonio Rodríguez Melquiades

DOI 10.22533/at.ed.5211924053

CAPÍTULO 4 44

SIMILARIDADES E DISSIMILITUDES DAS CARACTERÍSTICAS DOS CORREDORES DE TRANSPORTE PÚBLICO EM CIDADES GLOBAIS

Maria Ivana Vanderlei

Leonardo Herszon Meira

Oswaldo Cavalcanti da Costa Lima Neto

DOI 10.22533/at.ed.5211924054

CAPÍTULO 5 60

SHOPPING CENTER COMO ATRATIVO DE CONDOMÍNIOS VERTICAIS E AS INFLUÊNCIAS NO TRÁFEGO VIÁRIO

Maximillian Nascimento da Costa

Jussara Socorro Cury Maciel

DOI 10.22533/at.ed.5211924055

CAPÍTULO 6 72

TRANSPORTES, ACESSIBILIDADE URBANA E AS CALÇADAS NA CIDADE DE SÃO PAULO

Lucas de Souza Ramalhaes Feitosa

Roberto Righi

DOI 10.22533/at.ed.5211924056 
REGULAÇÃO DO USO DO ESPAÇO PÚBLICO EM CIDADES DE PEQUENO PORTE: UMA ANÁLISE TEÓRICA ENTRE AS POLÍTICAS PÚBLICAS, A LEGISLAÇÃO E A PRÁTICA

Dannúbia Ribeiro Pires

Leonardo Herszon Meira

Maria Victória Leal de Almeida Nascimento

DOI 10.22533/at.ed.5211924057

CAPÍTULO 8 104

A RELAÇÃO ENTRE O DESEMPENHO ESCOLAR E MELHORIAS DECORRENTES DE PROGRAMAS DE TRANSPORTE ESCOLAR RURAL: UM ESTUDO EM SANTA MARIA DO CAMBUCÁ - PE

Maria Victória Leal de Almeida Nascimento

Mauricio Oliveira de Andrade

Dannúbia Ribeiro Pires

DOI 10.22533/at.ed.5211924058

CAPÍTULO 9

AVALIAÇÃO DE PROPRIEDADES MECÂNICAS DE MISTURAS ASFÁLTICAS A QUENTE DOSADAS PELA METODOLOGIA SUPERPAVE

Matheus Covelo Machado

Heraldo Nunes Pitanga

Taciano Oliveira da Silva

Adriano de Freitas Teixeira

Valéria Martins da Costa Pena

Giovani Levi Sant'Anna

DOI 10.22533/at.ed.5211924059

CAPÍTULO 10 135

CARACTERÍSTICAS DE VULNERABILIDADE EM IDOSOS E OBESOS NAS TRAVESSIAS DE PEDESTRE

Frederico Souza Gualberto

Janaína Amorim Dias

Heloísa Maria Barbosa

Marcelo Franco Porto

Marconi Gomes da Silva

DOI 10.22533/at.ed.52119240510

CAPÍTULO 11

151

DESASTRES NATURAIS: SELEÇÃO E LOCALIZAÇÃO ESPACIAL DE ABRIGOSPARA FLAGELADOS

Manuela Marques Lalane Nappi

João Carlos Souza

DOI 10.22533/at.ed.52119240511

SOBRE OS ORGANIZADORES 


\section{USO DE MODELAGEM DINÂMICA DE SISTEMAS CONECTADA A UM SIG PARA A GERÊNCIA DE PAVIMENTOS URBANOS}

\section{José Leomar Fernandes Júnior Universidade de São Paulo - Escola de \\ Engenharia de São Carlos}

São Carlos - SP

Simone Becker Lopes

Universidade Federal de Santa Catarina - Centro de Engenharia da Mobilidade

Joinville - SC

RESUMO: Neste trabalho, aplica-se a modelagem dinâmica, com uso do programa Vensim, a um Sistema de Gerência de Pavimentos Urbanos (SPGU), em estudo de caso realizado com dados de cidade brasileira de médio porte. O método desenvolvido aprimora o processo de tomada de decisão por parte dos profissionais responsáveis pela manutenção e reabilitação dos pavimentos, permitindo, também, a compatibilização com o planejamento de intervenções em outras infraestruturas urbanas (água, esgoto, energia elétrica, gás, telefonia etc.), o que pode resultar em significativos benefícios para a sociedade. Todas as vias foram avaliadas e foi feito um diagnóstico da extensão e do nível de severidade de cada tipo de defeito encontrado. Os dados foram inseridos em um banco de dados vinculado a um SIG (Sistema de Informações Geográficas), facilitando o acesso às informações e a visualização dos problemas.
O Sistema de Gerência de Pavimentos Urbanos Dinâmico (SGPUD) constitui um exemplo de processo sinérgico, com transferência de tecnologia para a sociedade, que une o poder público (prefeituras), a universidade e a iniciativa privada, representada pelas empresas prestadoras de serviços na área de infraestrutura urbana.

PALAVRAS-CHAVE: sistemas de gerência; pavimentos urbanos; modelagem dinâmica; SIG.

ABSTRACT: In this work, the dynamic modeling, using the Vensim program, is applied to an Urban Pavement Management System (UPMS), in a case study conducted with data from a mediumsized Brazilian city. The developed method improves the process of decision making by the professionals responsible for the maintenance and rehabilitation of pavements, allowing also the compatibility with the planning of interventions in other urban infrastructures (water, sewage, electricity, gas, telephony etc.). ), which can result in significant benefits to the society. All links were evaluated and a diagnosis was made for each distress type, assessing the extent and level of severity. The data were inserted in a database linked to a GIS (Geographical Information System), facilitating the access to the information and the visualization of the problems. The Dynamic Urban Pavement 
Management System (DUPMS) is an example of a synergistic process, with technology transfer to society, linking public power (prefectures), university and private enterprise, represented by companies providing services in the area of urban infrastructure.

KEYWORDS: management system; urban pavements; dynamic modeling; GIS.

\section{I INTRODUÇÃO}

É inquestionável a importância da utilização de um Sistema de Gerência de Pavimentos (SGP) para se ter um melhor desempenho e a devida alocação de recursos nas atividades de manutenção e reabilitação (ZANCHETTA, 2017). Igualmente inquestionável é que também os SGP devem ser continuamente aprimorados, incorporando novas e melhores ferramentas.

No âmbito das cidades brasileiras de médio e grande porte, nas quais os Sistemas de Gerência de Pavimentos Urbanos (SGPU) poderiam contribuir para a otimização das atividades de manutenção e reabilitação (M\&R) dos pavimentos, ainda tem prevalecido a tomada de decisão de forma aleatória, com base apenas na experiência de alguns profissionais e em decisões políticas, o que tem levado a uma situação de desperdício dos já escassos recursos financeiros, equipamentos e mão de obra.

A falha gerencial envolve a falta de um diagnóstico da condição dos pavimentos, a partir do qual poderiam ser sugeridas estratégias de intervenções, do "nada a fazer" até a "reconstrução", passando pelas "manutenções corretiva e preventiva" e pelo "reforço estrutural", restringindo-se, atualmente, aos reparos de segmentos com necessidades extremas, selecionados com base em reclamação da população, alertas da mídia ou vontade política.

Este trabalho procura contribuir para o desenvolvimento de sistemas de gerência de pavimentos urbanos para cidades de médio e grande porte, com uso de modelagem dinâmica de sistemas, que consiste em estabelecer interações em que a mudança em uma variável afeta outras variáveis, que por sua vez voltam a afetar a variável inicial. O resultado final contempla a definição das estratégias de intervenção para cada segmento, a previsão do custo total das intervenções, a priorização dos segmentos e o ano indicado para a realização das atividades, de acordo com o orçamento anual disponível.

Uma contribuição complementar deste trabalho se dá através do uso de um Sistema de Informação Geográfica (SIG), com o qual é possível gerar mapas temáticos, em que as informações fornecidas pelo modelo de simulação dinâmica são apresentadas de forma visual, o que pode facilitar a análise por parte da equipe responsável pela tomada de decisão quanto às atividades de manutenção e reabilitação dos pavimentos. 


\section{I SISTEMA DE GERÊNCIA DE PAVIMENTOS URBANOS DINÂMICO}

Um Sistema de Gerência de Pavimentos (SGP), segundo Haas et al. (1994), consiste na coordenação das atividades de planejamento, projeto, construção, manutenção, avaliação e pesquisa de pavimentos, com o objetivo de utilizar informações confiáveis para obter o máximo retorno com os recursos disponíveis.

Quando se trabalha em nível de rede, como é o caso deste estudo, utilizamse informações abrangendo toda a malha viária, procurando-se tomar decisões relacionadas ao planejamento e programação das intervenções. São definidos os segmentos da malha viária e são coletados dados referentes a cada trecho, como idade, estrutura do pavimento, histórico das intervenções, condição do pavimento, classificação funcional e volume de tráfego (LOPES et al., 2008), com base nos quais é feita a tomada de decisão (Figura 1).

\subsection{Modelagem Dinâmica}

Um sistema de modelagem dinâmica é aquele no qual se permite ter um entendimento de como todos os elementos interagem entre si, de modo que a mudança em uma variável afeta outras variáveis do sistema, até que estas últimas voltem a afetar a variável inicial.

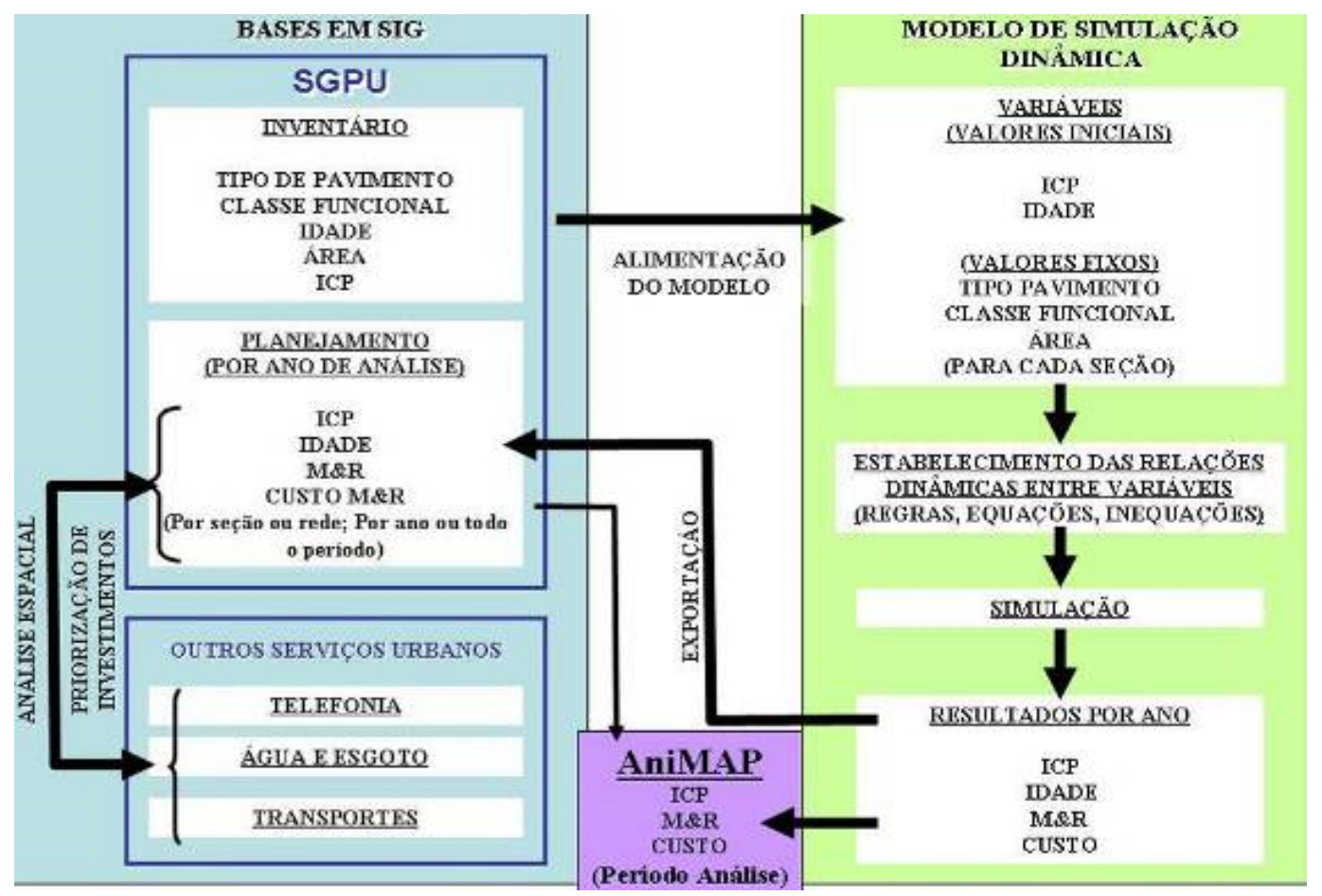

Figura 1: Fluxograma do método de análise proposto

Para a aplicação da Dinâmica de Sistemas foi utilizado o software Vensim, que possui versões acadêmicas distribuídas gratuitamente. É possível representar facilmente um modelo mental através da modelagem visual, escrevendo as variáveis na tela do programa e definindo suas relações com setas, sendo possível, também, definir o modelo formal através das equações matemáticas, que regem o comportamento de 
cada variável. Através da simulação e análise dos resultados, expressos na forma de gráficos e tabelas, pode-se aprimorar o modelo e melhorar o processo. Com esta ferramenta os dados são trabalhados de modo a se obter informações que respondam as perguntas: Onde realizar atividades de M\&R? Quais atividades realizar? Qual será o custo dessas atividades? Quando realizar tais atividades?

\subsection{Sistema de Informações Geográficas}

Um Sistema de Informações Geográficas (SIG) consiste em um conjunto de ferramentas capaz de adquirir, armazenar, transformar e emitir informações espaciais e não-espaciais. (SILVA et al., 2008). Assim, é inquestionável que os sistemas de transportes sejam uma das áreas nas quais o SIG pode desempenhar um importante papel.

Após utilizar o programa Vensim para se obter as informações desejadas sobre quais, onde e quando realizar atividades de M\&R, um SIG pode ser utilizado para transformar as informações em imagens, através de mapas temáticos, que permitem mostrar os cenários atuais e fazer previsões de cenários futuros.

\section{I MONTAGEM DO MODELO DE SGPUD}

\subsection{Diagrama de Relações Causais}

A primeira etapa para a construção de um modelo dinâmico é a criação de diagramas causais, ou seja, diagramas que permitam visualizar, através de setas, qual a interação entre as variáveis consideradas. É possível observar quais fatores influenciam cada variável e quais e são influenciados por elas.

No caso do modelo utilizado para este estudo, as variáveis se relacionam da seguinte forma:

- O ICP, a idade, o VDM e a classe funcional determinam o Índice de Prioridade (IP) de cada trecho;

- O IP determina a ordem em que os trechos devem receber as atividades de manutenção;

- A atividade de M\&R de cada trecho é determinada em função do ICP, da idade e do VDM;

- A partir da ordem definida, o custo unitário de cada atividade de M\&R e o orçamento anual disponível determinam quais trechos devem receber manutenção a cada ano.

Conforme um trecho recebe uma atividade de manutenção, seu ICP é modificado, retornando ao começo do ciclo. A Figura 2 apresenta um modelo simples de Diagrama de Relações Causais, que serviu de ponto de partida para os modelos desenvolvidos neste estudo, em que foram considerados os seguintes fatores: Índice de Condição do 
Pavimento (ICP); idade do pavimento; Volume Diário Médio (VDM) e classe funcional da via (arterial, coletora, local).

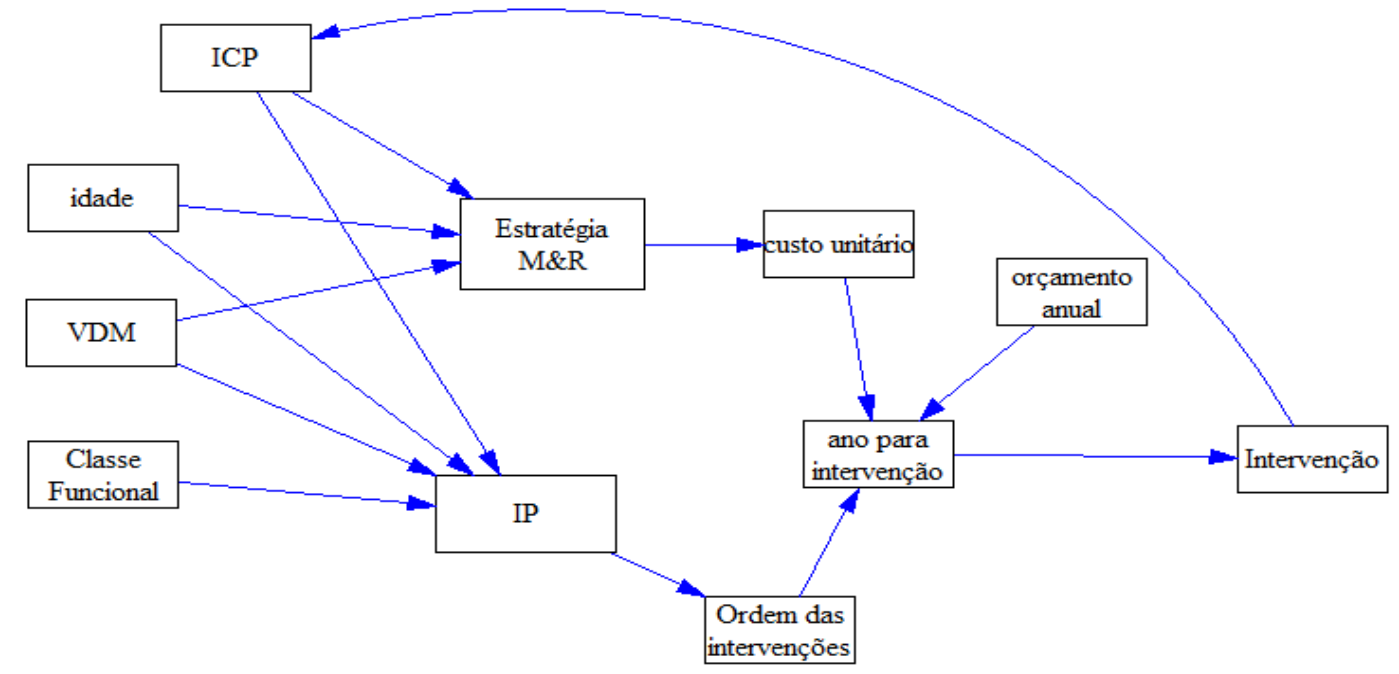

Figura 2: Diagrama de Relações Causais inicial de um SGPU

O conceito de ICP (Índice de Condição do Pavimento) foi desenvolvido na década de setenta pelo Corpo de Engenheiros do Exército dos Estados Unidos (USACE) com o intuito de quantificar a condição de pavimentos de estradas militares, ruas e áreas de estacionamento. Pode ser avaliado subjetivamente ou calculado a partir de resultados de uma avaliação de defeitos no campo, na qual se registram os tipos de defeitos encontrados e sua severidade e extensão. A partir destas informações são deduzidos pontos de um total de 100, em que 100 é o limite superior da condição muito boa e 0 é o limite inferior da condição muito ruim.

A idade do pavimento é o tempo transcorrido desde a sua construção, exceto nos casos em que já houve alguma atividade de reabilitação na via, como reforço ou reconstrução. Nestes casos, no momento em que a atividade é realizada, pode-se considerar que a idade do pavimento volta a "zero", já que as atividades de reabilitação têm como característica uma mudança na estrutura do pavimento, deixando-o com características semelhantes às características de um pavimento novo.

O tráfego pode ser quantificado pelo volume diário médio (VDM), que é o volume médio de tráfego referente a 24 horas, num certo local. Quanto à classificação funcional, o Código Brasileiro de Trânsito estabelece que as vias urbanas podem ser divididas em quatro classes funcionais: vias de trânsito rápido, via arterial, via coletora e via local. Via de trânsito rápido é aquela caracterizada por acessos especiais, com trânsito livre, sem interseções em nível, sem acessibilidade direta aos lotes lindeiros e sem travessia de pedestres em nível. Via arterial é aquela caracterizada por interseções em nível, geralmente controlada por semáforo, com acessibilidade aos lotes lindeiros e às vias secundárias e locais, possibilitando o trânsito entre as regiões da cidade. Via coletora é aquela destinada a coletar e distribuir o trânsito que tenha necessidade de 
entrar ou sair das vias de trânsito rápido ou arteriais, possibilitando o trânsito dentro das regiões da cidade. E via local, por fim, é aquela caracterizada por interseções em nível não semaforizadas, destinada apenas ao acesso local ou a áreas restritas.

Cada uma das variáveis tem um comportamento que varia com o tempo e podem ser descritas de maneiras distintas. Esta mudança temporal de comportamento é de grande importância para a modelagem dinâmica, já que a situação encontrada hoje não é a mesma que será encontrada após alguns anos, interferindo assim nos resultados finais. A unidade de tempo utilizada será um ano.

A idade do pavimento evolui proporcionalmente ao tempo, sendo que sua contagem recomeça quando é realizada alguma atividade de reabilitação na via. Por sua vez, a classe funcional de uma via tende a não mudar quando se olha um período de tempo como o desta análise (oito anos), a não ser que haja algum projeto especial com este objetivo, que pode ser desde uma mudança no tráfego de um conjunto de ruas, que pode levar uma via local a funcionar como via coletora, ou medidas de moderação do tráfego ("traffic-calming"), que pode retirar o fluxo intenso de uma rua e fazer com que ela deixe de ser coletora e passe a ser local, ou até mesmo fazer com que uma via local vire uma via de pedestres.

O ICP tende a diminuir com o tempo, em função das solicitações do tráfego, das intempéries e do próprio envelhecimento. Zerbini (1999) desenvolveu, com base nos dados da cidade de Araraquara, equações que descrevem o comportamento do ICP com o tempo, para cada tipo de classe funcional e histórico de manutenção das vias. As equações são apresentadas na Tabela 1, em que:

- $\quad$ ICP = Índice de Condição do Pavimento após t anos;

- $t=$ anos decorridos da avaliação.

\begin{tabular}{lll}
\hline & Com Manutenção & Sem Manutenção \\
\hline Vias Arteriais & $I C P=97,95 \cdot 0,9920^{t}$ & $I C P=96,81 \cdot 0,9910^{t}$ \\
\hline Vias Coletoras & $I C P=98,53 \cdot 0,9940^{t}$ & $I C P=97,87 \cdot 0,9930^{t}$ \\
\hline Vias Locais & ICP $=98,89 \cdot 0,9940^{\mathrm{t}}$ & $I C P=97,87 \cdot 0,9930^{t}$ \\
\hline
\end{tabular}

Tabela 1: Equações dos modelos de desempenho desenvolvidos por Zerbini (1999)

Com o objetivo de adaptar as equações disponíveis para uma situação na qual se tenha as informações atuais dos pavimentos, porém não se conhece a sua idade, é proposto o uso do ICP (ICP inicial), que é a condição do pavimento no momento inicial da análise. Dessa forma, a degradação do pavimento começa a ser contada do momento em que a avaliação é feita e acontece de forma constante, conforme apresentado na Tabela 2, em que:

- $\quad \mathrm{ICP}_{\mathrm{t}}=$ Índice de Condição do Pavimento após t anos; 
- $\quad \mathrm{ICP}_{\mathrm{i}}=$ Índice de Condição do Pavimento no momento da avaliação;

- $\mathrm{t}=$ anos decorridos da avaliação.

\begin{tabular}{lll}
\hline & Com Manutenção & Sem Manutenção \\
\hline Vias Expressas e Arteriais & $I C P_{\mathrm{t}}=I C P_{\mathrm{i}} \cdot 0,9920^{t}$ & $I C P_{\mathrm{t}}=I C P_{\mathrm{i}} \cdot 0,9910^{t}$ \\
\hline Vias Coletoras e Locais & $I C P_{\mathrm{t}}=I C P_{i} \cdot 0,9940^{t}$ & $I C P_{\mathrm{t}}=I C P_{i} \cdot 0,9930^{t}$ \\
\hline
\end{tabular}

Tabela 2: Equações propostas para medida de desempenho do pavimento em situações onde não há registro da idade do pavimento

O VDM, com o passar dos anos, evolui de acordo com a Equação 1:

$$
V D M_{n}=V D M_{0}(1+i)^{n}
$$

Sendo:

- $\operatorname{VDM}_{\mathrm{n}}=$ VDM no ano $\mathrm{n}$;

- $\mathrm{VDM}_{0}=\mathrm{VDM}$ no ano zero;

- $\mathrm{n}=$ anos;

- $\quad \mathrm{i}=$ taxa de crescimento do VDM, adotada igual a 5\% neste trabalho.

\section{2 Índice de Prioridade}

Para se definir quais vias têm prioridade no recebimento das atividades de manutenção ou reabilitação, é utilizado um Índice de Prioridade (IP), determinado em função do ICP, da idade, do VDM e da classe funcional da via (Equação 2). Os cinco níveis dos fatores considerados no cálculo do IP são apresentados na Tabela 3.

$$
I P=0,7\left[\left(n i v_{-} I C P-1\right) \cdot 5+\text { niv_IDADE }\right]+0,3[(\text { niv_VDM-1) } 3+\text { niv_CF }]
$$

em que:

- $\quad$ IP = índice de prioridade;

- $\quad$ niv_ICP = nível no qual se enquadra o ICP da via;

- $\quad$ niv_IDADE = nível no qual se enquadra a idade da via;

- $\quad$ niv_VDM = nível no qual se enquadra o VDM da via;

- niv_CF = nível no qual se enquadra a classe funcional da via. 


\begin{tabular}{|c|c|c|c|c|c|}
\hline $\begin{array}{l}\text { ICP } \\
(0-100)\end{array}$ & $\begin{array}{c}1 \\
\text { Muito Ruim } \\
0-30\end{array}$ & $\begin{array}{c}2 \\
\text { Ruim } \\
30-50\end{array}$ & $\begin{array}{c}3 \\
\text { Regular } \\
50-70\end{array}$ & $\begin{array}{c}4 \\
\text { Bom } \\
70-90\end{array}$ & $\begin{array}{c}5 \\
\text { Muito Bom } \\
90-100\end{array}$ \\
\hline $\begin{array}{l}\text { IDADE } \\
\text { (anos) }\end{array}$ & $\begin{array}{c}1 \\
\text { Muito Velho } \\
>20\end{array}$ & $\begin{array}{c}2 \\
\text { Velho } \\
20-15\end{array}$ & $\begin{array}{c}3 \\
\text { Regular } \\
15-10\end{array}$ & $\begin{array}{c}4 \\
\text { Novo } \\
10-5\end{array}$ & $\begin{array}{c} \\
\text { Muito Novo } \\
<5\end{array}$ \\
\hline $\begin{array}{l}\text { VDM } \\
\text { (UVP/1000) }\end{array}$ & $\begin{array}{c}1 \\
\text { Muito Alto } \\
>30\end{array}$ & $\begin{array}{c}2 \\
\text { Alto } \\
30-15\end{array}$ & $\begin{array}{c}3 \\
\text { Regular } \\
15-5\end{array}$ & $\begin{array}{c}4 \\
\text { Baixo } \\
5-1\end{array}$ & $\begin{array}{c} \\
\text { Muito Baixo } \\
<1\end{array}$ \\
\hline
\end{tabular}

Tabela 3: Definição dos níveis dos fatores ICP, Idade e VDM

\subsection{Escolha da Estratégia de M\&R}

De acordo com as informações disponíveis sobre cada pavimento, é possível fazer a escolha da atividade de M\&R que deve ser realizada no trecho, de modo que atenda às suas necessidades. A técnica de apoio à decisão utilizada neste trabalho foi a Árvore de Decisão (Fernandes Jr. et al., 2006), sendo a estratégia de M\&R escolhida em função do ICP, da Idade e do VDM do segmento analisado. Os fatores de entrada são considerados em níveis, como apresentado na Tabela 3, e as Estratégias disponíveis são as apresentadas na Tabela 4.

\subsection{Fator de Decisão: Custo}

Pesquisa realizada por Lima (2007), com respostas de diversos municípios brasileiros de médio porte, constatou que um dos fatores mais levados em consideração na hora da decisão sobre qual trecho deve sofrer intervenção é o custo, pois o orçamento anual disponível é um fator limitante. Assim, neste trabalho, após a hierarquização de todos os trechos, de acordo com o IP, e da determinação, para cada um deles, da melhor estratégia de manutenção ou reabilitação, calcula-se o custo total da intervenção recomendada para cada trecho a partir do custo unitário e da área que necessita de manutenção. Com o custo acumulado, na ordem decrescente de prioridade, e conhecendo-se o orçamento anual disponível, determinam-se quais atividades podem ser desenvolvidas naquele ano e quais devem ser feitas nos anos seguintes. Além disso, essa análise também pode servir solicitações de dotação orçamentária complementar, a fontes estatais e privadas, inclusive estrangeiras.

\begin{tabular}{ccc}
\hline Estratégia & Descrição & $\begin{array}{c}\text { Custo unitário } \\
\left(\mathbf{R} \$ \mathbf{m}^{2}\right)\end{array}$ \\
\hline $\mathbf{0}$ & Não fazer nada & - \\
\hline $\mathbf{1}$ & Manutenção Corretiva & 2,00 \\
\hline $\mathbf{2}$ & Manutenção Preventiva & 5,00 \\
\hline $\mathbf{3}$ & Reforço Convencional & 18,00 \\
\hline $\mathbf{4}$ & Reforço com Fresagem & 25,00 \\
\hline
\end{tabular}




\section{I TESTE DO SGPUD}

Com o objetivo de testar o uso da ferramenta de modelagem dinâmica a um Sistema de Gerência de Pavimentos Urbanos, foi utilizada, inicialmente, uma base de dados fictícia, com 10 trechos viários homogêneos, ou seja, com características estruturais e funcionais semelhantes dentro do segmento. As características de cada segmento encontram-se na Tabela 5 , que fornece informações relativas à área da seção (largura da via multiplicada pelo comprimento do trecho), à classe funcional (via de trânsito rápido: 1; arterial: 2; coletora: 3; ou local: 4), ao ICP (0 a 100), idade (tempo, em anos, decorrido desde a construção do trecho ou da última atividade de reabilitação) e ao VDM.

O modelo gerado é apresentado na Figura 3, que mostra a tela do programa Vensim, indicando todos os parâmetros envolvidos na análise e as relações entre eles, indicadas por setas.

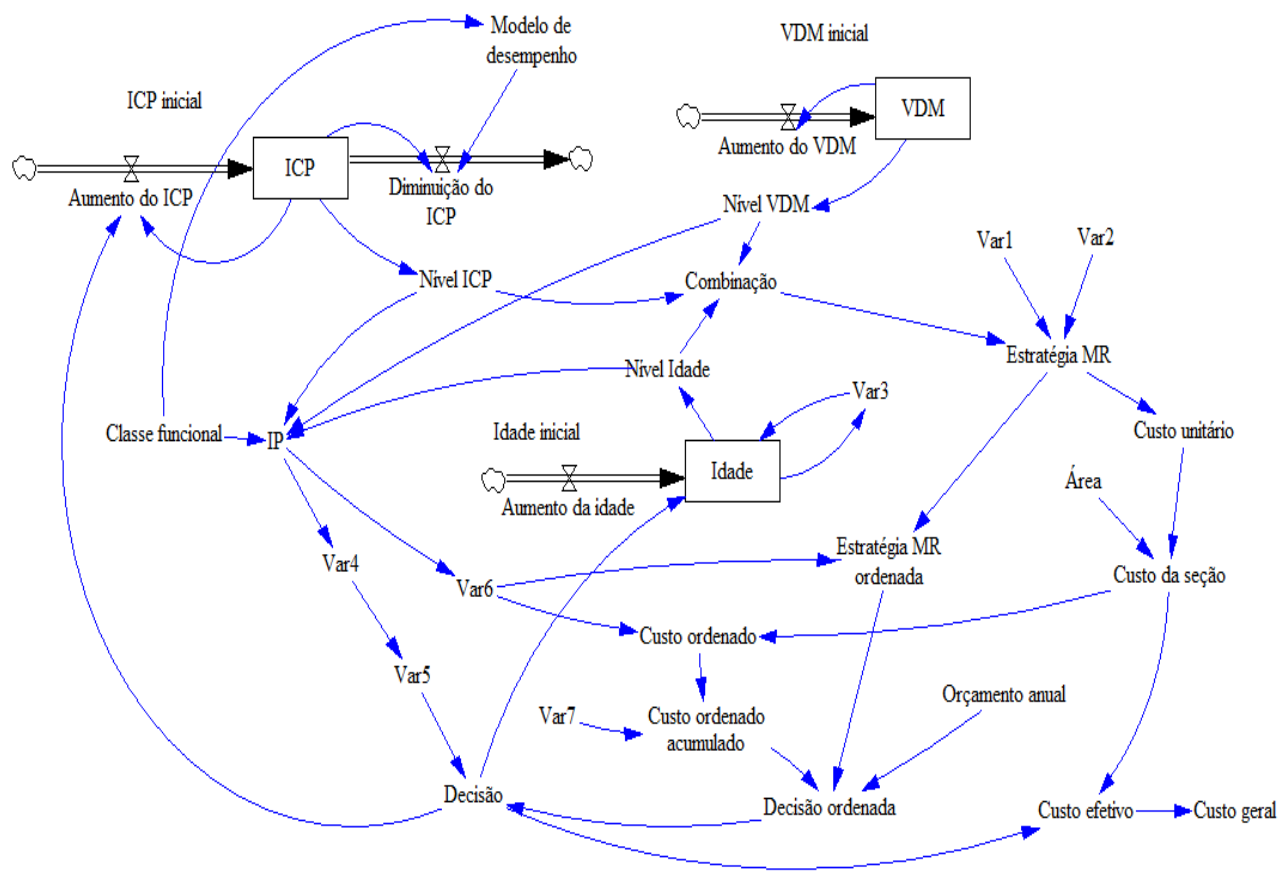

Figura 3: SGPU modelado através do programa Vensim

\begin{tabular}{cccccc}
\hline Segmento & $\begin{array}{c}\text { Área } \\
\left(\mathbf{m}^{2}\right)\end{array}$ & $\begin{array}{c}\text { Classe } \\
\text { Funcional }\end{array}$ & ICP (0-100) & $\begin{array}{c}\text { Idade } \\
(\text { anos })\end{array}$ & $\begin{array}{c}\text { VDM } \\
(\text { UVPs/1000) }\end{array}$ \\
\hline 1 & 1500 & 3 & 80 & 13 & 10 \\
\hline
\end{tabular}




\begin{tabular}{cccccc}
\hline $\mathbf{2}$ & 1500 & 3 & 60 & 15 & 15 \\
\hline $\mathbf{3}$ & 1000 & 4 & 70 & 10 & 7 \\
\hline $\mathbf{4}$ & 1000 & 4 & 35 & 7 & 5 \\
\hline $\mathbf{5}$ & 1000 & 4 & 50 & 5 & 1 \\
\hline $\mathbf{6}$ & 1500 & 2 & 30 & 20 & 30 \\
\hline $\mathbf{7}$ & 1500 & 2 & 60 & 10 & 30 \\
\hline $\mathbf{8}$ & 1000 & 3 & 70 & 7 & 10 \\
\hline $\mathbf{9}$ & 1000 & 4 & 65 & 7 & 5 \\
\hline $\mathbf{1 0}$ & 1000 & 4 & 45 & 2 & 4 \\
\hline
\end{tabular}

Tabela 5: Dados de entrada do modelo

Com o uso do programa Vensim e com os dados dos dez segmentos apresentados na Tabela 5 foi feita uma simulação com período de análise de 8 anos, considerandose o orçamento anual disponível para cada ano igual a $\mathrm{R} \$ 75.000,00$. Foi considerado que, para cada tipo de intervenção, a condição do pavimento é melhorada de acordo com o indicado na Tabela 6.

\begin{tabular}{lcc}
\hline \multicolumn{1}{c}{ Após a Atividade de M\&R: } & O ICP do trecho será: & E sua idade será: \\
\hline Não fazer nada & o mesmo & a mesma \\
\hline Manutenção Corretiva & 80 & a mesma \\
\hline Manutenção Preventiva & 85 & a mesma \\
\hline Reforço Convencional & 90 & 0 (zero) \\
\hline Reforço com Fresagem & 95 & 0 (zero) \\
\hline Reconstrução & 100 & 0 (zero) \\
\hline
\end{tabular}

Tabela 6: Valores de ICP e idade após intervenção

A Figura 4 indica a evolução do ICP ao longo do tempo, em que cada linha representa um trecho analisado e os picos observados significam que uma intervenção foi realizada naquele trecho, resultando em uma melhora no ICP.

Para os trechos onde foram realizadas atividades de reabilitação, a contagem da idade é reiniciada, passando novamente a zero, conforme indicado na Figura 5. Nos trechos onde foram realizadas atividades de manutenção, a idade continua a ser contada, de acordo com o tempo decorrido. 
ICP

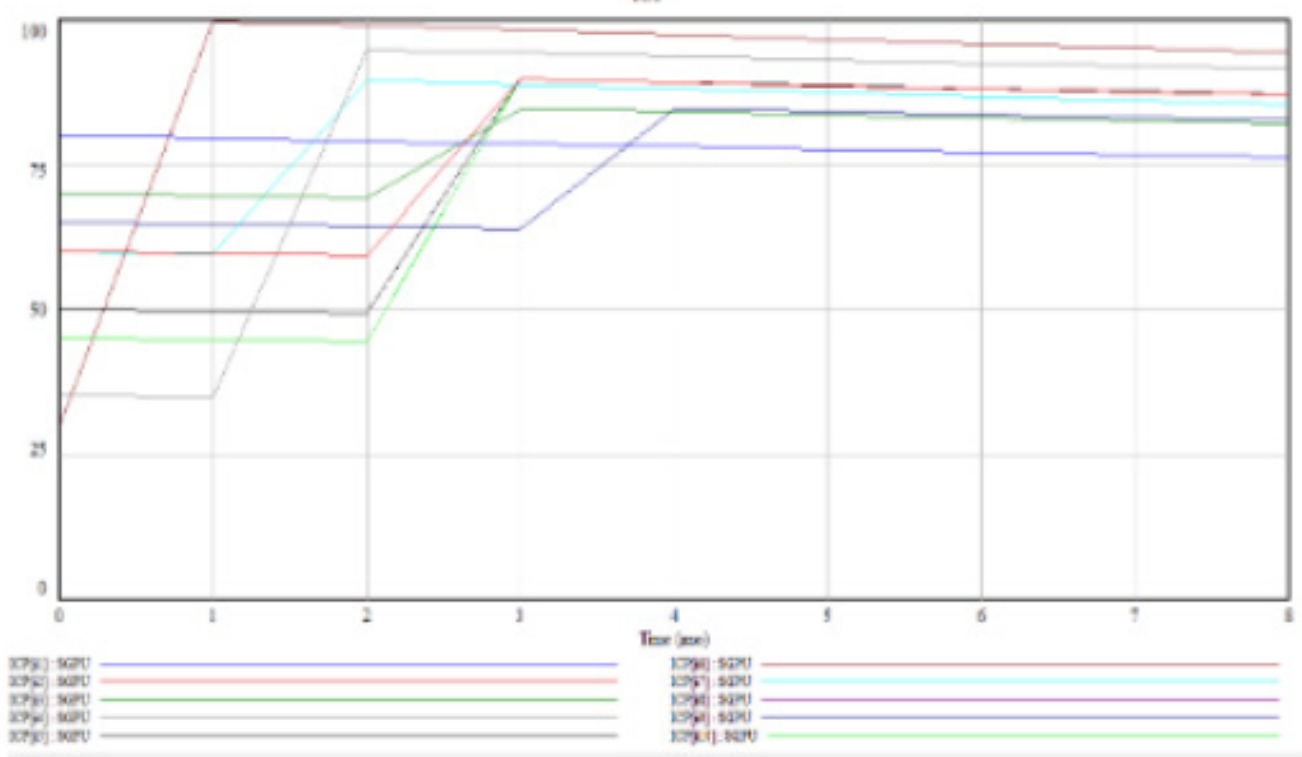

Figura 4: Evolução do ICP com o tempo, considerando-se as intervenções realizadas

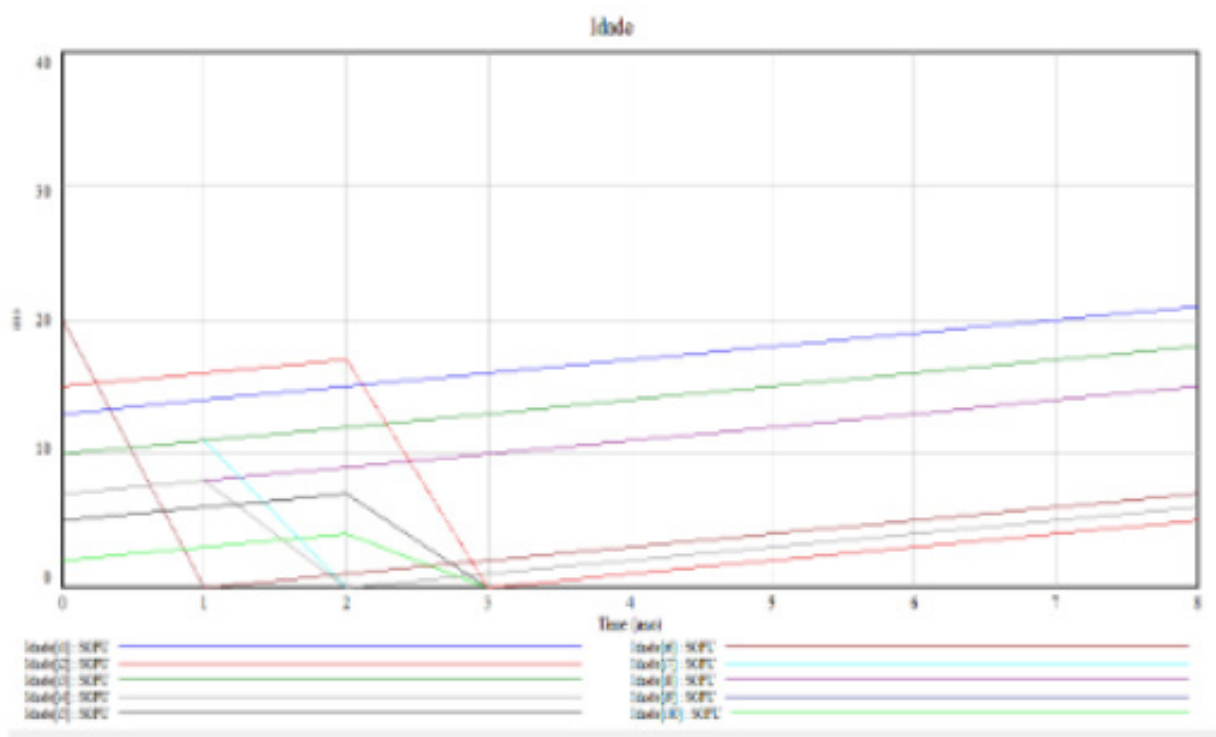

Figura 5: Evolução da idade do pavimento, considerando-se as intervenções realizadas

Conforme as atividades são realizadas, vão sendo contabilizados os custos de cada uma delas, conforme apresentado na Figura 6. Pode-se observar que, a partir do ano 4, não houve necessidade de manutenção das vias, tendo o custo ficado nulo.

O Modelo de SGPUD desenvolvido neste trabalho foi testado com os dados de uma cidade de médio porte (aproximadamente 400.000 habitantes). A análise em nível de rede apresenta a relação das estratégias de manutenção e reabilitação mais indicada para cada uma das seções da rede viária pavimentada (Figura 7). 


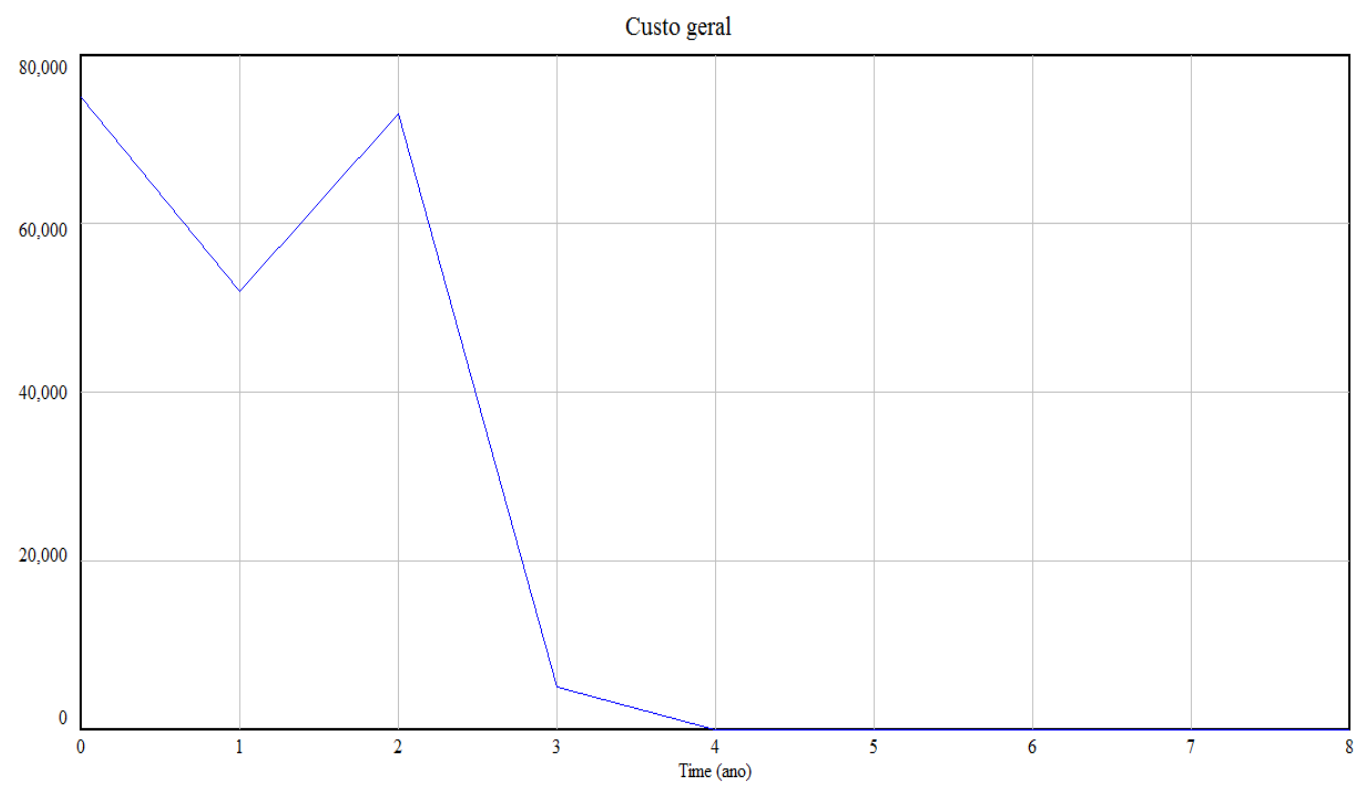

Figura 6: Custo anual, resultado da soma dos custos das atividades realizadas a cada ano

Em síntese, com base em dados de inventário (volume de tráfego e idade) e, principalmente, na avaliação da condição dos pavimentos (ICP), fez-se a seleção da estratégia de manutenção e reabilitação, cujo custo unitário multiplicado pela área da seção fornece o custo da intervenção, sendo o acumulado dos custos de intervenção em cada segmento, na ordem decrescente de prioridade, confrontados com os recursos financeiros e materiais necessários, para definição do ano recomendado para cada intervenção.

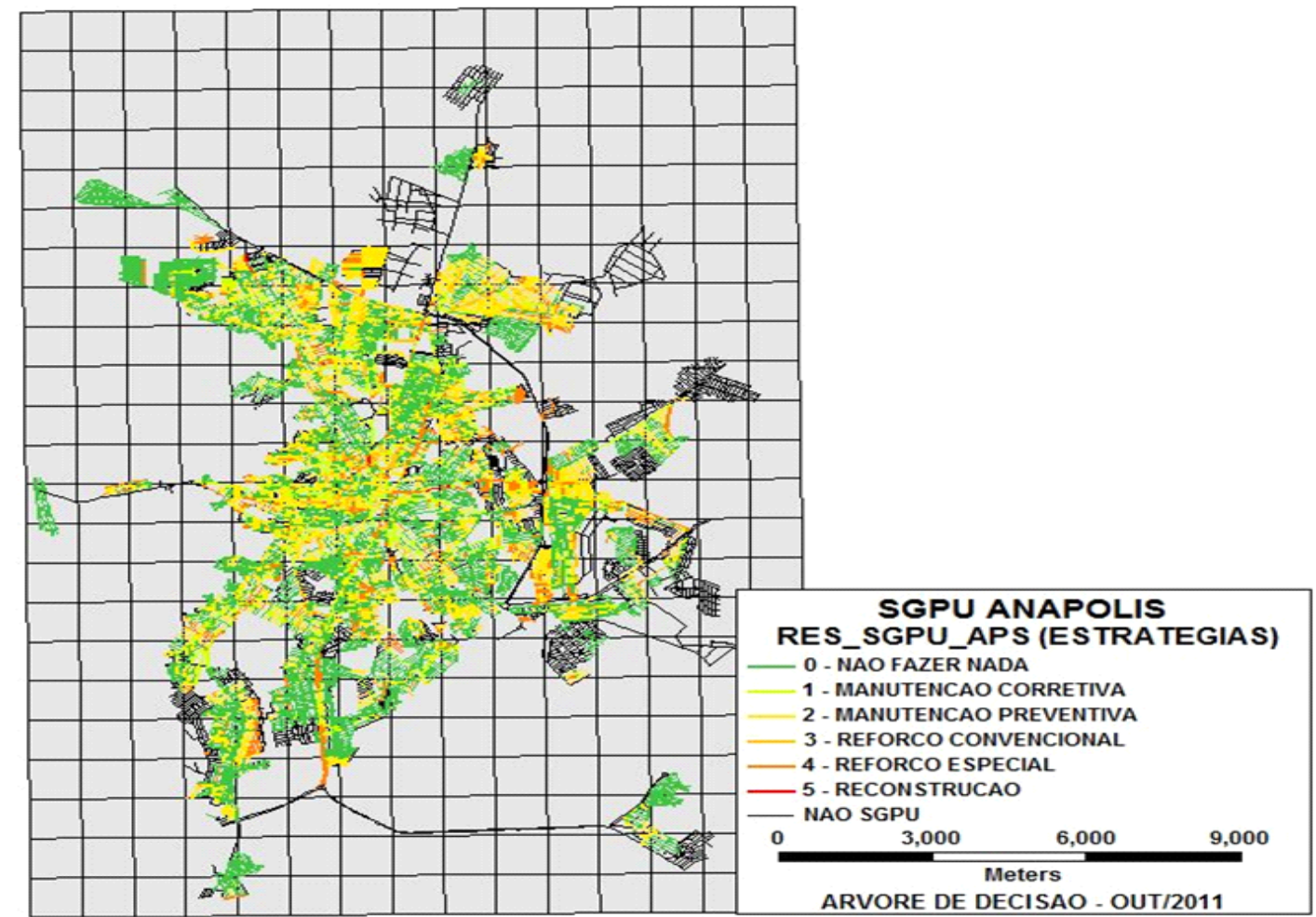

Figura 7: Recomendação de Atividades de Manutenção e Reabilitação para cada segmento 


\section{I CONCLUSÕES}

Neste estudo foi aplicada a modelagem dinâmica de sistemas a um Sistema de Gerência de Pavimentos Urbanos (SPGU), com uso do programa Vensim, tendo sido desenvolvido um método para formalização do processo de tomada de decisão por parte dos profissionais responsáveis pelas intervenções nos pavimentos, que permite, também, a compatibilização das estratégias de manutenção e reabilitação dos pavimentos com o planejamento de intervenções em outras infraestruturas urbanas (água, esgoto, energia elétrica, gás, telefonia etc.), com potencial para reduzir significativamente o custo total para a sociedade.

O método também foi aplicado a uma base de dados real, de uma cidade brasileira de médio porte, sendo os resultados apresentados de maneira visual, através de mapas temáticos, com o uso de um Sistema de Informações Geográficas (SIG). Todas as vias municipais foram avaliadas e foi feito um diagnóstico de cada tipo de defeito existente em cada logradouro, avaliando-se a extensão, o nível de severidade e a causa provável dos defeitos, propondo-se, ao final, medidas mitigadoras para cada seção levantada.

Os dados foram inseridos em um banco de dados vinculado a um SIG, que cadastrou a condição do pavimento em todos os logradouros municipais, facilitando o acesso às informações e a visualização dos problemas. O Sistema de Gerência de Pavimentos Urbanos Dinâmico (SGPUD) implantado tem informações que, devidamente analisadas, permitem à Prefeitura Municipal racionalizar a aplicação dos recursos.

Trata-se de um exemplo de processo sinérgico, com transferência de tecnologia para a sociedade, que une o poder público (prefeituras), a universidade e a iniciativa privada, representada pelas empresas prestadoras de serviços na área de infraestrutura urbana.

Os benefícios já alcançados pelo município em que o estudo de caso foi desenvolvido incluem:

- formação e aperfeiçoamento técnico dos gestores públicos e dos tomadores de decisão;

- incentivo à interdisciplinaridade, pois diversos técnicos de formações distintas trabalham e opinam nos serviços a serem executados (Engenheiros Civis, Arquitetos, Economistas, Administradores);

- $\quad$ incorporação da prática de manutenção preventiva das infraestruturas críticas do município, não se utilizando somente as opções remendos (tapa-buracos emergenciais) e recapeamentos sem projeto;

- a aplicação racional dos recursos, avaliada ao longo de três anos, reduziu os custos com a pavimentação asfáltica e, principalmente, melhorou a qualidade dos pavimentos, confirmando as evidências obtidas na simulação inicial, que considerou apenas 10 segmentos hipotéticos ;

- melhoria do processo licitatório para contratação de empresas especializa- 
das em atividades de manutenção (corretiva e preventiva), reabilitação e reforço de pavimentos flexíveis;

- trata-se de processo economicamente viável, pois o custo da implantação do SGPU foi inferior a 1\% do custo das atividades de manutenção e reabilitação previstas;

- possibilidade de envio de propostas e solicitações de verba ao Governo Federal e órgãos financiadores, como por exemplo, Ministério das Cidades, Banco Mundial, agências estrangeiras (JICA, GTZ etc.), pois as informações e análises têm sólida base técnica.

\section{REFERÊNCIAS}

Fernandes Jr., J. L.; Oda, S.; Zerbini, L. F. (2006) Defeitos e atividades de manutenção e reabilitação em pavimentos asfálticos. Gráfica EESC-USP. São Carlos.

Haas, R.; Hudson, R. W.; Zaniewsk, J. (1994) Modern Pavement Management. Editora Krieger Publishing Company, Malabar - Florida.

Lima, J. P. (2007) Modelo de decisão para a priorização de vias candidatas às atividades de manutenção e reabilitação de pavimentos. Tese de Doutorado - EESC - USP, São Carlos.

Lopes, S. B.; Pfaffenbichler, P.;Emberger, G.; Riedl, L.; Fernandes Jr., J. L. (2008) Gerência de Pavimentos Urbanos com Uso de Modelagem Dinâmica de Sistemas Diretamente Conectada com um SIG. Anais do XXII Congresso de Pesquisa e Ensino em Transportes, ANPET, Rio de Janeiro.

Silva, A. N. R.; Ramos, R. A. R.; Souza, L. C. L.; Rodrigues, D. S.; Mendes, J. F. G. (2008) SIG: uma plataforma para introdução de técnicas emergentes no planejamento urbano, regional e de transportes. São Carlos, SP, gráfica EdUFSCar.

Zanchetta, F. (2017) Sistema de Gerência de Pavimentos Urbanos: Avaliação de Campo, Modelo de Desempenho e Análise Econômica. Tese (Doutorado), Escola de Engenharia de São Carlos, Universidade de São Paulo.

Zerbini, L. F. (1999) Desenvolvimento de modelos de desempenho para utilização em sistemas de gerência de pavimentos urbanos. Dissertação de Mestrado - EESC - USP, São Carlos. 


\section{CAPÍTULO 2}

\section{MODELOS DE CONTROLE SEMAFÓRICO PARA OTIMIZAÇÃO DE FLUXO DE TRÁFEGO EM VIAS URBANAS}

Ana Caroline Meireles Soares Universidade Federal do Maranhão - UFMA Departamento de Engenharia de Eletricidade São Luís - Maranhão

João Viana da Fonseca Neto Universidade Federal do Maranhão - UFMA Departamento de Engenharia de Eletricidade São Luís - Maranhão

Patrícia Helena Moraes Rêgo Universidade Estadual do Maranhão - UEMA Departamento de Engenharia da Computação São Luís - Maranhão

RESUMO: Neste trabalho são propostos modelos para controle de tráfego urbano em cruzamentos isolados através de estratégias traçadas aos temporizadores utilizando controle fuzzy e análise de agrupamento. $\mathrm{O}$ objetivo do trabalho é apresentar três modelos de controle semafórico que consigam atuar da forma mais eficaz possível dada a situação atual em que o trânsito se encontre, e assim, controlar o fluxo de veículos em cruzamentos isolados através das estratégias traçadas aos semáforos. Os modelos propostos levam em consideração cruzamentos que apresentam Condição de Saída Única (CSU), isto é, cruzamentos com pelo menos uma origem que tem somente um destino permissível, em contraste aos modelos convencionais, os quais são aplicáveis apenas aos cruzamentos onde cada origem está associada a mais de um destino, definição esta presente na maioria dos cruzamentos da cidade em estudo. Os modelos são compostos de três partes principais: a primeira parte é constituída da estimação da matriz OD (origem - destino) que é baseada em filtragem de Kalman a partir da contagem de tráfego nos cruzamentos da cidade em estudo. Esses dados são usados como entrada para a realização da segunda parte, que consiste em utilizar técnicas de agrupamento para extrair os conjuntos fuzzy, e com isso, inseri-los no controlador fuzzy que representa a terceira parte da metodologia aqui proposta, onde é estimado o melhor tempo para o semáforo.

PALAVRAS-CHAVES: Controle de tráfego, Estimação de Matriz OD, Sistema Fuzzy, Técnicas de agrupamento, Controle adaptativo.

ABSTRACT: In this paper, some models are proposed to control urban traffic in isolated crossings through strategies traced to the timers using fuzzy control and cluster analysis. The methodology is based on presenting three traffic control models that can act in the most effective way possible given the current situation in which the traffic is, and thus control the flow of vehicles in isolated crossings through the strategies traced to traffic lights. The proposed 
models take into account crossings that present Single-Exit Condition (CSU), that is, crossings with at least one origin that has only one permissible destination, in contrast to conventional models, which are applicable only to crosses where each origin is associated with more than one destination. This type of condition is adopted due to the fact that most of the traffic lights in the city where the case study was applied present this condition, which made it impossible to obtain the OD matrix in a traditional way. The models are composed of three main parts: the first part consists of the estimation of the OD matrix (origin - destination) that is based on Kalman filtering from the traffic count at the crossroads of the study city. This data is used as an input to perform the second part, which consists of using clustering techniques to extract the fuzzy sets, and with that, insert them into the fuzzy controller that represents the third part of the methodology proposed here, where it is estimated best time for the traffic.

KEYWORDS: Traffic control, OD Matrix Estimation, fuzzy system, clustering techniques, adaptive control.

\section{I INTRODUÇÃO}

A população urbana cresce rapidamente nos centros urbanos e todo este crescimento faz com que a infraestrutura de transportes fique saturada, gerando lentidão, congestionamentos e aumentando o tempo que as pessoas passam dentro dos veículos (DESSBESELL, 2015), por isso tem-se investido muito em estratégias inovadoras, que originam o conceito de Sistemas Inteligentes de Transporte (SIT), que tendem a proporcionar novas formas inovadoras suscetíveis a criar mobilidade sustentável nas comunicações e na sociedade da informação (FIGUEREDO, 2005).

Segundo (CASCETTA, 2009), o sistema de transporte consiste não apenas de elementos organizacionais ou físicos que interagem entre si para produzir oportunidade de transporte, como também da demanda (passageiros) que procura absorver as melhores oportunidades de transporte de um lugar a outro. Atrelado a este conceito de sistema de transporte, e a definição de SIT por (FIGUEREDO, 2005), surge a percepção de Smart Cities, que consistem em sistemas onde pessoas e processos interagem estrategicamente entre si com a finalidade de obter melhoria na qualidade de vida da população.

Muitas soluções, além do incentivo aos transportes de massa e ao uso de bicicletas, são mencionadas por especialistas em Urbanismo e Geografia Urbana e muitos são os debates com base neste assunto. Além destas soluções, uma das ferramentas mais eficazes utilizadas para soluções de problemas práticos são as técnicas de otimização de processos, que auxiliam no equacionamento adequado do transporte urbano, que é uma preocupação presente em todos os países devido à grande quantidade de moradores nas cidades (FERRAZ e TORRES, 2004).

Muitos trabalhos são desenvolvidos na área de otimização e controle de tráfego. (MARQUES, 2012) propõe um trabalho baseado na modelagem e otimização de 
um sistema de transporte genérico, com o objetivo de encontrar um número ótimo para o dimensionamento da frota de veículos rodoviários. Partindo a uma linha similar, porém voltada para o controle, (DESSBESELL, 2015) propõe a simulação de controle adaptativo de tráfego urbano com o uso de sistema multiagentes através de estratégias traçadas aos semáforos. Já (LI, DRIDI e EL-MOUDNI, 2016) tem a proposta de um novo controle cooperativo com o objetivo de reduzir o tempo de atraso em uma interseção de vias que não apresentam semáforos. A otimização é realizada com o uso do algoritmo genético aplicado na sequência de passagem e enviado a cada veículo individualmente, onde os fluxos compatíveis são dinamicamente combinados.

Outros são baseados em sistemas inteligentes, como (FIGUEIREDO, 2005), que propõe um desenvolvimento de um simulador para apoio em tomada de decisão baseado em uma abordagem microscópica de condições reais de tráfego. Além de variados tipos de controle como o proposto por (CHEN, CHEN e HSIUNG, 2016), que propõe uma solução para os congestionamentos de trânsito através de um novo Modelo de Controle Preditivo (MCP) baseado em sistema de controle de luz.

Devido à grande demanda por melhorias no sistema de transporte, este trabalho tem a proposta de levantar modelos que possam ser aplicado na cidade de São Luís do Maranhão. A ideia principal é traçar estratégias de tempos aos semáforos com o objetivo de otimizar o fluxo de tráfego e com isso, aplicar-se um controle de tráfego da região, evitando ou diminuindo os congestionamentos. Para alcançar estes objetivos técnicas de agrupamento e controle fuzzy são propostas, o que enriquece e valoriza o trabalho proposto.

\section{I METODOLOGIA}

O presente trabalho está embasado nas metodologias propostas por (ANGULO, ROMERO, et al., 2011) e (JAMSHIDNEJAD, SCHUTTER e MAHJOOB, 2015), porém algumas adequações são realizadas nas metodologias propostas para adaptar a aplicação na cidade em estudo. No presente trabalho são apresentados os resultados para três abordagens diferentes, utilizando técnicas de agrupamento diferentes das mencionadas nos artigos base, além disso, a abordagem desta dissertação está aplicada a cruzamentos isolados e não a cruzamentos em rede, como retratou os dois trabalhos supracitados.

A metodologia é dividida em três partes principais, sendo a primeira composta pela Estimação das matrizes OD. Esta primeira etapa é baseada no trabalho de (LI e MOOR, 1999), onde a estratégia é encontrar um vetor de probabilidades utilizando um estimador de estados, e adicionar as restrições de igualdade e desigualdades aos valores encontrados pelo estimador, obtendo-se assim, um resultado mais confiável. Ao trabalho base, é inserida uma etapa adicional ao algoritmo como contribuição ao método, visto que, ao ser aplicado em seu formato original aos cruzamentos com CSU, não apresentou resultados satisfatórios. O fato dos métodos tradicionais não 
apresentarem resultados ao ser aplicado no estudo de caso em questão se deve ao CSU (Condição de Saída Única), condição apresentada na maioria dos cruzamentos na cidade e que impossibilita o uso do mesmo algoritmo. Esta condição permitiu a estes autores a autoria do artigo (SOARES, DA FONSECA NETO e RÊGO, 2018).

A metodologia desta etapa do trabalho consiste em considerar quatro cenários reais da cidade em estudo e mostrar os problemas que podem surgir para o cálculo da matriz OD devido a estrutura do sistema. Os cenários utilizados podem ser visto nas figuras 01 a 03, sendo o cenário 03 dividido em dois: um considerando o CSU e outro considerando sem CSU para representar os cruzamentos convencionais.

Figura 1 - Cruzamento Colares Moreira

Figura 2 - Cruzamento Areinha

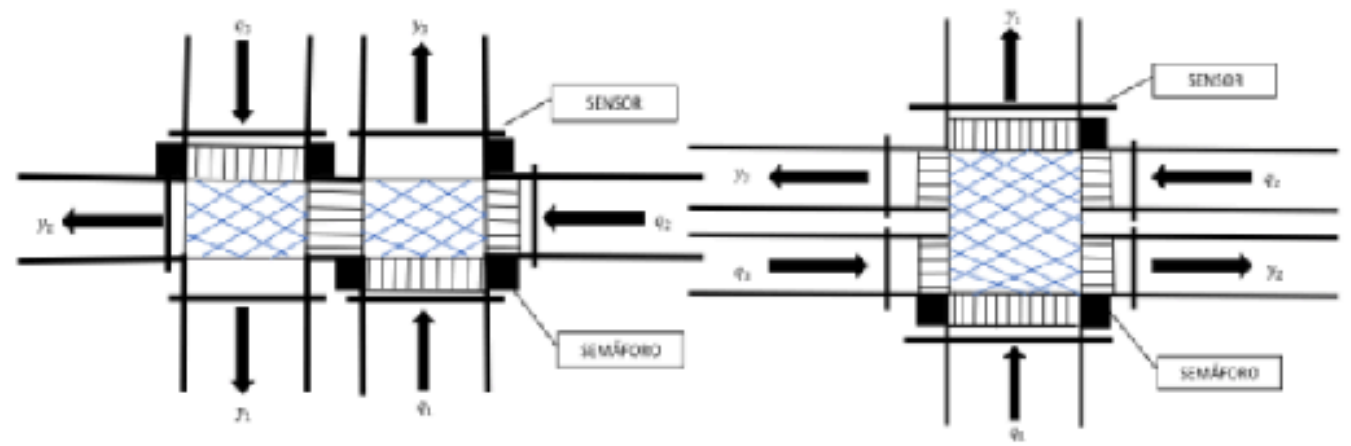

Figura 3 - Cruzamento Joảo Paulo

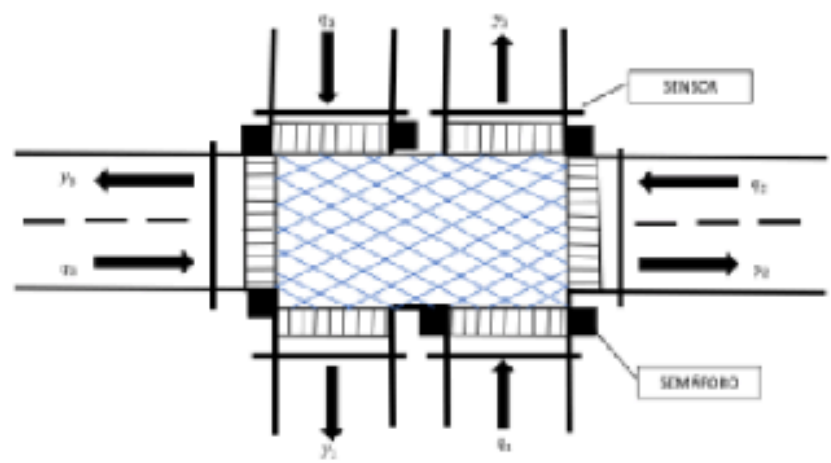

Deve-se formular uma tabela de movimentos conflitantes e proibidos, definir as dimensões das variáveis para o cruzamento em estudo e realizar a estimação do vetor de probabilidades através do filtro de Kalman.

Considerando os quatro cenários em estudo e as equações consideradas, é possível montar as matrizes de parâmetros "verdadeiros" que foram utilizadas na simulação (Tabela 1). Os parâmetros verdadeiros são as probabilidades de cada veiculo sair de uma via e adentrar outra via representado pela probabilidade, onde representa a origem e o o destino da viagem, através do valor correto destas probabilidades é possível estimar o fluxo de carros no próximo instante de tempo. Estes valores são usados para testar o algoritmo. 


$\boldsymbol{B}$
$=\left[\begin{array}{ccc}\mathbf{0} & \mathbf{0} & \mathbf{1} \\ \mathbf{0 , 5} & \mathbf{0 , 3} & \mathbf{0 , 2} \\ \mathbf{0 , 6} & \mathbf{0 , 4} & \mathbf{0}\end{array}\right] \quad B=\left[\begin{array}{ccc}0,3 & 0,5 & 0,2 \\ 0,4 & 0 & 0,6 \\ 0 & 1 & 0\end{array}\right] \quad B=\left[\begin{array}{cccc}0 & 0,4 & 0,6 & 0 \\ 0 & 0 & 1 & 0 \\ 0,8 & 0,1 & 0 & 0,1 \\ 0,7 & 0,25 & 0,05 & 0\end{array}\right]=\left[\begin{array}{cccc}0 & 0.23 & 0,414 & 0,356 \\ 0,051 & 0 & 0,149 & 0,8 \\ 0,352 & 0,358 & 0 & 0,29 \\ 0,083 & 0,843 & 0,074 & 0\end{array}\right]$

Tabela 1 - Tabela de "valores verdadeiros"

Os valores encontrados pelo algoritmo criado podem ser encontrados na Tabela 2.

\begin{tabular}{|c|l|cccccc|}
\hline $\mathrm{n}^{\circ}$ & \multicolumn{1}{|c|}{ Valores encontrados } & \multicolumn{5}{|c|}{ Valores de $\mathrm{b}_{\mathrm{j}}(\mathrm{t})$} \\
\hline \multirow{3}{*}{$\mathbf{0 1}$} & Estimador de Kalman & 0.3009 & 0.3988 & 0.4993 & 1.0011 & 0.1998 & 0.6008 \\
\cline { 2 - 8 } & Refinados pelas restrições - & 0.3005 & 0.3990 & 0.5002 & 1.0000 & 0.1994 & 0.6010 \\
\cline { 2 - 8 } & Valores Reais & 0.500 & 0.6000 & 0.3000 & 0.2000 & 1.0000 & 0.2000 \\
\hline \multirow{3}{*}{02} & Estimador de Kalman & 0.3008 & 0.3993 & 0.5020 & 0.9979 & 0.2007 & 0.5993 \\
\cline { 2 - 8 } & Refinados pelas restrições - & 0.3001 & 0.4000 & 0.4999 & 1.0000 & 0.2000 & 0.6000 \\
\cline { 2 - 8 } & Valores Reais & 0.3000 & 0.4000 & 0.5000 & 1.0000 & 0.2000 & 0.6000 \\
\hline \multirow{3}{*}{$\mathbf{}$} & Estimador de Kalman & 0.7996 & 0.7003 & 0.3991 & 0.1006 & 0.2503 & 0.5990 \\
& & 0.9984 & 0.0525 & 0.1001 & & & \\
\cline { 2 - 8 } & Refinados pelas restrições - & 0.8053 & 0.6957 & 0.4092 & 0.0954 & 0.2448 & 0.5908 \\
& & 1.0000 & 0.0596 & 0.0993 & & & \\
\cline { 2 - 8 } & Valores Reais & 0.8000 & 0.7000 & 0.4000 & 0.1000 & 0.2500 & 0.6000 \\
& & 1.0000 & 0.0500 & 0.1000 & & & \\
\hline \multirow{3}{*}{3.2} & Estimador de Kalman & 0.0521 & 0.3518 & 0.0821 & 0.2292 & 0.3586 & 0.8431 \\
& & 0.4126 & 0.1497 & 0.0747 & 0.3545 & 0.8004 & 0.2913 \\
\cline { 2 - 8 } & Refinados pelas restrições - & 0.0552 & 0.3377 & 0.0920 & 0.2231 & 0.3684 & 0.8358 \\
& & 0.4118 & 0.1519 & 0.0723 & 0.3652 & 0.7929 & 0.2940 \\
\cline { 2 - 7 } & Valores Reais & 0.0510 & 0.3520 & 0.0830 & 0.2300 & 0.3580 & 0.8430 \\
& & 0.4140 & 0.1490 & 0.0740 & 0.3560 & 0.8000 & 0.2900 \\
\hline
\end{tabular}

Tabela 2 - Valores de $b_{i}(t)$ para comparação

O que permite comprovar que o algoritmo funcionou de forma correta, pois a diferença entre o valor estimado e o valor encontrado pelo algoritmo apresentam valores muito semelhantes.

Esta primeira etapa torna-se necessária para a coleta dos dados de fluxo em cada via dos cruzamentos estudados, pois em posse das probabilidades, seria possível prever o fluxo de carro que adentraram um cruzamento. Esses dados serão usados como entrada para a utilização das técnicas de agrupamento não-fuzzy e fuzzy.

Nesta segunda etapa, a intenção é utilizar técnicas de agrupamento como forma de extrair os conjuntos fuzzy a serem considerados no sistema de inferência. Optouse por apresentar três abordagens diferentes para encontrar os conjuntos usados no sistema fuzzy A primeira abordagem consiste em escolhê-los de forma manual, sem uso de nenhuma técnica computacional, apenas o conhecimento do próprio projetista. A segunda e a terceira usando técnicas de agrupamento. Foram escolhidas duas 
conhecidas técnicas: K-means e o Fuzzy C-means. O K-means foi escolhido não só por sua popularidade em agrupamento de dados, como também pela sua simplicidade e velocidade, além de ser um algoritmo base para outros métodos de agrupamento. $O$ Fuzzy C-means apresenta um funcionamento parecido, porém com uma característica fuzzy, pois apresenta o grau de pertinência e um fator de ponderação.

A primeira abordagem consiste no sistema de inferência fuzzy sem a utilização de algoritmos de agrupamento para a formação dos conjuntos fuzzy, ou seja, apenas através do conhecimento empírico do projetista. Como cada cruzamento apresenta características particulares, seria muito trabalhoso para o projetista ter que formar grupos para cada cruzamento, por isso, se propõe na segunda abordagem que estes mesmos conjuntos sejam formados pelo agrupamento não fuzzy K-means, tendo pouca ou nenhuma interferência do projetista. Na terceira abordagem a proposta está em utilizar uma técnica de agrupamento fuzzy (Fuzzy C-means) na intenção de obter resultados gerados pelo sistema fuzzy ainda mais satisfatórios, tendo menos ainda a interferência do projetista, aumentando a autonomia do sistema de controle. $O$ objetivo é apresentar ao final do trabalho três modelos baseados nas três abordagens, mostrando as vantagens e desvantagens de cada modelo.

Após isso, a definição do melhor tempo estimado para o semáforo é encontrada considerando três abordagens diferentes: a primeira, onde o próprio projetista define os conjuntos fuzzy, ou seja, a primeira etapa do trabalho serve apenas como base para a decisão do projetista; a segunda, onde estes conjuntos são encontrados por técnica de agrupamento não-fuzzy e a terceira, onde os conjuntos são determinados por técnica de agrupamento fuzzy. Vale ressaltar que nas duas últimas abordagens, a primeira etapa torna-se essencial, diferente da primeira abordagem onde esta serve apenas como base para as decisões. Com isso formula-se três modelos de controle fuzzy que estimam o melhor tempo para o semáforo, e que atuam de forma adaptativa ao contexto real, evitando ou minimizando os congestionamentos.

\section{I RESULTADOS}

Considerando as três abordagens, os seguintes modelos são apresentados:

- Modelo 01 - Representado pela Figura 4. Este modelo pode funcionar sem o uso do banco de dados fornecido pelas matrizes OD, porém essas informações permitem a melhor escolha dos conjuntos fuzzy ao projetista. $O$ modelo, como mostra a figura, é formado a partir dos seguintes passos: Definição dos conjuntos fuzzy - Formação das funções de pertinência do formato triangular - Definição dos tempos dos semáforos. 


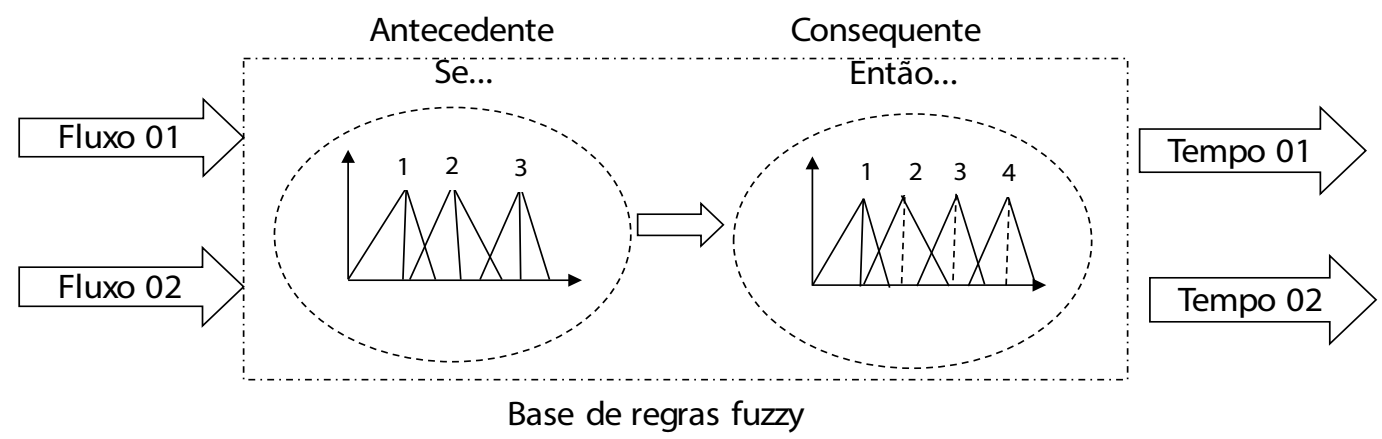

Figura 4 - Modelo 01

- Modelo 02 - Representado pela Figura 5, basicamente consiste em: Coleta de dados - Estimação de - Obtenção das matrizes OD para formar o banco de dados - Agrupamento K-means dos dados de entrada e saída de forma independente - Definição das funções de pertinência do formato triangular a partir dos dados agrupados - Formação das regras fuzzy com base nas funções formadas - Definição dos tempos dos semáforos pelo consequente.

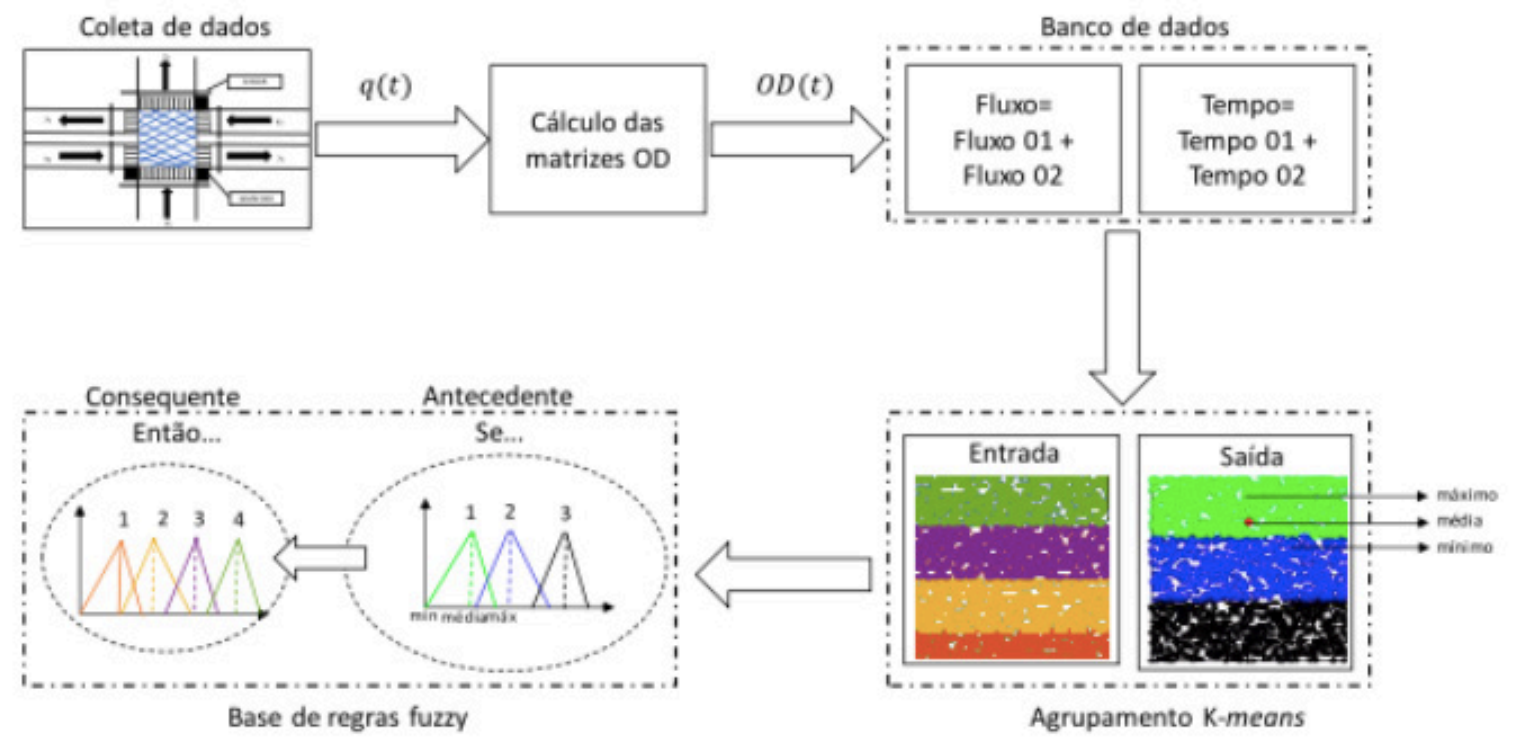

Figura 5 - Modelo 02

- Modelo 03 - Representado pela Figura 6, difere-se do Modelo 02 por utilizar outro tipo de algoritmo de agrupamento, que permite formação automática das funções de pertinência, sem definição do projetista pelo seu formato. Representado pela consiste em: Coleta de dados - Estimação de - Obtenção das matrizes OD para formar o banco de dados - Agrupamento Fuzzy C-means dos dados de entrada e saída de forma independente - Formação automática dos conjuntos fuzzy com funções de pertinência em formato de gaussiana para formação das regras fuzzy - Definição dos tempos dos semáforos. 


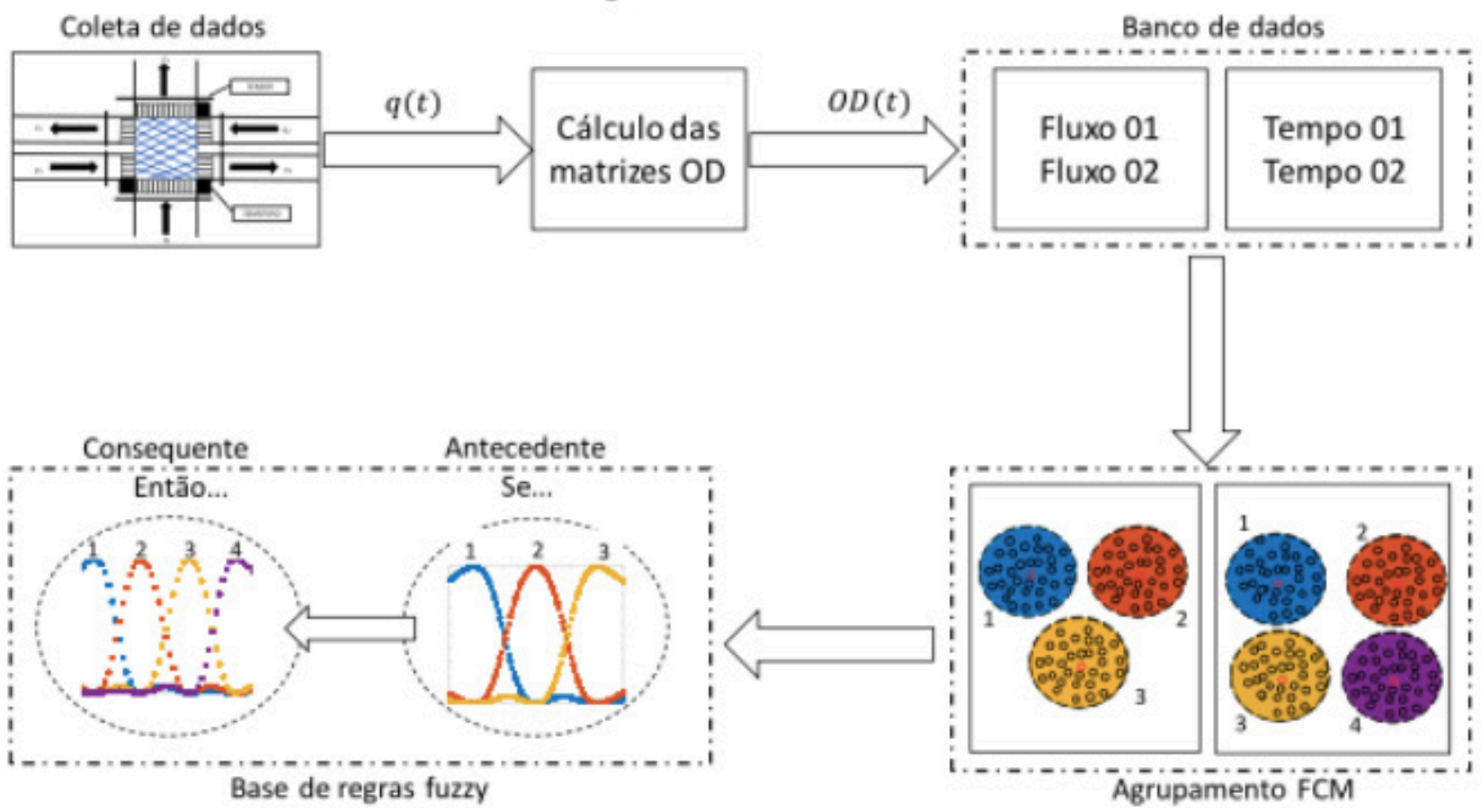

Figura 6 - Modelo 03

Através destas medidas, pretende-se controlar o fluxo de veículos em um cruzamento isolado.

Para avaliação dos modelos propostos foram considerados um conjunto de dados experimentais com uma amostra de 20 pares ordenados (Fluxo01, Fluxo02) para serem usados como entrada, simulando uma coleta de aproximadamente 3 horas. Os dados podem ser vistos na Figura 7.

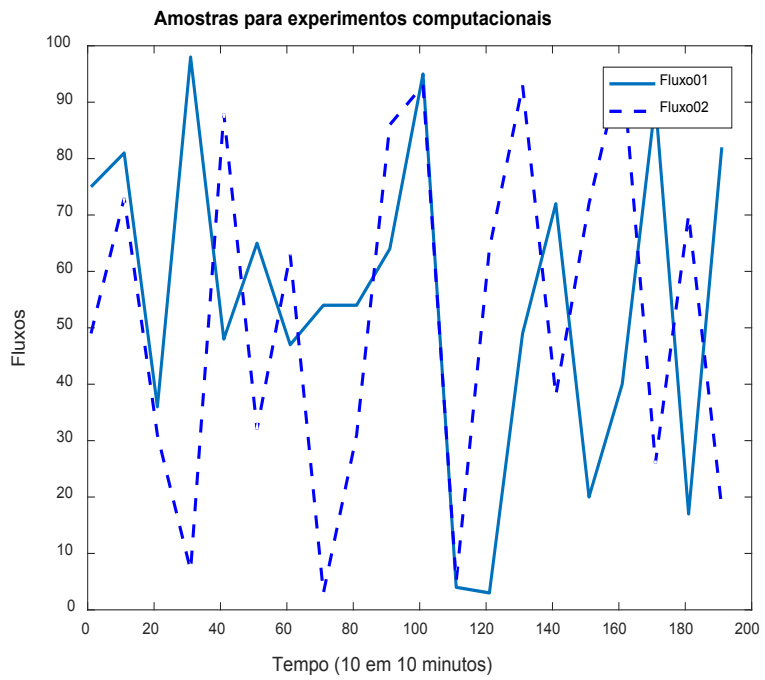

Figura 7 - Dados experimentais

\section{I CONSIDERAÇÕES FINAIS}

Neste trabalho foi apresentado o desenvolvimento de três modelos de controle de tráfego para cruzamentos isolados, onde são traçadas estratégias aos temporizadores 
de semáforos utilizando controle fuzzy e análise de agrupamento. Para isso, o trabalho é dividido em três partes principais: Estimação da matriz OD, agrupamento de dados para formação dos conjuntos fuzzy e estimação do melhor tempo para os semáforos.

O Modelo 01 não apresenta abordagem adaptativa, pois os conjuntos são definidos pelo próprio projetista, devendo este fazer alterações sempre que necessário. Já os dois últimos modelos ajustam seus conjuntos de forma adaptativa. A estratégia de apresentar os três modelos é adotada para que sejam feitas conclusões com base nas técnicas utilizadas.

Para os resultados dos modelos apresentados é possível expor algumas conclusões: O Modelo 01, onde os conjuntos fuzzy são definidos com base no conhecimento do projetista, apresenta a desvantagem de não ser adaptativo e por isso, em um determinado momento em que o fluxo de carros supera os valores definidos nos conjuntos formados, o controlador não vai conseguir estimar o tempo. Além disso, é muito complicado para o projetista ter que analisar vários cruzamentos de forma isolada e decidir cada conjunto, pois cada cruzamento apresenta fluxo de carros diferentes, e um valor que pode representar uma grande quantidade de carros em um local, pode representar pouca quantidade em outro, ou vice-versa, sendo esta a principal desvantagem do modelo. Como vantagem deste, é possível citar a simplicidade de implementação e o baixo tempo de processamento do algoritmo, visto que não depende da etapa de estimação da matriz OD.

Já o Modelo 02 é composto por um controlador adaptativo fuzzy indireto. O fato de apresentar atuação adaptativa é a sua principal vantagem. Como desvantagem é ressaltada a limitação do modelo na formação das funções de pertinência, que são convencionadas ao formato triangular, o que nem sempre será a melhor representação dos conjuntos. É possível que seja feita uma análise preliminar de cada cruzamento e escolhido um outro tipo da função de pertinência, mas para isso, pequenas alterações devem ser feitas no modelo e adequá-lo à situação proposta, sendo esta possibilidade de adequação considerada uma vantagem do modelo. O tempo de processamento do algoritmo neste modelo é o mais elevado dos três apresentados, mesmo assim, podese considerar uma boa opção de implementação do mundo real.

No Modelo 03 as funções de pertinência são geradas automaticamente pelo algoritmo de agrupamento, mostrando esta vantagem sobre os outros modelos apresentados, e com isso, muitas linhas de código são eliminadas neste modelo, o que reduz significativamente o tempo de processamento do algoritmo, que é o menor de todos os modelos apresentados. A única desvantagem encontrada até o momento consiste na complexidade um pouco maior desse modelo em relação a implementação, porém nada significativo comparado aos resultados.

Tendo em vista os resultados apresentados pelos três modelos é possível perceber que todos apresentam resultados satisfatórios, com pouca variação de um modelo para outro, exceto em alguns instantes, mas que não apresentam diferenças significativas se testadas a longo prazo. Os três modelos apresentam suas vantagens 
e desvantagens, cabendo ao projetista a decisão de qual dos três modelos melhor se encaixa na problemática adotada.

Todas as etapas deste trabalho podem ser encontradas em (SOARES, DA FONSECA NETO e RÊGO, 2018).

\section{REFERÊNCIAS}

ANGULO, E. et al. An adaptive approach to enhanced traffic signal optimization by using softcomputing techniques. Expert Systems with Applications, p. 2235-2247, 2010.

ANGULO, E. et al. An adaptive approach to enhanced traffic signal optimization by using softcomputing techniques. Expert Systems with Applications, 2235-2247, n. 38, 2011. 2235-2247.

CASCETTA, E. Transportation System Analysis: Models and Applications. New York: Springer, 2009.

CHEN, Y.-R.; CHEN, K.-P.; HSIUNG, P.-A. Dynamic Traffic Light Optimization and Control System using Model-Predictive Control Method. International Conference on Intelligent Transportation Systems (ITSC), n. 19, 1-4 Novembro 2016. 2366-2371.

CREMER, M.; KELLER, H. A new class of dynamic methods for the identification of origindestination flows. Transportation Research 21B. [S.I.]: [s.n.]. 1987. p. 117-132.

DESSBESELL, G. Dissertação de Mestrado: SIMULAÇÃo DE CONTROLE ADAPTATIVO DE TRÁFEGO URBANO ATRAVÉS DE SISTEMA MULTIAGENTES E COM BASE EM DADOS REAIS. Santa Cruz do Sul. 2015.

DESSBESELL, G. J. Tese de Doutorado: Simulação de controle adaptativo de tráfego urbano através de sistema multiagentes e com base em dados reais. Santa Cruz do Sul. 2015.

FERRAZ, A. C. P.; TORRES, I. G. E. Transporte publico urbano. 2ª . ed. São Carlos: RiMa, 2004.

FIGUEIREDO, L. M. B. Tese de doutorado: Sistemas Inteligentes de Transporte. Porto. 2005.

FIGUEREDO, L. M. B. Dissertação de mestrado: Sistemas Inteligentes de Transporte. Porto. 2005.

JAMSHIDNEJAD, A.; SCHUTTER, B. D.; MAHJOOB, M. Urban traffic control using fuzzy multi agent system. European Control Conference (ECC). Linz,Austria: July 15-17. 2015.

LI, B.; MOOR, B. D. Recursive estimation based on the equality-constrained optimization for intersection origin-destination matrices. Transportation Research Part B 33. [S.I.]: Elsevier Science Ltd. 1999. p. 203-214.

LI, J.; DRIDI, M.; EL-MOUDNI, A. A cooperative traffic control for the vehicles in the intersection based on the Genetic Algorithm. IEEE, p. 627-632, 2016.

MARQUES, J. A. L. C. Dissertação de mestrado: Modelagem e otimização para planejamento de transporte de passageiros com restrições de custo e qualidade de serviço. São Luís. 2012.

SIMON, D. Optimal State Estimation - Kalman, H, and Nonlinear Approches. Canadá: John Wiley \& Sons, 2006.

SOARES, A. C. M.; DA FONSECA NETO, J. V.; RÊGO, P. H. Estimation of origin-destination matrix via meta heuristic search with substitution in intersections presenting single-exit condition. International 
Conference on Electrical, Electronics, Computers, Communication, Mechanical and Computing, 28 e 29 Janeiro 2018.

SOARES, A. C. M.; DA FONSECA NETO, J. V.; RÊGO, P. H. M. Modelos de controle semafórico fuzzy adaptativo para cruzamentos - Aplicado a cruzamentos isolados. [S.I.]: OmniScriptum Publishing Group, 2018.

SÖDERSTRÖM, T.; STOICA, P. System Identification. New York London Toronto Sydney Tokyo: Prentice Hall, 1989. 


\section{CAPÍTULO 3}

\section{MODELAGEM DE UMA REDE LOGISTICA REVERSA PARA COLETA E TRANSPORTE DE RESÍDUOS SÓLIDOS URBANOS}

Adelaida Pallavicini Fonseca Universidade de Brasília, Departamento de

Engenharia Civil e Ambiental

Brasília - Distrito Federal

Milton Jonás Monteiro Universidade Federal de Tocantins, Curso de Administração Palmas - Tocantins

José Antonio Rodríguez Melquiades Universidad Nacional de Trujillo, Escuela de Informática Trujillo, Perú

RESUMO: A pesquisa bibliográfica revela uma preocupação dos governos federais com a destinação final dos resíduos sólidos urbanos (RSU) com o objetivo de preservar a saúde da população, o meio ambiente urbano e rural. Por exemplo, no Brasil observa-se a criação da Lei 12.305/10 e, no Peru, da Lei 27.314/2000. Neste contexto e para o caso das cidades brasileiras esperava-se que, com o comando legal de desativação dos lixões até 2014, surgissem medidas que viabilizassem a coleta seletiva, reciclagem e reutilização para cerca de $80 \%$ do volume total de resíduos sólidos coletados e destinados a locais impróprios. Nesse sentido esta pesquisa tem como objetivo principal modelar e planejar uma rede logística reversa para uma região urbana. Os resultados obtidos mostram ser possível realizar a modelagem matemática desse tipo de problema com baixo investimento, assim como aplicá-la em várias regiões sem necessidade de grandes mudanças no modelo proposto.

PALAVRAS-CHAVES: Logística reversa, redes de transporte, resíduos sólidos urbanos.

ABSTRACT: The literature reveals a concern of Federal Governments with the disposal of municipal solid waste (MSW) in order to preserve the health of the population, the urban and rural environment. For example, in Brazil there has been the creation of Law 12,305 / 10 and, in Peru, of Law 27,314 / 2000. In this context and for the case of Brazilian cities, it expected that, with the legal command for the deactivation of landfills by 2014 , measures would be adopted in order to enable the selective collection, recycling and reuse for about $80 \%$ of the total volume of collected solid waste and intended to inappropriate places. In this sense, this research aims to model and plan a reverse logistics network to an urban area. The results show to be possible perform mathematical modeling of this problem with low investment, as well as apply it in various regions without major changes in the proposed model.

KEYWORDS: Reverse logistics, transport networks, urban solid waste. 


\section{I INTRODUÇÃO}

A acessibilidade predial na maioria das cidades já se encontra comprometida, em virtude da falta do cumprimento das normas técnicas brasileiras quanto ao desenho e construção de calçadas e passeios, assim como na disposição não padronizada dos elementos de infraestrutura de mobilidade urbana (CERNA, 2014).

O problema se agrava com a colocação indiscriminada dos RSU (seja como for o armazenamento) nas calçadas e nas vagas de estacionamento, como apontam as pesquisas de Monteiro (2013), Oliveira (2014) e Abreu (2015). Esses três autores levantaram a situação da coleta e transporte dos RSU nas quadras comerciais da cidade de Brasília. Um deles focou o problema no Setor Comercial Norte (MONTEIRO, 2013) e os outros dois nas quadras comerciais do Plano Piloto (ABREU, 2015; OLIVEIRA, 2014). Os diagnósticos apresentados nesses trabalhos mostram a dificuldade de gestão dos RSU na cidade.

O modelo de gestão dos Serviços de Limpeza Urbana é similar em aproximadamente todas as cidades brasileiras, sendo que a situação de acondicionamento residencial ou predial, coleta e transporte, tratamento e disposição final dos RSU, infelizmente é a mesma em quase todas as cidades, segundo dados da ABRELPE $(2010,2014)$.

Não se pode negar que existem muitas iniciativas da população e de várias organizações não governamentais tratando de reverter essa situação, no entanto, elas não têm a infraestrutura adequada para operacionalizar várias ações da cadeia logística reversa, nem muito menos as competências e atribuições necessárias para exercer o mesmo papel que lhe cabe aos órgãos gestores.

De todo o exposto, conclui-se que o tema é bastante desafiador, pois embora a sociedade possa ter consciência da riqueza descartada cotidianamente e de potenciais ganhos econômicos, sociais e ambientais que poderiam ser auferidos, soluções abrangentes parecem caminhar a passos lentos.

Em sentido contrário, os indicadores apontam avanço acelerado na produção de bens que um dia serão descartados, no aumento nos custos de operação da coleta e transporte, construção e manutenção de aterros e de outras facilidades e na constante falta de recursos públicos para obras públicas e gestão.

A rigor, pode-se concluir que o maior problema que todas as cidades têm, está na falta de uma rede logística reversa que integre todos os participantes formais e informais, privados ou não, que atuam e trabalham com os RSU, aliada a um bom sistema de informação gerencial e de controle operacional.

Há necessidade de se implantar políticas públicas adequadas, que possibilitem saltos qualitativos, permitindo assim migrar rapidamente a sistemas integrados que reincluam os RSU na cadeia produtiva, aproveitando o seu potencial produtivo e de geração de renda, assim como o seu conteúdo energético. A Lei n 12.305/2010, é enfática neste sentido. 
Nessa perspectiva da nova legislação e do estágio pouco avançado em que se encontra em relação à coleta, transporte, tratamento e disposição final dos resíduos é que motivou o desenvolvimento dessa pesquisa, que tem como objetivo principal, modelar e planejar uma rede logística reversa para uma região urbana, dimensionando o fluxo de RSU que será movimentado ao longo da rede e determinando o número e capacidade das estações de coleta e das unidades produtivas e especiais necessárias para o atendimento dessa região, quanto a coleta, transporte e disposição final dos RSU.

Com a otimização do modelo de coleta e transporte de RSU é possível reorganizar o sistema logístico reverso de uma cidade de forma a conseguir um melhor dimensionamento da rede, com a consequente diminuição do número de veículos que circulam na cidade e de contêineres e sacolas de lixo espalhados pela cidade, criando um ambiente mais sustentável e saudável.

Para isso, foram definidas quatro seções contadas a partir dessa introdução, que apresenta o contexto do problema e o objetivo do artigo. A segunda seção levanta os elementos abordados na literatura sobre modelos de redes logísticas, de distribuição (direita) e reversa e de gestão de RSU. Base que subsidia a modelagem da rede logística proposta apresentada na seção seguinte. Em seguida, há o encerramento do artigo com a conclusão da pesquisa realizada.

\section{I MODELOS DE REDES LOGISTICAS E GESTÃO DE RESÍDUOS SÓLIDOS}

Neste item apresenta-se um levantamento do estado da arte dos principais modelos matemáticos utilizados na estruturação de redes logísticas, de forma geral, e na gestão de resíduos sólidos. Assim, fez-se uma seleção daqueles modelos que podiam vir a contribuir com os objetivos do trabalho. O processo de seleção compreendeu os seguintes passos:

a. Revisão bibliográfica sobre modelos matemáticos relacionados ao tema da pesquisa;

b. Compreensão clara da proposta de cada modelo e suas técnicas de solução;

c. Analise dos requerimentos de dados para executar os modelos;

d. Busca de uma base de dados existentes nos diferentes agentes envolvidos na logística e gestão de resíduos sólidos para testar esses modelos;

e. Avaliação de uma ferramenta computacional que permitisse executar os modelos selecionados e simular várias soluções;

f. Análise da experiência alcançada com cada modelo para fundamentar a modelagem proposta na pesquisa (MELQUIADES, 2015).

Devido à complexidade de uma série de modelos utilizados na literatura cientifica 
para estruturar redes logísticas, otimizar rotas e, sistemas de distribuição e coleta com vários pontos de origens e destinos e pontos de triagens, buscou-se aqueles modelos mais simplificados que fossem factíveis de serem programados e validados.

Vale ressaltar que a literatura é muito vasta quanto a esse tema, no entanto, nem todos os modelos podem ser testados, já que, muitas vezes apresentam alguma incompatibilidade, como conflito nas restrições, ou falta de alguma hipótese ou premissa.

Diante desse quadro, observou-se que era importante contar com uma ferramenta computacional que possibilitasse a execução dos modelos selecionados e preferencialmente não tivesse nenhum custo. Assim, realizou-se uma busca intensiva de softwares livres na Internet, chegando-se à conclusão que a melhor ferramenta computacional para ser utilizada era o software GLPK (MAKHORIM, 2008). O GLPK mostrou-se uma ferramenta muito pratica quanto a sua capacidade de execução dos algoritmos testados e de trabalhar com um número bastante considerável de variáveis e dados de entrada.

\subsection{Modelos de Redes Logísticas}

Uma proposta baseada num modelo de programação inteira mista não linear para o desenho de rede logística de distribuição integrada (direta e reversa) foi apresentada por Jeung (2005). Neste modelo a função objetivo minimiza os custos totais, que representam os custos operacionais, os custos de funcionamento das facilidades fornecidas e os custos de fluxos diretos e reversos. A técnica de solução desenvolvida para solucionar o problema foi um algoritmo genético.

Já Srivastava (2008) apresenta no nível metodológico uma estrutura conceitual combinando a modelagem descritiva com as técnicas de otimização para abordar o problema de logística reversa. Dessa forma, formula um modelo conceitual de logística reversa baseado em multiperíodo e com agregação de valor ao sistema. O modelo está fundamentado em três níveis: retorno dos produtos pós-venda e pós-consumo; captação desses produtos nos centros de coleta; transporte desses produtos aos centros de manutenção e remodelação ou aos centros de manufatura.

Um modelo de programação linear que minimiza o custo total para o transporte em uma rede de logística reversa foi proposto por Lee J. et al(2008). O modelo compreende três etapas: 1) os RSU coletados nas estações de coleta (ec) são transportados para os centros de triagem ( $c d)$; 2) nos centros de triagem ( $c d$ ) é realizada uma classificação dos RSU sob três critérios, RSU que podem ser reutilizados são transportados para os centros de reciclagem ( $r$ ); RSU que precisarem de algum processo então são transportados para os centros de transformação $(c t)$ e; aqueles resíduos sem valor são transportados para os centros de eliminação (e); e 3) os RSU processados nos centros de transformação $(c t)$ são transportados para as fábricas $(f)$.

Nessa última etapa proposta por Lee J. et al (2008), mantêm-se a seguinte 
premissa, se a quantidade de matéria-prima $(m)$ que vem dos centros de transformação (ct) é menor do que a demanda das fábricas $(f)$, então estas devem comprar essa matéria prima de seus outros fornecedores, mas se existe matéria-prima suficiente para atender a demanda das fábricas então, não se faz necessário os outros fornecedores, no entanto, o excesso deve ser distribuído aos centros de reciclagem ( $r$ ) e/ou centros de eliminação $(e)$.

Para resolver o modelo de logística reversa, Saman et al (2009) propõem um modelo de programação linear inteira mista para otimizar os custos de transporte e custos fixos de funcionamento das diferentes unidades produtivas que compõem a rede logística reversa. O modelo permite também, determinar o número necessário das diferentes unidades produtivas que compõem a rede.

O modelo de Saman et al (2009) também, funciona em várias etapas: os RSU são entregues nos centros de atenção ao cliente (I), que depois são enviadas as estações de coleta $(e c)$. Nas estações de coleta se realiza uma triagem. Os RSU's com possibilidades de serem reciclados ou recuperados são enviados aos centros de recuperação $(c r)$ e aqueles que não tem mais utilidade são encaminhados aos centros de eliminação $(e)$.

Devido à complexidade do problema os autores fazem uso da metaheurística simulated annealing para obter soluções. O modelo matemático procura otimizar a rede logística reversa, buscando atender a demanda dos clientes que descartam seus RSU no sistema. O modelo de otimização trata de determinar, em função das capacidades estabelecidas ás unidades produtivas da rede, o número de unidades necessária de cada uma delas, assim como as quantidades de volume de carga que deve sair de cada uma delas de forma a minimizar os custos de transporte na rede.

Sterle (2010) explica que é possível desenvolver um sistema de logística urbana em dois níveis, baseando-se numa extensão do PRV. O modelo consiste em concentrar a carga que chega para a área urbana em um determinado conjunto de plataformas $(C P)$, localizadas no cordão externo (limítrofe) da área urbana. Nessas plataformas $(p)$ a carga é classificada segundo a localização geográfica do destinatário da carga e distribuída a um conjunto de centros menores (CS) localizados nos bairros ou distritos pertencentes à área urbana. Esses centros são denominados pelo autor como unidades satélites $(s)$.

Devido a natureza combinatória do problema tem-se uma complexidade computacional para resolver o modelo, assim observa-se que quando mais componentes ou variáveis são acrescentados, o tempo de processamento para encontrar uma solução vai ficando bem maior. Dessa forma, Sterle (2010) propõe uma meta heurística (busca tabu) que resolve o problema em pouco tempo computacional, mas não garante que a solução seja ótima.

O Modelo de Qureshi et al (2010) é uma variante do Problema de Roteirização e Programação de Veículos com Janelas de Tempo (PRVPJT) conhecido como o Problema de Roteirização e Programação de Veículos com Janelas de Tempo Meio 
Suave (PRVPJTMS). O modelo proposto pelo referido autor aplica penalidade ao veículo quando este se atrasa e chega depois do tempo estabelecido na janela de tempo do cliente. A representação matemática do modelo de Qureshi et al (2010 é semelhante ao PRVJT, mas a janela de tempo é estendida para , onde .

Conforme Badran (2006) o gerenciamento dos RSU compreende o gerenciamento de três grandes sistemas. O primeiro é relacionado ao sistema físico-operacional, que começa com a otimização do processo de coleta dos resíduos, continua com o tratamento adequado (reciclagem e/ou reutilização) até a disposição final dos mesmos, seguindo as normas ambientais exigidas.

O segundo sistema diz respeito aos aspectos institucionais, onde o gerenciamento deve considerar todos os agentes que participam direta e indiretamente em todos os processos de forma a garantir o funcionamento do sistema, qualidade do serviço, a preservação do meio ambiente e o bem-estar da comunidade. Isso inclui a forma de relacionamento e participação de todos, contemplando programas de conscientização e responsabilidade social. O terceiro sistema refere-se ao sistema jurídico e regulatório.

Quanto ao sistema físico-operacional há várias propostas para otimizar os processos e determinar a quantidade necessária de estações. Um modelo de programação linear inteira mista para a seleção das estações de coleta necessárias numa região urbana ou cidade foi proposta por (BADRAN, 2006). Ele divide a região urbana em zonas (z), os RSU que são coletados nessas zonas são transportados as estações de coleta $(e c)$. Nesse local, os RSU passam por uma triagem, os que são plausíveis de recuperação ou de reciclagem são transportados para os centros de triagem (cd) e o resto é transportados para os aterros (a).

\subsection{Proposta de modelagem para coleta e transporte de rsu}

Em geral, a configuração de uma rede logística reversa de uma cidade segue a estrutura apresentada na Figura 1. Independente de como seja feita o processo de coleta e transporte dos RSU em uma cidade, esta pesquisa propõe três etapas do processo de modelagem da rede logística reversa:

a. Roteirização da coleta dos RSU gerados nas zonas urbanas e transporte dos mesmos para as estações de coleta;

b. Transporte dos RSU das estações de coleta selecionadas até os centros especializados sob duas propostas diferentes, as quais se descrevem a continuação;

c. Teste e validação do modelo com a aplicação em um estudo de caso. 


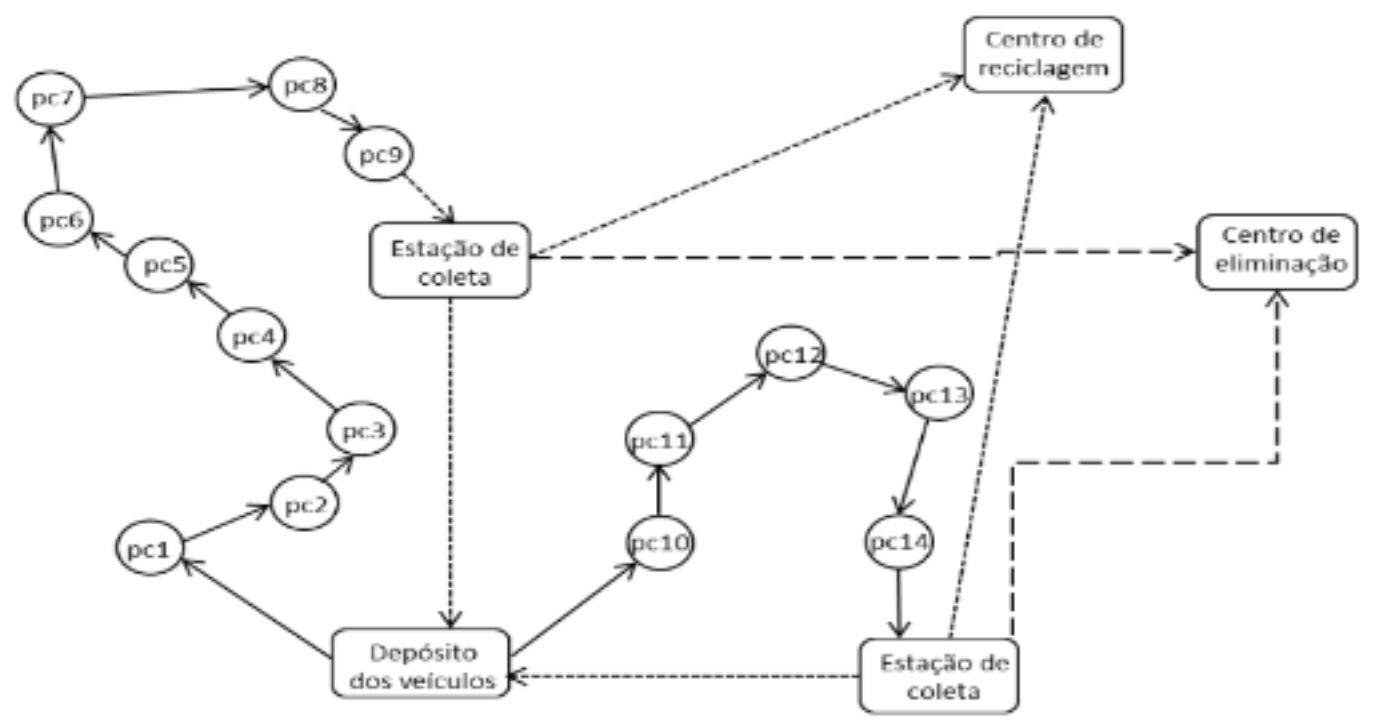

Figura 1: Esquema do processo de coleta e transporte de RSU

Fonte: Elaboração própria

Dependendo do comportamento da comunidade e da política do governo local, pode apresentar-se duas situações, os usuários não separam devidamente os RSU ou caso contrário, separam. Caso se dê a primeira situação precisar-se-á de centros de triagem para fazer a devida separação, o que aumenta os custos do sistema, devido a necessidade de investimento na construção de uma instalação desse tipo e aos seus custos de manutenção e operação. Na Figura 2 ilustra-se o primeiro caso. Na segunda situação (caso) são eliminados os centros de triagem.

\subsection{Primeira Etapa}

A primeira etapa do processo de modelagem da rede logística reversa consiste em formular o problema de roteirização e seleção das estações de coleta. Baseado no PRVJT e no modelo de Buhrkal et al (2012) formula-se um modelo que minimize o custo total obtido no processo de geração do melhor plano de roteirização, que atenda a demanda de todos os pontos de coleta e o transporte dos RSU coletados para as estações de coleta selecionadas.

A inserção de janelas de tempo no modelo é com o propósito de estabelecer períodos prefixados para a coleta de RSU nos pontos de coleta. Essa variável permitirá otimizar a frota ao longo do dia e estabelecer melhor as estações de coleta. Vários autores, entre eles, Buhrkal et al (2012) agregam um componente interessante em seus modelos matemáticos, que consiste em quantificar as emissões de $\mathrm{CO}_{2}$ dos veículos alocados em uma rota, mostrando sua relevância.

Esse elemento somado à função objetivo do modelo influencia no processo de roteirização e seleção das estações de coleta, já que na medida em que aumenta o valor da emissão de $\mathrm{CO}_{2}$ pelo aumento do número de veículos circulando na rede viária, o modelo procura encontrar outra combinação que minimize os custos de transporte e de instalação das estações de coleta. Tomando em consideração esse 
aspecto, passa-se a utilizar esse componente na formulação matemática do modelo proposto na pesquisa.

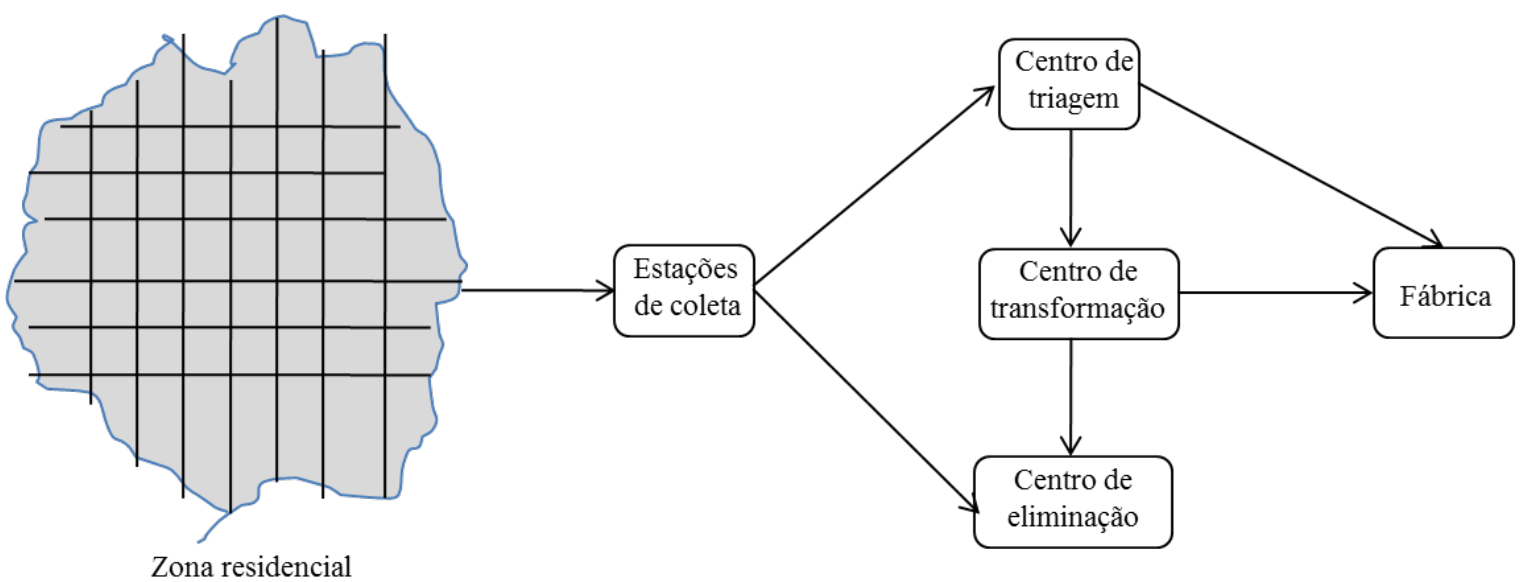

Figura 2: Proposta do Caso I

Fonte: Elaboração própria

Função Objetivo:

$$
\operatorname{Min} C T=\sum_{i, j=1 ; i \neq j}^{p^{\prime}} \sum_{k=1}^{k^{\prime}} c_{i, j} x_{i, j, k}+\sum_{e c=1}^{n} c f_{e c} y_{e c}+\sum_{i, j=1 ; i \neq j}^{p^{\prime}} \sum_{k=1}^{k^{\prime}} c c\left(\frac{e m_{k}}{q_{k}}\right) x_{i, j, k}
$$

Minimizar os custos de transporte na roteirização e transporte as estações de coleta + custos de abertura das estações de coleta selecionadas + quantificação das emissões de $\mathrm{CO}_{2}$ pelos veículos utilizados no processo de roteirização e transporte

Sujeito a:

- Restrição 1, garante que o veículo k deixa o depósito para iniciar uma rota;

$$
\sum_{j=1}^{h^{\prime}} x_{0, j, k}=1, \quad \forall k \in K
$$

- Restrição 2, garante que o veículo k depois, de visitar a última estação de coleta retorna ao depósito;

$$
\sum_{e c=1}^{n} x_{e c, 0, k}=1, \quad \forall k \in K
$$


- Restrição 3, cada ponto de coleta é atendido exatamente uma vez;

$$
\sum_{i=1 ; i \neq j}^{p^{\prime}} \sum_{k=1}^{k^{\prime}} x_{i, j, k}=1, \quad \forall j \in P C
$$

- Restrição 4, estabelece a conservação de fluxo entre pontos de coleta e estações de coleta;

$$
\sum_{i=1}^{p^{\prime}} x_{i, j, k}=\sum_{i=1}^{p^{\prime}} x_{j, i, k}, \quad \forall j \in P C \cup E C ; \quad k \in K
$$

- Restrição 5, estabelece as janelas de tempo para o atendimento nos pontos de coleta;

$$
a_{i} \leq W_{i, k} \leq b_{i}, \quad \forall i \in P C ; k \in K
$$

(6)

- Restrição 6, modela o tempo de atendimento nos pontos de coleta;

$$
W_{i, k}+s_{i}+t_{i, j} \leq W_{j, k}+100000\left(1-x_{i, j, k}\right) \quad \forall i, j \in P C \cup E C ; k \in K ; i \neq j
$$

- Restrição 7, estabelece que os veículos comecem o processo de coleta vazio e terminem vazios depois de concluir esse processo;

$$
\sum_{i=0, i=8}^{u} D_{i, k}=0, \quad \forall k \in K
$$

- Restrição 8, relação que estabelece o equilíbrio dos RSU acumulados nos pontos de coleta e nas estações de coleta;

$$
D_{i, k}+q_{i} \leq D_{j, k}+100000\left(1-x_{i, j, k}\right), \forall i \in P C \cup E C ; j \in N ; k \in K ; i \neq j
$$

- Restrição 9, a quantidade de RSU coletados tem que ser menor ou igual as capacidades dos veículos coletores; 


\section{$D_{i, k} \leq q_{k}, \quad \forall i \in P C ; k \in K$}

- Restrição 10, estabelece que o atendimento dos pontos de coleta pelos veículos é limitado;

$$
\sum_{i=1}^{p^{\prime}} \sum_{j=1}^{h^{\prime}} x_{i, j, k} \leq S, \quad \forall k \in K
$$

- Restrição 11, somente é possível atribuir uma estação de coleta a um veículo, caso a estação fosse selecionada para oferecer atendimento;

$$
x_{i, e c, k} \leq y_{e c}, \quad \forall i \in N ; e c \in E C ; k \in K ; i \neq e c
$$

- Restrições de não negatividade das variáveis e das variáveis binárias;

$$
\begin{gathered}
D_{i, k} \geq 0, \quad \forall i \in N ; k \in K \\
W_{i, k} \geq 0, \quad \forall i \in N ; k \in K \\
x_{i, j, k}=\{0,1\}, \quad \forall i, j \in N ; \quad k \in K \\
y_{e c}=\{0,1\}, \quad \forall e c \in E C
\end{gathered}
$$

Fórmula proposta pela Volvo Trucks (2010) para emissão de CO2 em kg/(ton-km) e inserida na FO do modelo:

$$
\text { Emissao CO2 em } \frac{\mathrm{kg}}{\text { ton. } \mathrm{km}}=c c\left(\frac{\mathrm{em}_{k}}{q_{k}}\right)
$$

\subsection{Segunda Etapa}

Consiste em analisar o processo de transporte dos RSU coletados nessas estações para os centros especializados, de acordo com os casos I e II levantados no 
início de este item. O processo de transporte foi otimizado fazendo uma variação do modelo proposto em Lee J. et al. (2009). Para o Caso I, apresenta-se o modelo que otimiza os custos de transporte dos RSU entre os diferentes centros especializados ou unidades produtivas que compõem a rede logística reversa. Ao modelo é agregado o componente de quantificação de emissões de $\mathrm{CO}_{2}$ produzidos pelos veículos no processo de transporte. Para o Caso II foi feita uma variação do modelo apresentado para o Caso I, mas sem considerar os centros de triagem.

Caso I: Função Objetivo:

$$
\begin{aligned}
\text { Min CT } & =\sum_{e c, c d=1}^{n, n^{\prime}} c_{e c, c d} x_{e c, c d}+\sum_{e c, e=1}^{n, e^{\prime}} c 1_{e c, e} x 1_{e c, e}+\sum_{c d, f=1}^{n^{\prime}, f^{\prime}} c 2_{c d, f} x 2_{c d, f} \\
& +\sum_{c d, c t=1}^{n^{\prime \prime}, n^{\prime \prime}} c 3_{c d, c t} x 3_{c d, c t}+\sum_{c t, f=1}^{n^{\prime \prime}, e r} c 4_{c t, f} x 4_{c t, f}+\sum_{c t, e=1}^{k^{\prime}, m^{\prime}, m^{\prime}} c 5_{c t, e} x 5_{c t, e} \\
& +\sum_{k, i, j=1}^{\sum_{e c, c d=1}^{n, n^{\prime}}} f f_{k, i, j} Y_{k, i, j}+\frac{\sum_{k=1}^{k^{\prime}} c c\left(\frac{e m_{k}}{q_{k}}\right)\left(Y_{k, e c, c d}\right)\left(D i s t_{E c_{c D}}\right)}{m}
\end{aligned}
$$

Minimizar os custos de transporte entre os centros especializado se reduzir as emissões de $\mathrm{CO}_{2}$

Sujeito a:

- Restrição 1, modela as capacidades das estações de coleta;

$$
\sum_{c d, e=1}^{n \prime, e \prime} x_{e c, c d} \leq a_{e c}, \quad \forall e c \in E C
$$

- Restrição 2, modela as capacidades dos centros triagem;

$$
\sum_{c d, f=1}^{n ", f \prime}\left(x 2_{c d, f}+x 3_{c d, c t}\right) \leq b_{c d}, \quad \forall c d \in C D, f \in F
$$

- Restrição 3, modela as capacidades dos centros de transformação; 


$$
\sum_{f, e=1}^{f \prime, e \prime}\left(x 4_{c t, f}+x 5_{c t, e}\right) \leq u_{c t}, \quad \forall c t \in C T
$$

- Restrição 4, limita o uso dos veículos para aquelas rotas selecionadas;

$$
\sum_{k=1}^{k^{\prime}} b_{-} b_{k, e c, c d} Y_{k, e c, c d} \leq x_{e c, c d}, \quad \forall e c, \in E C, c d \in C D
$$

- Restrição 5, mantem o equilíbrio do fluxo de carga nas estações de coleta, centros de triagem e centros de transformação;

$$
\sum_{k=1}^{k^{\prime}} b_{-} b_{k, e c, c d} Y_{k, e c, c d} \leq x_{e c, c d}, \quad \forall e c, \in E C, c d \in C D
$$

- Restrição 6, mantem o equilíbrio do fluxo de carga nas estações de coleta, centros de triagem e fábricas;

$$
\sum_{e c=1}^{n} x_{e c, c d}=\sum_{f=1}^{f^{\prime}} x 2_{c d, f}, \quad \forall c d \in C D
$$

- Restrição 7, mantem o equilíbrio do fluxo de carga nos centros de triagem, transformação e fábricas;

$$
\sum_{c d=1}^{n \prime} x 3_{c d, c t}=\sum_{f=1}^{f \prime} x 4_{c t, f}, \quad \forall c t \in C T
$$

- Restrição 8, mantem o equilíbrio do fluxo de carga nos centros de triagem, 
transformação e centros de eliminação;

$$
\sum_{c d=1}^{n^{\prime}} x 3_{c d, c t}=\sum_{e=1}^{e \prime} x 5_{c t, e}, \quad \forall c t \in C T
$$

- Restrições de não negatividade de todas as variáveis (inclusive as binárias);

$$
\begin{array}{r}
x_{e c, c d}, x 1_{e c, e}, x 2_{c d, f}, x 3_{c d, c t}, x 4_{c t, f}, x 5_{c t, e} \\
Y_{k, i, j}=\{0,1\}, \forall k \in K, i, j \in N
\end{array}
$$

\subsection{Estudo de Caso para o Distrito de Trujillo no Peru}

Para aplicar o disposto na Lei Geral de Resíduos Sólidos 27314/2000 de Perú e testar e validar os modelos propostos nessa pesquisa foi necessário fazer uma série de levantamento de informações e estudos complementares. Como estudo de caso foi escolhido o Distrito de Trujillo que pertence à Província de Trujillo no Departamento de La Libertad, da República de Perú. O Distrito de Trujillo, localizado a 34 metros acima do nível do mar, tem uma área de $39,36 \mathrm{~km}^{2}$ (2,2 \% da Província de Trujillo) e uma população de 317.900 habitantes (INEI, 2014). A densidade populacional é de 7.035 $\mathrm{hab} / \mathrm{km}^{2}$.

Assim, os modelos programados com a ferramenta computacional GLPK utilizaram como dados de entrada as informações do Distrito de Trujillo, fornecida pelo Serviço de Gestão Ambiental de Trujillo (SEGAT, 2014). Para operacionalização da coleta dos RSU, essa instituição, divide o Distrito em cinco zonas, além do centro da cidade (CC). A Tabela 1 mostra o número de residências por classe econômica e social e por zona geradora de RSU, assim como o volume total gerado por zonas e a taxa de geração em kg/residência/dia segundo a classe econômica e social com um nível de confiança de 95\%.

O total de RSU gerados no Distrito de Trujillo é de aproximadamente 153.772,33 $\mathrm{kg} / \mathrm{dia}$, os quais são coletados por domicilio pela empresa responsável. Esta não conta com um plano de rotas que otimize o serviço de coleta. O sistema utilizado é empírico e intuitivo. No plano Integral de Gestão Ambiental de resíduos sólidos para a Província de Trujillo (2010-2020) reconhece-se que a coleta dos RSU tem chegado algumas vezes a $100 \%$ de cobertura, mas é realizada sem respeitar os horários estabelecidos.

Depois do processo de coleta, os RSU são transportados direto para o lixão El 
Milagro. Trujillo não tem aterro sanitário, assim também não têm estações de coleta, centros de triagem e de transformação devidamente formalizados e controlados pelo Município. Para melhorar esse quadro, essa pesquisa validou os modelos fazendo o planejamento da rede logística reversa da Zona 5 do Distrito de Trujillo. Como a Zona 5 é muito extensa, questão que poderia vir inviabilizar os testes, ela foi separada em três subzonas e modeladas separadamente. Assim, a primeira subzona compreende os subsetores de La Merced e La Arboleda_San Eloy, a segunda, o subsetor de San André e a terceira, o subsetor de Monserrate. Por restrições de número de páginas somente se apresentará os resultados do primeiro subsetor.

\begin{tabular}{c|c|c|c|c|c|c|c|c|c|c}
\hline Zona & A & B & C & $\begin{array}{c}\text { Resid } \\
\text { encias }\end{array}$ & \% & $\begin{array}{c}\text { Quantidade } \\
\text { gerada de } \\
\text { RSU (kg/ } \\
\text { dia) }\end{array}$ & A & B & C & Média \\
\hline 1 & 2.429 & 6.518 & 2.212 & 11.159 & 19 & $29.906,12$ & 3,16 & 2,44 & 3,06 & 2,68 \\
\hline 2 & - & 8.209 & 3.022 & 11.231 & 20 & $29.088,29$ & - & 2,53 & 2,87 & 2,59 \\
\hline 3 & - & 9.813 & 3.667 & 13.480 & 23 & $38.418,00$ & - & 2,85 & 2,85 & 2,85 \\
\hline 4 & - & 6.293 & 2.337 & 8.630 & 15 & $22.179,10$ & - & 2,52 & 2,77 & 2,57 \\
\hline 5 & 2.686 & 7.002 & 2.339 & 12.027 & 21 & $31.510,74$ & 2,55 & 2,46 & 2,87 & 2,62 \\
\hline CC & 1.043 & - & - & 1.043 & 2 & $2.670,08$ & 2,56 & - & - & 2,56 \\
\hline Total & $\mathbf{6 . 1 5 8}$ & $\mathbf{3 7 . 8 3 5}$ & $\mathbf{1 3 . 5 7 7}$ & $\mathbf{5 7 . 5 7 0}$ & $\mathbf{1 0 0}$ & $\mathbf{1 5 3 . 7 7 2 . 3 3}$ & $\mathbf{2 , 7 5}$ & $\mathbf{2 , 5 7}$ & $\mathbf{2 , 8 8}$ & $\mathbf{2 , 6 6}$ \\
\hline & $\mathbf{1 0} \%$ & $\mathbf{6 6} \%$ & $\mathbf{2 4 \%}$ & & & & & & & \\
\hline
\end{tabular}

Tabela 1: Residências por classe econômica e social e por zonas geradoras de RSU - Volume de RSU gerado por zona por dia e taxas de geração em kg/residência/dia

Fonte: Baseado em Huerta (2012)

2.5.1 Etapa 1: Aplicação do Modelo PRVJT nos Subsetores La Merced e La Arboleda_San Eloy

De acordo com Huerta (2012), La Merced tem 589 residências e gera 1.566,74 kg/dia de RSU e a La Arboleda_San Eloy abrange 530 residências e produz 1.409,80 kg/dia de RSU. Com esses dados estimou-se 20 pontos de coleta para La Merced e 17 para La Arboleda_San Eloy 17, em total, 37 pontos de coletas com uma capacidade de 90 quilogramas/ponto. Fizeram-se as seguintes considerações: conservar a capacidade dos veículos coletores igual aos que atualmente realizam o serviço no Município de Trujillo, 7 toneladas; manter o tempo de atendimento em cada ponto de coleta em aproximadamente 4 minutos e, a janela de tempo no intervalo de 7:00 às 10:00 horas.

Os resultados mostram que é possível o atendimento dos pontos de coleta somente com um veículo coletor e uma estação de coleta. A Figura 3 mostra a rota e a ordem em que o veículo visita os pontos coletores, ele inicia no ponto D0, depois passa coletando os RSU de todos os pontos coletores, uma vez que visita o último ponto coletor se dirige à estação de coleta selecionada, ec1, para descarregar e depois retorna de novo ao D0. O custo total de operação do sistema foi de $\$ 173.995,00$, 
um valor bem aceito pelos especialistas da SEGAT, além de ser bem menor que o atual cenário, embora não foi possível quantificar essa redução. O CO2 gerado foi de $0,003984 \mathrm{~kg} / \mathrm{ton}-\mathrm{km}$.

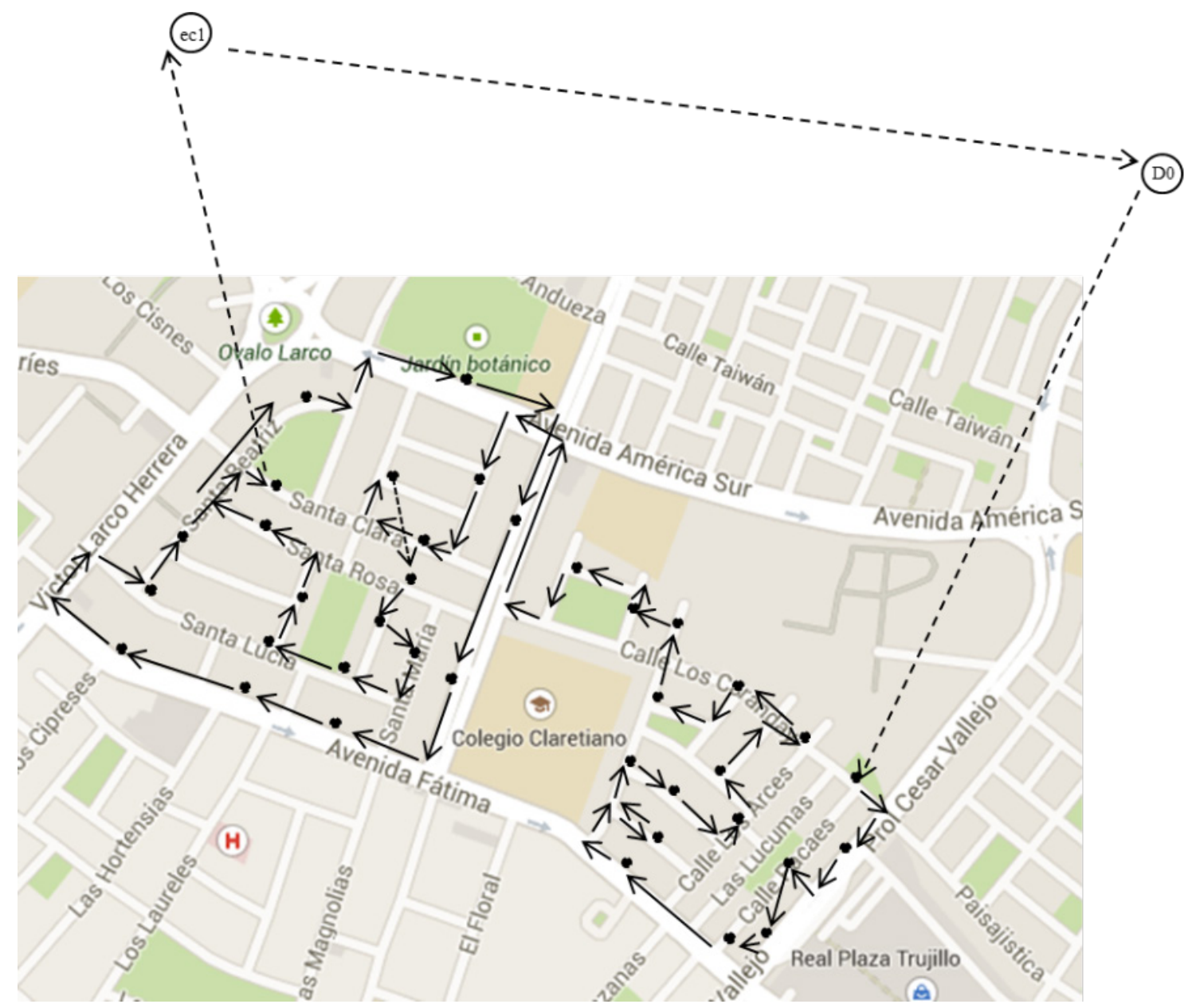

Figura 3: Roteirização nos Subsetores La Merced_La Arboleda_San Eloy Fonte: Resultados obtidos com o GLPK

\subsubsection{Etapa 2: Aplicação do Modelo de Transporte nos Subsetores La Merced} e La Arboleda_San Eloy: Caso I e Caso II

Para o Caso I, dos 2.977,54 kg de RSU coletados e alocados na ec1, 2.577,00 é transferido para o centro de triagem $c d 1$, o restante, 400,54 kg é enviado para o cd2. Daqui têm-se duas alternativas, se os RSU estão higienizados e prontos para utilização como matéria prima, eles são encaminhados diretos para a única fábrica da rede logística reversa. Caso contrário, eles são transferidos aos centros de transformação. O cd2 envia seus 400,54 kg ao ct2, o cd1 remete 1.750,00 kg para o ct1 e 827,00 kg para o ct2. Depois do processo de transformação, o ct1 expede $1.700,00 \mathrm{~kg}$ para a fábrica e o ct2, 1.200,00 kg. Ou seja, a fábrica recebe em total $2.900,00 \mathrm{~kg}, 77,00 \mathrm{~kg}$ a menos que quando vem direto dos centros de triagem. Esses 77,00 kg são encaminhados para o centro de eliminação. 


\section{Caso I}

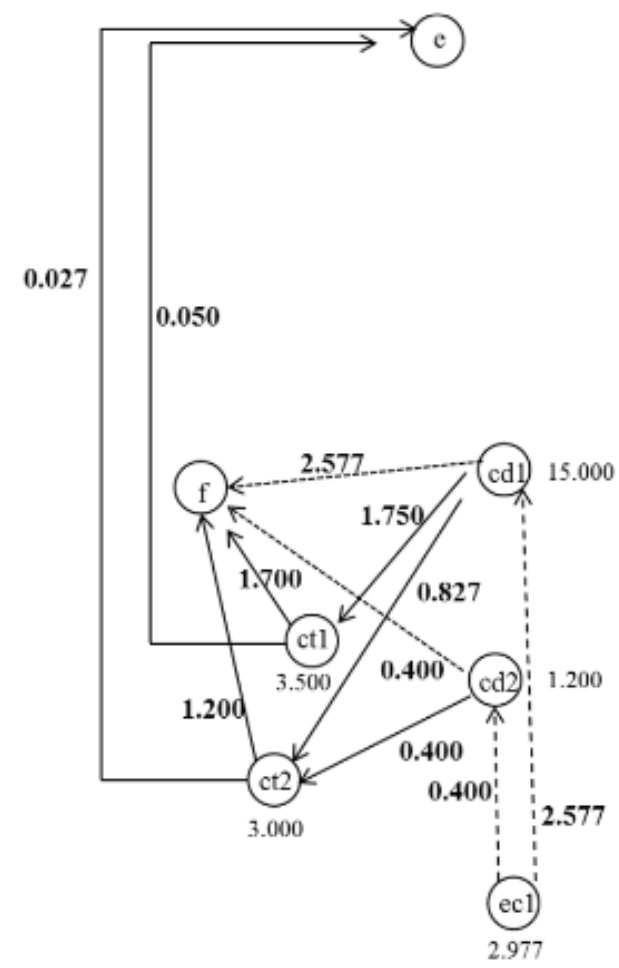

Caso II

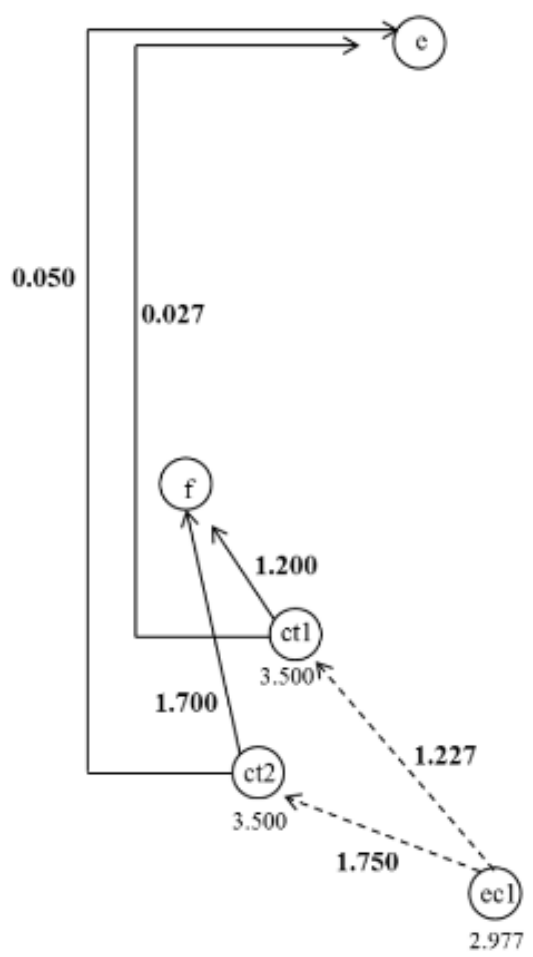

Figura 4: (a) Transporte dos RSU para os centros especializados, Caso I. (b) Transporte dos RSU para os centros especializados, sem centro de triagem, Caso II

Nota: Os valores das unidades estão em decimais, notação em espanhol

Fonte: Resultados obtidos com o GLPK

No caso II não existem os centros de triagem, assim dos $2.977,00 \mathrm{~kg}$ de RSU que recebe a estação de coleta $e c 1,1.227,00 \mathrm{~kg}$ são transportados para o centro de transformação ct1 e o restante, $1.750,00$ kg para o ct2. Do centro de transformação ct1 são remetidos $1.200 \mathrm{~kg}$ para a fábrica e $27,00 \mathrm{~kg}$ para o centro de eliminação. Do ct2 são enviados $1.700,00$ kg à fábrica e 50,00 kg para o centro de eliminação.

\section{I CONCLUSÕES E RECOMENDAÇÕES}

A modelagem proposta calcula os fluxos na rede logística reversa, permitindo dimensionar a quantidade e capacidade das unidades produtivas e dos veículos, sendo possível aplicá-lo em várias regiões, sem necessidade de grandes mudanças na modelagem proposta. No modelo de roteirização com o GLPK obteve-se como resultado o roteamento ótimo para o atendimento dos clientes (pontos de coleta) e alocação apropriada das estações de coleta, de forma a facilitar o acesso de veículos e reduzir os custos de transporte e os conflitos com o fluxo de tráfego da rede viária da cidade em estudo, por meio da seleção das melhores rotas. Já no modelo de transporte, o GLPK mostra as quantidades de RSU coletadas das estações de coleta selecionadas que são transportadas para os centros especializados para seguir algum processo segundo seja o valor de tais resíduos. Uma contribuição adicional, foi a 
mensuração do $\mathrm{CO}_{2}$ gerado pelos veículos coletores e de transporte obtidos com o GLPK.

A modelagem proposta nessa pesquisa baseia-se na não existência da coleta domiciliar, ou seja, parte-se da premissa que a população participa ativamente da coleta seletiva e leva seus RSU até um ponto de coleta. Essa premissa reduz sensivelmente os custos de coleta e de transporte dos RSU, fato que ficou demonstrado nos testes realizados, uma economia que tem seus reflexos em toda a rede, já que reduz a frota de veículos pesados circulando pelas vias urbanas. Neste caso, o governo local desempenha um papel importante, porque tudo dependerá das políticas e intervenções dele, o que deverá fazer que o plano de ação e diretrizes cumpra as metas da Lei dos Resíduos Sólidos.

\section{REFERÊNCIAS}

ABREU, P. H. Projeto de Acessibilidade para o Transporte de Carga e Coleta de Resíduos Sólidos nas Quadras Comerciais do Plano Piloto. 2015. 55f. Trabalho de Projeto Final do Curso de Engenharia Civil - Faculdade de Tecnologia, Universidade de Brasília, Distrito Federal, 2015.

ASSOCIAÇÃO BRASILEIRA DE EMPRESAS DE LIMPEZA PÚBLICA E RESÍDUOS - ESPECIAIS.). Panorama dos Resíduos Sólidos no Brasil 2013. ABRELPE, 2014.

BADRAN, M.F.; EL-HAGGAR, S.M. Optimization of municipal solid waste management in Port Said - Egypt. Waste Management, Elsevier, v. 26, p. 534-545, 2006. ISSN: 0956-053X. DOI:10.1016/j. wasman.2005.05.005.

BUHRKAL, K.; LARSEN, A.; ROPKE, S. The waste collection vehicle routing problem with time windows in a city logistics context. The Seventh International Conference on City Logistics. Procedia - Social and Behavioral Sciences, Elsevier, v. 39, p.241-254, december, 2012. DOI:10.1016/j. sbspro.2012.03.105.

CERNA, N. S. S. Contribuição para modelagem de um sistema de avaliação da qualidade dos elementos de infraestrutura de mobilidade urbana. 2014. Dissertação (Mestrado em Transportes) Faculdade de Tecnologia, Universidade de Brasília, Distrito Federal, 2014.

HUERTA, G.; VÁSQUEZ, J. Estudio de caracterización de los residuos sólidos urbanos. Distrito de Trujillo. Municipalidad Provincial de Trujillo, Perú, 2012.

INSTITUTO NACIONAL DE ESTADISTICA - INEI. Estado de la población peruana 2014a. Disponível em http://www.inei.gob.pe/media/MenuRe-cursivo/publicaciones_digitales/Est/Lib1157/libro.pdf. Acesso em 20/08/2014.

JEUNG KO H.; EVANS, G.W. A genetic algorithm-based heuristic for the dynamic integrated forward/ reverse logistic network for 3PL. Computer \& Operations Research, Elsevier, 2005. DOI:10.1016/j. cor.2005.03.004.

LEE, J.; GEN, M.; RHEE, K. Reverse logistic network problem using priority-based genetic algorithm. International journal of information system for logistics and management. 2008.

MAKHORIN, A. Modeling language GNU MathProg. Draft Edition for GLPK, Version 4.34, 2008.

MELQUIADES, J. A.R. Modelagem para a roteirização do processo de coleta e transporte dos 
resíduos sólidos urbanos. 2015. Tese (Doutorado em Transportes) - Faculdade de Tecnologia, Universidade de Brasília, Distrito Federal, 2015.

MONTEIRO, M. J. Logística Reversa: uma proposta de gestão integrada de resíduos sólidos nos setores comerciais. 2013. Dissertação (Mestrado em Transportes) - Faculdade de Tecnologia, Universidade de Brasília, Distrito Federal, 2013.

OLIVEIRA, C.P. Planejamento Integrado e Participativo de Coleta Seletiva nas Quadras Comerciais do Plano Piloto. 2014. 48 f. Trabalho de Projeto Final do Curso de Engenharia Civil Faculdade de Tecnologia, Universidade de Brasília, Distrito Federal, 2014.

SERVICIO DE GESTIÓN AMBIENTAL DE TRUJILLO - SEGAT. Mapa de zonas de limpieza pública. 2014. Disponível em http://www.segat.gob.pe/. Acesso em 27/02/2014.

SRIVASTAVA, S.K. Network design for reverse logistics. OMEGA, The International Journal of Management Science, Elsevier, v.36, issue 4, p.535-548. August 2008. DOI:10.1016/j. omega.2006.11.012. 


\section{SIMILARIDADES E DISSIMILITUDES DAS CARACTERÍSTICAS DOS CORREDORES DE TRANSPORTE PÚBLICO EM CIDADES GLOBAIS}

Maria Ivana Vanderlei Universidade Federal de Pernambuco - Recife -

PE/Brasil

\section{Leonardo Herszon Meira}

Universidade Federal de Pernambuco - Recife -

PE/Brasil

Oswaldo Cavalcanti da Costa Lima Neto

Universidade Federal de Pernambuco - Recife -

PE/Brasil

RESUMO: Este artigo tem como objetivo apresentar as similaridades e dissimilitudes dos corredores de transporte, analisando as variáveis operacionais e econômicas, com modos de transportes diferentes e suas relações com as características específicas das cidades globais. Os objetivos foram obtidos através do levantamento das informações socioeconômicas das cidades e das características dos corredores de transporte, realizando agrupamentos das características dos corredores, examinando as variáveis mais importantes e fazendo uma análise dos dados. Sendo utilizada a metodologia de tratamento dos dados coletados, com a comparação e constatação de semelhanças e diferenças, através da análise dos resultados, possibilitando a comparação dos modos de transportes. A hipótese apresentada é que a análise e comparação entre os corredores já implantados ou em implantação, poderá auxiliar os gestores na tomada de decisão, na escolha do modo de transporte a ser implantado nas cidades que gerenciam.

PALAVRAS-CHAVES: Corredores de Transporte Público, BRS, BRT, VLT, Metrô

ABSTRACT: This article aims to present the similarities and dissimilarities of transportation corridors, analyzing the operational and economic variables, with different transport modes and their relation with the specific characteristics of global cities. The objectives were obtained by surveying the socioeconomic information of the cities and the characteristics of the transport corridors, by grouping the characteristics of the corridors, examining the most important variables and analyzing the data. The methodology used for the treatment of the collected data was used, with the comparison and verification of similarities and differences, through the analysis of the results, allowing the comparison of modes of transport. The hypothesis presented is that the analysis and comparison between the corridors already deployed or in implantation, can help the managers in the decision making, of the choice of the mode of transport to be implanted in the cities that they manage.

KEYWORDS: Public Transportation Corridors, BRS, BRT, VLT, Subway 


\section{I INTRODUÇÃO}

Este artigo tem como objetivo apresentar as similaridades e dissimilitudes dos corredores de transporte em diferentes cidades do mundo, analisando as variáveis operacionais e econômicas dos diferentes modos de transporte presentes e estudando suas relações com as características destas cidades.

Os objetivos são alcançados através do levantamento das informações socioeconômicas das cidades e das características dos corredores de transporte, realizando agrupamentos das características dos corredores, analisando as variáveis mais importantes e efetuando um tratamento estatístico para a análise dos dados.

Sendo utilizada a metodologia de tratamento dos dados coletados, com a comparação e constatação de semelhanças e diferenças dos corredores e de suas respectivas cidades, através da análise dos resultados, possibilitando a comparação dos modos de transportes. A hipótese apresentada é de que a análise e comparação entre os corredores já implantados ou em implantação, poderá auxiliar os gestores na tomada de decisão, na escolha do modo de transporte a ser implantado nas cidades que gerenciam.

Esta análise é efetuada através de condicionantes conceituais e metodológicos que permitem perceber as características dos modos de transporte e assim agrupar as similaridades e dissimilitudes dos corredores de transporte já implantados em algumas cidades do mundo e, através das experiências anteriores, aproveitar as boas ideias e inovações para diminuir os impactos negativos, e melhorar a mobilidade da cidade.

Segundo o relatório da Moovit (2016), as cidades globais enfrentam muitos problemas com a mobilidade, com longos tempos de espera e de viagem, grandes distâncias percorridas, viagens a pé e déficit nos transportes públicos. Esta situação é responsável por uma constante preocupação dos gestores das cidades em melhorar a qualidade dos transportes público para oferecer melhor qualidade de vida.

A cidade de São Paulo aparece no Relatório global sobre o uso do transporte público nas grandes cidades (MOOVIT, 2016), numa posição a baixo de Toronto onde as pessoas gastam em média 96 minutos nos deslocamentos de ida e volta ao trabalho. Em São Paulo, são 93 minutos, contra os 87 minutos de Nova York e 62 minutos em Berlim e Madri, que estão na melhor posição do ranking em relação ao tempo perdido. Em relação a América Latina São Paulo está a baixo só de Bogotá, que gasta 97 minutos, enquanto cidade do México gasta 88, Santiago 84, Buenos Aires 79 e a melhor colocada é Montevideo que gasta 65 minutos nos deslocamentos de ida e volta ao trabalho.

Estes longos tempos de viagens é um fator que torna o transporte público um ponto crítico para que os cidadãos tenham acesso a bens e serviços em áreas urbanas, com interferência direta na sua qualidade de vida, e ainda mais, influindo na atividade econômica e na conectividade social das cidades. Para a maioria da população o 
transporte público é a única maneira de acessar empregos, educação, serviços e outras atividades essenciais para a promoção do desenvolvimento econômico e social das cidades.

O aumento da mobilidade urbana é importante para o desenvolvimento das cidades, porém atenção especial deve ser dedicada ao uso racional do espaço urbano. "Pois uma faixa dedicada aos ônibus apresenta uma capacidade de transporte, em média, dez vezes superior a uma dedicada ao transporte privado" (Lindau, 2013), constata assim, a necessidade de se investir em corredores que deem prioridade ao transporte público, reduzindo os congestionamentos.

Devido ao impasse da mobilidade, cresce as discussões em torno das questões sobre a qualidade dos transportes público em relação a qualidade do serviço ofertado e a potencialidade das alternativas de transportes, com a finalidade de encontrar alternativas para reduzir os acidentes de trânsito, poluição do ar, sonora e ambiental e congestionamentos, com a política do governo de facilitar o crédito para aquisição de automóveis particular e motocicletas, o transporte público precisa torna-se mais atrativo, revendo suas características. (ANTP, 2010).

Em razão dos problemas de mobilidade, ocorreu a ampliação da discussão acerca dos melhores modos de transporte nas grandes cidades, surgindo várias propostas de projetos de mobilidade. Entretanto, este estudo visa analisar os modelos de transporte coletivo urbano em torno da melhor solução para cada cidade de acordo com suas especificidades.

O processo de escolha do modo de transporte público mais adequado às necessidades da população enfrenta muitos problemas, além das características técnicas, operacionais e dos custos de implantação e operação do modo de transporte, interpõe-se as questões políticas. Os conflitos de interesses políticos e privados, com impactos sociais e econômicos, interferem fortemente nos processos decisórios. Por isso, é importante que a escolha do modo de transporte seja a mais adequada para a cidade, garantindo que o usuário do transporte coletivo seja beneficiado. (ITDP, 2008).

Este estudo está desenvolvido em cinco etapas. Na primeira, é feita a definição do escopo da análise. A segunda compreende uma revisão bibliográfica sobre o que caracteriza o desempenho de sistemas dos modos de transporte público. Na terceira etapa consta o levantamento e análises das variáveis dos modos de transportes em alguns corredores. A quarta constitui a aplicação da metodologia de comparação e constatação de semelhanças e diferenças, através da análise dos resultados, possibilitando a comparação dos modos de transportes. E, no final, na quinta etapa é realizada a análise dos resultados obtidos, avaliando o desempenho dos corredores de transporte com suas características próprias e as particularidades de cada cidade. 


\section{I MODOS DE TRANSPORTE}

O objetivo deste artigo é demostrar as similaridades e dissimilitudes em corredores de transporte público em cidades globais, operando com: faixa de tráfego mista; BRS; BRT; VLT e Metrô e verificar a relação entre as variáveis operacionais e econômicas.

Os modos de transporte levados em consideração no estudo são:

- Faixa de Tráfego Misto - são os corredores nos quais não existe a implantação da prioridade ao transporte público;

- $\quad$ BRS (Bus Rapid System), corredor de ônibus com segregação viária, separadas por pintura, por barreiras físicas, por tachões, ou controle eletrônico, do tráfego dos demais veículos, mas contemplam cruzamentos com outros veículos e com pedestres no mesmo nível (Vuchic, 2007);

- BRT (Bus Rapid Transit), um transporte rápido de massa que alia a qualidade do transporte ferroviário à flexibilidade do sistema ônibus (Levinson et al., 2003; Wright e Hook, 2007; FTA, 2009);

- - VLT (Light Rail Transit) ou Veículo Leve sobre Trilho. O VLT é uma composição ferroviária com trilhos de superfície que precisa de energia elétrica. (Mobilize, 2015).

- METRÔ "sistema de transporte público ferroviário, pesado, operando sobre trilho com separação de nível ou enterrados” (ITDP,2008).

\subsection{Faixa de Tráfego Misto}

A faixa de tráfego misto deve ser utilizada quando a demanda e frequência das linhas são baixas, com capacidade para atender demandas no valor de 500 a 5.000 passageiros por hora, por sentido. Esta alternativa de transporte apresenta baixo custo de infraestrutura e de operação, com curto prazo de execução, sendo apropriado para cidades com pouca demanda. Porém, carregando consigo o estigma negativo da tecnologia de ônibus, com maior poluição do ar e do ambiente. Além da imagem negativa, este serviço pode não proporcionar novas benfeitorias para o conforto do usuário, podendo inclusive perder passageiros para o veículo privado (ITDP, 2008). "Porém, quando as demandas, o número de ônibus e a quantidade de linhas superpostas tornaram a operação ineficiente e complexa, as limitações rapidamente apareceram" (LERNER, 2009).

Para Lerner (2009) são problemas típicos desses corredores: superposição excessiva de linhas, provocando baixas velocidades médias, não ultrapassando de 15 a 17 km/h; embarque e desembarque confusos; número excessivo de unidades operando no corredor; atrasos dos veículos nos cruzamentos, formação de longas filas para o embarque.

\subsection{BRS}

Oserviço de BRS reduzoscongestionamentos e aumentaa velocidadeoperacional. 
Os usuários são beneficiados com uma redução nos tempos de deslocamento e melhoria na sustentabilidade do meio ambiente, na otimização da frota, na redução da emissão de gases poluentes e na redução do consumo de combustíveis.

As faixas exclusivas dos corredores podem estar localizadas no lado direito ou no canteiro central, identificados por sinalização horizontal e vertical, por uma faixa contínua azul, ou pelo pavimento da faixa pintado. A eficiência destas faixas é ampliada quando há controle por fiscalização eletrônica ou segregação física.

A implantação do serviço BRS, com prioridade ao transporte público, deve apresentar: faixas preferenciais para ônibus; otimização da oferta de ônibus; escalonamento dos pontos de paradas; fiscalização eletrônica e informação aos usuários (FETRANSPOR, 2013). Este modo pode ser implantado rapidamente, não sendo necessário grandes recursos, nem grandes investimentos e desapropriações, (FREITAS, et al., 2015).

Porém, o BRS apresenta desvantagem em relação aos outros modos de transporte, em função dos conflitos com o transporte privado. Estas interferências reduzem os tempos de viagens e a capacidade, podendo provocar acidentes de trânsito, e poluição ambiental, danos a utilização da ocupação do espaço urbano e, também, o estigma negativo da tecnologia de ônibus. Porém, é importante destacar que as novas tecnologias implantadas e em estudo estão possibilitando que aos corredores que priorizam a circulação do ônibus, segundo os dados do BRTData. org (BRT Center Excellence et al. 2017) têm uma abrangência em, 164 cidades, que contam com sistema de prioridade ao ônibus. Estas cidades tem uma extensão de 4.811 quilômetros desta modalidade e beneficiam diariamente mais de 32.044.915 passageiros.

\subsection{BRT}

Segundo Pereira (2011), mesmo o BRT já estando estabelecido como uma boa alternativa de qualidade para o transporte público é necessário ter total conhecimento dos elementos do projeto, em função da grande flexibilidade. Pois os estudos revelam a variedade do desempenho dos BRT, de acordo com as características físicas e operacionais e suas implicações.

Porém o BRT é um termo que pode ser usado como um sistema de transporte urbano que utiliza ônibus, com investimentos e melhorias na infraestrutura, nos veículos e nas características operacionais que podem resultar em uma qualidade de serviço mais atrativa. (Mobilize, 2011).

A NTU (2013), através do engenheiro Otávio Cunha defini o BRT como um sistema "que se inspirou na qualidade, na eficiência, na segurança do Metrô", sendo um sistema de ônibus articulado que rodam em canaletas exclusivas. A NTU (2013) acrescenta que "O BRT precisa ter a via segregada, exclusiva; garantir o embarque/ desembarque em nível na plataforma; apresentar velocidade comercial elevada; o 
pagamento antecipado da passagem e informações aos usuários através da central de controle operacional".

Para o ITDP (2008) a definição para BRT, baseia-se em "ônibus operando em faixa exclusivas, com prioridade de passagem, embarque em nível e priorização em interseção, seja nas paradas ou obra de arte". Os cidadãos necessitam do transporte público para realizar seus acessos aos bens e serviços oferecidos pelas cidades, sendo o BRT um dos mecanismos de custo mais eficientes para cidades podendo desenvolver e expandir uma rede de transporte público com um serviço veloz e de qualidade (ITDP, 2008). Para Lerner (2009) o "BRT é um termo geral utilizado para sistemas de transporte urbano com ônibus, com melhorias de infraestrutura, veículos e medidas operacionais resultam em uma qualidade de serviço mais atrativa", ou seja, sistema de ônibus de alta capacidade, operando em pista exclusiva, surgiu na cidade de Curitiba.

Para aumentar a sua competitividade com outros modos de transporte, tanto privados quanto público, até mesmo o sistema sobre trilho, o sistema de BRT tem que oferecer padrões de qualidade em condições de competitividade, "parte desta evolução passa por aproveitar os avanços tecnológicos e operacionais para aprimorar a oferta do serviço". (PEREIRA, 2011).

O sistema BRT apresenta-se como uma opção para qualificar o transporte público. Esta qualificação é resultado da combinação das configurações físicas e operacionais que melhoram o desempenho de sistemas tradicionais de ônibus, tornando o modo de transporte sobre pneus mais competitivo. (PEREIRA, 2011). O BRT combina a velocidade e a confiabilidade de modos sobre trilhos com a flexibilidade operacional e os baixos custos do veículo convencional. Tendo como características vias segregadas, veículos articulados, sistema de bilhetagem e pagamento antecipado, prioridade de passagem e embarque/desembarque no nível do veículo (DENG; NELSON, 2010).

Segundo a definição de Brizon (2012), BRT é um modo de transporte público por ônibus em via exclusiva e estações de embarque/desembarque no mesmo nível entre o piso do ônibus e o da estação, com cobrança antecipada, o que agiliza os procedimentos e possibilitando uma alta eficiência operacional. Podendo chegar a uma capacidade de 35 mil passageiros hora, e com a implantação de faixas de ultrapassagem, pode ter grande flexibilidade dos serviços oferecidos, através de esquemas operacionais e consequente aumento da capacidade.

O BRT tem a capacidade de atender demandas de 3.000 a 45.000 passageiros/ hora/sentido, operando com boa velocidade comercial e custos de infraestrutura relativamente baixos no valor de US\$ 0,5 a 14 milhões por km, podendo não requerer subsídios operacionais. Este modo de transporte, também, traz o estigma negativo da tecnologia de ônibus e maior poluição do ar e ambiental. (ITDP, 2008). 


\title{
2.4 VLT - Veículo Leve sobre Trilhos
}

Segundo Mobilize 2015, em entrevista com Peter Alouche, "o VLT é um transporte sobre trilhos de média capacidade que não tem a via totalmente segregada". E para Renato Anelli "O Veículo Leve sobre Trilho é uma solução de menor impacto na cidade, em projetos de via feitos com mais cuidado" acrescentando "O antigo bonde ressurge com nova tecnologia, que permitiu veículos mais leves, econômicos e silenciosos".

O ITDP (2008) define VLT como "veículos único, ou composição curta, com faixa exclusiva sobre trilho, passagem em nível e com prioridade e conexões elétricas ao longo de toda a extensão das linhas". Para Boorse (2007), VLT é um sistema metroviário com força motriz elétrica e linhas exclusivas e que proporciona embarque e desembarque no nível de passeio, oferecendo integração com os demais modos de transportes. 0 VLT cuja matriz energética é elétrica, permite a melhoria das condições ambientais. $O$ sistema elétrico consegue oferecer um conforto ambiental e sonoro, sendo o usuário o principal impactado (BENEDETTI, 2013). Os veículos geralmente circulam pelas ruas e partilham o espaço com o tráfego comum, ou precisam esperar nos cruzamentos, os quais, mesmo possuindo "canaletas" exclusivas, ainda compartilham o espaço dos cruzamentos, com veículos de passeio.

Brizon (2012), ainda argumenta que o VLT:

\begin{abstract}
"se apresenta no meio urbano como um projeto associado a: renovação urbana; adaptação perfeita ao meio urbano e paisagístico; torna a cidade mais humana, mais habitável; permite uma adaptação estética perfeita ao meio urbano; adaptável ao traçado, podendo subir rampas e realizar curvas fechadas; compatibilidade com a área dos pedestres; pode ser implantado por etapas; integra-se facilmente com o sistema de ônibus; limpo, nenhuma emissão, tração elétrica sem poluição; seguro, rápido, confortável; consegue na prática atrair os automobilistas; tem ciclo de vida de mais de 30 anos; alternativa de tempo durável e de desenvolvimento sustentável; favorece o desenvolvimento e o comércio local".
\end{abstract}

Segundo a definição de Brizon (2012), VLT é um modo de transporte público que atende a oferta de transporte existente entre o ônibus e o metrô, podendo atender a uma demanda intermediária, sendo assim uma alternativa para o transporte de media capacidade, tendo um custo de implantação acessível. E Para a ITDP (2008), o VLT, tem a capacidade de atender demandas moderadas de passageiros no valor de 5.000 a 12.000 passageiros por hora, por sentido, polui pouco, com desempenho silencioso, se ajusta a ruas estreitas e por ter uma boa imagem, pode atrair usuários para o transporte coletivo. Porém as desvantagens do VLT é que apresenta custos de infraestrutura no valor de UU\$ 15 a 45 milhões por Km, podendo requerer subsídios operacionais com limitações quanto à capacidade de passageiros. (ITDP, 2008).

\subsection{Metrô}

Para Brizon (2012) as definições técnicas de uma linha de metrô não decorrem apenas de exigências do sistema metroviário, mas de aspectos como uso e ocupação 
do solo, preservação do meio ambiente e do patrimônio histórico, com características geológicas, topográficas, geotécnicas, especificações do material rodante e características do sistema viário.

O metrô tem a capacidade de atender demandas altas de passageiros no valor de 30.000 a 80.000 passageiros por hora, por sentido, podendo alcançar velocidade comercial de 28 a $35 \mathrm{~km} / \mathrm{h}$, além de ocupar pouco espaço público, poluir pouco e por ter uma boa imagem, pode atrair usuários para o transporte coletivo. Porém as desvantagens do metrô é que apresenta altos custos de infraestrutura no valor de US\$ 45 a 359 milhões por Km, com longos períodos de desenvolvimento e construção, podendo requerer subsídios operacionais inclusive pela baixa demanda e consequente baixa recuperação de faturamento durante os períodos fora do pico. (ITDP, 2008).

Para Lerner (2009) construir uma rede completa de metrô atualmente talvez não seja mais possível em função dos elevados custos de implantação, para muitas das cidades que possuem redes extensas, mas tiveram sua construção iniciada quando os custos de se trabalhar no subsolo eram viáveis. Ainda segundo Lerner (2009) "Cada cidade precisa extrair o melhor de cada modo de transporte que tenha, seja na superfície, seja subterrâneo. A chave reside em não se ter sistemas competindo no mesmo espaço e utilizar tudo aquilo que a cidade tem da forma mais efetiva".

Os modos de transportes devem ser analisados de acordo com as características econômicas e operacionais, onde deve ser levando em consideração as variáveis de cada modo, para que possam auxiliar na escolha, visando melhorar a mobilidade das cidades. O custo de implantação é um fator muito forte na decisão de escolha, assim como, o tempo de implantação, a expertises da tecnologia, favorecendo o modo rodoviário. Porém a emissão de poluentes, o impacto ambiental, as desapropriações, a imagem e a requalificação da cidade pesam contra esta alternativa. São fatores que favorecem a decisão pelo modo ferroviário. Em relação a capacidade de transporte de passageiros pode haver variações de acordo com cada modo e sua demanda específica, além das características da cidade.

Para o ITDP (2008), são muitas as variáveis que podem interferir na escolha do tipo de tecnologia de transporte público, e neste estudo são consideradas as variáveis em relação ao custo: investimentos (custo de propriedade e infraestrutura), prazo de implementação; projeto: capacidade, tempo de viagem, confiabilidade, segurança e os impactos: econômicos e sociais.

\section{I METODOLOGIA}

A metodologia do estudo consiste, em uma primeira etapa, do levantamento dos dados atuais dos corredores de transporte de algumas cidades globais. $\mathrm{Na}$ segunda etapa da realização do agrupamento dos dados levantados, em função das similaridades e identificação das variáveis mais relevantes. Para no final realizar análises 
comparativas entre as características de aspectos gerais, tais quais: localização, extensão e demanda, ou as características físicas e de desempenho operacional.

Como o desempenho dos sistemas de transportes públicos variam em função da configuração das características operacionais de cada corredor de transporte, que por sua vez pode ser verificada através da demanda transportada, do custo de implantação, ou dos dados específicos de cada cidade como população, densidade e dados econômicos como PIB.

Neste levantamento foram pesquisadas 10 cidades com sistema de transporte público dos 5 modos de transportes definidos no início do estudo. Sendo o primeiro, os corredores de transporte com sistema tronco alimentador implantado, porém sem nenhuma estrutura física de prioridade ao transporte coletivo, com faixa de tráfego misto. O segundo, são as faixas exclusivas ao transporte público, denominadas de BRS. O terceiro se refere aos corredores de BRT, com faixas exclusivas, pagamento da tarifa antecipado e acesso ao veículo no mesmo nível que a plataforma. O quarto grupo formado por VLT e o quinto por Metrô. Este agrupamento foi realizado em função das características físicas e operacionais dos corredores.

A comparação entre os corredores já implantados ou em implantação foi utilizada para auxiliar na análise nos 27 corredores de transporte distribuídos nas 10 cidades globais, definidas previamente, sendo feita a primeira etapa, levando em consideração as redes de metrô, onde foram implantados metrô de grande capacidade, sendo levantado as variáveis: custo de implantação, quilometragem acrescida, características operacionais de rede de transporte, no qual o corredor foi inserido, demanda transportada ou prevista em cada corredor analisado e o tempo de construção e em relação as características das cidades, variáveis como população, densidade e PIB.

Em seguida foi realizado um levantamento dos corredores de faixa de tráfego misto, BRS e BRT, nas mesmas cidades, ou em alguns casos, cidades próximas do mesmo país. Para fazer a comparação dos corredores e verificar as similaridades ou não entre eles. O objetivo desta aplicação é avaliar e comparar as características dos corredores por modo de transporte. Através de análise quantitativa dos custos e extensão, análise visual e da capacidade ou motivação em investir em mobilidade, vinculada a situações socioeconômicas.

\section{I RESULTADOS ESPERADOS, SIMILARIDADES E DISSIMILITUDES}

A rede do Metrô de Nova York é composta por 22 linhas, com comprimento total de aprox. 350 km e com 472 estações. Na construção da $1^{\text {a }}$ fase da linha Second Avenue Subway foram acrescidos 3,2 Km e 3 estações, para transportar a mais 200.000 passageiros/dia, com um custo de implantação de US\$ 4,45 bilhões, a construção deste trecho levou 10 anos para ser concluído. (MTA, 2017).

A rede de Toronto tem quatro linhas de metrô, 11 rotas de bonde e 140 rotas de ônibus. O Projeto de extensão de Metrô Spadina de Toronto-York - TYSSE tem 
extensão de 8,6 km e 6 estações, ao custo de US\$ 3,18 bilhões. A construção levou 7 anos para ser concluída. (TTC, 2017).

O Metrô de Berlin é conhecido como o U-Bahn e atualmente opera com dez linhas, em uma rede de 146 km e 173 estações. A linha U55 U-Bahn Hauptbahnhof está em construção, com 2,2 km e 3 estações, irá interligar com a linha U5, com um orçamento de US\$ 525 milhões. De acordo com a previsão, esta linha irá retirar 3.000 a 3.500 carros por dia, da via Unter den Linden e transportará 150.000 passageiros por dia, em 10 anos de construção. (PROJEKT U5, 2017).

O Metrô de Montreal, operado pela Société de Transport de Montréal -STM, integra 68 estações em quatro linhas medindo 66,0 km e utiliza trens com rodas de borracha. O sistema transporta 286,7 milhões de passageiros por ano. Segundo Cazelli (2008), a extensão da linha do metrô até Laval é de 5,2km, com 3 estações a um custo de US\$ 745 milhões. (STM, 2017).

O Metrô de Madri opera com 13 linhas, 301 estações, com um comprimento total de $294 \mathrm{~km}$ e demanda em 2015 de 569,73 milhões de passageiros por ano. A expansão da linha 2, Las Rosas, teve um acréscimo de 4,1km e 4 estações, ao custo de US\$ 134,9 milhões. A construção foi executada em 2,5 anos. (METRO MADRID, 2017).

O Metrô de Seul é um dos mais extensos, com 9 linhas urbanas de Seul, e 7 linhas suburbanas. Foi inaugurado em 1974 e tem 287 km com 10 linhas e 266 estações. Com mais de 8 milhões de passageiros por dia. A implantação da linha Shinbundang com 31Km e 12 estações foi construída a um custo de 2,104 bilhões de dólares, em 11 anos (DX LINE, 2017). E na linha Busan Transport Corporation a ampliação da linha urbana, com extensão de $7,98 \mathrm{~km}$, seis novas estações com um custo de US\$ 869,32 milhões de dólares em 7 anos. (KORAIL, 2017).

O Singapore Mass Rapid Transit - MRT, foi inaugurado em 1987 e tem 121 estações e 171 quilômetros em 5 linhas. A linha Thomson-East Coast, que custará US\$ 18 bilhões, deve transportar 500 mil passageiros diariamente, com 43 km e 31 estações. (SMRT, 2017).

O Metrô de Londres opera com 16 linhas, 268 estações e aproximadamente 400 km, numa média de 2,67 milhões de usuários por dia, atualmente está em construção a Linha Elizabeth com 100 km, 100540 estações e o objetivo é atender aos 200 milhões de passageiros por ano, a um custo de US\$19,076 bilhões. (TRANSPORT FOR LONDON, 2017).

O Metrô de São Paulo opera com 6 linhas e 68 estações, com 78 km de extensão, para transportar uma demanda de 4,7 milhões de passageiros/dia. A Linha 4-Amarela está em expansão de 5,4km, e 4 estações a um custo de US\$306,29 milhões. (METRÔ SÃO PAULO, 2017).

O Metrô do Rio de Janeiro tem um total de 41 estações em 3 linhas com 58km, transportando 850 mil passageiros/dia. A Linha 4-Amarela com 16 km e 5 estações levou 6 anos para ficar pronta, ao custou US\$2,97 bilhões, transportar 300.000 
passageiros/dia. (METRO RIO, 2017).

\begin{tabular}{|c|c|c|c|c|c|c|c|}
\hline CIDADE & $\begin{array}{l}\text { LINHA (a) } \\
\text { Nome da linha }\end{array}$ & $\begin{array}{l}\text { POP (b) } \\
\text { Habitantes }\end{array}$ & $\begin{array}{l}\text { DENS. (c)/ } \\
\mathrm{km}^{2}\end{array}$ & $\begin{array}{c}\text { PIB }(d) \\
\text { Per capita } \\
\text { US\$/ } \\
\text { hab. }\end{array}$ & $\begin{array}{c}\text { Ext }(e) \\
\text { km }\end{array}$ & $\begin{array}{c}\text { CUSTO (f) } \\
\text { US\$ } \\
\text { Milhão }\end{array}$ & $\begin{array}{l}\text { Custo/ } \\
\text { Km } \\
\text { Milhão } \\
\text { US\$/km }\end{array}$ \\
\hline New York & $\begin{array}{l}\text { Second } \\
\text { Avenue }\end{array}$ & 8.175 .133 & $6.737,50$ & 66.488 & 3,2 & $4.450,00$ & $1.390,63$ \\
\hline Toronto & $\begin{array}{l}\text { Spadina-York } \\
\text { (Ext.) }\end{array}$ & 2.503 .281 & $3.973,50$ & 39.527 & 8,6 & $3.180,00$ & 369,77 \\
\hline Berlim & U5 Extension & 3.460 .725 & $3.898,50$ & 38.643 & 2,2 & 525,00 & 238,64 \\
\hline Montreal & $\begin{array}{c}\text { Laval Metro } \\
\text { Ext. }\end{array}$ & 1.651 .235 & $4.542,30$ & 34.260 & 5,2 & 745,00 & 143,27 \\
\hline Madrid & $\begin{array}{l}\text { Line } 2 \text { Las } \\
\quad \text { Rosas }\end{array}$ & 3.213 .271 & $5.304,40$ & 42.296 & 4,1 & 134,90 & 32,90 \\
\hline Seul & Shinbundang & 10.421 .782 & $17.211,30$ & 32.179 & 31,0 & $2.104,00$ & 67,87 \\
\hline Singapura & $\begin{array}{c}\text { Thomson MRT } \\
\text { Line }\end{array}$ & 5.076 .700 & $7.148,30$ & 55.252 & 43,0 & $18.000,00$ & 418,60 \\
\hline Londres & Elizabeth Line & 8.416 .535 & $5.354,00$ & 162.200 & 100,0 & $19.076,00$ & 190,76 \\
\hline São Paulo & Linha 4 & 11.244 .369 & $7.381,70$ & 17.034 & 5,4 & 306,29 & 56,72 \\
\hline Rio & $\begin{array}{l}\text { Linha } 4 \text { - } \\
\text { Amarela }\end{array}$ & 15.993 .583 & 365,30 & 17.326 & 16,0 & $2.970,00$ & 185,63 \\
\hline
\end{tabular}

Tabela 1: Dados das linhas de Metrô de Cidades Globais

Fonte: (a), (e) e (f) dados obtidos pelo site dos órgãos responsáveis, de acordo com item 4; (b) e (c) DB City (d) OECD, GDP Os dados estão em dólares internacionais constantes de 2010.

\begin{tabular}{|c|c|c|c|c|c|c|c|c|c|}
\hline CIDADE & BRT & $\begin{array}{l}\text { Ext } \\
\mathrm{Km}\end{array}$ & $\begin{array}{c}\text { Custo / } \\
\text { km } \\
\text { Milhão } \\
\text { US\$/ } \\
\text { Km }\end{array}$ & BRS & $\begin{array}{l}\text { Ext } \\
\mathrm{Km}\end{array}$ & $\begin{array}{c}\text { Custo / } \\
\text { km } \\
\text { Milhão } \\
\text { US\$/ } \\
\text { km }\end{array}$ & $\begin{array}{c}\text { Faixa } \\
\text { tráfego } \\
\text { Misto }\end{array}$ & $\begin{array}{l}\text { Ext } \\
\mathrm{Km}\end{array}$ & $\begin{array}{c}\text { Custo / } \\
\text { km } \\
\text { Milhão } \\
\text { US\$/ } \\
\text { km }\end{array}$ \\
\hline New York & Healthl ine & 7,2 & 17,544 & $\begin{array}{l}\text { M34/ } \\
\text { M34A }\end{array}$ & 4,0 & 6,75 & & & \\
\hline Toronto & Viva Yellow & 2,6 & & & & & $\begin{array}{l}\text { Viva } \\
\text { Yellow }\end{array}$ & 2,4 & \\
\hline Berlim & Line 5 & 4,08 & & & & & Line 5 & 11,02 & \\
\hline Montreal & & & & & & & & & \\
\hline Madrid & Bus VAO & 16,1 & 3,300 & Linia 64 & 17,44 & 0,66 & Linia64 & 4,36 & 0,66 \\
\hline Seul & $\begin{array}{l}\text { Siheung } \\
\text { Hangang-ro }\end{array}$ & 17,7 & & & & & & & \\
\hline Singapura & & & & & & & & & \\
\hline Londres & $\begin{array}{l}\text { East } \\
\text { London } \\
\text { Transit }\end{array}$ & 26,5 & 14,400 & & & & $\begin{array}{l}\text { The } \\
\text { Busway }\end{array}$ & 15,0 & \\
\hline São Paulo & $\begin{array}{l}\text { Expresso } \\
\text { Tiradentes }\end{array}$ & 12,0 & 10,083 & $\begin{array}{l}\text { Campo } \\
\text { Limpo }\end{array}$ & 17,2 & & & & \\
\hline Rio & $\begin{array}{c}\text { Trans } \\
\text { Olímpica }\end{array}$ & 26,0 & 25,790 & $\begin{array}{c}\text { BRS } \\
\text { Copaca }\end{array}$ & 4,0 & & $\begin{array}{l}\text { Trans. } \\
\text { Oeste }\end{array}$ & 4,0 & 8,770 \\
\hline
\end{tabular}

Tabela 2: Dados das linhas de BRT, BRS, Faixas de Tráfego misto de Cidades Globais

Fonte: BRT Center Excellence; EMBARQ; IEA e SIBRT, (2017), $1^{*}$ Cleveland, $2^{\star}$ Hamburg, 3* Barcelona e $4^{*}$ Cambridge. 


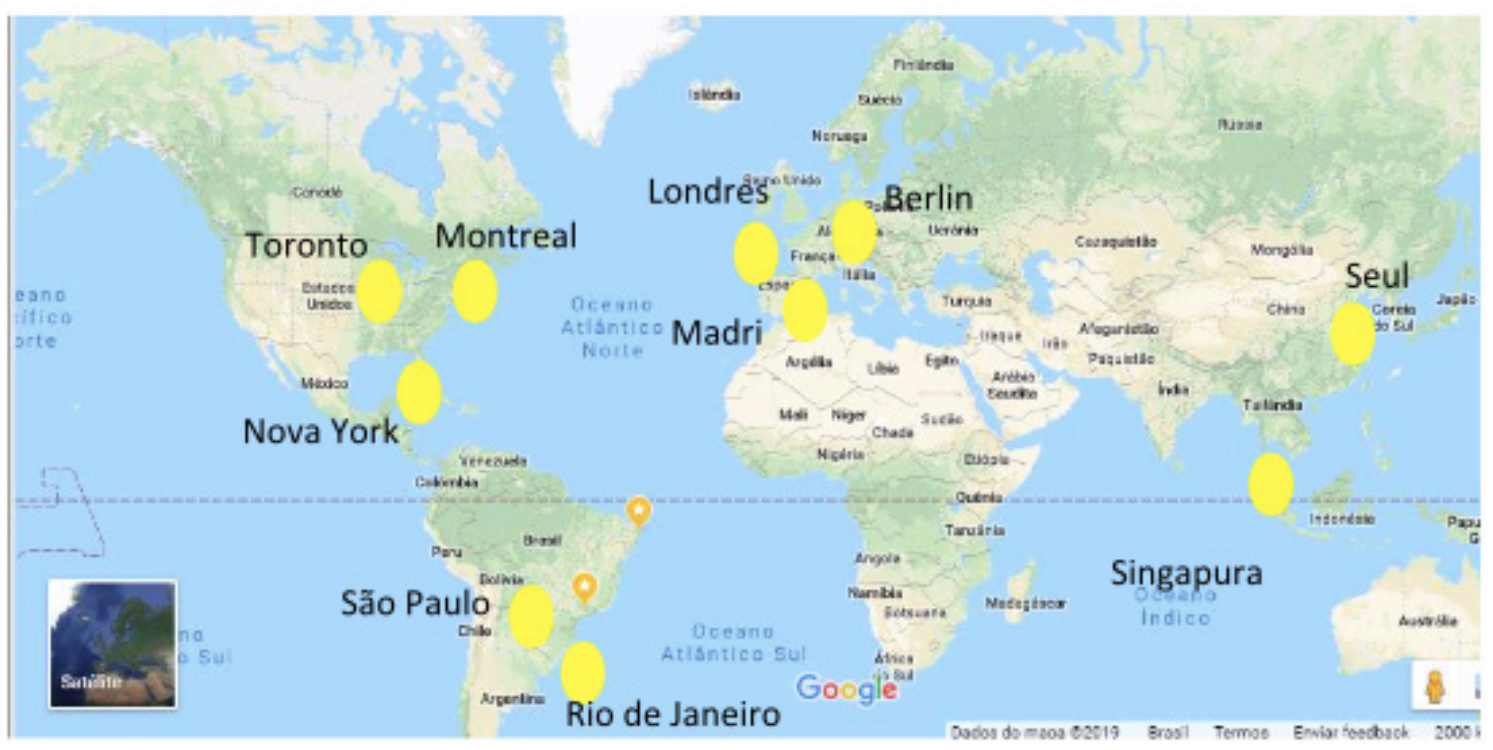

Figura 1: Cidades Globais

Fonte: www.google.com.br/maps

As cidades globais são grandes centros de atividade políticas, econômicas, culturais e serviços definidas também como metrópoles mundiais, são grandes aglomerações urbanas que funcionam como centros de influência nacional e internacional.

A tabela 1 mostra os dados das linhas de metrô, nas 10 cidades globais, escolhidas em função das expansões que foram construídas nas redes de metrô pesado (subterrâneos), com destaque para a linha Elizabeth, na rede de Londres, pela sua função de ligar a cidade de leste a oeste, com $100 \mathrm{~km}$ de extensão, na rede principal de metrô, segundo a Transport for London, (2017). As linhas de Nova York, Singapura e Berlin, tem um custo/km muito elevado, para a implantação da rede em área central, em cidades muito adensadas. As ampliações nas redes de Berlin e São Paulo têm função estruturadora, fazendo ligações importantes na rede atual de transporte público. Cidades com grandes adensamentos como Londres, Seul, Singapura e São Paulo têm uma necessidade maior de implantar redes de metro de grande capacidade, para viabilizar o deslocamento de demandas elevadas. As cidades asiáticas Seul e Singapura têm investido bastante na rede de transporte público e, atualmente estão entre as 10 maiores cidades em tamanho da rede de metrô. A linha 4-Amarela do Rio de janeiro foi construída devido aos investimentos para os jogos olímpicos Rio 2016, porém com uma função estruturadora de ligar a linha1 do metrô em Ipanema com a do BRT na Barra da Tijuca.

A tabela 2 apresenta o custo total $/ \mathrm{km}$ de US\$25,79 em milhões de dólares, investidos na implantação do corredor de BRT linha Transolímpica e a tabela 1 apresenta o custo total de US\$185,63 milhões de dólares para o metrô linha 4-Amarela, no Rio de janeiro. A mesma relação pode ser verificada na linha de BRT, em São Paulo, a Expresso Tiradentes, com um custo de US\$10,83 milhões de dólares $/ \mathrm{km}$ e a expansão da Linha 4 do metrô com US\$ 56,72 milhões de dólares/km. Esta análise 
também pode ser verificada em Londres e Madri, onde o custo das linhas de BRT são de US\$14,40 e US\$ 3,30 milhões de dólares/km e nas linhas de metrô os custos são de US\$190,76 e US\$32,30 milhões de dólares/km respectivamente.

A cidade de Londres que possui um PIB per capita de US\$162.200,00/hab., investe US\$19,076 bilhões na implantação da linha de metrô, Elizabeth Line e US\$ 381,6 milhões na linha de BRT East London Transit.

As cidades de Nova York e Londres possuem grandes redes de metro, 350km e 400 km, respectivamente, porém Nova York está com apenas 10,0 km de acréscimo previsto para a complementação da linha Second Avenue e Londres com a implantação de mais $100 \mathrm{~km}$ para a linha Elizabeth Line.

Segundo Wright e Hook (2007), as cidades do mundo desenvolvidas e em desenvolvimento requerem sistema transporte de alto desempenho que possibilitem o atendimento de demandas elevadas de forma sustentável. Diante desta exigência os sistemas de transportes devem apresentar uma capacidade compatível com a demanda existente e uma velocidade operacional que atenda as questões técnicas e principalmente aos anseios da população.

Durante muito tempo sem investimentos em mobilidade urbana, muitos governos estão voltando a investir na melhoria do transporte público, como forma de combater o impacto social, econômico e ambiental dos congestionamentos nas cidades. Porém, atualmente, a crise econômica agravou a situação dos recursos, existindo poucos recursos a serem investido no transporte público. Desta forma é preciso ter um excelente planejamento, segurança e cautela para alocar os recursos de forma a obter o melhor retorno para as cidades. Segundo o ITDP (2008) "o planejamento urbano deve ser pensado de forma a tirar o maior proveito dos sistemas de transporte público e das novas tecnologias e oferecer moradia, emprego e outros serviços públicos".

O investimento adequado em transporte público em uma cidade passou a ser uma ciência deixando de ser apenas uma decisão política, pois segundo Peñalosa (2015), "Uma cidade com bom sistema de transporte é mais atrativa aos investidores e portanto, gera mais empregos. Há mais segurança e melhora significativamente os espaços da cidade".

\section{I ANÁLISE E CONCLUSÕES}

O que é constatado na implantação dos modos de transportes analisados no estudo, são as grandes quantidades de recursos investidos, para atender as necessidades de deslocamentos das cidades globais, e desta forma, estas experiências servem de exemplo para as outras cidades do mundo, analisando suas vantagens e desvantagens e procurando verificar as similaridades com o seu sistema local de transporte.

Outro aspecto verificado é a diversidade dos modos de transporte implantados 
nas cidades, onde mesmo as cidades que possuem uma rede de metrô elevada, continuam a implantar outros modos, tais como BRT ou BRS, VLT, com o objetivo de alocar o modo de transporte mais adequado a demanda local.

As construções dos corredores de transporte levam o longo período de implantação, provocando um desconforto para os cidadãos, devendo ser feito um planejamento rigoroso da execução e um envolvimento dos afetados diretamente pelas obras.

Este projeto apresenta um cenário da complexidade da escolha de um sistema de transporte a ser implantado numa determinada cidade. Apenas os parâmetros populacionais e econômicos das cidades citadas e os modos de transporte com suas características e custos já produzem uma quantidade elevada de tópicos a serem estudados e quantificados para subsidiar o processo decisório.

Quando é implantada a prioridade ao transporte coletivo, toda a sociedade é beneficiada e o sistema de transporte transfere benefícios diretos para a população, com o aumento da velocidade operacional e consequentemente menores tempos de viagem e mais tempo disponível para as atividades sociais e econômicas.

\section{REFERÊNCIAS}

Benedetti M. (2013). BRT x VLT Análise econômica da substituição do sistema de transporte público do eixo anhanguera da cidade de Goiânia, Universidade Federal De Goiás, Escola De Engenharia Civil, Curso De Graduação Em Engenharia Civil, Goiânia.

Brizon L. C. (2012). Avaliação dos impactos econômicos e economia de combustível fóssil com a implantação do metrô de Curitiba no eixo norte/sul, Dissertação de Mestrado apresentada ao Programa de Pós-graduação em Engenharia de Transportes, COPPE, da Universidade Federal do Rio de Janeiro, como parte dos requisitos necessários à obtenção do título de Mestre em Engenharia de Transportes.

BRT Center Excellence; EMBARQ; IEA e SIBRT, (2017). Global BRT Data: version 3.27, última modificação em august 15, 2017. Disponível em. Acessado em 11/09/2017.

Boorse, J. W. A (2007). Comparative Discussion of the Light Rail Transit Mode and the Bus Rapid Transit Initiative. In: JOINT INTERNATIONAL LIGHT RAIL CONFERENCE: a world of applications and opportunities, 2006, St. Louis, Estados Unidos da América. Anais. St. Louis: TRANSPORTATION RESEARCH CIRCULAR E-C112, p. 441-450.

Cazelli, M. (2008), Investimentos em sistemas metro ferroviários utilizando engenharia e análise do valor. Dissertação de Mestrado apresentada ao Curso de Mestrado em Engenharia de Transportes do Instituto Militar de Engenharia, como requisito parcial para a obtenção do título de Mestre em Ciências em Engenharia de Transportes. Rio de Janeiro.

DB City, (2017), Disponível em acessado em 27/06/2017.

Deng, T; Nelson, J. D. (2010). The Impact of Bus Rapid Transit on Land Development: A Case Study of Beijing, China. World Academy of Science, Engineering and Technology, Issue 0042, n. 66, p. $1182-1206$.

DX LINE, (2017). Disponível em acessado em 08/07/2017. 
FETRANSPOR, (2013). Manual de implementação BRS - BuS Rapid SeRvice.

Freitas, C. L.; Teixeira, E.; Silva, E.; Brizon, L.; Pires, L.; Paula, M. e Gonçalves, R. (2015). Metodologia de reestruturação de sistemas de transporte público em munícipios de médio porte. XXIX ANPET, Ouro Preto, Minas Gerais.

FTA (2009). Characteristies of Bus Rapid Transit for Decision-Making. Disponível em acessado 22/06/2017. Highway Capacity Manual, (2000). Tansportation Research Board.

ITDP (2008). Manual de BRT - Bus Rapid Transit, Guia de Planejamento, The William and Flora Hewlett Foundation.

KORAIL, (2017). Disponível em acessado em 30/06/2017.

Lerner, J. (2009). Avaliação Comparativa das modalidades de Transporte Público Urbano. Associação Nacional das Empresas de Transportes Urbanos, Curitiba, Brasil.

Levinson H; Zimmerman S.; Clinger J.; Rutherord S.; Smith R. L.; Cracknell J. e Soberman R., (2003). Bus rapid transit, Volume 1: Case Studies in Bus Rapid Transit. Transit Cooperative Research Program: Report 90, Washington, DC, USA.

Lindau, L. A. (2013) O papel do transporte coletivo na visão estratégica de cidades competitivas. In: NTU, Mobilidade Sustentável para um Brasil Competitivo. Associação Nacional das Empresas de Transportes Urbanos, Brasília.

Metrô São Paulo (2017). Disponível em acessado em 08/07/2017.

Metro Madrid, (2017). Disponível em https://www.metromadrid.es, acessado em 28/06/2017.

METRO RIO, (2017). Disponível em acessado em 09/07/2017.

MTA, (2017), Metropolitan Transportation Authority, Disponível em acessado em 22/06/2017.

Mobilize - Mobilidade Urbana Sustentável (2011). Estudo Mobilize 2011 Diagnóstico da mobilidade urbana sustentável em capitais brasileiras, Dispovível em acessado em 14/06/2017. - (2015). Disponível em, acessado em 14/06/2017.

Moovit (2016) Relatório global sobre o uso do transporte público nas grandes cidades. Disponível em, acessado em 14/06/2016.

NTU (2013). Faixas Exclusivas de Ônibus Urbano Experiências de Sucesso. Associação Nacional das Empresas de Transportes Urbanos, Brasília, DF, Brasil.

OECD.Stat, Organisation for economic co-operation and development, (2017). Disponível em acessado em 03/07/2017.

Peñalosa, E., (2015). Disponível em acessado em 09/05/2017.

Pereira, B. M. (2011). Avaliação do desempenho de configurações físicas e operacionais de sistemas BRT. Dissertação do Mestrado em Engenharia de Produção-Programa de pós-graduação em engenharia de produção, como requisito parcial à obtenção do título de Mestre, na área de concentração de Sistemas de transportes. UFRGS.

PROJEKT U5, (2017), Projek trealisierungs GmbH U5, Disponível em, acessado em 26/06/2017. SMRT (2017). Disponível em acessado em 30/06/2017. 
STM - Société de transport de Montréal, Disponível em acessado em 28/06/2017.

Transport for London, (2017). Disponível em, acessado em 08/07/2017.

TTC-Comissão de Transporte de Toronto, Disponível em, acessado em 26/06/2017.

Vuchic, V. (2007). Urban Transit: Systems and Technology. New Jersey: John Wiley \& Sons, Inc.

Wright, L. e Hook, W. (2007). Bus Rapid Transit Planning Guide ( $3^{\mathrm{a}}$ ed.). Institute for Transpot and Development Policy, New York. 


\section{CAPÍTULO 5}

\section{SHOPPING CENTER COMO ATRATIVO DE CONDOMÍNIOS VERTICAIS E AS INFLUÊNCIAS NO TRÁFEGO VIÁRIO}

Maximillian Nascimento da Costa Instituto Federal de Educação, Ciência e

Tecnologia do Amazonas

Manaus - AM

Jussara Socorro Cury Maciel

Instituto Federal de Educação, Ciência e

Tecnologia do Amazonas

Manaus - AM

RESUMO: É comum a existência de Shopping Centers nas grandes cidades, principalmente em áreas mais populosas, onde a oferta de consumidores é mais atrativa. Porém o oposto também pode acontecer, a implantação de um Polo Gerador de Viagens (PGV) atraindo o adensamento urbano. Este trabalho tem como principal objetivo realizar uma análise no tráfego viário local provocado pelo aumento expressivo de construções de condomínios residenciais verticais após a inauguração de um Shopping Center no bairro Ponta Negra em Manaus. Através de revisão bibliográfica e pesquisa de campo, considerando os condomínios residenciais verticais, inaugurados recentemente, englobados na área de influência deste Polo Gerador de Viagens e realizar uma estimativa de contribuição veicular ao tráfego viário local por um empreendimento em fase final de construção, onde serão implantados mais dois condomínios verticais. Com isso, tornar- se de fácil visualização dados técnicos como o Fator Horário de Pico e o Nível de Serviço para a via local e corroborar para a proposição de estratégias de ordenamento ao trânsito local no horário de pico matinal em decorrência das viagens provocadas, principalmente, por origens/destinos escolar e/ou de trabalho.

PALAVRAS-CHAVE: Polo Gerador de Viagem, tráfego viário, saturação viária, Fator Horário de Pico e adensamento urbano.

\section{ABSTRACT}

Shopping malls in large cities are common, especially in more populated areas, where the consumer offer is more attractive. However, the opposite can also happen, the implementation of a Trip Generator Hub (TGH) attracting urban density. Thisworkhasasmainobjectivetoanalyze the local road traffic caused by the expressive increase of vertical residential condominium buildings after the inauguration of a Shopping Center in the Ponta Negra neighborhood in Manaus, through bibliographical review and field research, considering the residential condominiums vertical, recently inaugurated, encompassed in the area of influence of this Trip Generator Hub and make an estimate of vehicular contribution to the local road traffic for a project in the final phase of construction, where two more vertical condominiums will be implemented. In this way, technical data such 
as the Peak Time Factor and the Service Level for the local route can be easily viewed and corroborated for the proposition of local traffic planning strategies in the morning peak hours because of the trips caused, mainly, by school and / or work origins / destinations.

KEYWORDS: Trip Generator Hub, road traffic, road saturation, Peak Time Factor and urban density.

\section{I INTRODUÇÃO}

Nas últimas décadas, Manaus passou por um processo de crescimento demográfico e migratório, principalmente entre as décadas de 70 e 90, com a consolidação da Zona Franca de Manaus, havendo impactos diretos no sistema viário existente. A população da cidade mais que dobrou nesse período, passando de 473.548 para 1.011.403 habitantes, levando a urbanização aos limites territoriais e, assim desenvolvendo as Zonas Norte e Oeste. Desta última década em diante, mais precisamente até 2015 a população dobrou novamente, passando para 2.020.311 habitantes (MANAUSTRANS, 2015), fazendo com que o sistema viário ficasse cada vez mais saturado, principalmente o eixo Norte-Sul.

Acompanhando essas mudanças, o comportamento e a preferência da população em relação à mobilidade e a distância das respectivas rotas de origem-destino, notase a convergência às atividades centralizadas nas próprias Zonas Urbanas, evitando e/ou diminuindo as viagens até a Zona Central de Negócio (ZCN), provocando o surgimento dos Shopping Centers como Polos Geradores de Viagens (PGV's).

De forma simplificada, os Polos Geradores de Viagens (PGV's) são definidos como equipamentos potenciais geradores de impactos nos sistemas viários e de transportes (congestionamentos, acidentes e naturais repercussões no ambiente) como também no desenvolvimento socioeconômico e na qualidade de vida da população (REDPGV, 2017).

Em 2012, após a implantação e inauguração do Shopping Ponta Negra, no bairro Ponta Negra - Zona Oeste de Manaus, tendo mais de 1.600 vagas de estacionamento e gerando 2.500 postos de emprego, aliado à uma elevada oferta de imóveis em forma de condomínios horizontais e verticais com estrutura de lazer completo nos solos urbanos valorizados de Manaus (Martins, 2008), provocaram um adensamento de dez condomínios verticais no entorno do Shopping Center, mudando significativamente o trânsito local que é composto de apenas uma via principal (Avenida Coronel Teixeira) de ligação aos demais bairros e ao centro da cidade.

Em matéria publicada no jornal Diário do Amazonas, Henrique Saunier, repórter do portal @d24am.com, afirma que o Bairro Ponta Negra é uma das áreas mais cobiçadas para investimentos imobiliários e o superintendente do Shopping Ponta Negra, Rodrigo Vitali, afirma que a região deverá ter um crescimento de $50 \%$ que era de aproximadamente 200 mil habitantes a época da inauguração, dados que podem 
ser confirmados pelo Plano de Mobilidade Urbana de Manaus/2015, com projeção até 2035.

Segundo Portugal e Goldner (2003), os Polos Geradores de Viagens (PGV's) são "empreendimentos de distintas naturezas que têm em comum o desenvolvimento de atividades em um porte e escala capazes de gerar um contingente significativo de viagens", assim pode-se enquadrar, tanto o Shopping Center em questão quanto os condomínios verticais como PGV's.

Segundo Kneib et al. (2010), a formação e consolidação de PGV's e, consequentemente, subcentros urbanos (policentralidade), podem gerar dois comportamentos em relação à mobilidade viária: positiva ou negativa, dependendo da infraestrutura de transporte coletivo e incentivo aos modos não motorizados.

A implantação e operação de um empreendimento como Shopping Center atribui características de centralidade à área e atrai um grande número de pessoas, gerando um determinado número de viagens. Altera os padrões de uso e ocupação do solo, atraindo novas atividades e novas construções. Assim, o aumento de demanda por áreas na proximidade provoca uma valorização dos terrenos, atraindo mais atividades, mais construções, e consequentemente um número adicional de viagens, formando um processo cíclico (Kneib, 2004).

Para Grigolon e Silva (2006), a ocupação dos lotes no entorno do PGV seriam os empreendimentos mais novos, cujos lotes teriam sido retidos para valorização imobiliária pois, à medida que se afastam do Polo, a "idade" dos imóveis comerciais cresce devido à influência de empreendimentos já existentes nas vizinhanças tendo como consequência de menores valores dos imóveis, fazendo com que a ocupação desses lotes valorizados propicie impactos diretos para os sistemas de transporte.

Dessa maneira, este trabalho tem por finalidade estudar de forma quantitativa o impacto viário, na única e principal avenida que liga o bairro Ponta Negra ao centro de Manaus, em decorrência dos novos condomínios verticais e realizar uma estimativa de contribuição veicular na via local de um determinado empreendimento imobiliário com dois condomínios (complexo residencial Reserva Inglesa), que está em construção e previsto para ser entregue em 2017.

\section{I METODOLOGIA}

Após pesquisa e revisão bibliográfica, onde foi possível entender as definições e conceitos sobre Polos Geradores de Viagens e saturação viária, e a realização de três pesquisas de campo para coletas de dados, sendo necessárias e oportuna para analisar o comportamento de ocupação do solo no entorno de PGV do tipo Shopping Center, e os demais PGV's do tipo residencial (em vermelho), conforme demonstra a Figura 1, promovendo uma visualização clara e identificação dos fenômenos de forma antecipada e objetiva. 


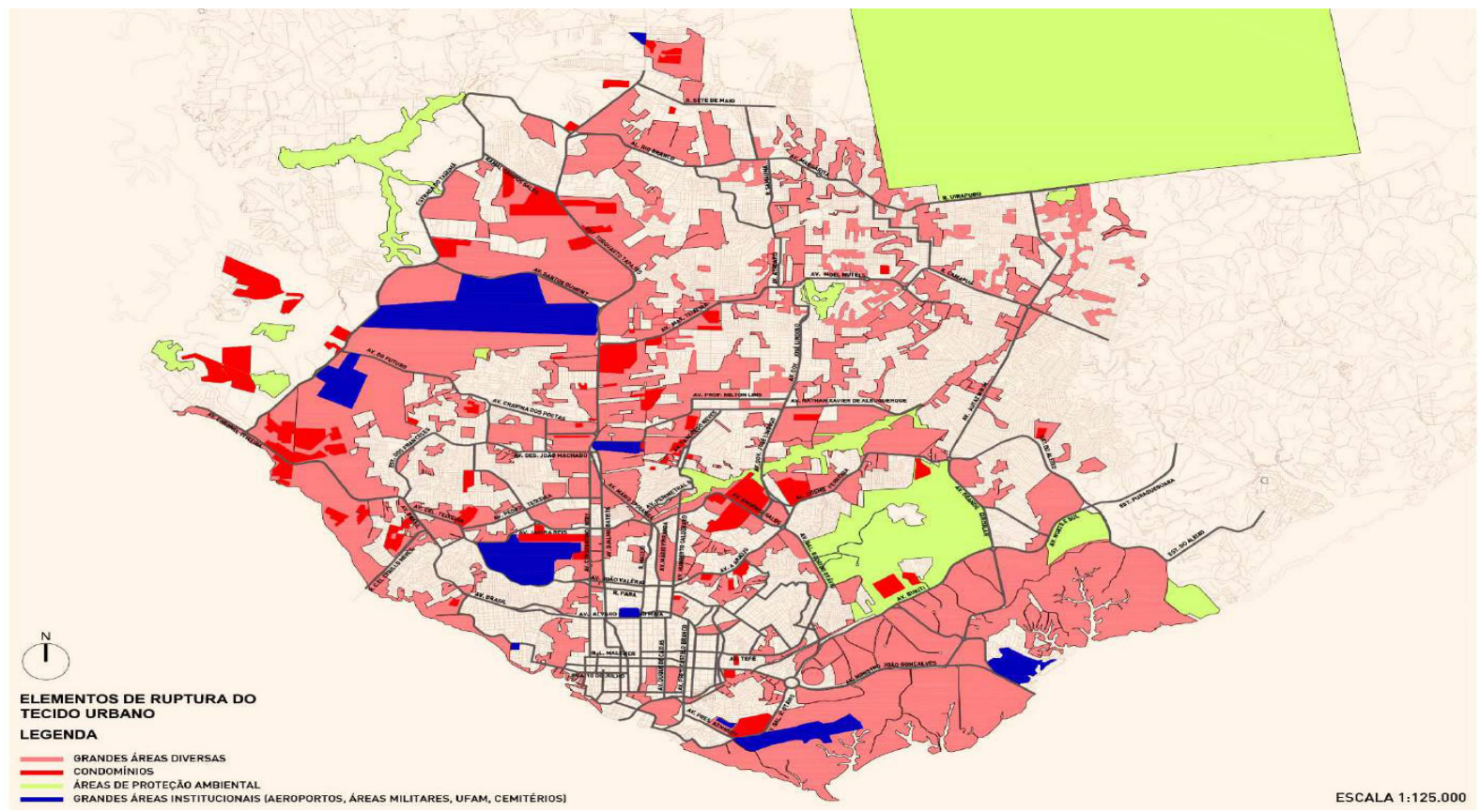

Figura 1 - Elementos de Ruptura do tecido urbano

A primeira pesquisa de campo foi na forma de entrevista junto às incorporadoras dos empreendimentos imobiliários, no entorno do Shopping Ponta Negra, para determinar o número de unidades domiciliares existentes que seriam oferecidos ao mercado (caso do empreendimento em construção - Reserva Inglesa) e os já ocupados (demais condomínios verticais - objetos do estudo) para que fosse possível obter uma estimativa de contribuição veicular na Avenida Coronel Teixeira (principal e única via de acesso aos demais bairros e centro da cidade), no bairro Ponta Negra na cidade de Manaus.

Em uma segunda fase, uma nova pesquisa de campo foi realizada para realizar uma contagem veicular na Avenida Coronel Teixeira, no trecho que compreende os acessos aos condomínios verticais, construídos e à concluir, para determinar o volume de tráfego viário e a hora de pico matinal utilizando os métodos de contagem com utilização de filmagens realizadas em pontos estratégicos, onde não possuíam semáforos, desvios ou possibilidades de duplicações veiculares, facilitando a visualização dos deslocamentos veiculares de forma direcional, conforme preconizadas no Manual de Estudos de Tráfego (DNIT, 2006).

Na terceira pesquisa de campo, porém simultaneamente com a segunda e com as mesmas técnicas de filmagem, uma nova contagem foi realizada para determinar os quantitativos de viagens geradas no período matinal (saídas considerando como origem/destino: o trabalho e a escola), de forma a analisar os quantitativos e percentuais que cada condomínio vertical contribui para o aumento de veículos na via em estudo.

Com os dados extraídos das pesquisas de campo, foi possível definir o Fator Horário de Pico (FHP) para avaliar a intensidade de trânsito existente e, posteriormente, verificar, por estimativa, o acréscimo veicular provocado pelos condomínios em construção, comparando com a capacidade da via e os níveis de serviço, utilizando 
como parâmetros o Highway Capacity Manual - HCM para vias Classe II (DNIT, 2006).

\section{I ANÁLISE DOS RESULTADOS}

\subsection{Delimitação da área de influência}

Reafirmando o trabalho de Grigolon e Silva (2006), em análise espacial no entorno do PGV (Shopping Ponta Negra), anteriores à divulgação de sua instalação, haviam diversos lotes em valorização, sem qualquer construção. Porém, com a concretização do Polo Gerador de Viagem inaugurado, e até mesmo durante as obras de implantação, consolidaram-se 08 empreendimentos imobiliários verticais nas adjacências do "polo de influência", sendo um dele, o Reserva Inglesa, com 02 condomínios residenciais verticais que se encontram em construção.

Para a construção da Tabela 1, foi necessário buscar informações utilizando os meios eletrônicos e de comunicação disponíveis, além de realizar entrevistas pessoalmente através de formulário elaborado de forma simples e autoexplicativo, expondo o interesse da pesquisa para fins científicos e na colaboração em soluções alternativas para os prováveis problemas vindouros.

\begin{tabular}{|c|c|c|c|c|}
\hline $\begin{array}{l}\text { Referência } \\
\text { Figura } 1\end{array}$ & Empreendimento & $\begin{array}{l}\text { Incorporadora / } \\
\text { Construtora }\end{array}$ & Inauguração & Unidades \\
\hline$A$ & $\begin{array}{l}\text { Reserva Inglesa } \\
\quad \text { (Liverpool) }\end{array}$ & Capital Rossi & Em construção & 360 \\
\hline B & $\begin{array}{l}\text { Reserva Inglesa } \\
\text { (London) }\end{array}$ & Capital Rossi & Em construção & 288 \\
\hline $\mathrm{C}$ & $\begin{array}{l}\text { Parque Ponta Negra } \\
\text { (Reserva das Praias) }\end{array}$ & Direcional S.A. & 2015 & 680 \\
\hline $\mathrm{D}$ & $\begin{array}{l}\text { Parque Ponta Negra } \\
\text { (Reserva das Águas) }\end{array}$ & Direcional S.A. & 2016 & 120 \\
\hline E & River Side Ponta Negra & PDG & 2017 & 336 \\
\hline $\mathrm{F}$ & Life Ponta Negra & Capital Rossi & 2014 & 288 \\
\hline$G$ & Gran Vista Ponta Negra & Direcional S.A. & 2013 & 340 \\
\hline $\mathrm{H}$ & Turim Premium & $\begin{array}{l}\text { Premium } \\
\text { Engenharia }\end{array}$ & 2011 & 416 \\
\hline 1 & $\begin{array}{l}\text { Weekend Club Ponta } \\
\text { Negra }\end{array}$ & Direcional S.A. & 2012 & 900 \\
\hline J & View Club \& Home & PDG & 2014 & 300 \\
\hline \multicolumn{4}{|c|}{ TOTAL } & 4.028 \\
\hline
\end{tabular}

Tabela 1: Empreendimentos residenciais verticais construídos por influência do PGV Fonte: Coletado nas Incorporadoras - 2017

A Tabela 1 indica que, com a divulgação da implantação do Shopping Ponta 
Negra, as Incorporadoras/Construtoras, visando à possibilidade do efeito "polo de influência" (Martins, 2008) e valorização imobiliária do entorno, injetaram grandes recursos na localidade para tentar atender/atrair as classes média e alta de Manaus.

Os empreendimentos em estudo foram distinguidos das demais construções existentes no bairro, inauguradas posteriormente à inauguração do PGV do tipo Shopping Center, por terem sido caracterizadas como uma área de influência primária (Portugal e Goldner, 2003), ou seja, de qualquer ponto dessa área, considera-se que o futuro usuário atinja o Shopping Center entre 5 e 10 minutos realizando viagem por automóvel, dependendo das condições apresentadas pelo tráfego e do acesso da região.

Para melhor visualização dos Polos Geradores de Viagens (condomínios residenciais verticais) construídas dentro da área de influência de outro Polo Gerador de Viagens (Shopping Center), posteriormente a inauguração do segundo, foi utilizado imagens em terceira dimensão do software livre Google Earth, conforme Figura 2.

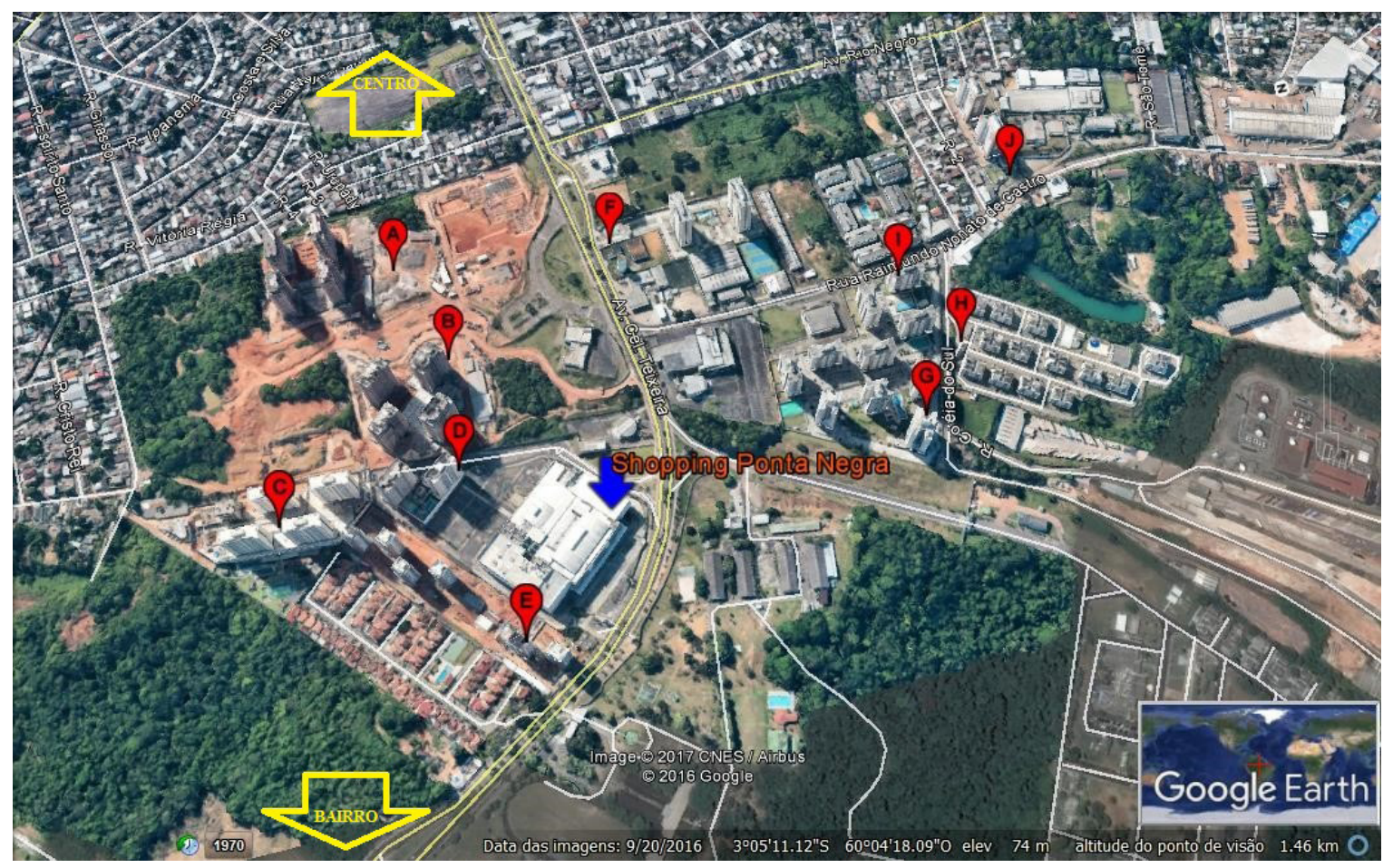

Figura 2 - Condomínios verticais enquadrados na área de influência primária do PGV

\subsection{Determinação do Fator Horário de Pico (FHP)}

Segundo o conceito do Manual de Estudos de Tráfego (DNIT, 2006), o Fator Horário de Pico é o volume da hora de pico do período de tempo considerado, dividido pelo quádruplo do volume do período de quinze minutos da Hora de Pico com maior fluxo de tráfego, representada pela fórmula:

$$
F H P=\frac{V h p}{4 V 15 \max }
$$


onde:

$\mathrm{FHP}=$ fator horário de pico

Vhp = volume da hora de pico

V15max $=$ volume do período de quinze minutos com maior fluxo de tráfego dentro da hora de pico

Assim, para verificar a hora de pico matinal no trecho delimitado foi realizada uma contagem veicular com início às $06 \mathrm{~h} 15 \mathrm{~min}$ e término às $08 \mathrm{~h} 15 \mathrm{~min}$, contabilizando a cada 15 minutos, utilizando câmeras posicionadas nos dois retornos e acessos da Avenida Coronel Teixeira do trecho compreendidos na área de influência e durante a semana (quarta-feira), tomando o cuidado de escolher uma semana onde não tivesse feriados e em período escolar, de forma a obter dados consistentes e dentro da realidade do cotidiano dos moradores de Manaus, gerando a Tabela 2.

\begin{tabular}{c|c|c}
\hline HORA & SENTIDO CENTRO (3 faixas) & SENTIDO BAIRRO (3 faixas) \\
\hline $06: 15-06: 30$ & 598 & 269 \\
\hline $06: 30-06: 45$ & 834 & 452 \\
\hline $06: 45-07: 00$ & 951 & 586 \\
\hline $07: 00-07: 15$ & 1.027 & 591 \\
\hline $07: 15-07: 30$ & 1.187 & 693 \\
\hline $07: 30-07: 45$ & 890 & 519 \\
\hline $07: 45-08: 00$ & 794 & 617 \\
\hline $08: 00-08: 15$ & 768 & 503 \\
\hline Volume da Hora de & 4.055 & 2.389 \\
\hline Pico & & \\
\hline
\end{tabular}

Tabela 2: Contagem veicular para determinação do FHP Fonte: Coletados in loco pelo autor - 2017

O horário escolhido foi proposital de forma que o FHP matinal não sofresse influência de viagens geradas pelo Shopping Center, pois o interesse é analisar o impacto viário provocado pelos condomínios surgidos posteriormente ao PGV citado.

Constatando assim, que o horário de pico, no período matinal (período escolar), ficou compreendido de 06:45 h às 07:45 h, ficando bem próximo do horário de pico indicado por Portugal e Goldner (2003), e o tendo o volume da hora pico com 4.055 veículos no sentido centro e 2.389 veículos no sentido bairro. Já o FHP teve como resultado o valor de 0,854 , que é considerado normal para áreas urbanas, já que os valores nessas áreas geralmente situam-se entre 0,80 e 0,98. Porém, valores acima de 0,95 são indicativos de grande volume de tráfego, podendo ter, inclusive, restrições de capacidade durante o horário de pico (DNIT, 2006). 


\subsection{Viagens geradas pelos condomínios verticais}

Para determinar a contribuição veicular dos condomínios verticais em estudo, durante o mesmo período de coleta de dados na Avenida Coronel Teixeira, foram registradas as saídas de veículos motorizados com destino ao acesso à via analisada, conforme Tabela 3.

\begin{tabular}{|c|c|c|c|c|c|c|c|c|}
\hline $\begin{array}{l}\text { Horário/ } \\
\text { intervalo }\end{array}$ & $\begin{array}{l}\text { Parque } \\
\text { Ponta } \\
\text { Negra }\end{array}$ & $\begin{array}{l}\text { River } \\
\text { Side } \\
\text { Ponta } \\
\text { Negra }\end{array}$ & $\begin{array}{l}\text { Life } \\
\text { Ponta } \\
\text { Negra }\end{array}$ & $\begin{array}{l}\text { Gran Vista } \\
\text { Ponta Negra }\end{array}$ & $\begin{array}{c}\text { Turim } \\
\text { Premium }\end{array}$ & $\begin{array}{c}\text { Weekend } \\
\text { Club Ponta } \\
\text { Negra }\end{array}$ & $\begin{array}{c}\text { View Club } \\
\text { \& Home }\end{array}$ & Total \\
\hline $\begin{array}{c}06: 15 \text { à } \\
06: 30\end{array}$ & 11 & 2 & 9 & 12 & 17 & 38 & 6 & 95 \\
\hline $\begin{array}{c}06: 30 \text { à } \\
06: 45\end{array}$ & 17 & 4 & 15 & 15 & 33 & 54 & 11 & 149 \\
\hline $\begin{array}{c}06: 45 \text { à } \\
07: 00\end{array}$ & 23 & 5 & 18 & 22 & 43 & 72 & 13 & 196 \\
\hline $\begin{array}{c}07: 00 \text { à } \\
07: 15\end{array}$ & 29 & 4 & 13 & 24 & 34 & 87 & 12 & 203 \\
\hline $\begin{array}{c}07: 15 \text { à } \\
07: 30\end{array}$ & 34 & 5 & 16 & 29 & 32 & 79 & 15 & 210 \\
\hline $\begin{array}{c}07: 30 \text { à } \\
07: 45\end{array}$ & 19 & 2 & 14 & 19 & 31 & 62 & 17 & 164 \\
\hline $\begin{array}{c}07: 45 \text { à } \\
08: 00\end{array}$ & 19 & 2 & 11 & 23 & 35 & 69 & 7 & 166 \\
\hline $\begin{array}{c}08: 00 \text { à } \\
08: 15\end{array}$ & 14 & 1 & 11 & 18 & 29 & 54 & 5 & 132 \\
\hline Total & 166 & 25 & 107 & 162 & 254 & 515 & 86 & 1.315 \\
\hline $\begin{array}{l}\text { Volume } \\
\text { da Hora } \\
\text { de Pico } \\
\end{array}$ & 105 & 16 & 61 & 94 & 140 & 300 & 57 & 773 \\
\hline
\end{tabular}

Tabela 3: Contribuição veicular por empreendimento

Fonte: Coletados in loco pelo autor - 2017

No horário de pico (06:45 à 07:45) um total de 773 veículos dos 4.055 do volume da hora de pico foi somente dos condomínios residenciais verticais construídos após a implantação do Shopping Center instalado no Bairro Ponta Negra, perfazendo uma contribuição de $23,55 \%$ para o acréscimo no tráfego local.

Por meio dos dados expostos nas Tabelas 1 e 3 foi possível montar o Gráfico 1, que expõe a taxa de contribuição por empreendimento. 


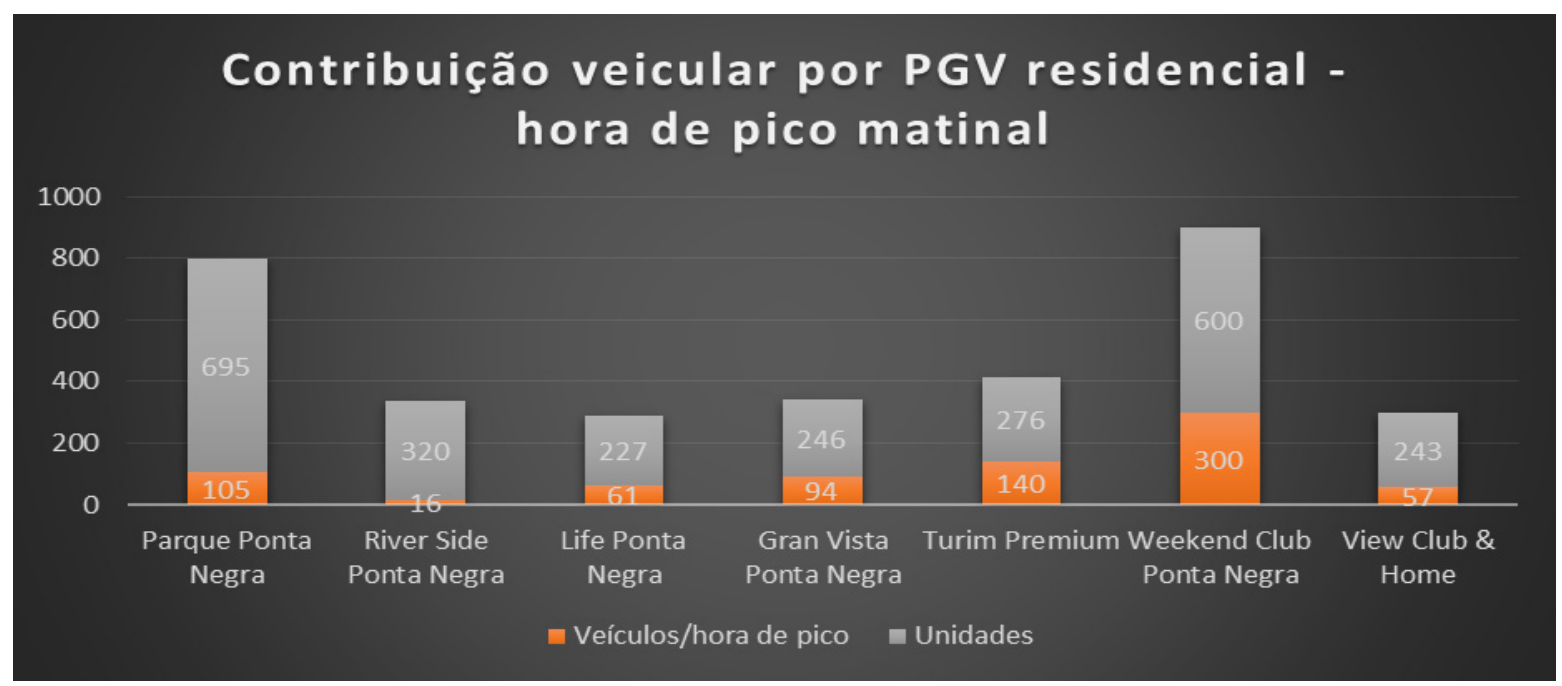

Gráfico 1. Contribuição veicular por PGV do tipo residencial vertical

Possibilitando, assim, o cálculo das taxas de geração de viagens veiculares para cada empreendimento, realizando uma razão entre o número de unidades ofertadas e a contribuição veicular durante o horário de pico. Por fim obtendo uma média ponderada para a área de influência do PGV estudado, conforme a Tabela 4.

\begin{tabular}{c|c|c|c|c|c|c|c|c}
\hline Empreendimentos & $\begin{array}{c}\text { Parque } \\
\text { Ponta } \\
\text { Negra }\end{array}$ & $\begin{array}{c}\text { River } \\
\text { Side } \\
\text { Ponta } \\
\text { Negra }\end{array}$ & $\begin{array}{c}\text { Life } \\
\text { Ponta } \\
\text { Negra }\end{array}$ & $\begin{array}{c}\text { Gran } \\
\text { Vista } \\
\text { Ponta } \\
\text { Negra }\end{array}$ & $\begin{array}{c}\text { Turim } \\
\text { Premium }\end{array}$ & $\begin{array}{c}\text { Weekend } \\
\text { Club Ponta } \\
\text { Negra }\end{array}$ & $\begin{array}{c}\text { View } \\
\text { Club \& } \\
\text { Home }\end{array}$ & $\begin{array}{c}\text { Média } \\
\text { ponderada }\end{array}$ \\
\hline $\begin{array}{c}\text { Taxas de geração } \\
\text { de viagens }\end{array}$ & 0,13 & 0,05 & 0,21 & 0,28 & 0,34 & 0,33 & 0,19 & 0,22 \\
\hline
\end{tabular}

Tabela 4: Taxas de geração de viagens veiculares

Fonte: cálculos do autor - 2017

\subsection{Estimativas de quantidade de viagens pelo complexo residencial Reserva Inglesa}

Como observado na Tabela 1, o empreendimento Reserva Inglesa é composto por dois condomínios e possui um total de 648 unidades, sendo um empreendimento importante a ser considerado, pois se encontra dentro da área de influência do PGV primário (Shopping Center) e com grande possibilidade de contribuição veicular. Infelizmente não foi possível saber quantas unidades já foram comercializadas, pois assim seria possível realizar uma estimativa mais próxima da realidade e definir um FHP futuro após a conclusão da construção.

Tomando como fonte o trabalho de Portugal e Goldner (2003) e o quadro de Taxas de Geração de Viagens - Via do Polo Gerador, conforme Figura 3, foi possível 
estimar a quantidade de viagens a serem geradas por um tipo de polo gerador de viagens específico (REDPGV).

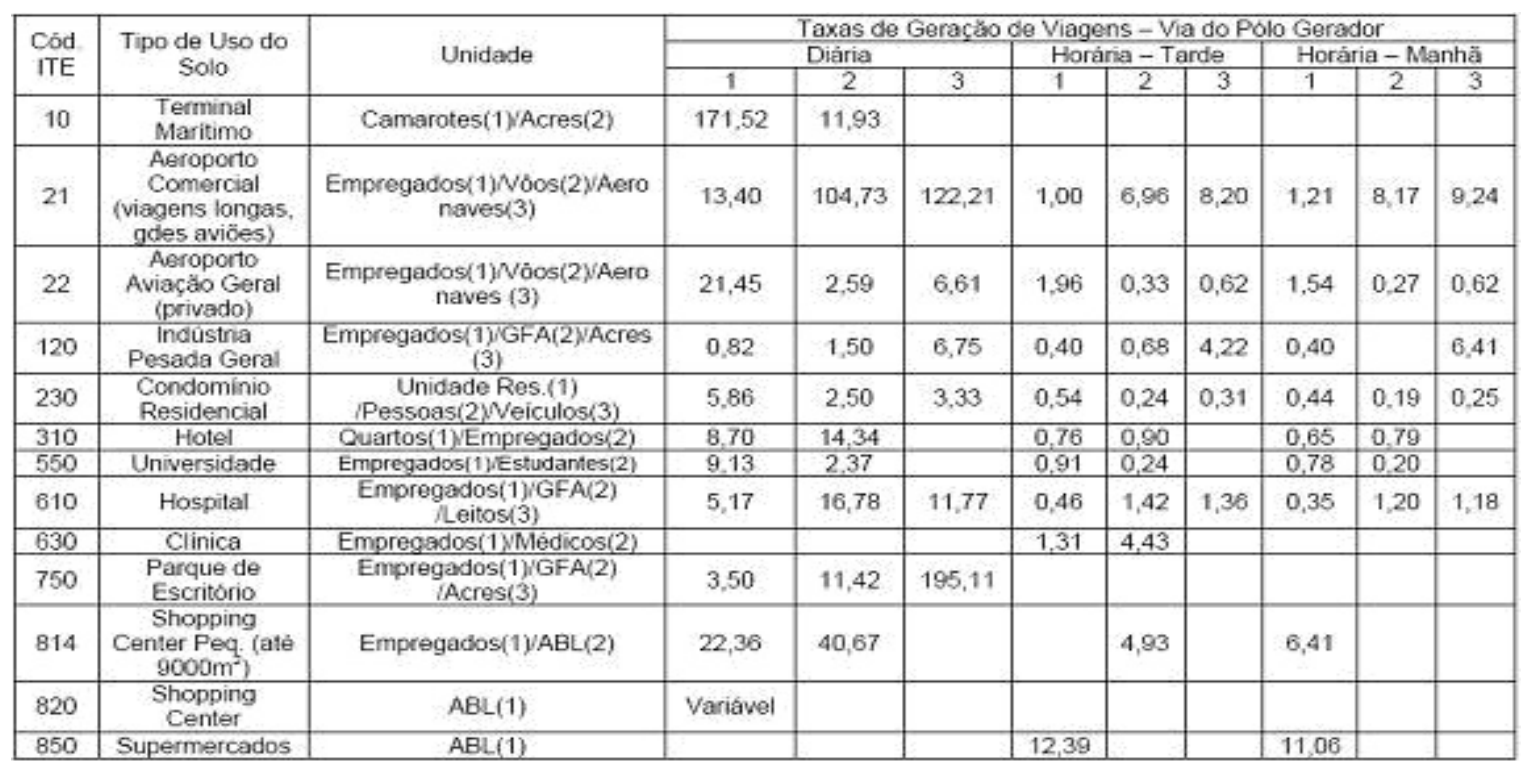

Figura 3 - Taxas de Geração de Viagens - Via do Polo Gerador

Com base no exposto, considerando as unidades do empreendimento em construção e a taxa para condomínio residencial, chegou-se na estimativa representada pela Tabela 5.

\begin{tabular}{|c|c|c|c|}
\hline Condomínio & $\mathfrak{N}^{\circ}$ unidades (1) & $\begin{array}{c}\text { Taxa para Condomínio } \\
\text { Residencial (Cód ITE 230) }\end{array}$ & Viagens geradas \\
\hline Liverpool & 360 & 0,44 & 159 \\
\hline London & 288 & & 127 \\
\hline \multicolumn{2}{|c|}{ Total } & 286 \\
\hline
\end{tabular}

Tabela 5. Estimativa de geração de viagens no horário de pico (manhã)

Analisando essa estimativa, o volume veicular passaria para 4.341, durante horário de pico, contribuindo para um aumento de $7 \%$ no volume existente, o que corroboraria para uma aproximação acentuada da capacidade máxima da via, que é de 5.100 carros de passeio por hora para vias Classe II (HCM apud DNIT, 2006), o que definiria a via com Nível de Serviço do tipo D e para o tipo E, se considerarmos os demais empreendimentos com todas as unidades ocupadas.

\section{I CONSIDERAÇÕES FINAIS}

Antes da implantação do Shopping Ponta Negra no bairro Ponta Negra, em Manaus, o volume veicular era de 3.282 na Avenida Coronel Teixeira, tendo como Nível de Serviço do tipo do C para conforto de trafegabilidade e capacidade da via durante o horário de pico - manhã.

Com a divulgação, construção e inauguração do PGV do tipo Shopping Center, e 
concomitantemente, o adensamento de construções de condomínios residenciais do tipo vertical, o volume veicular passou para 4.055 (aumento de $23 \%$ ), podendo chegar a $30 \%$ se considerarmos a geração de viagens produzidas pelo complexo residencial Reserva Inglesa, que está em fase final de construção.

Outro fator a considerar é que alguns dos PGV do tipo residencial, já inaugurados, apresentaram uma baixa taxa de geração de viagens, como o Parque Ponta Negra $(0,13)$ e o River Side Ponta Negra $(0,05)$, inaugurados, respectivamente em 2016 e 2017, ou seja, muito recente. O que pode indicar a existência de diversas unidades não ocupadas, já que o país passou recentemente por um período difícil na economia, principalmente no mercado imobiliário.

De tal forma que, caso realmente sejam esses motivos da baixa taxa de geração de viagens supracitados, ao longo do tempo, essas mesmas taxas subirão e causará maior impacto negativo para a Avenida Coronel Teixeira.

Quanto à Taxa de Geração de Viagens por hora de pico referenciada pela tabela do ITE (Figura 3), com média de 0,44 para condomínios residenciais, utilizando como parâmetro, as unidades disponíveis, fica evidente que essa taxa será o dobro da encontrada nesta pesquisa de campo $(0,22)$, visto que essa taxa tende a aumentar quando mais unidades forem sendo ocupadas naqueles empreendimentos lançados recentemente.

É possível observar que o volume de veículos na área de influência do Shopping Ponta Negra aumentou de forma expressiva nos últimos cinco anos e que, através da pesquisa de campo, foi possível identificar que a capacidade da via em estudo está próxima do seu limite, assim como o Fator Horário de Pico tem aumentado, e aumentará ainda mais após a inauguração do complexo residencial Reserva Inglesa, onde os transtornos como congestionamentos serão inevitáveis.

Por isso, este estudo pode ser aproveitado para proposições de medidas mitigadoras, ou até mesmo, para soluções práticas e consistentes aos efeitos negativos do adensamento urbano com relação ao trânsito local, tais como melhorias no transporte público, inclusão e incentivo de novos modais, investimentos em infraestrutura, ampliação da malha viária, entre outras, visto que tais análises tempestivas podem contribuir para decisões futuras.

\section{AGRADECIMENTOS}

Os autores agradecem ao Instituto Federal de Educação, Ciência e Tecnologia do Amazonas (IFAM) pelos programas internos de incentivo aos alunos, proporcionando apoio e motivando à pesquisa. Agradecem à Coordenação do Curso de Engenharia Civil, assim como a todos os professores, pelo apoio prestado à pesquisa e aos colegas alunos que debateram e encorajaram pela busca dos resultados obtidos. 


\section{REFERÊNCIAS}

Cybis, H. B.; Lindau, L. A.; Araújo, D. R. C. (1999) Avaliando o impacto atual e futuro de um pólo gerador de tráfego na dimensão de uma rede viária abrangente. Revista Transportes, v. 7, n. 1, p. 6485.

DENATRAN. Manual de procedimentos para o tratamento de polos geradores de tráfego. Brasília: Denatran/FGV, 2001. 81f.

DNIT. Manual de estudos de Tráfego. Rio de Janeiro: DNIT/IPR, 2006. 384f.

Grigolon, A. B. (2007) Impactos dos padrões de crescimento espacial e de transportes no entorno de pólos geradores de viagens. Dissertação apresentada ao Programa de Pós-Graduação em Engenharia Civil: Planejamento e Operação de Sistema de Transporte da Universidade de São Carlos. São Carlos.

Grieco, E. P.; Portugal, L. S. (2010) Taxas de geração de viagens em condomínios residenciais em Niterói - estudo de caso. Revista Transportes, v. XVIII, n. 1, p. 86-94.

ITE (2012). Institite of Transportation Engineers. Trip Generation Handbook. Washington, DC, EUA.

Kneib, E. C. (2004) Caracterização de empreendimentos geradores de viagens: contribuição conceitual à análise de seus impactos no uso, ocupação e valorização do solo urbano. Dissertação apresentada ao Programa de Pós-Graduação em Transportes da Universidade de Brasília. Brasília.

Kneib, E. C.; Silva, P. C. M; Portugal, L. S. (2010) Impactos decorrentes da implantação de pólos geradores de viagens na estrutura espacial das cidades. Revista Transportes, v. XVIII, n. 1, p. 27-35.

MANAUSTRANS. Plano de mobilidade de Manaus - PlanMobManaus. Manaus: ManausTrans, 2015. Vol. 1, 312 f.

Martins, M. J. F. (2008) Análise do mercado imobiliário em Manaus. Dissertação apresentada ao Programa de Pós-Graduação em Desenvolvimento Regional da Universidade Federal do Amazonas. Manaus.

Portugal, L. S.; GOLDNER, L. G. Estudo de polos geradores de tráfego e de seus impactos nos sistemas viários e de transportes. São Paulo: Editora Edgard Blücher, 2003.

REDPGV - Rede Íbero-Americana de estudo em polos geradores de viagens. Disponível em: <http:// redpgv.coppe.ufrj.br/.>. Acesso em: 20 de Abril de 2017.

Torquato, T. L. L; Junior, A. A. R. (2014) Modelos de geração de viagens para condomínios residenciais horizontais. Revista Transportes, v. 22, n. 1, p. 56-64.

TRB (2010). Highway Capacity Manual. Transportation Research Board. Whashington, DC, EUA. 


\section{TRANSPORTES, ACESSIBILIDADE URBANA E AS CALÇADAS NA CIDADE DE SÃO PAULO}

Lucas de Souza Ramalhaes Feitosa Universidade São Francisco

Bragança Paulista-SP

Roberto Righi

Universidade Presbiteriana Mackenzie

São Paulo-SP

RESUMO: Este capítulo mostra as características das estratégias recentes para melhoria da acessibilidade urbana, através das intervenções nas calçadas da cidade de São Paulo, adotadas pela Prefeitura Municipal de São Paulo. Representam resposta qualitativa e quantitativa ao incremento da importância dos deslocamentos realizados a pé que constituem $97,3 \%$ do total do transporte não motorizado, que passaram de 5,9 para 12,9 milhões de viagens de 1977 a 2017. A iniciativa voltase a tornar a cidade mais acessível para os pedestres, possuindo ou não algum tipo de deficiência.

PALAVRAS-CHAVE:Acessibilidade Urbana; Calçadas e Pedestre; Transporte nãomotorizado, Pessoa com Mobilidade Reduzida.

ABSTRACT: This chapter shows the characteristics of the recent strategies to improve urban accessibility, through interventions in the sidewalks of the city of São Paulo, adopted by the Municipality of São Paulo. They represent a qualitative and quantitative response to the increase in the importance of walking movements, which constitute $97.3 \%$ of total non-motorized transport, from 5.9 to 12.9 million trips from 1977 to 2017 . The initiative to make the city more accessible for pedestrians, with or without some kind of disability.

KEYWORDS: Urban Accessibility; Affordable Sidewalks, Pedestrian; Disabled Person, Person with Reduced Mobility.

\section{I INTRODUÇÃO}

Este capítulo mostra a problemática, os mecanismos legais, normativos, a iniciativa da prefeitura e o panorama existente de promoção da acessibilidade urbana através da reforma e adequação da calçada para acessibilidade de pedestres na cidade de São Paulo.

As calçadas fazem parte do espaço urbano, mas para torna-las acessíveis, devemse eliminar as barreiras físicas existentes como buracos, degraus, entre outros para que as pessoas possam circular nas calçadas, melhor utilizar os mobiliários e equipamentos urbanos. Segundo Lanchoti e Bruna (2010), a mobilidade das pessoas nos espaços urbanos é atributo básico para a cidadania e a sociedade, Porém, as dificuldades presentes nos espaços públicos para o acesso das pessoas com ou 
sem deficiência, está em pauta em vários municípios do Brasil. Na cidade de São Paulo iniciativas foram tomadas para melhorar essa situação através do poder público municipal. A Prefeitura Municipal de São Paulo (PMSP) desenvolve o "Programa de Recuperação de Calçadas", objetivando padronizar e tornar acessíveis às calçadas da cidade por meio de reformas, eliminando imperfeições e trocando revestimentos para tornar melhor e mais segura a circulação dos pedestres com deficiência ou não.

A PMSP também reforçou a obrigatoriedade, através de legislação municipal, para que todos os proprietários de imóveis particulares adequem à calçada aos parâmetros estabelecidos na NBR 9050:2015 da ABNT, na cartilha "Passeio Livre", no Decreto Municipal 45.904/2005 e nas Leis Municipais 15.442/2012 e 15.733/2013. Através deste instrumento o munícipe de imóvel residencial ou comercial é responsável pela conservação e manutenção do passeio público em frente a sua edificação, de acordo com legislação municipal pautada pela normatização brasileira.

\section{I METODOLOGIA}

A metodologia de pesquisa adotada para o levantamento sobre acessibilidade urbana é desenvolvida através de pesquisas de referências técnicas, legislativas e normativas. Dentre as mais relevantes estão: Lei Municipal 15.442/2012, Lei Municipal 15.733/2013, Decreto Municipal 45.904/2005 que determinam os parâmetros para adaptação à acessibilidade das calçadas na cidade de São Paulo e penalidades cabíveis, referenciadas às determinações da NBR 9050:2015 da ABNT.

\section{I ACESSIBILIDADE URBANA}

Infelizmente, a acessibilidade e o desenho universal são conceitos ainda pouco utilizados no Brasil, tanto nos edifícios, quanto no planejamento e nos projetos urbanos. A não utilização desta abordagem na concepção das cidades gera resultados desastrosos, e a adaptação inadequada pode levar a verdadeiros remendos, segundo Cambiaghi (2012).

Ainda de acordo com Cambiaghi, a sustentabilidade possui relação direta com a acessibilidade, pois uma cidade sustentável se fundamenta em ambientes inclusivos através da eliminação de barreiras físicas ou arquitetônicas e com a promoção da participação das pessoas com ou sem deficiência nos ambientes públicos.

A definição estabelecida pela NBR 9050:2015 da ABNT para acessibilidade é:

[...] possibilidade e condição de alcance, percepção e entendimento para utilização, com segurança e autonomia, de espaços, mobiliários, equipamentos urbanos, edificações, transportes, informação e comunicação, inclusive seus sistemas e tecnologias, bem como outros serviços e instalações abertos ao público, de uso público ou privado de uso coletivo, tanto na zona urbana como na rural, por pessoa com deficiência ou mobilidade reduzida (NBR 9050:2015 da ABNT, p. 2) 
Esta definição para acessibilidade deixa claro que a autonomia e independência para a pessoa com deficiência e mobilidade reduzida devem ser privilegiadas não apenas para espaços edificados, mas também nos espaços e nos equipamentos urbanos.

Já a definição para o desenho universal, também na norma brasileira pertinente é:

[...] concepção de produtos, ambientes, programas e serviços a serem utilizados por todas as pessoas, sem necessidade de adaptação ou projeto específico, incluindo os recursos de tecnologia assistiva (NBR 9050:2015 da ABNT, p. 4)

Esta definição da NBR 9050:2015 da ABNT para o desenho universal deixa claro que a concepção do projeto deve privilegiar o maior número de pessoas que possuam ou não deficiência e que não tenha a necessidade de adaptações posteriores. Este conceito pode ser empregado no desenvolvimento de projeto de novos bairros e contribui diretamente para a inclusão social.

O grande desafio para acessibilidade urbana como expôs o presidente do Conselho de Arquitetura e Urbanismo do Brasil (CAU/BR), Haroldo Pinheiro, no debate de acessibilidade no Congresso Nacional em 2016 é que "O espaço urbano deve já nascer a partir do conceito do desenho universal, não só as edificações, mas a cidade como um todo". (CAU, 2016, on-line). Esta afirmação que os espaços urbanos devem nascer com desenho universal, é mais fácil de ser empregada no desenvolvimento de novos bairros, mas para cidades consolidadas como São Paulo, a postura a ser adotada tem que ser outra mais complexa e deve ocorrer através da reforma que vise a adequação a acessibilidade, principalmente nas calçadas.

Infelizmente, as cidades brasileiras são precárias no aspecto da mobilidade urbana para os pedestres com ou sem deficiência. Hoje ocorrem esforços do Poder Público Federal, através do Ministério das Cidades, visando realizar ações referentes à acessibilidade e mobilidade urbana nas cidades brasileiras que não proporcionam qualidade suficiente para deslocamentos a pé, conforme apontado por Aguiar (2010).

\section{I VIAS PÚBLICAS}

A via pública, segundo São Paulo (2008), compreende também a calçada que é destinada à circulação dos pedestres. Já o espaço da ilha e o canteiro junto ao leito carroçável são espaços agregados à circulação dos veículos de transporte, podendo ser coletivo ou individual.

Segundo a Secretaria Municipal da Pessoa com Deficiência e Mobilidade Reduzida (SÃO PAULO, [2008?], p. 79) da cidade de São Paulo, o automóvel é "o principal elemento da via pública e o maior beneficiário das politicas de transporte urbano." Esse panorama, ainda de acordo com esta Secretaria, começou a mudar, pois o pedestre passou a ganhar mais atenção do poder público, através da consciência 
social e o surgimento das preocupações com a acessibilidade nas calçadas.

As preocupações com a acessibilidade deve ser algo presente em toda a população, desde o motorista em seu carro, ou na população que se desloca a pé nas cidades brasileiras e não pode se esquecer de que "em algum momento do dia, todos nós somos pedestres." (SÃO PAULO, 2008, p. 79)

Os desafios diários dos pedestres vão desde ruas sem calçadas, a passeios públicos mal conservados, esburacados ou cheio de obstáculos físicos como degraus que podem colocar a saúde das pessoas em risco.

Segundo o Instituto Brasileiro de Geografia e Estatística (IBGE) em 2010, o percentual de pessoas com deficiência no Brasil é de 23,9\% do total da população, muito distante da média mundial que gira em torno de $10 \%$ segundo a Organização das Nações Unidas (ONU BR, s.d.). Provavelmente, esta distorção decorre dos padrões errôneos adotados pelo IBGE, como a auto declaração do cidadão ao responder a pesquisa, informando que possui algum tipo de deficiência.

Outra questão é o envelhecimento da população, segundo a OMS (2015) a perspectiva é de que até 2050 no Brasil se triplicará o número de pessoas com mais de 60 anos e haverá crescente aumento do numero de acidentes originados dos veículos automotores, que resultarão em sequelas como perda de movimento e dificuldade de locomoção. Estas projeções fazem com que surjam questionamentos de como o poder público deve encaminhar as questões de acessibilidade nas cidades de forma a promover a inclusão social das pessoas com ou sem deficiência na utilização dos espaços públicos.

Deve-se considerar que o ideal a ser perseguido é ocorra o convívio pacífico entre os pedestres e os veículos automotores, de forma a que todos possam usufruir e conviver nos espaços públicos.

\section{I MOBILIDADE DA REGIÃO METROPOLITANA DE SÃO PAULO}

A Região Metropolitana de São Paulo (RMSP), como ilustra a figura 01, é formada por 39 municípios e está dividida em 6 sub-regiões segundo a Pesquisa de Mobilidade realizada em 2012. Segundo o Plano de Desenvolvimento Urbano Integrado (PDUI), a RMSP é considerada a principal aglomeração urbana da América do Sul e a sexta no mundo, de acordo com a Organização das Nações Unidas (ONU) em 2014. 


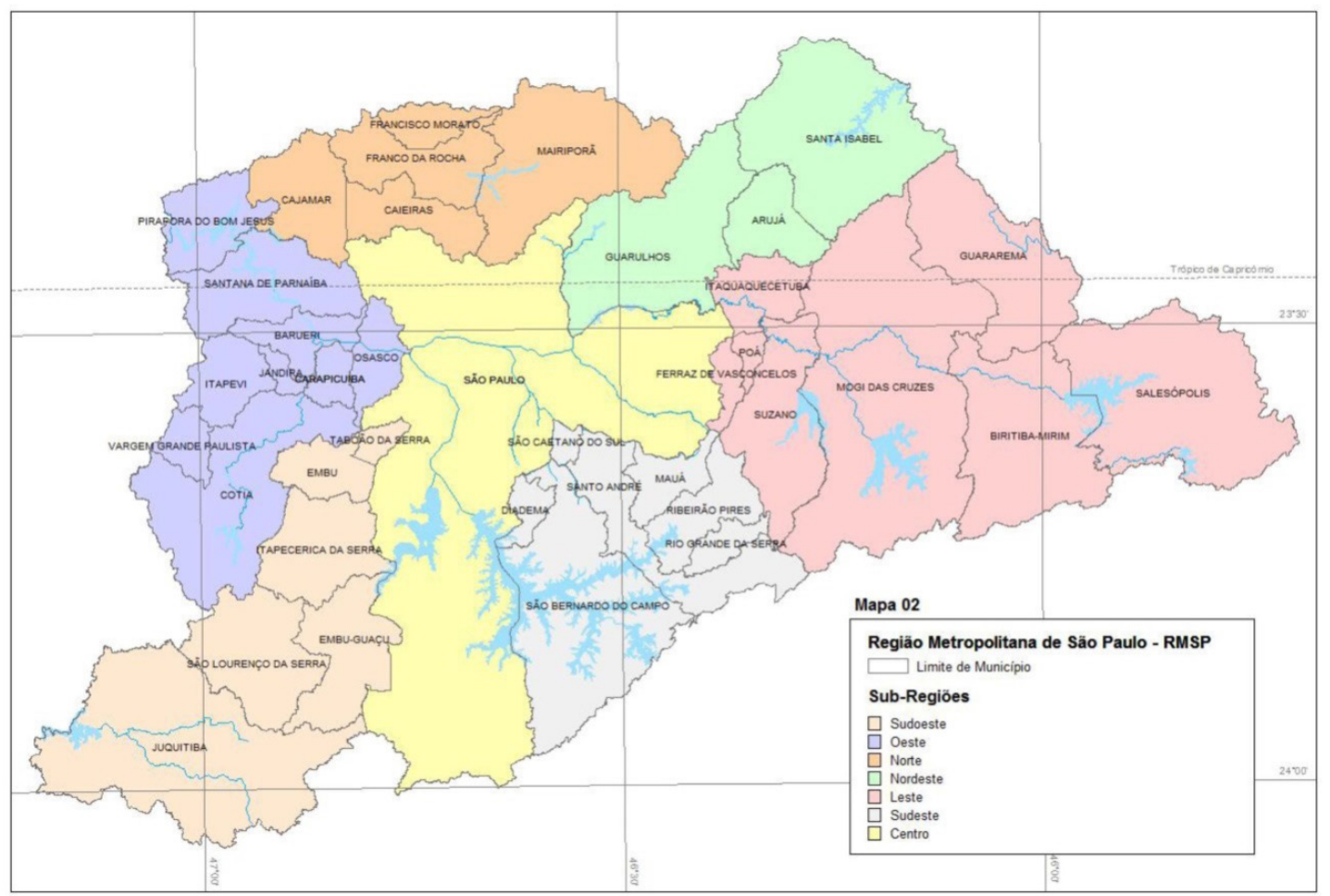

Figura 1 - Região Metropolitana de São Paulo

Fonte: Pesquisa de Mobilidade - 2012

Aprofundando a questão do transporte, a Pesquisa Origem Destino 2017 da Região Metropolitana de São Paulo realizada pelo Metrô, mostra que as viagens por transporte motorizado versus não motorizado é de $68 \%$ contra $32 \%$ respectivamente. É interessante notar que no transporte não motorizado, 97,3\% de deslocamentos são realizados a pé, mostrando a importância de seu encaminhamento. Por outro lado, a porcentagem de distribuição de modalidades para o modo motorizado mostra que o transporte coletivo apresentou $54,2 \%$ enquanto que o transporte individual foi responsável por $45,8 \%$ das viagens. O modo transporte motorizado levou em consideração: o ônibus, metrô, trem, automóvel, motocicleta, transporte escolar e fretado.

No panorama geral da RMSP, referente à composição das viagens motorizadas e não motorizadas, o que é mais relevante para esta pesquisa é o aumento considerável no período compreendido entre 1977 a 2017 nas viagens diárias feitas a pé, conforme mostra o gráfico 1. 


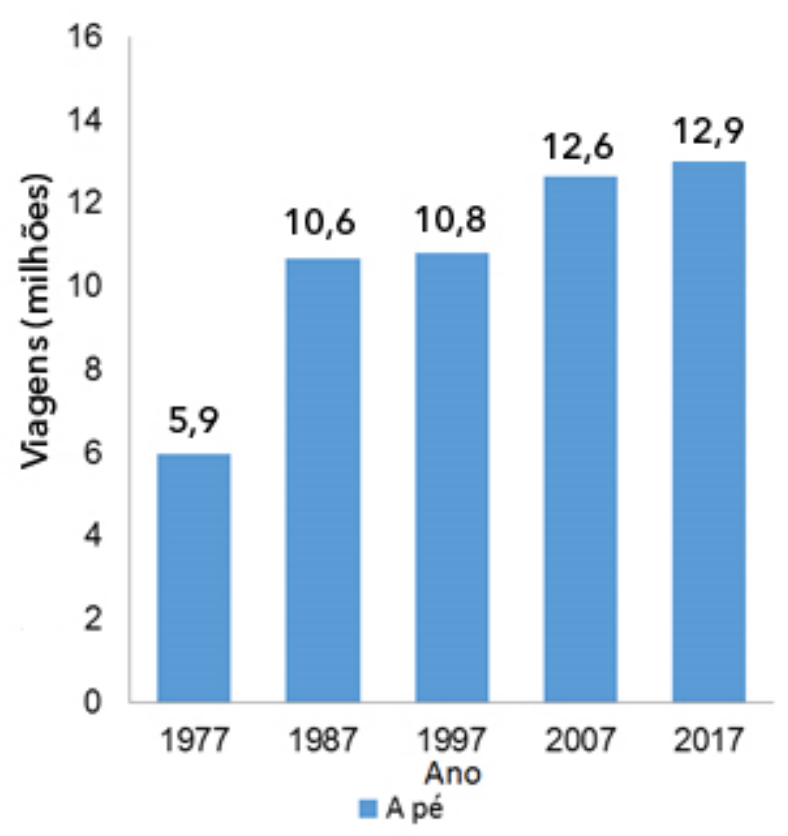

Gráfico 1 - Evolução das Viagens Diárias a Pé - Região Metropolitana de São Paulo 1977 a 2017

Fonte: realizado pelos autores a partir da Pesquisa de Mobilidade 2012 e Pesquisa Origem e Destino 2017

De acordo com estudos dos autores referentes ao gráfico 1, houve o crescimento nos últimos 40 anos das viagens a pé realizadas na RMSP, num incremento relativo de aproximadamente $119 \%$.

Para melhor compreender os dados deve-se considerar que as viagens a pé se constituem em geral em percursos curtos ou complementares a outras modalidades de transportes, tendo em vista a dimensão e as dificuldades impostas pelo meio metropolitano. Desta forma, é essencial raciocinar que as viagens a pé quase sempre estão integradas ao sistema de transporte em sua amplitude final, compreendendo-se desta forma a sua especificidade quanto ao conforto, segurança, conveniência e etc.

Segundo São Paulo (2008) um dos motivos para o incremento do deslocamento a pé por uma parcela crescente da população ocorre em razão da falta de recursos financeiros e alto custo do transporte. O custo de transporte segundo Bermann (2009) tem impacto muito significativo no orçamento mensal para famílias de baixa renda, pois ela geralmente reside em localizações distantes e periféricas.

Portanto, os dados apresentados mostram a importância de tornar as calçadas da RMSP acessíveis para a população circular, sem enfrentar os problemas originados por barreira física que são encontradas atualmente não só aqui, como também nos demais grandes centros urbanos brasileiros.

\section{I CALÇADAS EM SÃO PAULO}

A postura adotada pela Prefeitura Municipal de São Paulo para adequar as vias urbanas a acessibilidade e atender as necessidades dos pedestres, conforme apontado 
no item anterior desta pesquisa é de reformar as calçadas. A cidade de São Paulo segundo Rocha (2012) possui aproximadamente 17 mil quilômetros de ruas e 30 mil quilômetros de calçadas e o "Programa de Recuperação de Calçadas" da Secretaria de Coordenação das Subprefeituras, na tentativa de melhorar as condições das calçadas reformaram mais de 100 mil metros quadrados entre 2005 e 2006 em 187 vias. Mais recentemente, as vias mais relevantes para os autores e que passaram por reformas nas calçadas na cidade de São Paulo foram a Rua Augusta (2006), Rua Oscar Freire (2006), Avenida Paulista (2008), Avenida Faria Lima (2011) e Rua Pinheiros (2012).

Mas, apesar das reformas junto às calçadas nas vias citadas, muitas delas possuem problemas como no caso da Rua Augusta, com o tipo de revestimento em intertravado de concreto que se tornou em verdadeiras armadilhas, pois alguns se encontram soltos ou defeituosos (figura 2) ou com buracos (figura 3), podendo provocar tropeções, torções ou quedas dos pedestres comprometendo a circulação da pessoa em cadeira de rodas. Outro problema encontrado junto à calçada da Rua Augusta ocorre com a instalação parcial do piso tátil de alerta (figura 4) junto ao telefone público e que pode causar acidentes a pessoa com deficiência visual ou não.

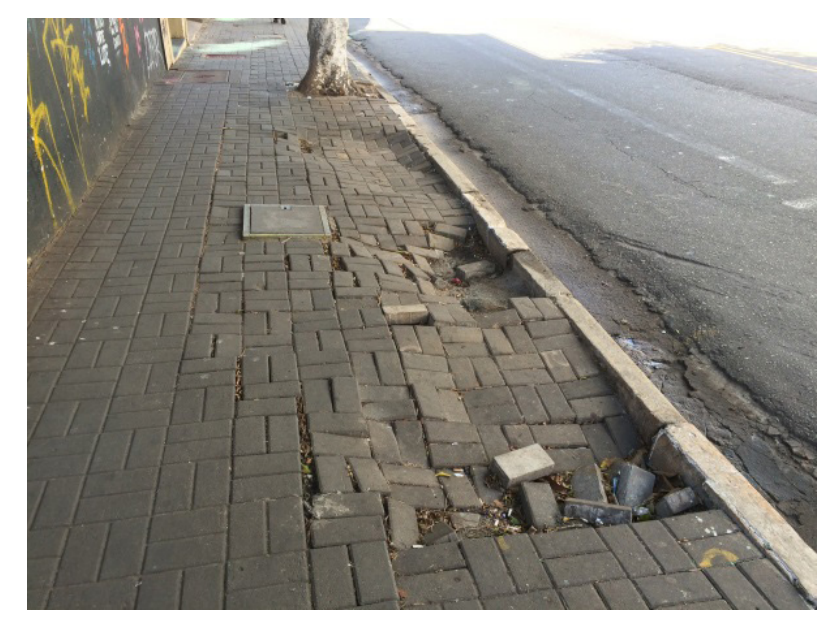

Figura 2 - Inter travado de Concreto solto ou defeituoso na calçada Rua Augusta - 2016 Fonte: arquivos fotográficos dos autores

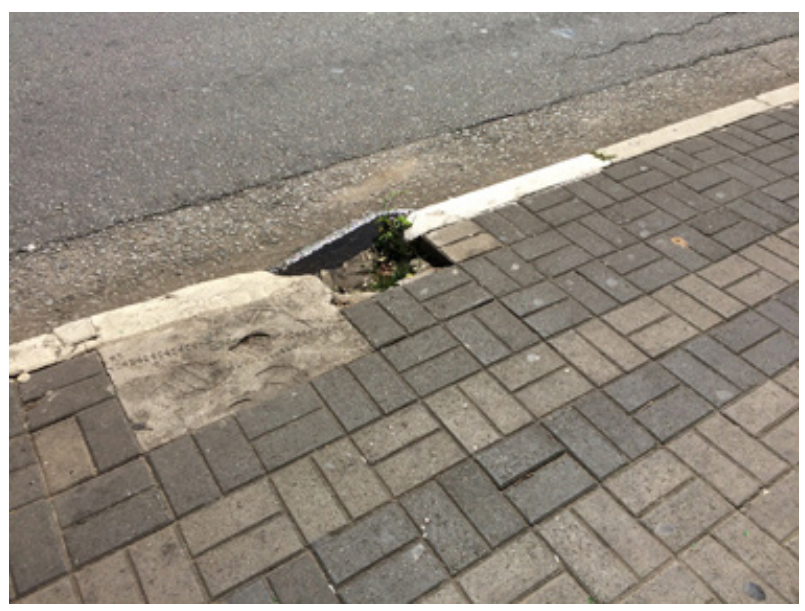

Figura 3 - Buraco na calçada Rua Augusta - 2016

Fonte: arquivos fotográficos dos autores 


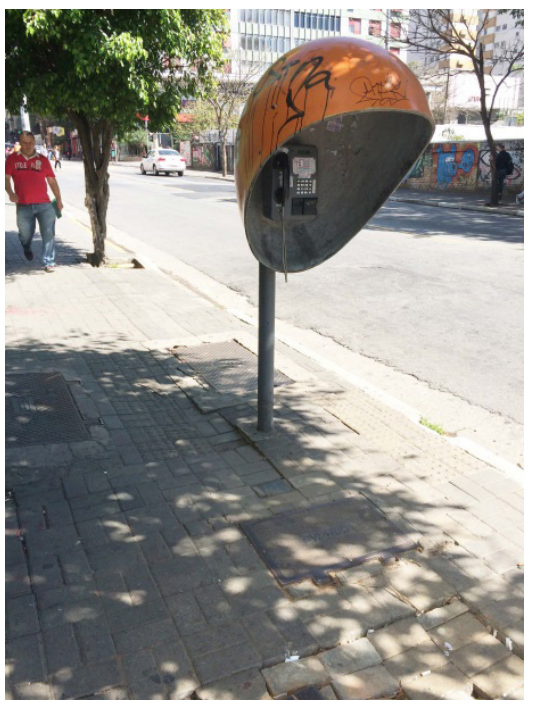

Figura 4 - Telefone público na calçada Rua Augusta - 2016

Fonte: arquivos fotográficos dos autores

As figuras de 2 a 4 foram tiradas pelos autores no trecho da Rua Augusta entre a Praça Roosevelt e a Rua Marques de Paranaguá.

Os problemas encontrados na Rua Augusta também são ocasionados pela má execução da instalação do intertravado, manutenções nas redes de concessionárias de água, luz e telefonia e pela falta de manutenção por parte da municipalidade e proprietário de imóveis. Um dos autores desta pesquisa, Feitosa acompanhou a reforma da calçada na Rua Augusta e constatou que o intertravado de concreto foi instalado sem a preparação necessária, como o estabelecido pelo "Manual de Pavimento Intertravado" da Associação Brasileira de Cimento Portland (ABCP).

A maneira indicada pelo manual, determina a instalação se dê em 4 passos que são:

a. Subleito que é composto pelo solo natural ou por empréstimo através de troca de solo deve ser compactado em camadas de $15 \mathrm{~cm}$, conforme condições do local;

b. Base é feita por material granular tipo bica corrida ou brita com espessura mínima de $10 \mathrm{~cm}$ e deve ser compactada sobre o subleito;

c. Camada de assentamento é composta por material granular (areia) com função de assentamento das peças de concreto e para o nivelamento do pavimento. Deve ser feita manualmente através de régua niveladora correndo sobre mestras ou guias;

d. Camada de revestimento são as peças de concreto e o material de rejuntamento que permitem o trafego de pessoas no caso da utilização em calçadas ou nas vias de veículos.

As etapas a, b e d são compactadas através de placa vibratória que tem como finalidade melhorar o assentamento das peças de concreto e trava-las, mas na reforma 
da calçada da Rua Augusta não foi observada a utilização da placa por Feitosa. A não utilização de placa vibratória faz com que não seja possível "travar" o intertravado de concreto, possibilitando que ele saia com mais facilidade do local onde foram instalados. Esse problema também é observado em outras calçadas que foram reformadas com intertravado de concreto em São Paulo como o caso da Rua Voluntários da Pátria no bairro de Santana na zona norte da cidade.

A figura 5 mostra a estrutura típica para instalação e utilização do intertravado de concreto segundo a ABCP.

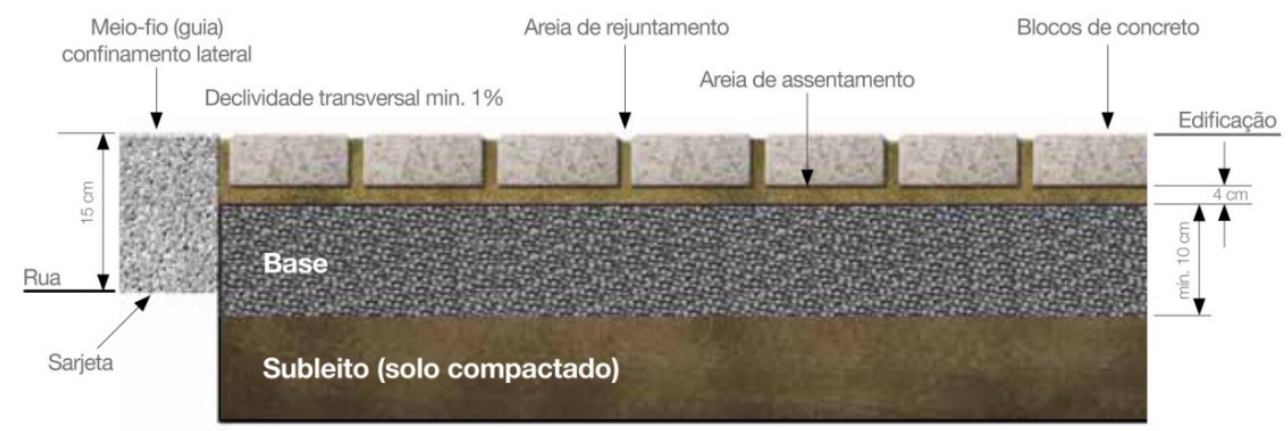

Figura 5 - Estrutura Típica do Intertravado de Concreto

Fonte: Associação Brasileira do Cimento Portland - 2010 (p. 15)

Em São Paulo, outras vias como mostra a figura 6, também passaram por intervenções junto a calçadas em 2010.

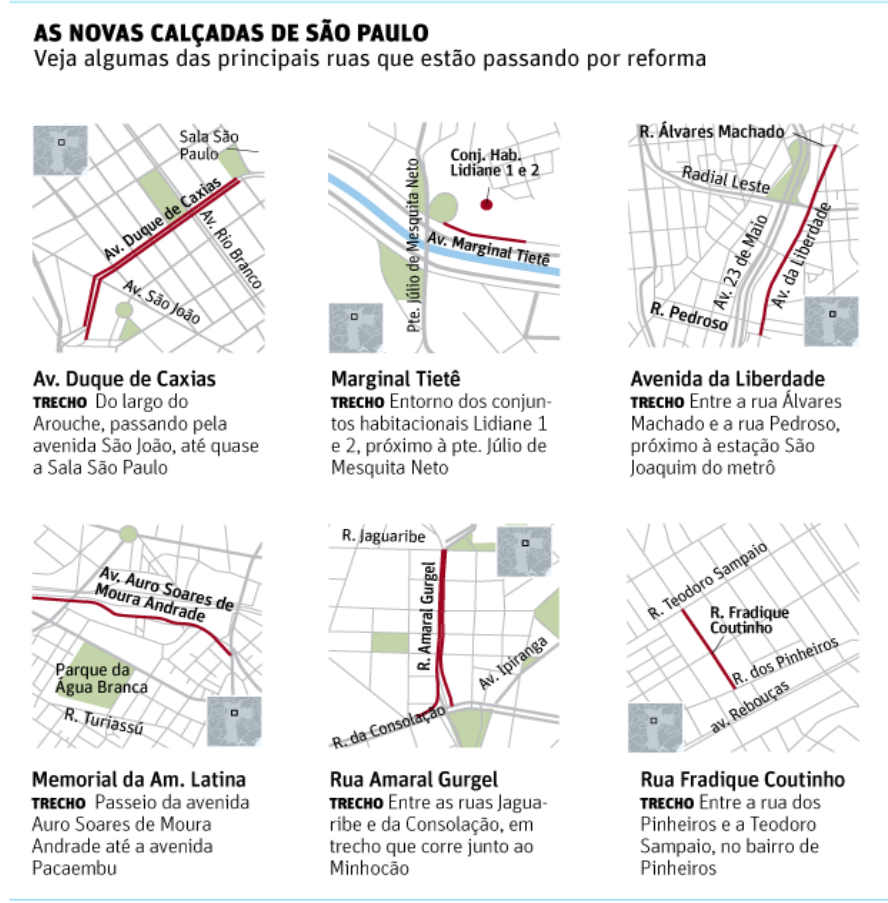

Figura 6 - As novas Calçadas de São Paulo - 2010

Fonte: http://www1.folha.uol.com.br/cotidiano/2010/07/774443-apos-reforma-calcadas-de-sp-tem-problemas-depavimentacao-e-acessibilidade.shtml. Acesso em: 10 jun. 2016 
O resultado das intervenções nas calçadas em São Paulo em 2013 foram 112,5 mil metros quadrados e 171 mil em 2014, de acordo com Garcia (2015, on-line).

A meta estabelecida em 2015 pela gestão passada da PMSP para adequação das calçadas era reformar 1 milhão de metros quadrados, dividido entre 28 Subprefeituras existentes na cidade de São Paulo. Esta meta superestimada é muito distante de ser alcançada nos dois últimos anos de mandato, e a maior parte das intervenções nas calçadas concentra-se na zona sul (Capela do Socorro), conforme tabela 1.

\begin{tabular}{|c|r|}
\hline Subprefeitura & area $\mathbf{~}^{2}$ \\
\hline Cidade Ademar & $52.696,00$ \\
\hline Aricanduva & $12.480,00$ \\
\hline Butantã & $12.292,50$ \\
\hline Campo Limpo & $24.000,00$ \\
\hline Capela do Socorro & $244.803,00$ \\
\hline Cidade Tiradentes & $21.383,00$ \\
\hline Casa Verde & $35.200,00$ \\
\hline Ermelino Matarazzo & $80.592,00$ \\
\hline Freguesia/Brasilândia & $9.219,90$ \\
\hline Guaianases & $2.926,51$ \\
\hline Itaquera & $22.790,40$ \\
\hline Itaim Paulista & $112.536,00$ \\
\hline Jabaquara & $22.010,00$ \\
\hline Lapa & $4.770,00$ \\
\hline
\end{tabular}

\begin{tabular}{|c|r|}
\hline Subprefeitura & area $\mathbf{~}^{\mathbf{2}}$ \\
\hline M'Boi Mirim & $4.800,00$ \\
\hline Vila Maria/Vila Guilherme & 330,00 \\
\hline São Miguel Paulista & $10.751,95$ \\
\hline Parelheiros & $84.900,00$ \\
\hline Penha & $2.080,00$ \\
\hline Pirituba/Jaraguá & $32.400,00$ \\
\hline Perus & $35.259,00$ \\
\hline Santo Amaro & $34.608,00$ \\
\hline Sapopemba & $42.540,00$ \\
\hline Sé & $19.157,00$ \\
\hline São Mateus & $10.200,00$ \\
\hline Santana/Tucuruvi & $12.075,00$ \\
\hline Vila Mariana & $31.500,00$ \\
\hline Vila Prudente & $21.700,00$ \\
\hline Total geral & $1.000 .000,26$ \\
\hline
\end{tabular}

Tabela 1 - Metragem Quadrada de Intervenção nas Calçadas de São Paulo por Subprefeitura 2015

Fonte: http://capital.sp.gov.br/portal/noticia/5639\#ad-image-4. Acesso em: 15 jul. 2016

Do 1 milhão de metros quadrados estabelecidos, de acordo com a Prefeitura, 290 mil $\mathrm{m}^{2}$ já foram executados e $100 \mathrm{mil} \mathrm{m}^{2}$ e estavam aguardando a liberação de verba do governo federal em 2015.

Segundo a Folha de São Paulo (2016), a meta para reformar as calçadas na cidade de São Paulo encontrava-se atrasada e a maneira encontrada pela antiga gestão para alavanca-la foi de iniciar a reforma nas calçadas da região central. A calçada do centro da cidade que passou por intervenção, inicia-se no cruzamento da Avenida São João com a Rua Helvetia, indo até a Avenida General Olímpio da Silveira, totalizando dois quilômetros sob o Elevado Presidente João Goulart, mais conhecido como "Minhocão". A gestão anterior da prefeitura conseguiu cumprir apenas 36,1\% da meta estabelecida para reforma das calçadas na cidade de acordo com a Folha de São Paulo (2016).

Apesar destas intervenções nas calçadas na cidade de São Paulo, outro fator primordial abordado por um dos autores deste artigo, Righi (2013) em entrevista a Milan (2013) para Gazeta do Povo, é a avaliação e percepção da população referente às calçadas das cidades da Região Metropolitana de Curitiba. Nesta cidade apesar de existirem muitas calçadas, ruas e avenidas consideradas pelos pesquisadores da 
Universidade Federal do Paraná, como inadequadas, as pessoas entrevistadas as julgaram suficientes para o uso, o que surpreendeu os pesquisadores. Para explicar esta reação, Righi conclui que: "Costuma faltar referência a esta população para entender o que é uma boa avenida. Quem teve a oportunidade de viajar mais para outros países tende a ser mais crítico". A população precisa avaliar às intervenções nas calçadas de São Paulo, como também nas calçadas existentes nas cidades paranaenses, pois em ambos os locais costumam existir buracos ou algum tipo de interferência, como barreiras físicas que comprometem a circulação do pedestre, possuindo ou não deficiência.

Roberto Righi, um dos autores desta pesquisa, foi um dos sócios fundadores da Associação Brasileira de Pedestres (ABRASPE) em 1981, que tem como objetivo a luta pelos direitos dos pedestres e principalmente dos mais frágeis. A ABRASPE concentra-se, desde a sua fundação, no combate a irregularidade das calçadas através de denúncias junto às autoridades públicas e na divulgação das necessidades dos pedestres.

A PMSP disponibiliza em seu site uma cartilha que se chama "Passeio Livre" que tem como objetivo recuperar a paisagem urbana, resgatar as calçadas, promover à acessibilidade para pessoa com deficiência e mostrar diretrizes de intervenção. Nesta cartilha, estabelece à divisão da calçada em três faixas seguindo a determinação do Decreto Municipal 45.904/2005, que estabelece a "[...] padronização dos passeios públicos do Município [...]" e a NBR 9050:2015 da ABNT que segue os mesmos padrões como mostra figura 7.

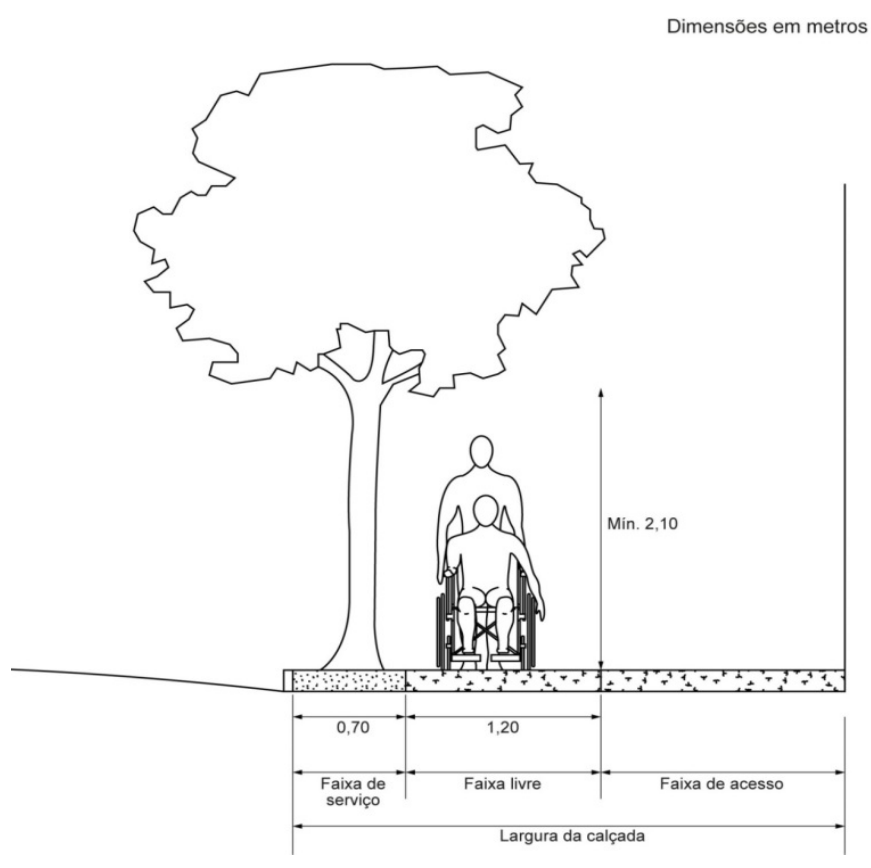

Figura 7 - Faixas de uso da calçada - Corte

Fonte: NBR 9050:2015 da ABNT (p. 75)

As três faixas junto à calçada são:

a. Faixa de serviços é destinada para arvores, poste de sinalização de transi- 
to ou iluminação, mobiliário urbano, como floreiras ou bancos e rampa de acesso de veículos e com largura mínima de 0,70m;

b. Faixa Livre devem possui largura mínima de 1,20 m, sem nenhuma interferência como arvores, postes e etc. Ela é destinada exclusivamente a circulação de pedestres, não tendo nenhuma interferência e sua inclinação transversal não pode ser maior que $2 \%$;

c. Faixa de acesso é o espaço destinado para vegetação, rampa, toldos e mobiliários móveis, como mesas de bar. São consideradas como uma faixa de apoio à propriedade de acordo com a cartilha "Passeio Livre" (2012, p. 7).

A proposta indicada pela PMSP, apesar de tecnicamente correta, é infelizmente irreal e impossível de ser implantada em quase $100 \%$ das ruas paulistanas, que raramente possuem calçadas que exceda um metro de largura, principalmente nos bairros mais periféricos da cidade.

Observa-se na cartilha a maneira como o piso tátil direcional deve ser empregado nas calçadas muito amplas, principalmente em face de imóveis que não estejam construídos no alinhamento do lote, como em caso dos postos de combustível. Rebaixamentos de calçadas também estão na cartilha e na NBR 9050:2015 da ABNT e são importantes, pois facilitam a passagem do nível da calçada para rua. Ela deve ser utilizada conjuntamente com faixa de pedestre conforme figura 8.

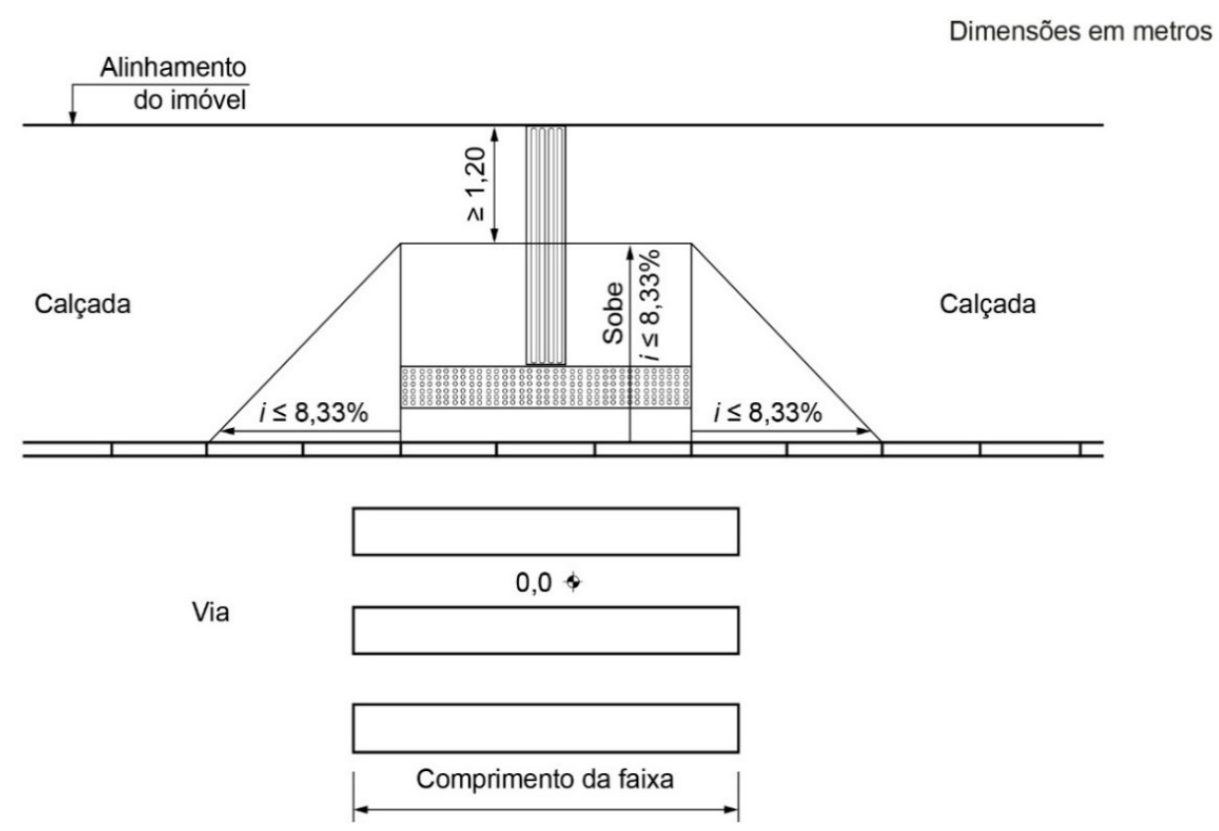

Figura 8 - Rebaixamento de Calçada - Vista Superior Fonte: NBR 9050:2015 da ABNT (p. 80)

O Decreto Municipal 45.904/2005 que determina a "[...] padronização dos passeios públicos [...]", também especifica o tipo de material para calçadas das vias locais e coletoras que devem ser em concreto pré-moldado ou moldado "in loco", bloco de concreto intertravado ou ladrilho hidráulico. 
O revestimento do tipo mosaico português ou pisos de pedras naturais (granito e basalto) podem ser utilizados desde que no subsolo do passeio público não tenha instalação de infraestrutura e mediante consulta a prefeitura. Esses tipos de revestimento para calçadas não são indicados, pois causam trepidações em cadeira de rodas e podem ocasionar acidentes a pessoa com deficiência.

Vale salientar que a Lei Municipal 15.442/2012 - Art. 7 determina-se que:

Os responsáveis por imóveis, edificados ou não, lindeiros a vias ou logradouros públicos dotados de guias e sarjetas, são obrigados a executar, manter e conservar os respectivos passeios na extensão correspondente à sua testada, na conformidade da normatização específica expedida pelo Executivo.

Esta determinação, apesar de recente, apenas reforça uma postura tradicional adotada no urbanismo luso-brasileiro e paulistano. Esta posição provavelmente é um dos motivos que leva a falta de padronização e qualidade das calçadas, já que elas dependem de iniciativas particulares e pulverizadas, só uma rigorosa regulamentação e fiscalização poderiam melhorar este efeito.

As calçadas não podem apresentar buracos, ondulações, desníveis que impeçam circulação livre e segura dos pedestres, pois os responsáveis por mantê-las, os proprietários ou possuidores do imóvel podem ser autuados e penalizados com multa, caso não mantenham a calçada. A Prefeitura Municipal de São Paulo, através da Lei Municipal 15.442/2012 que "Dispõe sobre a limpeza de imóveis, o fechamento de terrenos não edificados e a construção e manutenção de passeios [...]" e a Lei Municipal 15.733/2013 que "[...] torna sem efeito multas aplicadas [...]", estabelece e atualiza através de novos parâmetros de fiscalização das calçadas e de acordo com a última lei citada, a multa poderá ser cancelada, caso as calçadas se tornem adequadas.

\section{I CONSIDERAÇÕES FINAIS}

Promover a acessibilidade urbana, em uma cidade como São Paulo que possui alta incidência de pessoas com algum tipo de deficiência, é necessária. O caminho para isto é um desafio social para os profissionais que estão diretamente ligados na construção das cidades, como os arquitetos, engenheiros e os responsáveis pelas políticas públicas, segundo Cambiaghi (2012) que devem promover o desenho universal e a acessibilidade na concepção de bairros e edifícios.

No desenvolvimento de projetos urbanos para novos bairros é mais fácil de empregar os conceitos do desenho universal, mas para cidades brasileiras, como São Paulo objeto desta pesquisa, tem que se adaptar levando em consideração a adequação dos parâmetros estabelecidos pelas legislações pertinentes de acessibilidade e a NBR 9050:2015 da ABNT, às situações reais.

Outro ponto observado é que o transporte individual não pode ser a primeira prioridade nas intervenções urbanas, dada à quantidade de deslocamentos feitos a 
pé, que exige calçadas melhores na cidade de São Paulo.

As reformas das calçadas na cidade de São Paulo devem ser bem executadas e fiscalizadas, para não apresentar problemas como buracos ou intertravados de concreto soltos, como nos casos estudados.

A população deve ser instruída e participar em prol de melhores calçadas e contribuir como um agente fiscalizador, trabalhando conjuntamente com a PMSP e a ABRASPE com o objetivo que a cidade se torne menos hostil aos cidadãos possuindo ou não deficiência. Para os casos das calçadas com largura inferior ao recomendado pela NBR 9050:2015 da ABNT de no mínimo 1,20 m para a faixa livre e 0,70 m para a faixa de serviços, deve se estabelecer que ela possua piso firme, estável, que a faixa livre não possua nenhuma interferência e prever também a flexibilização, em casos específicos que a largura seja inferior a 1,00 m, mas que não comprometa a circulação de pedestres com segurança.

A PMSP na tentativa de melhorar o panorama existente das vias públicas da cidade estabelece o Programa de Recuperação de Calçadas, mas o resultado em alguns casos é deficiente, como apontado na pesquisa. A Prefeitura deve ser mais criteriosa no aceite das obras, pois alguns dos problemas apontados atualmente já existem, no momento da entrega, ocasionados pela má execução.

Portanto, promover acessibilidade através da mobilidade nas calçadas, garante o direito constitucional de ir e vir dos cidadãos. Caso a Prefeitura Municipal de São Paulo conseguir estabelecer maior fiscalização no cumprimento das Leis Municipais 15.422/2012 e 15.773/2013, mantendo o Programa de Recuperação de Calçadas, certamente a cidade passa a ser menos hostil aos cidadãos e principalmente para pessoas com deficiência, idosos e pessoas com mobilidade reduzida, pois todos ganham com uma cidade mais inclusiva através da acessibilidade urbana.

Assim o desenho universal e acessibilidade são primordiais para as pessoas que possuem ou não deficiência, pois asseguram a circulação pelos espaços com autonomia e segurança. Os locais acessíveis devem ser valorizados pela população, que deve questionar como a acessibilidade e desenho universal estão sendo empregado nas cidades.

\section{REFERÊNCIAS}

AGUIAR, F. O. Acessibilidade Relativa dos Espaços Urbanos para Pedestres com Restrições de Mobilidade. 170 p. Tese (Doutorado em Engenharia de Transporte) - Universidade de São Paulo, São Carlos, 2010.

ASSOCIAÇÃO BRASILEIRA DO CIMENTO PORTLAND (São Paulo). Manual de Pavimento Intertravado: Passeio Público. São Paulo: Abcp, 2010. Disponível em: <http://solucoesparacidades. com.br/wp-content/uploads/2012/08/ManualPavimentoIntertravado.pdf >. Acesso em: 20 ago. 2016.

ASSOCIAÇÃO BRASILEIRA DE NORMAS TÉCNICAS. NBR 9050: Acessibilidade a edificações, mobiliário, espaços e equipamentos urbanos. 3. ed. Rio de Janeiro, 2015. 148 p. 
BERMANN, Célio et al. Energia Para Quê e Para Quem no Brasil. São Paulo: Instituto de Eletrotécnica e Energia, 2009. 39 slides, color.

CAMBIAGHI, Silvana Serafino. Acessibilidade e Desenho Universal. In: PADOVANO, Bruno Roberto; NAMUR, Marly; SALA, Patricia Bertacchini. São Paulo: em busca da sustentabilidade. São Paulo: Edusp, 2012. p. 192-204.

CAU (Brasil). CAU/BR debate acessibilidade em audiência no congresso. 2016. Disponível em: < http://www.caubr.gov.br/?p=57797>. Acesso em: 7 jul. 2016.

COORDENAÇÃO DAS SUBPREFETIURAS. Passeio Livre: Conheça as regras para arrumar a sua calçada. São Paulo: Pmsp. 38 p. Disponível em: <http://www.prefeitura.sp.gov.br/cidade/secretarias/ upload/subprefeituras/calcadas/arquivos/cartilha_-_draft_10.pdfs. Acesso em: 25 jun. 2016.

FEITOSA, L.S.R, RiGHI, R., Acessibilidade Arquitetônica e Desenho Universal no Mundo e Brasil. In: FÓRUM AMBIENTAL DA ALTA PAULISTA, 12.,2016, Tupã. Anais eletrônicos... Tupã: XII FAAP, 2016. Disponível em: <https://www.amigosdanatureza.org.br/eventos/data/inscricoes/284/form1501149.pdts. Acesso em: 05 ago. 2016.

FOLHA DE SÃO PAULO (São Paulo). Após reforma, calçadas de SP têm problemas de pavimentação e acessibilidade. 2010. Disponível em: <http://www1.folha.uol.com.br/ cotidiano/2010/07/774443-apos-reforma-calcadas-de-sp-tem-problemas-de-pavimentacao-eacessibilidade.shtml>. Acesso em: 22 mar. 2016.

FOLHA DE SÃO PAULO (São Paulo). Prefeitura começa reforma de calçada na região central de São Paulo. 2016. Disponível em: <http://www1.folha.uol.com.br/cotidiano/2016/01/1733932-prefeituracomeca-reforma-de-calcadas-na-regiao-central-de-sao-paulo.shtml>. Acesso em: 22 mar. 2016.

GARCIA, Janaina. Terra. SP: Prefeitura reformará calçadas irregulares e cobrará do dono. 2015. Disponível em: < https://noticias.terra.com.br/brasil/cidades/prefeitura-de-sao-paulo-reformaracalcadas-irregulares-e-cobrara-dono,9c840b8e9f5d7bacc6244e96e1518b3cqx6jRCRD.html>. Acesso em: 15 jun. 2016

IBGE. Censo demográfico 2010. Rio de Janeiro: IBGE, 2012.

LANCHOTI, José Antônio; BRUNA, Gilda Collet,. Desempenho da Mobilidade no Espaço Urbano Construído na Cidade de Riberão Preto-SP - Uma Proposta de Avaliação. In: PRADO, Adriana R. de Almeida; LOPES, Maria Elisabete; ORNSTEIN, Sheila Walbe. Desenho universal: caminhos da acessibilidade no Brasil. São Paulo: Annablume, 2010. p. 197-208.

MILAN, Pollianna. Gazeta do Povo. População é pouco exigente com qualidade de ruas, aponta pesquisa. 2013. Disponível em: <http://www.gazetadopovo.com.br/vida-e-cidadania/populacao-epouco-exigente-com-qualidade-de-ruas-aponta-pesquisa-1 nnq9990270vbu6f0dlt8wjpi>. Acesso em: 15 ago. 2016.

OMS. Relatório Mundial de Envelhecimento e Saúde, 2015. Disponível em: <http://sbgg.org.br/wpcontent/uploads/2015/10/OMS-ENVELHECIMENTO-2015-port.pdf>. Acesso em: 10 jan. 2016.

ONU BR (Brasil). Nações Unidas no Brasil. A ONU e as pessoas com deficiência. [20--?]. Disponível em: <https://nacoesunidas.org/acao/pessoas-com-deficiencia/>. Acesso em: 20 jul. 2016.

Prefeitura Municipal de São Paulo. São Paulo terá 1 milhão de metros quadrados de novas calçadas. 2015. Disponível em: <http://capital.sp.gov.br/portal/noticia/5639\#ad-image-0>. Acesso em: 05 ago. 2016.

ROCHA, Regina (Brasil). Mobilize Brasil. Calçadas de São Paulo: problemas do tamanho da megalópole. 2012. Disponível em: <http://www.mobilize.org.br/noticias/2127/calcadas-de-sao-paulo- 
SÃO PAULO (Município). Decreto $n^{\circ}$ 45.122, de 12 de Agosto de 2004. Consolida a regulamentação das Leis $n^{\circ} 11.345$, de 14 de abril de 1993, $n^{\circ} 11.424$, de 30 de setembro de 1993, n 12.815, de 6 de abril de 1999, e $n^{\circ} 12.821$, de 7 de abril de 1999, que dispõem sobre a adequação das edificações à acessibilidade das pessoas com deficiência ou com mobilidade reduzida. Diário Oficial do Município, São Paulo, SP, 13 ago. 2004. Disponível em: < http://www3.prefeitura.sp.gov.br/cadlem/ secretarias/negocios_juridicos/cadlem/integra.asp?alt=13082004D\%20451220000 >. Acesso em: 17 mai. 2015.

Lei $n^{\circ} 15.442$, de 9 de Setembro de 2011. Dispõe sobre a limpeza de imóveis, o fechamento de terrenos não edificados e a construção e manutenção de passeios, bem como cria o DisqueCalçadas; revoga as Leis $n^{\circ} 10.508$, de 4 de maio de 1988, e $\mathrm{n}^{\circ} 12.993$, de 24 de maio de 2000, o art. 167 e o correspondente item constante do Anexo VI da Lei n 13.478 , de 30 de dezembro de 2002. Diário Oficial do Município, São Paulo, SP, 9 set. 2011. Disponível em: < http://www3.prefeitura. sp.gov.br/cadlem/secretarias/negocios_juridicos/cadlem/integra.asp?alt=10092011 L\%20154420000>. Acesso em: 17 mai. 2015.

Lei $n^{\circ} 15.733$, de 3 de Maio de 2013. Introduz alterações na Lei $n^{\circ} 15.442$, de 9 de setembro de 2011, bem como torna sem efeito multas aplicadas, conforme especifica. Diário Oficial do Município, São Paulo, SP, 3 maio 2013. Disponível em: < http://www3.prefeitura.sp.gov.br/cadlem/ secretarias/negocios_juridicos/cadlem/integra.asp?alt=04052013L\%20157330000 >. Acesso em: 17 mai. 2015.

Secretaria Municipal da Pessoa Com Deficiência e Mobilidade Reduzida. Mobilidade Acessível na Cidade de São Paulo: Edificações, Vias Públicas, Leis e Normas. São Paulo: SMPED, [2008?].

SÃO PAULO (Estado). Emplasa. Empresa Paulista de Planejamento Metropolitano. RMSP. [20--]. Disponível em: <https://www.pdui.sp.gov.br/rmsp/>. Acesso em: 15 ago. 2016.

. Metrô. Secretaria dos Transportes Metropolitanos. Pesquisa de Mobilidade da Região Metropolitana de São Paulo 2012: Síntese das informações, pesquisa domiciliar. 2013. Disponível em: <http://www.metro.sp.gov.br/metro/arquivos/mobilidade-2012/relatorio-sintese-pesquisamobilidade-2012.pdf>. Acesso em: 15 ago. 2016.

Metrô. Secretaria dos Transportes Metropolitanos. Pesquisa Origem Destino 2017: A maior e mais completa pesquisa de mobilidade urbana da região metropolitana de São Paulo. 2018. Disponível em: <http://www.metro.sp.gov.br/pesquisa-od/arquivos/2018_12_12_Balanco_OD2017_ Instituto_de_Engenharia_site_metro.pdf>. Acesso em: 15 jan. 2019. 


\section{CAPÍTULO 7}

\section{REGULAÇÃO DO USO DO ESPAÇO PÚBLICO EM CIDADES DE PEQUENO PORTE: UMA ANÁLISE TEÓRICA ENTRE AS POLÍTICAS PÚBLICAS, A LEGISLAÇÃO E A PRÁTICA}

Dannúbia Ribeiro Pires

Universidade Federal de Pernambuco - UFPE

Recife - PE

Leonardo Herszon Meira

Universidade Federal de Pernambuco - UFPE

Recife - PE

Maria Victória Leal de Almeida Nascimento

Universidade Federal de Pernambuco - UFPE

Recife - PE

RESUMO: Nas últimas décadas, o Brasil viveu um grande e rápido processo de urbanização. Esta grande e rápida ocupação brasileira veio acompanhada pela expansão horizontal das cidades e pela falta de planejamento do espaço urbano suficiente para atender esta demanda. Este trabalho tem como objetivo fazer uma análise teórica, em função da revisão bibliográfica realizada, das principais barreiras que geralmente são enfrentadas para a atuação de políticas públicas de regulação do uso do espaço público nas cidades brasileiras de pequeno porte (até 100 mil habitantes). Foi verificado que a legislação vigente não é devidamente seguida na prática, principalmente nas cidades de pequeno porte. Além do planejamento não ser pensado de forma integrada entre os diferentes modos de transporte, as políticas públicas de mobilidade urbana e de regulação do uso do espaço urbano atualmente são pensadas para as cidades médias ou grandes, sendo quase que esquecidas as necessidades das pequenas cidades brasileiras.

PALAVRAS-CHAVE: Políticas públicas. Espaço público. Cidades de pequeno porte.

ABSTRACT: In recent decades, Brazil lived a great and rapid urbanization process. This large and fast Brazilian occupation was accompanied by horizontal expansion of cities and lack of planning of the urban space enough to meet this demand. This paper aims to make a theoretical analysis, based on the bibliographical review, of the main barriers that are usually faced in the performance of the use of public space regulatory public policies in small Brazilian cities (up to 100 thousand inhabitants). It was found that the current legislation is not properly followed in practice, especially in small cities. In addition to planning not be thought in an integrated manner between the different transport modes, public policies for urban mobility and regulation of urban space use are currently designed for medium and large cities, and the small cities necessities are almost forgotten.

KEYWORDS: Public policy. Public place. Small towns. 


\section{I INTRODUÇÃO}

Em apenas cinco décadas no século passado a população brasileira passou de majoritariamente rural para predominantemente urbana. Uma das mais aceleradas urbanizações do mundo aconteceu sem a implementação de políticas indispensáveis para a inserção urbana digna da massa que abandonou e continua a abandonar o meio rural brasileiro, cuja estrutura agrária contribuiu para essa rápida evasão de população (BRASIL, 2004).

Muitos dos problemas urbanos hoje observados derivam desse intenso processo de migração e geralmente têm alguma relação com os sistemas de transporte e circulação. Questões como inadequação da oferta de transporte coletivo, congestionamentos, poluição sonora, poluição do ar e acidentes têm levado a um entendimento generalizado de que a maioria das cidades deve rever suas estratégias a fim de promover padrões sustentáveis de mobilidade (OLIVEIRA e SILVA, 2015).

Políticas públicas são um conjunto de ações e decisões do governo, voltadas para a solução (ou não) de problemas da sociedade. E no tocante ao espaço urbano, os problemas decorrentes da rápida urbanização junto com a falta de planejamento dos sistemas de transportes, faz-se pensar que para a adequada regulação deste espaço urbano, é necessário se desenvolver políticas públicas integradas ao planejamento urbano, de modo a se alcançar melhores condições de mobilidade nas cidades, com qualidade de vida adequada e preservação do meio ambiente (SEBRAE, 2008).

Esse processo de urbanização se agravou ainda mais com a aquisição do automóvel, por parte da classe média brasileira, a partir dos anos 1970, o que promoveu alterações na operação e gestão do sistema viário, que tem sido adequado ao uso mais eficiente do automóvel, em detrimento dos demais modos (ANDRADE e SERRÃO, 2007). De fato, à medida que um país experimenta um maior desenvolvimento socioeconômico, torna-se inevitável o aumento nos índices de motorização (número de veículos por habitante), pois a posse do veículo representa uma comodidade na qual poucas pessoas renunciam (FERRAZ e TORRES, 2004). Assim, este crescimento da frota veicular pode ser colocado como um dos fatores que contribuem para a falta de planejamento urbano, tornando-se uma barreira para a efetiva implantação de políticas públicas de mobilidade nas cidades brasileiras.

Os governos sempre tiveram dificuldade em controlar e orientar o uso, o desenvolvimento e a expansão das cidades. Para isso, a legislação estabelece normas que regulam o uso da propriedade urbana, visando uma melhor execução da política urbana, melhoria da segurança do bem-estar das pessoas e do equilíbrio ambiental (MINICHIELLO e RIBEIRO, 2013), como o Estatuto da Cidade, o Plano Diretor, o Ministério das Cidades e a Lei da Política Nacional de Mobilidade Urbana.

Portanto, infere-se que no momento de propor uma política nacional de desenvolvimento urbano é preciso entender as políticas públicas que vigoraram durante esse processo de urbanização e buscar alternativas para evitar que potenciais 
barreiras ao processo atuem de forma a inviabilizar sua execução, sempre analisando as normas regulamentadoras do uso do solo urbano. A partir desta discussão, surgiu a motivação deste trabalho, cujo objetivo é fazer uma análise teórica das principais barreiras à implantação das políticas públicas de regulação do uso do espaço público. Através desta análise, tentar entender o que realmente as impedem de serem aplicadas na prática e de acordo com a legislação vigente.

Esta análise será feita nas cidades brasileiras de pequeno porte. O critério de escolha destas cidades partiu da quase ausência de discussão nos trabalhos acadêmicos científicos acerca do tema proposto. Nestes, o enfoque das discussões é em sua quase totalidade direcionado para as cidades de médio e grande porte, e as pequenas cidades quase não estão contempladas nas análises e avaliações dos que se ocupam dos estudos sobre regulação do uso do espaço público. Sobre isso, Maté et al. (2014) lembra que o desenvolvimento econômico do Brasil nas últimas décadas não só impulsionou o crescimento dos grandes centros urbanos, mas também o de muitos municípios de pequeno e médio porte por todo o território nacional. E com esse crescimento, o modo de se locomover por entre a malha viária da pequena cidade sofreu modificações, principalmente diante do acesso facilitado aos automóveis.

Para atingir o objetivo proposto esse trabalho está estruturado em seis seções. Após esta seção introdutória, a seção 2 aborda o conceito de espaço público e como os diferentes usos do solo interferem na atuação das políticas públicas, bem como as principais barreiras encontradas na literatura que se opõem à sua implantação. A seguir, a seção 3 aborda o contexto brasileiro no tocante aos marcos legais de regulação do uso do espaço público. A seção 4 traz uma caracterização das cidades de pequeno porte, destacando os problemas comuns no tocante à regulação do espaço público. A seção 5 apresenta a comparação entre a teoria e a prática, a verificação se as políticas públicas atuantes nestas cidades de pequeno porte estão de acordo com a legislação regulatória vigente. Por fim, a seção 6 tece as considerações finais e traz recomendações para trabalhos futuros.

\section{I REGULAÇÃO DO USO DO ESPAÇO PÚBLICO}

O espaço urbano pode ser definido como o conjunto de diferentes usos da terra justapostos entre si. Tais usos definem áreas, como: o centro da cidade, local de concentração de atividades comerciais, de serviço e de gestão; áreas industriais e áreas residenciais, distintas em termos de forma e conteúdo social; áreas de lazer; e, entre outras, aquelas de reserva para futura expansão. Este conjunto de usos da terra é a organização espacial da cidade ou simplesmente o espaço urbano fragmentado (CORRÊA, 2002).

Ainda segundo o autor, os agentes sociais é que fazem e refazem a cidade (tais como proprietários fundiários, proprietários imobiliários, grupos sociais, estado etc.), ou 
seja, a produção do espaço urbano está ligada ao jogo de interesses destes agentes, e consequentemente os diferentes usos do solo. De acordo com Santos (2009), a utilização do solo urbano está destinada a poucos atores, gerando uma grande massa de excluídos sociais.

A forma como os diferentes usos do solo (residência, comércio, indústria e outros) se distribuem na cidade gera as atividades humanas como, morar, trabalhar, fazer compras, lazer etc., o que por sua vez, gera a necessidade de viagens entre os locais para o desenvolvimento destas diferentes atividades. Neste contexto, o sistema de transporte cria as oportunidades para esta interação, ou seja, promove a acessibilidade às diversas atividades. Desta forma, identifica-se um círculo de ações em que o uso do solo tem uma influência sobre o transporte, assim como, o transporte tem influência sobre o uso do solo e sobre ele próprio (CAMPOS, 2005).

Para Lautso et al. (2004), no relatório PROPOLIS, a maioria das análises ou questões teóricas para entendimento da relação transporte e uso do solo incluem conceitos técnicos (sistemas de mobilidade urbana), conceitos econômicos (cidades como mercado) e conceitos sociais (sociedade e espaço urbano) que podem ser assim resumidas:

- Impacto do uso do solo no transporte: o impacto de uma alta densidade residencial na redução do comprimento médio de viagem é possivelmente mínimo em relação ao aumento do custo de viagem, embora a densidade de empregos esteja positivamente correlacionada com o comprimento médio de viagem. Facilidades atrativas na vizinhança podem ser vistas como um fator que induz a redução do comprimento médio de viagens. Como localizações periféricas usualmente produzem viagens mais longas, o comprimento de viagem pode ser considerado negativamente correlacionado com o tamanho da cidade. Com relação a frequência de viagem, pouco ou nenhum impacto pode ser esperado a partir de políticas de uso do solo de acordo com a teoria dos encargos com o transporte. Densidade residencial e de empregos assim como, uma extensa aglomeração e uma boa acessibilidade ao transporte público tende a estar positivamente correlacionados com a utilização do transporte público, enquanto que uma vizinhança projetada com uma mistura de lugares de trabalho e residências com distâncias menores para viagens ao trabalho possivelmente aumentam a utilização de bicicletas e de caminhadas.

- Impacto do transporte no uso do solo: o impacto do transporte sobre o uso do solo é obtido a partir de uma mudança na acessibilidade a uma localização. Uma maior acessibilidade aumenta a atratividade para localização de todo tipo de uso do solo, influenciando assim, a direção de um novo desenvolvimento urbano. Se, porém, a acessibilidade cresce em toda a cidade, isto resulta numa maior dispersão da estrutura de assentamento.

- Impactos do transporte sobre o transporte: estes impactos são incluídos porque eles tendem a serem mais fortes do que os do uso do solo sobre o transporte e do transporte sobre o uso do solo. Enquanto o tempo e o custo de viagem têm um impacto negativo sobre as distâncias percorridas e a frequência de viagem, a acessibilidade tem um impacto positivo sobre estes 
mesmos parâmetros. Além disso, a escolha do modo de transporte depende da atratividade relativa de um modo comparado com todos os outros. $\mathrm{O}$ modo mais rápido e mais barato tem uma mais alta possibilidade de escoIha, ou seja, provavelmente será o modo com maior percentual de utilização.

O espaço público está cada vez mais sendo disputado pelos diferentes modos de transporte, sejam eles motorizados ou não. É comum a circulação de pedestres, ciclistas, motociclistas, carros, ônibus, caminhões e outros, dividindo o mesmo espaço limitado de ruas e avenidas, contribuindo, por exemplo, para o congestionamento das mesmas. As consequências do mau uso do espaço público são reflexos do não planejamento adequado para atender esta demanda pelos diferentes modos de transporte.

Uma política pública pode atuar em vários setores, inclusive no transporte urbano visando a o que se convencionou chamar de mobilidade sustentável. De acordo com Campos (2006), políticas públicas de mobilidade sustentável consistem na coordenação de ações conjuntas para produzir efeitos acumulativos de longo prazo atrelados ao balanceamento de metas ambientais, econômicas e sociais da sustentabilidade, incluindo as seguintes ações:

- Combinar políticas de tarifação de transporte público e uso de automóvel refletindo os custos externos causados e com diferenciação em relação a hora de pico e fora do pico, tanto quanto, em áreas congestionadas e não congestionadas.

- Direcionar os programas de investimento em transportes para as mudanças que possam ocorrer na demanda devido às políticas de ação anteriormente descritas e especialmente com relação ao aumento da demanda por meIhores transportes públicos, ou seja, mais rápidos e com melhores serviços.

- Desenvolver um plano de uso do solo dando suporte a necessidade por novas moradias próximas as áreas centrais, em cidades satélites ou ao longo de corredores bem servidos de transporte público, além da crescente necessidade e oportunidade de utilizá-lo.

No entanto, a realidade das políticas públicas locais brasileiras é que o conceito de mobilidade ainda parece estar associado apenas à circulação dos modos motorizados de transporte, priorizando o transporte particular. Quando, na verdade, as políticas públicas deveriam estar orientadas pela eficiência na gestão das cidades, contemplando estratégias para enfrentar questões sociais, econômicas e ambientais (PIRES e MEIRA, 2016).

Além disso, as falhas que ocorrem nos resultados de políticas públicas em geral são fruto da dissociação que se faz entre elaboração e implementação no processo de planejamento de acordo com algumas visões da prática ou escolas de pensamento. Todas essas visões separam claramente a elaboração da implementação de políticas públicas no processo de planejamento e colocam o planejamento como um processo de fazer-se planos (OLIVEIRA, 2006).

Segundo a Comissão Europeia (2003), para a implementação de uma estratégia 
de transportes e usos de solo é necessário a integração dos diversos processos e ações necessários à realização de qualquer política substancial - deliberação, implementação, monitorização, avaliação, identificação de políticas complementares, coordenação entre autoridades a diferentes níveis governamentais, participação de agentes privados, cidadãos e interessados - num quadro coerente, abrangente e duradouro, onde os processos individuais se possam reforçar mutuamente no cumprimento dos objetivos e no ultrapassar de barreiras para obtenção de sucesso na produção e resultados da política.

Há naturalmente diversas barreiras a serem ultrapassadas para se atingir uma maior coerência e continuidade nos processos de implantação de políticas públicas. Vários estudos se destacam sobre desafios e barreiras para implantação de políticas públicas (TEIXEIRA, 2002; SPECTRUM, 2004; TAKAHASHI, 2004; OLIVEIRA, 2006; SOUZA, 2006; SEBRAE, 2008; MEIRA, 2013).

A Tabela 1, compilada por Meira (2013), lista algumas barreiras que podem se opor ao êxito de uma política pública e quais as principais consequências geralmente encontradas quando essas dificuldades aparecem.

\begin{tabular}{|c|c|}
\hline $\begin{array}{l}\text { Principais barreiras às } \\
\text { Políticas públicas }\end{array}$ & Consequências \\
\hline Ação dos atores políticos & $\begin{array}{l}\text { - Situação e oposição buscando colocar em prática suas } \\
\text { ideologias. } \\
\text { - Divisão de forças estabelecida politicamente facilita ou } \\
\text { dificulta esta tarefa. } \\
\text { - Se há conflitos em demasia, geralmente também há } \\
\text { atraso e perda de sinergia. }\end{array}$ \\
\hline $\begin{array}{c}\text { Falta de procedimentos adaptados } \\
\text { à realidade dos países em } \\
\text { desenvolvimento }\end{array}$ & $\begin{array}{l}\text { - Ciclo das Políticas Públicas na maioria das vezes é } \\
\text { elaborado para experiências em países desenvolvidos. } \\
\text { - Isso gera a necessidade de diferenciar o planejamento } \\
\text { de políticas públicas entre os países desenvolvidos e os } \\
\text { países em desenvolvimento. }\end{array}$ \\
\hline $\begin{array}{l}\text { Deficiência nos canais de diálogo } \\
\text { e na participação popular }\end{array}$ & $\begin{array}{l}\text { - Sistema político, Estado e sociedade muitas vezes não } \\
\text { são articulados nos países em desenvolvimento. } \\
\text { - O tempo de democracia ainda não parece suficiente } \\
\text { para um sistema político-institucional efetivo. }\end{array}$ \\
\hline Questões financeiras & $\begin{array}{l}\text { - No Brasil a arrecadação do Estado chega perto dos } \\
40 \% \text { do PIB, mas os recursos públicos são direcionados } \\
\text { para pagamento de dívida, folha salarial ou rombos da } \\
\text { previdência. } \\
\text { - O Estado não consegue investir muito em políticas } \\
\text { públicas, limitando a capacidade de planejamento e de } \\
\text { execução. }\end{array}$ \\
\hline
\end{tabular}




\begin{tabular}{|c|c|}
\hline $\begin{array}{c}\text { Capacidade de gestão no } \\
\text { planejamento de políticas públicas }\end{array}$ & $\begin{array}{l}\text { - Falta uma melhor articulação entre as organizações } \\
\text { envolvidas no planejamento das políticas públicas. } \\
\text { - Grande centralização do processo de planejamento. } \\
\text { - Visão do planejamento como um processo técnico, } \\
\text { governamental, de caráter econômico e visionário. }\end{array}$ \\
\hline Barreiras legais & $\begin{array}{l}\text { - Decisões têm (ou deveriam ter) a participação de todos } \\
\text { os atores da sociedade em instâncias deliberativas e isso } \\
\text { facilitaria o consenso. } \\
\text { - Decisores com mandato público tem poderes sobre } \\
\text { recursos e políticas públicas, mas podem esbarrar em } \\
\text { problemas legais. }\end{array}$ \\
\hline $\begin{array}{l}\text { Falta de coordenação entre os } \\
\text { órgãos gestores públicos }\end{array}$ & $\begin{array}{l}\text { - Exemplo: rua acaba de ser asfaltada e a empresa de } \\
\text { saneamento realiza um reparo de rotina, destruindo parte } \\
\text { do pavimento. } \\
\text { - Consomem recursos que poderiam ser utilizados para } \\
\text { outros fins. }\end{array}$ \\
\hline Processo de tomada de decisão & $\begin{array}{l}\text { - Estabelecem-se relações entre os grupos decisores e os } \\
\text { atores interessados e influenciados pelas decisões. } \\
\text { - Geram direitos e obrigações recíprocos. } \\
\text { - Deve-se garantir que o que for decidido esteja de acordo } \\
\text { com os interesses/necessidades demandados pela } \\
\text { maioria da população. }\end{array}$ \\
\hline
\end{tabular}

Tabela 1: Principais barreiras às políticas públicas e suas consequências. Fonte: Meira (2013).

\section{I MARCO LEGAL BRASILEIRO DE REGULAÇÃO DO USO DO ESPAÇO PÚBLICO}

A expansão da urbanização no Brasil é um processo relativamente recente, somente a partir de 1970, há pouco mais de 30 anos, que os dados censitários revelaram uma população urbana superior à rural. As mudanças profundas por que passaram a sociedade e a economia brasileira, só se consolidaram com o acelerado processo de crescimento da economia urbano-industrial e com a expansão dos sistemas de transportes e comunicações (BRITO e PINHO, 2012).

Juntamente com esta grande e rápida ocupação brasileira, ocorreu o crescimento horizontal das cidades, sem infraestrutura técnica adequada para atender esta demanda populacional (MEIRA, 2013). Com o passar dos anos, as transformações no uso e ocupação do solo urbano não foram acompanhadas pelas necessárias mudanças no sistema de transportes das cidades (RIBEIRO et al., 2001). E é percebido que a infraestrutura de transporte frequentemente falha em atender as necessidades de mobilidade de uma população em crescimento (BOHLER-BAEDEKER et al., 2014).

Como ponto-chave do marco legal brasileiro da regulação do uso do espaço público, em termos de políticas públicas com enfoque na área urbana, pode ser citada 
a aprovação do Estatuto da Cidade (Lei Federal $n^{\circ}$. 10.257, de 10 de julho de 2001), que regulamenta os artigos 182 e 183 da Constituição Federal, estabelece diretrizes gerais da política urbana e dá outras providências.

Esta Lei, denominada Estatuto da Cidade, estabelece normas de ordem pública e interesse social que regulam o uso da propriedade urbana em prol do bem coletivo, da segurança e do bem-estar dos cidadãos, bem como do equilíbrio ambiental. A política urbana tem por objetivo ordenar o pleno desenvolvimento das funções sociais da cidade e da propriedade urbana, mediante as seguintes diretrizes gerais, resumidamente abordadas por Braga (2012):

- Promoção do direito à cidade, através da regularização fundiária, do acesso à moradia, à infraestrutura e aos equipamentos urbanos;

- Promoção da gestão democrática da cidade, por meio da participação do cidadão (diretamente ou através de associações) em todas as etapas do processo de planejamento e tomada de decisões;

- Combate à especulação imobiliária, diretamente através do cerceamento da retenção especulativa do solo e indiretamente, através da recuperação dos investimentos públicos geradores de valorização do solo urbano;

- Promoção da sustentabilidade ambiental urbana através da ordenação e controle do uso, ocupação e expansão do solo urbano e da proteção ao patrimônio natural e construído.

$\mathrm{Na}$ esfera municipal, o marco regulatório para a política urbana foi trazida também pelo Estatuto da Cidade, através do instrumento denominado Plano Diretor. De acordo com o Estatuto da Cidade, a propriedade urbana cumpre sua função social quando atende às exigências fundamentais de ordenação da cidade expressas no Plano Diretor, assegurando o atendimento das necessidades dos cidadãos quanto à qualidade de vida, à justiça social e ao desenvolvimento das atividades econômicas, respeitadas as diretrizes nele contidas.

O Plano Diretor deve ser aprovado pela Câmara Municipal. É o instrumento básico da política de desenvolvimento e expansão urbana, sendo obrigatório para cidades com mais de 20 mil habitantes, cidades integrantes de regiões metropolitanas e aglomerações urbanas e cidades integrantes de áreas de interesse público, entre outros. É parte integrante do processo de planejamento municipal, devendo o plano plurianual, as diretrizes orçamentárias e o orçamento anual incorporar as diretrizes e as prioridades nele contidas. Segundo Minichiello e Ribeiro (2013) é por meio dele que o município desenvolverá suas competências de promover, no que couber, adequado ordenamento territorial, mediante planejamento e controle do uso, do parcelamento e da ocupação do solo urbano.

O Estatuto da Cidade impõe ainda obrigação ao Poder Público municipal de promover a elaboração do Plano Diretor e estabeleceu - à época - prazo de cinco anos a contar do início de sua vigência. Aos gestores públicos que não atendessem a esta obrigação, estariam praticando improbidade administrativa, o que poderia significar a 
perda do cargo e a suspensão dos direitos políticos dos agentes públicos (LIMA, 2005). O Plano Diretor deve ser compatível com a política de mobilidade urbana, propondo a elaboração de um Plano de Transporte Urbano Integrado para as cidades com mais de 500 mil habitantes (PEREIRA et al., 2012).

Além destas políticas urbanas, outro ponto-chave foi a criação, no final de 2002 , do Ministério das Cidades, cuja apresentação destaca que foram incorporadas as áreas de transporte e mobilidade urbana, trânsito, questão fundiária e planejamento territorial. Ele foi estruturado levando em consideração a reunião das áreas mais relevantes (do ponto de vista econômico e social) e estratégicas (sustentabilidade ambiental e inclusão social) do desenvolvimento urbano, com o objetivo de assegurar o acesso à moradia digna, à terra urbanizada, à água potável, ao ambiente saudável e à mobilidade com segurança (BRASIL, 2004).

Apesar do Ministério das Cidades mostrar-se preocupado com a elaboração de textos técnicos, que na maioria dos casos, dedicam-se a padronizar ações urbanas brasileiras, tornando-as mais didáticas e ilustrativas, não havia um instrumento específico que tratava do tema mobilidade urbana. Até que foi instituído mais um ponto-chave na gestão política de mobilidade nas cidades com a promulgação da Lei Federal $n^{\circ}$. 12.587, de 03 de janeiro de 2012, conhecida como "Lei de Mobilidade", que estabelece as diretrizes da Política Nacional de Mobilidade Urbana.

Esta, além de definir princípios e diretrizes compatíveis com os conceitos de mobilidade urbana sustentável, torna obrigatória a elaboração de Plano de Mobilidade Urbana para os municípios com mais de 20 mil habitantes, integrado e compatível com os respectivos planos diretores ou neles inseridos, aumentando o número de municípios obrigados a ter um Plano de Mobilidade Urbana de 38 para 3.065 (mais de 55\% do total de municípios brasileiros) (OLIVEIRA e SILVA, 2015). A Lei previa ainda que os municípios teriam três anos para aprovar seus planos de mobilidade e os que não tivessem ficariam impedidos de receber recursos orçamentários federais destinados à mobilidade urbana até que atendessem à exigência legal (BRASIL, 2012).

Recentemente, o governo federal editou a medida provisória (MP) $n^{\circ}$. 748, de 11 de outubro de 2016, que altera a Lei Federal $n^{\circ}$. 12.587, de 03 de janeiro de 2012. O objetivo da MP foi o de alterar o prazo de três para sete anos para que os municípios elaborem o Plano de Mobilidade Urbana e o integrem ao plano diretor municipal, existente ou em elaboração, contando da data de vigência desta Lei. A MP ainda completa que, encerrado este prazo, os municípios ficam impedidos de receber recursos orçamentários federais destinados à mobilidade urbana até que atendam à exigência estabelecida nesta lei (BRASIL, 2016).

\section{I CIDADES DE PEQUENO PORTE NO BRASIL}

Ao se adjetivar o substantivo cidade com a palavra "média" e/ou "pequena" fazse menção ao tamanho da cidade que, por sua vez, conduz ao estudo das redes 
e hierarquias urbanas. Ao se pretender averiguar o tamanho seja da malha urbana, seja do contingente populacional, necessita-se fazer uma medição, uma aferição do tamanho da cidade e/ou do contingente populacional. Tais dados são fornecidos pelas instituições de estatísticas. Geralmente os estudos funcionais ou que priorizam o sistema hierárquico das cidades usam terminologias similares às de cidades pequenas, médias e grandes. Para tanto, tomam como base os dados referentes a seus contingentes populacionais (LOPES e HENRIQUE, 2010).

Assim, de acordo com o IBGE (2017), na classe de cidades pequenas inseremse aquelas que possuem até 100 mil habitantes, entre 100 mil e 500 mil habitantes são consideradas cidades médias e aquelas com mais de 500 mil habitantes são consideradas grandes. Seguindo essa classificação, muitas das cidades brasileiras de pequeno porte, que são o foco deste trabalho, estão inseridas na classificação destacada pela "Lei de Mobilidade", ou seja, contêm mais de 20 mil e menos de 100 mil habitantes. Portanto, essa parcela de munícipios está obrigada a elaborar um Plano de Mobilidade Urbana, compatível com seus respectivos Planos Diretores.

As atuais políticas urbanas, em sua maioria são pensadas para as metrópoles e cidades médias ou grandes e são esquecidas as pequenas cidades. O planejamento urbano e a morfologia dessas cidades, por falta de estudos específicos, ficam submetidos aos exemplos de cidades maiores que têm sua base em problemáticas totalmente diferentes. É frequente a repetição de padrões formais, planos diretores, modelos administrativos e de planejamento não adequados ao sítio físico, nem à economia ou aos costumes locais, desvalorizando a identidade e as potencialidades da cidade pequena. A mesma problemática é verificada quando analisada a mobilidade urbana destas cidades, já que a exemplo dos maiores centros, também orientam seu crescimento baseado no automóvel, incentivando o desenvolvimento horizontal e pouco densificado, investindo em infraestruturas desnecessárias (MATÉ et al., 2014).

Além disso, existe a dificuldade de cidades pequenas muitas vezes não terem profissionais capacitados para executar o trabalho de ordenamento do uso do espaço público, sendo uma situação recorrente nas cidades pequenas de todo o Brasil. Outra peculiaridade destas cidades de pequeno porte é que muitas vezes elas não são atendidas por transporte público regular (ônibus) e sim por mototáxis, que fazem uso do espaço sem o devido planejamento para atender este modo de transporte, contribuindo para acarretar conflitos no sistema de circulação urbana.

\section{I ANÁLISE COMPARATIVA ENTRE A TEORIA E A PRÁTICA}

O processo de formulação das políticas públicas em geral, também chamado de ciclo das políticas públicas, pode ser resumido em quatro etapas: formulação (ou planejamento), elaboração, implantação e avaliação (SEBRAE, 2008). Muitas das barreiras que ocorrem no processo de formulação da política pública interferem 
diretamente no seu processo de implantação. Portanto, barreiras que podem se opor ao êxito de uma política pública, identificadas em qualquer uma das etapas, podem comprometer todo o ciclo.

Assim, após a revisão da literatura, foi possível resumir na Tabela 2 as principais barreiras às políticas públicas de mobilidade urbana que mais se aplicam nas cidades brasileiras de pequeno porte.

\begin{tabular}{c|l}
\hline Autor (es) & \multicolumn{1}{c}{ Barreiras } \\
\hline Teixeira (2002) & $\begin{array}{l}\text { - Diferentes visões sobre o tema pelos gestores } \\
\text { públicos. }\end{array}$ \\
\hline $\begin{array}{c}\text { Teixeira (2002); Sebrae (2008) } \\
\text { Teixeira (2002); Comissão Europeia }\end{array}$ & • Falta de participação da sociedade. \\
\hline $\begin{array}{c}\text { Comissão Europeia (2003); Spectrum } \\
(2004) ;\end{array}$ & $\begin{array}{l}\text { • Falta de corpo técnico capacitado para elaborar } \\
\text { os planos (diretores e/ou de mobilidade urbana). }\end{array}$ \\
\hline Oliveira (2006); Oliveira & $\begin{array}{l}\text { • Elaboração de planos (diretores e/ou de } \\
\text { mobilidade urbana) apenas para cidades grandes. }\end{array}$ \\
\hline
\end{tabular}

Tabela 2: Principais barreiras às políticas públicas nas cidades de pequeno porte. Fonte: Os autores (2017).

Teixeira (2002) destaca que as políticas públicas expressam o sentido do desenvolvimento histórico-social dos atores sociais na disputa para construir a hegemonia; refletem, pois, as concepções que têm do papel do Estado e da sociedade civil, constituindo programas de ações que respondem as suas carências e demandas. Como o processo de formulação da política pública envolve vários atores com projetos e interesses diferenciados e até contraditórios, há necessidade de mediações sociais e institucionais, para que se possa obter um mínimo de consenso e, assim, as políticas públicas possam obter eficácia.

Atualmente, a formulação da política pública pode refletir ou não os interesses da sociedade, a depender do grau de mobilização da sociedade para se fazer ouvir e do grau de institucionalização de mecanismos que viabilizem sua participação. $O$ processo de planejamento das políticas deve ser feito pelos atores políticos, mas com o auxílio dos diversos setores da sociedade civil (SEBRAE, 2008). A população ao ser ouvida, contribui com a qualidade das ações, uma vez que o elaborador saberá quais os problemas que no momento, mais afligem a população, permitindo assim traçar ações mais efetivas. Para isso, a necessidade do debate público e mobilização da sociedade civil em torno das alternativas junto aos atores, da transparência, da sua elaboração em espaços públicos e não nos gabinetes governamentais.

De acordo com a Constituição Federal, os municípios adquirem a autonomia política, através da elaboração de sua própria lei orgânica e demais leis e da escolha direta de seus governantes. Ampliam sua competência em áreas importantes como a 
política urbana e transportes coletivos. No entanto, com uma frágil base econômica, ao lado da ineficiência administrativa, os recursos próprios na maioria dos municípios não vão além dos 5\% do total da receita (TEIXEIRA, 2002). Dessa forma, a autonomia de realizar políticas próprias sem vinculação aos programas federais e estaduais é mínima.

Para um município ser capaz de criar e gerenciar políticas públicas de qualidade é necessário, além dos recursos financeiros, ter pessoas capacitadas responsáveis pelo planejamento para a coordenar estas ações. A administração local não investe em preparação e formação, muitas vezes devido à falta dos recursos financeiros necessários para a contratação de novo pessoal técnico ou formação do pessoal existente. Além disso, a Comissão Europeia (2003) completa que a barreira da língua é também importante, porque torna impossível a troca de informação e conhecimentos com colegas estrangeiros.

O maior problema são os recursos, que na realidade dos dias atuais, para serem transferidos dependem da posição política, do prestígio e da vinculação partidária dos prefeitos e parlamentares. Além disso, as receitas são distribuídas com critérios que concentram a renda tributária em poucos municípios, os de maior desenvolvimento econômico. Então, os municípios de menor desenvolvimento, não chegam a receber estes recursos e quando recebem, têm a difícil missão de distribuir nas áreas tradicionalmente objeto de políticas públicas, como meio ambiente, habitação, saneamento, educação, saúde, transporte urbano, entre outras. E ainda, investir na qualificação e formação dos profissionais responsáveis pelo planejamento e elaboração destas políticas públicas (OLIVEIRA, 2006).

Em consequência destas duas barreiras, falta de recursos e falta de corpo técnico capacitado para elaborar os planos, as pequenas cidades acabam por não elaborar seus próprios planos, ou simplesmente adotam os planos das grandes cidades, que evidentemente não retrataram as peculiaridades de cada localidade. Isso ocorre também devido à falta de órgãos especializados para a elaboração destes planos (COMISSÃO Europeia, 2003). Dificilmente, uma cidade pequena tem uma "Secretaria de Transportes e Infraestruturas", por exemplo, com pessoal técnico qualificado para tratar especificamente de assuntos relacionados ao transporte urbano.

O sistema de transporte tem o papel de promover a acessibilidade às diversas atividades geradas devido às formas de se utilizar o espaço urbano dentro de uma cidade. Para tanto existem os instrumentos legais e institucionais já citados, como o Estatuto da Cidade, o Plano Diretor, o Ministério das Cidades e a "Lei de Mobilidade". Pires e Meira (2016) enfatizam que as leis existem e suas definições e exigências são claras para cidades de pequeno, médio e grande porte. Porém, na prática não são devidamente seguidas, principalmente em se tratando de cidades de pequeno porte.

O planejamento de transportes não deve ocorrer de maneira isolada no contexto de uma cidade, seja ela de pequeno, médio ou grande porte, ele deve ocorrer em conjunto com os demais planejamentos e zoneamentos urbanos estabelecidos na 
legislação regulatória vigente. As políticas de transporte precisam ser pensadas de forma integrada, independentemente do porte da cidade, articulando os diferentes modos de transporte, conectadas com as demais decisões estabelecidas na legislação, visando a melhor organização espacial da cidade (ibid).

\section{I CONSIDERAÇÕES FINAIS}

Mesmo com os instrumentos legais e institucionais, as políticas públicas nas cidades de pequeno porte continuam a falhar. Uma das principais barreiras identificadas para estas cidades que se opões ao sucesso de uma política pública é a questão financeira. Os municípios têm menos recursos para serem aplicados nas diversas áreas, com isso a capacidade destes municípios de levar adiante políticas públicas de maneira que tenham resultados eficazes é limitada.

Além disso, faltam recursos humanos capacitados e motivados, equipamentos, experiência e competência técnica dos órgãos responsáveis para planejar as políticas públicas. É necessário se pensar em uma adaptação da estrutura financeira já existentes ou criação de uma nova estrutura financeira, compatível com as necessidades locais.

Um outro aspecto limitador do planejamento nas cidades de pequeno porte é a falta de uma melhor integração entre as várias organizações envolvidas no planejamento das diversas políticas públicas. Uma forma de eliminar a falta de integração existente entre os usos do solo e o planejamento dos transportes ao nível municipal, seria a criação de um órgão de planejamento urbano integrado entre os responsáveis pelo planejamento dos usos do solo da cidade e do tráfego.

Pires e Meira (2016) destacam que o estudo das cidades de pequeno porte não tem sido enfoque prioritário de pesquisas científicas na área, o que resulta em deficiência teóricas e metodológicas em planejamentos urbanos e planos diretores ineficientes e genéricos para este grupo de cidades. E é justamente pela falta de um projeto de ação específico que essas cidades se configuram a partir da reprodução de modelos das cidades maiores e, consequentemente, perdem a oportunidade de considerar a identidade própria o centro de seu planejamento.

Boa parcela das cidades pequenas necessitam da elaboração do plano diretor que contemple também um plano de mobilidade urbana, que pode ser facilmente orientado pelos princípios e diretrizes da mobilidade urbana sustentável. Independentemente do tamanho da cidade, a elaboração de um plano de mobilidade urbana é necessário e muito importante para adequada regulação do uso do espaço urbano. Porém, decorridos mais de três anos da aprovação da Lei, apenas alguns poucos municípios aprovaram seus Planos de Mobilidade Urbana.

Decorridos mais de 15 anos de avanços legais e institucionais, ainda não foram suficientes para mitigar os problemas relacionados a regulação do uso do espaço urbano nas cidades de pequeno porte brasileiras. Para avançar neste panorama atual, 
é necessário que as políticas públicas de mobilidade urbana estejam orientadas, conforme sua própria definição sugere, para a eficiência na gestão das cidades, sempre coordenando ações conjuntas, estratégias integradas entre os diferentes modos de transporte, de modo a atuar nestas cidades de pequeno porte de acordo com a legislação regulatória vigente (PIRES e MEIRA, 2016).

Como recomendações para trabalhos futuros, indica-se analisar a situação da atuação pública sob o ponto de vista da população. Para isso, é necessário entre outras ações - analisar o nível de participação popular durante o processo de planejamento, elaboração, implantação e avaliação da Política Pública de Mobilidade Urbana. Como forma de analisar o nível da participação popular, posteriormente, será realizada uma pesquisa de campo, com a elaboração de questionários, a serem aplicados a população de uma cidade brasileira de pequeno porte, de modo a identificar as prováveis deficiências nos canais de ligação entre a população e o poder público, e a qualidade da atuação das políticas públicas segundo a sociedade. O objetivo será complementar quantitativamente a análise teórica desenvolvida neste artigo, através de informações coletadas pelos questionários aplicados.

\section{REFERÊNCIAS}

ANDRADE, P. A. F.; e SERRÃO, K. H. L. O Estacionamento nos Centros Urbanos: Do Conflito às Estratégias para Área Central de João Pessoa - PB. Texto da Universidade Federal da Paraíba. João Pessoa - PB, 2007.

BOHLER-BAEDEKER, S.; KOST, C.; e MERFORTH, M. Planos de mobilidade urbana: abordagens nacionais e práticas locais. - Movendo-se na Direção do Planejamento de Transporte Urbano Estratégico, Sustentável e Inclusivo. Transporte Urbano Sustentável Documento técnico \#13. Ministério Federal da Cooperação Econômica e do Desenvolvimento (BMZ). Ed. Deutsche Gesellschaft fur Internacionale Zusammenarbeit (GIZ). Alemanha, 2014.

BRAGA, R. Mudanças Climáticas e Planejamento Urbano: Uma Análise do Estatuto da Cidade. Anais do VI Encontro Nacional da Associação Nacional de Pós-Graduação e Pesquisa em Ambiente e Sociedade (ANPPAS). Belém -PA, 2012.

BRASIL. Política Nacional de Desenvolvimento Urbano. Ministério das Cidades. Brasília - DF, 2004.

BRASIL. Lei Federal $n^{\circ}$. 12.587, de 03 de janeiro de 2012. Institui as diretrizes da Política Nacional de Mobilidade Urbana. Brasília - DF, 2012.

BRASIL. Medida Provisória $n^{\circ} .748$, de 11 de outubro de 2016. Altera a Lei $n^{\circ} .12 .587$, de 03 de janeiro de 2012, que institui as diretrizes da Política Nacional de Mobilidade Urbana. Brasília - DF, 2016.

BRITO, F. A.; e PINHO, B. A. T. D. A Dinâmica no Processo de Urbanização no Brasil, 1940-2010. Texto para discussão N ${ }^{\circ} 464$ da Universidade Federal de Minas Gerais/ CEDEPLAR. Belo Horizonte MG, 2012.

CAMPOS, V. B. G. Mobilidade Sustentável: Relacionando Transporte e Uso do Solo. Relatório Final - CNPQ do Instituto Militar de Engenharia (IME). Rio de Janeiro - RJ, 2005. 
CAMPOS, V. B. G. Uma Visão da Mobilidade Urbana Sustentável. Revista dos Transportes Públicos - ANTP. São Paulo - SP, v. 2, n. 110, p. 99-106. 2006.

COMISSÃO EUROPEIA. Alcançar a Sustentabilidade Através de Políticas Integradas de Transporte e Usos de Solo. Transport Planning Land-Use and Sustainability (TRANSPLUS). Relatório Final. Community Research, European Commission, 2003.

CORRÊA, R. L. O Espaço Urbano. Série Princípios. 4.ed. Ed. Ática. São Paulo - SP, 2002.

FERRAZ, A. C. P.; e TORRES, I. G. E. Transporte Público Urbano. 2.ed. revisada e atualizada. Ed: Rima. São Carlos - SP, 2004.

IBGE. Instituto Brasileiro de Geografia e Estatística. Brasília - DF, 2017. Disponível em <http:// www.cidades.ibge.gov.br/xtras/home.php?lang=>. Acessado em 26 de junho de 2017.

LAUTSO, K; SPIEKERMANN, K.; WEGENER, M.; SHEPPARD, I.; STEADMAN, P; MARTINO, A.; e DOMINGO, R. e GAYDA, S. Planning and Research of Policies Land Use and Transport for Increasing Urban Sustainability, PROPOLIS. DG Research, 2004.

LIMA, A. N. V. A (in) Segurança da Posse: Regularização Fundiária em Salvador e os Instrumentos do Estatuto da Cidade. Dissertação de Mestrado, Universidade Federal da Bahia. Salvador - BA, 2005.

LOPES, D. M. F.; e HENRIQUE; W. Cidades Médias e Pequenas: Teorias, Conceitos e Estudos de Caso. Série Estudos e Pesquisas (SEP). Ed. SEI, v. 87. Salvador - BA, 2010.

MATÉ, C.; DEBATIN NETO, A.; e SANTIAGO, A. G. A Mobilidade Urbana Sustentável nas Cidades Pequenas - O Caso de Pinhalzinho/SC. Anais do III Encontro da Associação Nacional de Pesquisa e Pós-graduação em Arquitetura e Urbanismo (ENANPARQ). São Paulo - SP, 2014.

MEIRA, L. H. Políticas Públicas de Mobilidade Sustentável no Brasil: Barreiras e Desafios. Tese de Doutorado, Universidade Federal de Pernambuco. Recife - PE, 2013.

MINICHIELLO, A. L. O.; e RIBEIRO, M. F. O Município Brasileiro e a Proteção ao Meio Ambiente no Desenvolvimento Econômico Sustentável à Luz do Estatuto da Cidade. Hiléia: Revista do Direito Ambiental da Amazônia, n. 19, p. 33-60. 2013.

OLIVEIRA, J. A. P. Desafios do Planejamento em Políticas Públicas: Diferentes Visões e Práticas. Revista de Administração Pública (RAP). Rio de Janeiro - RJ, v. 40, n.2, p. 273-288. 2006.

OLIVEIRA, G. M.; e SILVA, A. N. R. Desafios e Perspectivas para Avaliação e Melhoria da Mobilidade Urbana Sustentável: Um Estudo Comparativo de Municípios Brasileiros. TRANSPORTES. São Paulo - SP, v. 23, n. 1, p. 59-68. 2015.

PEREIRA, L. A. G.; MORAIS, S. D. Q.; e FERREIRA, W. R. A Geografia dos Transportes na Organização do Espaço Urbano: Mobilidade e Acidentes de Trânsito. Caminhos de Geografia. Uberlândia - MG, v. 13, n. 42, p. 240-257. 2012.

PIRES, D. R.; e MEIRA, L. H. Regulação do Uso do Espaço Viário em uma Cidade de Pequeno Porte da América Latina: o Caso de Gravatá - PE, Brasil. Anais do XIX CLATPU (Congreso Latinoamericano de Transporte Público y Urbano). Montevidéu - Uruguai, 2016.

RIBEIRO, K. S.; CABRAL, D. S.; OLIVEIRA, B. L.; MATTOS, B. L.; e SAMPAIO, R. M. Transporte Sustentável, Alternativas para Ônibus Urbanos. Texto da Universidade Federal do Rio de Janeiro. 
Rio de Janeiro - RJ, 2001.

SANTOS, C. D. A Formação e Produção do Espaço Urbano: Discussões Preliminares Acerca da Importância das Cidades Médias para o Crescimento da Rede Urbana Brasileira. Revista Brasileira de Gestão e Desenvolvimento Regional. Taubaté - SP, v. 5, n. 1, p. 177-190. 2009.

SEBRAE. Políticas Públicas: Conceitos e Práticas. Série Políticas Públicas, Volume 7. Serviço Brasileiro de Apoio às Micro e Pequenas Empresas - SEBRAE, Belo Horizonte - MG, 2008.

SOUZA, C. Políticas Públicas: Uma Revisão da Literatura. Sociologias. Porto Alegre - RS, ano 8, n. 16, p. 20-45. 2006.

SPECTRUM. Synergies and Conflicts of Transport Packages. Study of Policies regarding Economic instruments Complementing Transport Regulation and the Undertaking of Physical Measures, 2004.

TAKAHASHI, R. H. C. A Estrutura da Decisão Política na Formulação de Políticas Públicas. Instituto de Estudos Avançados Transdisciplinares (IEAT). Universidade Federal de Minas Gerais UFMG, Belo Horizonte - MG, 2004.

TEIXEIRA, E. C. O Papel das Políticas Públicas no Desenvolvimento Local e na Transformação da Realidade. Políticas Públicas - O Papel das Políticas Públicas. Associação de Advogados de Trabalhadores Rurais (AATR). Salvador - BA, 2002. 


\section{A RELAÇÃO ENTRE O DESEMPENHO ESCOLAR E MELHORIAS DECORRENTES DE PROGRAMAS DE TRANSPORTE ESCOLAR RURAL: UM ESTUDO EM SANTA MARIA DO CAMBUCÁ - PE}

Maria Victória Leal de Almeida Nascimento Universidade Federal de Pernambuco

Recife - PE

Mauricio Oliveira de Andrade Universidade Federal de Pernambuco

Recife - PE

Dannúbia Ribeiro Pires

Universidade Federal de Pernambuco

Recife - PE

RESUMO: Muitos alunos necessitam se deslocar diariamente para terem acesso à educação básica na zona rural. Este artigo buscou avaliar, a relação entre as melhorias no transporte e o desempenho escolar em um pequeno município nordestino. A estratégia adotada foi testar por regressão múltipla, os pesos de fatores avaliados pelos alunos com relação à melhoria de alguns aspectos do transporte escolar, como conforto, segurança, tempo e rota, como influenciadores da melhoria do desempenho do sistema educacional. O resultado do transporte foi avaliado pelos professores portrêscritérios: rendimento escolar, evasão escolar e pontualidade/assiduidade. Como resultado, os professores associaram as melhorias dos transportes a uma evolução positiva nos resultados escolares. No entanto, nas regressões não foi possível estabelecer de forma estatisticamente consistente, os pesos dos fatores avaliados pelos alunos e as relações com os resultados avaliados pelos professores. Conclui-se que há outras variáveis relevantes, além dos transportes que podem explicar o desempenho.

PALAVRAS-CHAVE: Políticas públicas. Desempenho Escolar. Transporte Escolar Rural.

ABSTRACT: Many students need to move daily to access basic education in rural areas. This article aims to evaluate the relationship between improvements in transportation and school performance a small Northeastern municipality. The strategy was to test by multiple regressions, factors evaluated by the students in relation to improvements in some aspects of school transport, such comfort, safety, time and route, as influencers of educational system performance improvement. The result of the transport was evaluated by the teachers by three criteria: school performance, school dropout and punctuality / attendance. As a result, teachers associated transport improvements with positive developments in school outcomes. However, in the regressions it was not possible to establish in a statistically consistent way, the weights of the factors evaluated by the students and the relationships with results evaluated by the teachers. It is concluded that there are other 
relevant variables besides transport that can explain the performance.

KEYWORDS: Public policies. School performance. Rural School Transportation.

\section{I INTRODUÇÃO}

O artigo 208, parágrafo VII da Constituição Federal assegura aos alunos de escolas públicas o direito ao transporte escolar, como forma de facilitar seu acesso à educação básica. A Lei n 9.394/96, mais conhecida como Lei de Diretrizes e Bases da Educação, no seu artigo $4^{\circ}$ parágrafo VIII, regulamenta o direito do aluno ao material didático-escolar, transporte, alimentação e assistência à saúde. Para fins de garantir o transporte, o Fundo Nacional de Desenvolvimento da Educação executa atualmente dois programas: o Programa Nacional de Apoio ao Transporte do Escolar (PNATE) e o Programa Caminho da Escola, que visam atender alunos da rede pública de educação básica, preferencialmente residentes em zonas rurais.

O transporte escolar é muito importante para assegurar a presença do aluno na escola, principalmente daqueles que vivem nas zonas rurais, pois têm maiores dificuldades de deslocamento. O transporte escolar rural (TER) pode ser definido como o transporte de alunos da sua residência até a escola e no sentido inverso, percorrendo a zona rural e o centro do município ou apenas a zona rural. Ele surgiu com o intuito de amenizar a segregação sofrida pelos alunos residentes em zonas rurais, viabilizando uma maior interação entre o meio rural e as instituições públicas de ensino (CARVALHO et al., 2015).

Segundo o IBGE (2010), no Brasil muitos municípios apresentam predominância de população rural. O Brasil tem 5.570 municípios, dos quais 3.915 têm menos de 20 mil habitantes (70,29\%). No Nordeste existem 1.794 municípios, das quais 1.196 têm menos de 20 mil habitantes (66,67\%). Desses 1.196 municípios com menos de 20 mil habitantes, 597 têm a população rural superior à população urbana. Isso leva à conclusão que praticamente um terço dos municípios nordestinos, caracteriza-se como pequenas cidades, com menos de 20 mil habitantes e de predominância rural.

Segundo Cavalcante e Junior (2013), diversos fatores influenciam o desempenho dos estudantes na escola. Podem ser internos ao funcionamento da escola, ou externos como fatores relacionados ao ambiente familiar ou à comunidade. Considerase difícil medir o grau de influência de cada fator individualmente, mas o conhecimento desses fatores tem relevância significativa, sendo esse, o primeiro passo na busca de melhorias nos resultados da escola (CAVALCANTE e JUNIOR, 2013). Políticas públicas eficazes de transporte podem ser um dos fatores externos que influenciam o desempenho escolar, pois são de extrema importância para o deslocamento dos alunos até a escola. Os veículos e as estradas utilizadas também podem influenciar negativamente, caso não sejam adequados e não se encontrem em um bom estado de funcionamento.

Nascimento et al. (2016), avaliaram as viagens realizadas e as mudanças 
percebidas pelos usuários do transporte escolar rural do município de Santa Maria do Cambucá - PE, após a implantação dos programas de TER do Governo Federal, que ocorreu nesse município apenas em 2015. Nas conclusões desse estudo foi sugerida a realização da avaliação do TER, também pelos gestores educacionais e professores, visando buscar uma relação com o desempenho educacional dos alunos. Este artigo tem como objetivo, dar continuidade à pesquisa realizada por Nascimento et al. (2016), avaliando através dos professores a importância dos fatores decorrentes de melhorias no TER, e o que essas melhorias no transporte podem impactar o desempenho do sistema educacional, considerando: i) melhoria no rendimento escolar (notas), ii) redução da evasão escolar e iii) aumento da pontualidade e assiduidade dos alunos.

\section{I POLÍTICAS PÚBLICAS E PROGRAMAS DE TRANSPORTE ESCOLAR}

Políticas públicas são ações, metas e planos que os governos (nacionais, estaduais ou municipais) traçam para alcançar o bem-estar da sociedade e o interesse público. Políticas públicas podem ser definidas como diretrizes e princípios norteadores de ação do poder público, e também como regras e procedimentos para as relações entre o Poder Público e a sociedade (TEIXEIRA, 2002). Política é a fase de formulação, onde as propostas ganham forma.

As políticas transformam-se em programas, quando se mostra a estratégia de implementação e, são criadas as condições iniciais para serem colocadas em prática (CUNHA, 2006). Já os programas são atividades organizadas para serem realizadas dentro de um orçamento e cronograma específico. Para assegurar o transporte dos estudantes da educação básica que residem na zona rural, o Ministério da Educação, por meio do Fundo Nacional de Desenvolvimento da Educação (FNDE), mantém dois programas de apoio ao transporte escolar, o Programa Nacional de Apoio ao Transporte Escolar (PNATE) e o Caminho da Escola.

O Programa Nacional de Apoio ao Transporte do Escolar (PNATE) foi instituído pela Lei $n^{\circ} 10.880$, de 9 de junho de 2004, com o objetivo de garantir o acesso e a permanência nos estabelecimentos escolares dos alunos do ensino fundamental público residentes em áreas rurais que utilizem transporte escolar, por meio de assistência financeira, em caráter suplementar aos estados, Distrito Federal e municípios. Já o Programa Caminho da Escola, criado pelo Ministério da Educação (MEC) através da Resolução $n^{\circ} 3$, de 28 de março de 2007 e consiste na concessão pelo Banco Nacional de Desenvolvimento Econômico e Social (BNDES), de linha de crédito especial para a aquisição, pelos estados e municípios, de ônibus e embarcações novas.

O transporte escolar tem o intuito de transportar os alunos das proximidades de sua residência até a escola. No caso do aluno residir ou estudar em zonas rurais, o transporte passa a ser denominado transporte escolar rural (TER). O Brasil é um país de grandes dimensões, e possui uma significativa população que reside na zona rural, o que leva o Poder Público a regular e garantir o transporte escolar, principalmente nas 
zonas rurais, onde o acesso é mais difícil, além do fato das famílias normalmente terem baixo poder aquisitivo. O transporte escolar, utilizado na ligação da zona rural de uma região para outra ou dessa zona rural para a sede do município, é condição essencial para o acesso e permanência da criança e adolescente na escola (CARVALHO e YAMASHITA, 2015). A dispersão das propriedades rurais e a má qualidade das vias de acesso, muitas delas carroçáveis e sem conservação, dificultam o transporte dos alunos.

O transporte escolar rural vem nos últimos anos, sendo alvo de vários estudos relativos às necessidades educacionais especiais (CAIADO e GONÇALVES, 2014), à evolução do modo rodoviário (CARVALHO et al., 2015), à análise sobre os custos (CARVALHO e YAMASHITA, 2015), à análise do fornecimento de transporte de casa para escola (HINE, 2009), avaliação dos benefícios do ônibus escolar (KINGHAM e USSHER, 2007), ao estudo de um modelo organizacional nos estados e municípios brasileiros (LOPES, 2009), ao estudo de políticas de transporte (PERGHER, 2014), ao diagnóstico do transporte (PINHEIRO, 2013), ao estudo de modelo de distribuição de recursos (SILVA e YAMASHITA, 2010), à análise de viabilidade (SCHUH et al., 2015) e à avaliação da operação dos ônibus escolares (SONG e KIM, 2013).

\section{I DESEMPENHO ESCOLAR E SUA RELAÇÃO COM OS TRANSPORTES}

Segundo Carvalhes (2017), desempenho escolar é "o procedimento adotado pela escola, para acompanhar e avaliar o grau de desenvolvimento do aluno e conhecer suas dificuldades e possibilidades a fim de programar as ações educacionais necessárias". Neste artigo buscou-se avaliar o desempenho escolar através de três critérios: rendimento escolar, evasão escolar e pontualidade/assiduidade. O rendimento escolar "representa os resultados obtidos, pelo aluno no decorrer do período escolar a partir de exames e provas finais quando adotados" (CARVALHES, 2017). A evasão escolar ocorre quando o aluno deixa de frequentar a escola e fica caracterizado como abandono escolar. A pontualidade, como o próprio nome sugere é quando o aluno é pontual, cumpre os horários. Já a assiduidade ocorre quando o aluno se faz presente no dia a dia e cumpre suas obrigações escolares.

Bezerra e Kassouf (2006) destacam que, dentre os principais fatores que afetam positivamente o desempenho escolar dos alunos residentes na zona urbana, estão a escolaridade da mãe, a renda familiar, a infraestrutura escolar de laboratórios e materiais audiovisuais, a escolaridade dos professores e o nível de salários. Em relação aos estudantes residentes nas zonas rurais, os fatores que mais afetam o desempenho escolar são: a rede de ensino pública, a renda familiar, a região onde a escola se localiza, a oferta de recursos educacionais como computadores e o número de pessoas no domicílio (BEZERRA e KASSOUF, 2006). Como visto, um dos fatores que podem afetar o desempenho escolar do aluno residente na zona rural, é a localidade da escola, ou seja, se a mesma se encontra próxima ou distante da 
sua residência. Pode-se inferir, que caso a localização da escola não seja próxima à residência, um fator adicional que pode influenciar o desempenho escolar do aluno é a eficiência do transporte utilizado.

Os indicadores de desempenho escolar e sua relação com os transportes, vem sendo objeto de alguns estudos como: análise do rendimento escolar de alunos da área rural em escola urbana (BACHA et al., 2006); análise das perspectivas para o transporte escolar rural sobre o desempenho escolar (CARVALHO et al., 2010); influência dos indicadores de qualidade de desempenho na educação (COSTA et al., 2014); estudo de um manual brasileiro para prática a nível municipal, sobre a terceirização do TER (CRUZ et al., 2010); estudo dos efeitos dos fatores familiares e escolares sobre o desempenho dos alunos (MACEDO, 2004); análise dos impactos no rendimento escolar dos alunos (MARTINS, 2010); e estudo das perspectivas dos gestores e planejadores/operadores (SANTOS, 2010).

\section{I DESCRIÇÃO DA ÁREA DE PESQUISA}

Santa Maria do Cambucá situada no Agreste de Pernambuco a 138 km do Recife tem uma população estimada para 2016 de 13.921 habitantes (IBGE, 2017) em uma área de $92,15 \mathrm{~km}^{2}$. Segundo o IBGE (2010), tinha população urbana de 3.275 habitantes $(25,15 \%)$ e população rural de 9.746 habitantes (74,85\%). Muitos outros pequenos municípios pernambucanos, nordestinos e brasileiros têm um perfil semelhante ao de Santa Maria do Cambucá (menos de 20.000 habitantes e predominância rural), dessa forma, as conclusões do presente estudo podem ser úteis a esses.

Para transportar os alunos para suas respectivas escolas, em 2014 o município de Santa Maria do Cambucá tinha disponíveis veículos improvisados ou não, como kombis, rural/utilitários Toyota Bandeirante, micro-ônibus e ônibus. A partir de 2015, com a melhoria do transporte escolar no município, através dos programas do Governo Federal, os serviços de transportes passaram a contar com oito veículos locados, sendo: cinco kombis e três ônibus, além de quatorze veículos oficiais próprios, sendo: quatro micro-ônibus, seis ônibus "Caminho da Escola" e quatro ônibus brancos.

Segundo Nascimento et al. (2016), após a implantação dos programas do Governo Federal para o transporte escolar rural (TER), o PNATE e o Caminho da Escola em 2015, observou-se que o transporte atual foi avaliado positivamente com resultados em média ligeiramente superiores em quase todos os critérios analisados, quando comparado à situação anterior. É importante salientar que o transporte escolar anterior, já apresentava algum nível de organização.

$\mathrm{Na}$ pesquisa de Nascimento et al. (2016) foram estudadas 15 escolas. Duas se localizam na zona urbana, João David de Souza (Ensino Médio) e Professor Agripino de Almeida (Ensino Fundamental e Infantil). Treze estão distribuídas na zona rural do município (Ensino Fundamental e Infantil): Luiz Ferreira de Oliveira, João Silvino, 
Bernardino Pedro da Silva, José Bezerra de Almeida, Teodora Bezerra de Almeida, Manoel Lourenço, José Quirino Barbosa de Farias, José Claudino dos Santos, Pe. França Falcão, José Urbano Ferreira, Manoel Andrade, José Borges do Nascimento e São José. As localizações das escolas podem ser observadas na Figura 1.

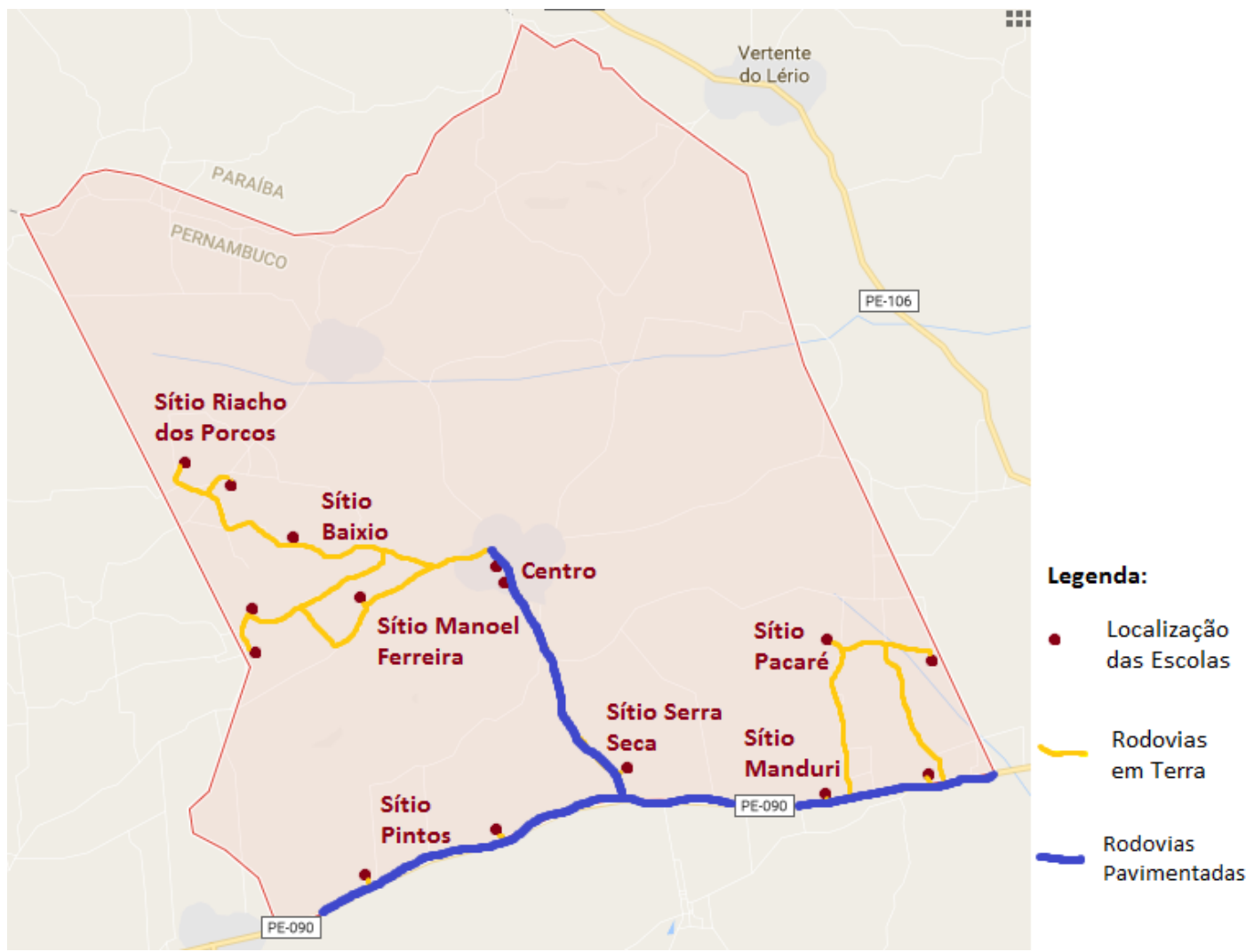

Figura 1: Mapa de Santa Maria do Cambucá com as localidades das escolas

\section{I METODOLOGIA}

Para avaliar a importância dos fatores decorrentes de melhorias no TER, e o que essas melhorias no transporte podem impactar o desempenho do sistema educacional, foi realizada pesquisa de campo qualitativa, por meio da aplicação de questionários com professores. Os professores que participaram da pesquisa ensinam nas escolas, onde os alunos foram entrevistados na pesquisa de Nascimento et al. (2016). Isso se deve à tentativa de associar as respostas dos alunos a dos professores. Os alunos fornecem os fatores de influência (variáveis explicativas) e os professores fornecem a variável resposta, ou o resultado da política pública associado às melhorias no TER.

Aos professores foi perguntado sobre o impacto da implantação dos programas do Governo Federal para o TER em 2015, com relação ao rendimento escolar médio dos alunos, à evasão escolar, à pontualidade e à assiduidade dos alunos. $\mathrm{Na}$ entrevista foram realizadas três afirmações e foi solicitado aos professores que eles respondessem, utilizando uma escala de Likert em cinco níveis, se: discordava totalmente (1), discordava parcialmente (2), não concordava e nem discordava (3), concordava parcialmente (4) e concordava totalmente (5). As afirmações foram as 
seguintes: i) A implantação dos programas do TER ajudou a elevar o rendimento escolar médio (notas) dos alunos; ii) A implantação dos programas do TER ajudou a reduzir a evasão escolar; e iii) A implantação dos programas do TER ajudou a aumentar a pontualidade e a assiduidade dos alunos.

Foram entrevistados professores em 15 escolas (duas escolas na zona urbana e treze escolas na zona rural do município) distribuídos da seguinte forma: i) três professores nas escolas João David de Souza, Professor Agripino de Almeida, Luiz Ferreira de Oliveira, Bernardino Pedro da Silva, Teodora Bezerra Almeida, José Quirino Barbosa de Farias e José Claudino dos Santos; ii) dois professores nas escolas João Silvino, José Bezerra de Almeida e José Urbano Ferreira foram entrevistados; e iii) e apenas um professor nas escolas Manoel Lourenço, Pe. França Falcão, Manoel Andrade, José Borges do Nascimento e São José. Nas escolas onde foram entrevistados um ou dois professores eles representam a totalidade.

A pesquisa de Nascimento et al. (2016) com os alunos, buscou obter uma amostra com distribuição proporcional à quantidade de alunos matriculados por escola e por nível de ensino, conforme informações da Secretaria Municipal de Educação, obtendose ao final 365 entrevistas. Nas análises dos resultados preliminares, verificou-se que a Escola José Bezerra de Almeida não era atendida pelo TER, antes da implantação dos programas do Governo Federal, com isso ficaria inviável uma comparação com o transporte atual. Sendo assim, foi realizada a análise com as 14 escolas restantes. Com a supressão das respostas dos alunos e professores da Escola José Bezerra de Almeida, ao final totalizaram 355 entrevistas analisadas com alunos e $30 \mathrm{com}$ professores.

Para traçar os perfis dos alunos entrevistados por Nascimento et al. (2016), e dos professores entrevistados na presente pesquisa, foi utilizada a estatística descritiva. Com os dados dos professores entrevistados e dos alunos, foi possível fazer um estudo através de regressão linear múltipla, a fim de aferir a influência dos fatores relativos à Regularidade/Pontualidade, Conforto, Segurança, Tempo e Rota do TER, avaliados pelos alunos, sobre o Rendimento Escolar, Evasão Escolar e Pontualidade/ Assiduidade avaliados pelos professores.

A análise da regressão consiste na aplicação de técnicas de estatística inferencial com o objetivo de verificar a existência de uma relação causal entre uma variável dependente, com uma ou mais variáveis independentes. No presente caso, as variáveis dependentes são as avaliadas pelos professores (Rendimento Escolar, Evasão Escolar e Pontualidade/Assiduidade) e as variáveis independentes são as avaliadas pelos alunos (Regularidade/Pontualidade, Conforto, Segurança, Tempo e Rota). Para a regressão linear, foram utilizadas as médias normalizadas das avaliações dos professores e alunos por escola. 


\section{I RESULTADOS E DISCUSSÕES}

Através da aplicação dos questionários, foram obtidos os perfis dos alunos e professores entrevistados, conforme Tabela 1.

\begin{tabular}{|c|c|c|c|c|}
\hline Entrevistados & Descrição & Classificação & Quantidade & Porcentagem \\
\hline \multirow{9}{*}{ Alunos } & \multirow{2}{*}{ Sexo } & Feminino & 183 & $51,55 \%$ \\
\hline & & Masculino & 172 & $48,45 \%$ \\
\hline & \multirow{3}{*}{$\begin{array}{c}\text { Nível de } \\
\text { Escolaridade }\end{array}$} & Educação Infantil & 45 & $12,68 \%$ \\
\hline & & Ensino Fundamental & 274 & $77,18 \%$ \\
\hline & & Ensino Médio & 36 & $10,14 \%$ \\
\hline & \multirow{4}{*}{ Idade } & $0-9$ & 133 & $37,46 \%$ \\
\hline & & $10-19$ & 219 & $61,69 \%$ \\
\hline & & $20-29$ & 2 & $0,56 \%$ \\
\hline & & $30-39$ & 1 & $0,28 \%$ \\
\hline \multirow{15}{*}{ Professores } & \multirow{2}{*}{ Sexo } & Feminino & 26 & $86,67 \%$ \\
\hline & & Masculino & 4 & $13,33 \%$ \\
\hline & \multirow{3}{*}{$\begin{array}{c}\text { Nível de } \\
\text { Escolaridade }\end{array}$} & Ensino Médio & 1 & $3,33 \%$ \\
\hline & & Graduação & 5 & $16,67 \%$ \\
\hline & & Pós-Graduação & 24 & $80,00 \%$ \\
\hline & \multirow{5}{*}{$\begin{array}{c}\text { Quanto tempo } \\
\text { trabalha como } \\
\text { Professor (anos) }\end{array}$} & $0-9$ & 1 & $3,33 \%$ \\
\hline & & $10-19$ & 9 & $30,00 \%$ \\
\hline & & $20-29$ & 16 & $53,33 \%$ \\
\hline & & $30-39$ & 3 & $10,00 \%$ \\
\hline & & $40-49$ & 1 & $3,33 \%$ \\
\hline & \multirow{5}{*}{$\begin{array}{l}\text { Quanto tempo } \\
\text { trabalha nessa } \\
\text { Escola (anos) }\end{array}$} & $0-9$ & 18 & $60,00 \%$ \\
\hline & & $10-19$ & 7 & $23,33 \%$ \\
\hline & & $20-29$ & 5 & $16,67 \%$ \\
\hline & & $30-39$ & 0 & $0,00 \%$ \\
\hline & & $40-49$ & 0 & $0,00 \%$ \\
\hline
\end{tabular}

Tabela 1: Perfil dos alunos e professores entrevistados

Foram entrevistados 355 alunos, sendo a maioria do sexo feminino (51,55\%). De acordo com o nível de escolaridade, a maioria dos entrevistados estuda no Ensino Fundamental (77,18\%), seguidos da Educação Infantil (12,68\%) e por último o Ensino Médio (10,14\%). A faixa etária que mais respondeu os questionários foi dos 10 aos 19 anos $(61,69 \%)$, seguindo dos com menos de 9 anos $(37,46 \%)$, de 20 a 29 anos (0,56\%) e por último de 30 a 39 anos (0,28\%).

Foram entrevistados trinta professores, a grande maioria do sexo feminino (86,67\%). Em geral os professores têm formação adequada ao magistério, pois 16,67\% são graduados em nível superior, 80\% têm algum tipo de pós-graduação e apenas um professor entrevistado possui unicamente o Ensino Médio. Com relação à experiência profissional específica, a maioria dos professores é muito experiente, pois $53,3 \%$ atua no magistério entre 20 e 29 anos e 13,3\% há mais de 30 anos, totalizando no conjunto $96,6 \%$ dos professores com mais de 10 anos de experiência. Já em relação ao tempo 
que eles trabalham na escola pesquisada, observa-se que a maioria trabalha menos de 9 anos (60,00\%), seguido dos que trabalham entre 10 e 19 anos (23,33\%) e entre 20 e 29 anos (16,67\%). Desse perfil pode-se concluir ser esse grupo suficientemente apto a contribuir com a presente pesquisa.

Com relação ao Rendimento Escolar, o nível de concordância sobre melhoras nas médias das notas variou entre concorda parcialmente e concorda totalmente (4 e 5). O mesmo ocorreu para a Evasão Escolar e a Pontualidade/Assiduidade. Embora quando comparadas as escolas entre si, pode ser observado que o aumento do Rendimento Escolar teve concordância máxima em apenas cinco escolas. Já a redução da Evasão Escolar apresentou concordância máxima em oito escolas e a Pontualidade e Assiduidade, teve avaliação máxima em dez escolas.

Dessa primeira observação pode-se concluir que o aumento da pontualidade e assiduidade dos alunos às aulas, decorrente de melhorias nos transportes, foi associado de forma mais intensa pelos professores. Apesar de relevante para todos, percebe-se também uma associação um pouco menos intensa com a elevação do rendimento escolar. Isso significa que embora esses critérios tenham sido avaliados de forma positiva, a Pontualidade/Assiduidade é considerada pelos professores como o critério onde o TER mais influenciou positivamente, seguido da redução da Evasão Escolar e por último Rendimento Escolar dos alunos, conforme pode ser visto nas linhas representativas das médias apresentadas na Figura 2.

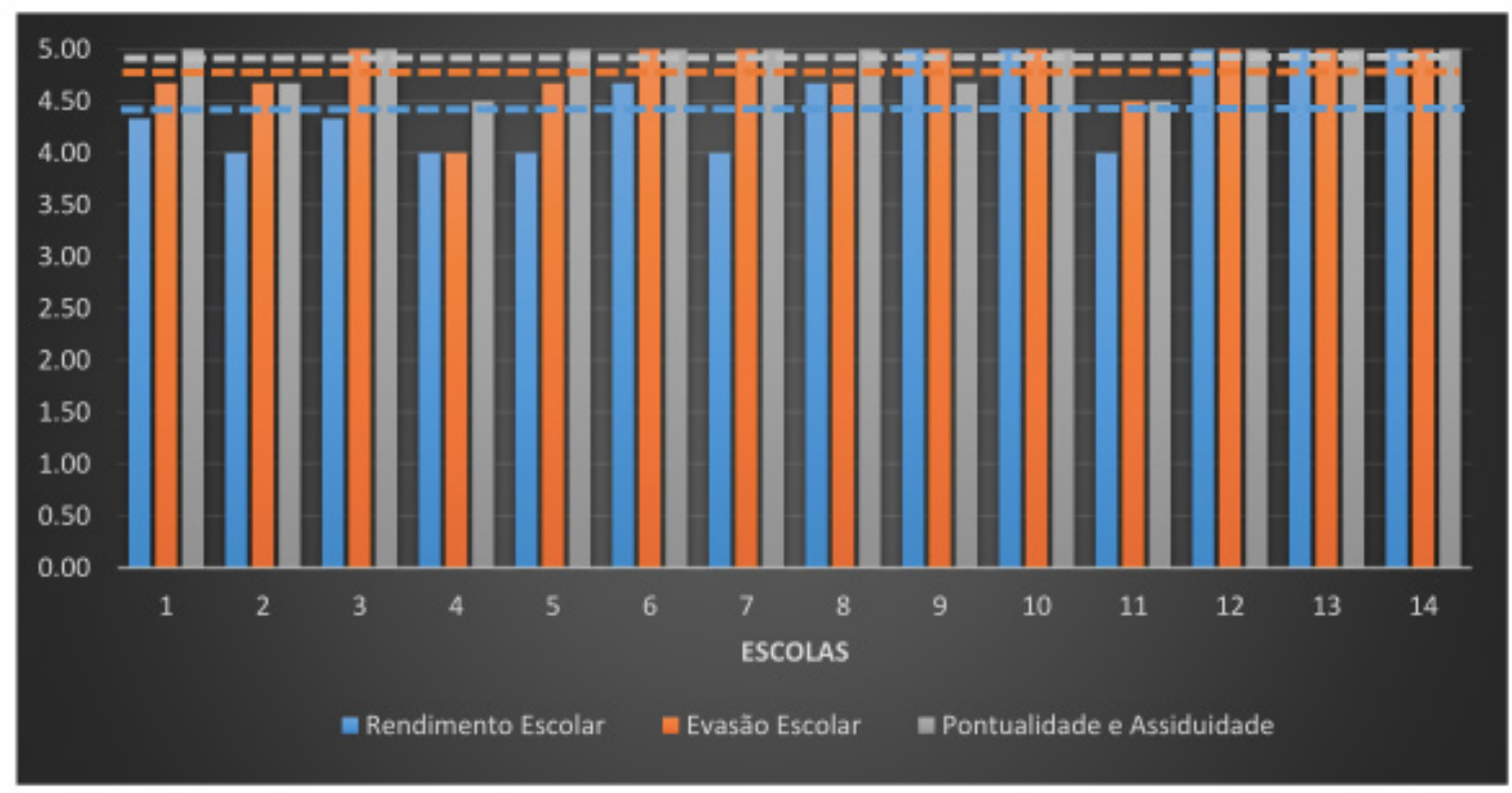

Figura 2: Avaliação dos professores

Para efeito de aplicação do modelo de regressão, as médias das notas dos professores foram normalizadas, como também as médias da avaliação que os alunos fizeram a respeito do TER utilizado após a implantação dos programas do Governo Federal. Na Tabela 2, constam as médias normatizadas da avaliação dos professores e dos alunos, por escola avaliada. 


\begin{tabular}{cccccccc}
\hline \multicolumn{3}{c}{ Avaliação dos Professores } & \multicolumn{5}{c}{ Avaliação dos Alunos } \\
\hline $\begin{array}{c}\text { Rendimento } \\
\text { Escolar }\end{array}$ & $\begin{array}{c}\text { Evasão } \\
\text { Escolar }\end{array}$ & $\begin{array}{c}\text { Pontualidade/ } \\
\text { Assiduidade }\end{array}$ & $\begin{array}{c}\text { Regularidade/ } \\
\text { Pontualidade }\end{array}$ & Conforto & Segurança & Tempo & Rota \\
\hline 0,87 & 0,93 & 1,00 & 0,93 & 0,59 & 0,66 & 0,75 & 0,68 \\
0,80 & 0,93 & 0,93 & 0,90 & 0,81 & 0,84 & 0,91 & 0,93 \\
0,87 & 1,00 & 1,00 & 1,00 & 0,85 & 0,75 & 0,90 & 0,90 \\
0,80 & 0,80 & 0,90 & 1,00 & 1,00 & 0,86 & 0,74 & 0,83 \\
0,80 & 0,93 & 1,00 & 1,00 & 1,00 & 1,00 & 1,00 & 0,96 \\
0,93 & 1,00 & 1,00 & 1,00 & 1,00 & 0,80 & 0,96 & 1,00 \\
0,80 & 1,00 & 1,00 & 1,00 & 1,00 & 1,00 & 1,00 & 1,00 \\
0,93 & 0,93 & 1,00 & 1,00 & 1,00 & 1,00 & 1,00 & 1,00 \\
1,00 & 1,00 & 0,93 & 1,00 & 1,00 & 0,90 & 0,85 & 0,75 \\
1,00 & 1,00 & 1,00 & 0,95 & 1,00 & 0,95 & 0,95 & 0,95 \\
0,80 & 0,90 & 0,90 & 1,00 & 0,94 & 0,91 & 1,00 & 1,00 \\
1,00 & 1,00 & 1,00 & 1,00 & 0,93 & 0,87 & 1,00 & 0,93 \\
1,00 & 1,00 & 1,00 & 1,00 & 0,95 & 0,80 & 1,00 & 1,00 \\
1,00 & 1,00 & 1,00 & 0,90 & 1,00 & 0,85 & 0,75 & 1,00 \\
\hline
\end{tabular}

Tabela 2: Avaliação dos professores e dos alunos

Para a análise desses dados foi utilizado o programa computacional IBM SPSS Statistics 23. Todos esses dados foram implantados no programa com intuito de através da regressão linear, entender quais desses critérios melhor explicam os resultados esperados expressos pela avaliação dos professores. Nas primeiras análises foi identificado que os alunos da zona urbana (Centro), avaliaram de forma muito variada, ou seja, os dados têm grande dispersão e não garantem a margem de erro de 5\% fixada no modelo. Com isso, optou-se por excluir as duas escolas da zona urbana (as duas primeiras da Tabela 2), na análise por regressão linear. Restaram apenas as doze escolas rurais para serem analisadas. Essa exclusão em princípio não distorce a natureza da análise, porque provavelmente os alunos das escolas urbanas que vivem no meio urbano, foram impactados de forma diferenciada dos alunos que residem na zona rural.

Com os dados restantes, o primeiro teste de hipótese realizado foi utilizando o Rendimento Escolar como variável dependente e a Regularidade/Pontualidade, Conforto, Segurança, Tempo e Rota como variáveis independentes. Este modelo pelo teste ANOVA apresentou significância geral com erro acima de 5\% $(0,095)$, apesar de apresentar coeficente de determinação $R^{2}$ é igual a 0,757 . Com relação à significância individual, apenas a variável "conforto" apresentou erro com significância acima de $5 \%$, no entanto, os coeficientes de regularidade/pontualidade, segurança e rota apresentaram sinais negativos (ver Tabela 3), o que contraria a hipótese levantada, de que melhorias nos transportes nesses aspectos, buscam propiciar elevação no rendimento escolar, e não o contrário. 


\begin{tabular}{lcccc}
\hline \multicolumn{1}{c}{ Variável } & $\begin{array}{c}\text { Coeficientes não } \\
\text { padronizados } \beta\end{array}$ & $\begin{array}{c}\text { Coeficientes } \\
\text { padronizado } \\
\text { Beta }\end{array}$ & t & Sig. \\
\hline (Constante) & 3,913 & & 3,492 & 0,013 \\
Regularidade/Pontualidade & $-\mathbf{3 , 3 8 5}$ & $-1,165$ & $-3,423$ & 0,014 \\
Conforto & 1,023 & 0,529 & 1,7 & $\mathbf{0 , 1 4}$ \\
Segurança & $-\mathbf{0 , 9 5 8}$ & $-0,892$ & $-2,692$ & 0,036 \\
Tempo & 1,280 & 1,382 & 3,119 & 0,021 \\
Rota & $-1,049$ & $-0,930$ & $-2,693$ & 0,038 \\
\hline
\end{tabular}

Tabela 3: Coeficientes da regressão e testes de significância individuais (Variável dependente: Rendimento Escolar)

O segundo teste de hipótese realizado foi utilizando a Evasão Escolar como variável dependente. Este modelo pelo teste ANOVA, apresentou significância geral com erro da estimativa padrão fora da margem de erro fixada $(=0,162)$ e com coeficente de determinação $\mathrm{R}^{2}$ é igual a 0,664. Com relação à significância individual, as variáveis "conforto", "segurança" e "rota" apresentaram também erros acima de 5\%. Também paradoxalmente, as variáveis "regularidade", "segurança" e "rota" apresentaram coeficientes com sinais negativos (ver Tabela 4). Estes sinais apontam situações que contradizem a hipótese, ou seja, a política pública implementada apresenta na média resultados que induzem a evasão escolar.

\begin{tabular}{|c|c|c|c|c|}
\hline Variável & $\begin{array}{c}\text { Coeficientes não } \\
\text { padronizados } \beta\end{array}$ & $\begin{array}{c}\text { Coeficientes } \\
\text { padronizado } \\
\text { Beta }\end{array}$ & $\mathrm{t}$ & Sig. \\
\hline (Constante) & 2,94 & & 3,418 & 0,014 \\
\hline Regularidade/Pontualidade & $-2,175$ & $-1,073$ & $-2,866$ & 0,029 \\
\hline Conforto & 0,258 & 0,193 & 0,596 & 0,596 \\
\hline Segurança & $-0,493$ & $-0,664$ & 0,121 & 0,121 \\
\hline Tempo & 0,944 & 1,475 & 0,024 & 0,024 \\
\hline Rota & $-0,549$ & $-0,704$ & 0,116 & 0,116 \\
\hline
\end{tabular}

Tabela 4: Coeficientes da regressão e testes de significância individuais (Variável dependente: Evasão Escolar)

E o terceiro teste de hipótese realizado foi utilizando a Pontualidade/Assiduidade como variável dependente. Este modelo pelo teste ANOVA, apresentou significância geral com erro da estimativa padrão ainda maior do que os modelos com as outras variáveis $(=0,497)$ e com coeficente de determinação $R^{2}$ de 0,40 ainda menor (ver Tabela 5). Com relação à significância individual, todas as variáveis apresentaram erros muito acima de 5\%. Também paradoxalmente, as variáveis "regularidade" e "segurança" apresentaram coeficientes com sinais negativos. Estes sinais apontam situações que contradizem a hipótese, ou seja, a política pública implementada apresenta na média resultados que não colaboram para pontualidade e assiduidade 
dos alunos.

\begin{tabular}{lcccc}
\hline \multicolumn{1}{c}{ Variável } & $\begin{array}{c}\text { Coeficientes não } \\
\text { padronizados } \beta\end{array}$ & $\begin{array}{c}\text { Coeficientes } \\
\text { padronizado } \\
\text { Beta }\end{array}$ & t & Sig. \\
\hline (Constante) & 1,513 & & 2,095 & $\mathbf{0 , 0 8 1}$ \\
Regularidade/Pontualidade & $-\mathbf{0 , 8 0 4}$ & $-0,604$ & $-1,262$ & $\mathbf{0 , 2 5 4}$ \\
Conforto & 0,068 & 0,077 & 0,174 & $\mathbf{0 , 8 6 7}$ \\
Segurança & $-\mathbf{0 , 1 3 9}$ & $-0,284$ & $-0,604$ & $\mathbf{0 , 5 8 8}$ \\
Tempo & 0,334 & 0,795 & 1,265 & $\mathbf{0 , 2 5 3}$ \\
Rota & 0,006 & 0,012 & 0,025 & $\mathbf{0 , 9 8 1}$ \\
\hline
\end{tabular}

Tabela 5: Coeficientes da regressão e testes de significância individuais (Variável dependente:

Pontualidade/Assiduidade)

Como visto, esses resultados não permitem afirmar que resultados na educação pública, como rendimentos e permanência do aluno na escola decorrem apenas de melhorias no transporte escolar. Essas dificuldades de medir fatores isolados já haviam sido relatadas por Cavalcante e Junior (2013). As razões para esses resultados podem ser muitas. Há variáveis relevantes não incluídas no modelo, que provêm de políticas públicas de educação mais amplas, como merenda escolar, material didático e assistência à saúde (BRASIL, 1996) e variáveis socioeconômicas como, renda familiar, escolaridade dos pais, infraestrutura da escola (BEZERRA e KASSOUF, 2006), (CAVALCANTE e JUNIOR, 2013). Outras razões podem estar ligadas à espacialidade dos dados coletados. Nem sempre mudanças em redes de transportes beneficiam igualmente usuários, uma vez que mudanças de frequências ou itinerários podem afetar pessoas de forma diferenciada. Esse fato pode ter ocorrido nesse estudo e não ter sido possível detectá-lo sem uma análise por estatística espacial.

\section{I CONSIDERAÇÕES FINAIS}

Essa pesquisa teve como finalidade, dar continuidade à pesquisa realizada por Nascimento et al. (2016), avaliando através dos professores a importância dos fatores decorrentes de melhorias no TER, e o que essas melhorias no transporte puderam impactar o desempenho do sistema educacional, considerando, rendimento escolar (notas), evasão escolar, pontualidade e assiduidade. Os professores avaliaram positivamente, com relação aos três critérios abordados, sendo a Pontualidade/ Assiduidade a mais bem avaliada, seguida da redução da Evasão Escolar e por último o Rendimento Escolar dos alunos.

Na regressão linear buscou-se identificar a correlação das variáveis dependentes (Rendimento Escolar, Evasão Escolar e a Pontualidade/Assiduidade) com as variáveis independentes (a Regularidade/Pontualidade, Conforto, Segurança, Tempo e Rota). E embora fosse a hipótese da pesquisa encontrar essa correlação válida, os critérios 
não tiveram um poder de explicação relevante. O erro referente ao teste ANOVA, deram todos acima de $5 \%$, nos 3 testes de hipóteses realizados, apesar dos $\mathrm{R}^{2}$ para o Rendimento e Evasão Escolar terem dado em torno de 0,70. Os coeficientes não padronizados $\beta$ tiveram valores negativos em alguns critérios, o que representa que as variáveis dependentes crescem inversamente as variáveis independentes, ou seja, não há confirmação da hipótese do resultado esperado da política.

Apesar da análise de regressão verificar que não há relação estatística consistente entre as variáveis estudadas, os professores consideram de extrema importância e relevância o TER, para o desempenho escolar de seus alunos. Eles acreditam que com a melhoria do TER, que ocorreu com a implantação dos programas do Governo Federal em 2015 nesse munícipio, os alunos foram beneficiados com relação a uma melhora no Rendimento Escolar, com a redução na Evasão Escolar e com o aumento da Pontualidade e Assiduidade.

Existem outras variáveis para testar a hipótese proposta de melhoria do rendimento, de redução da Evasão e de aumento da Pontualidade/Assiduidade dos alunos além do TER utilizado. Critérios que incluam o nível de infraestrutura da escola e sua posição espacial em relação à rede de transporte, a merenda escolar, o material didático, a renda familiar, a escolaridade dos pais, o nível de escolaridade e o salário dos professores, entre outros, irão ser abordados em estudos futuros para refinar a análise e testar o peso de outras políticas associadas.

\section{REFERÊNCIAS}

BACHA, S. M. C.; BRANDÃO, C. C. R. D.; SAUER, L.; BEDNASKI, A. V.; CAMPAROTO, M. Y. Rendimento escolar de alunos da área rural em escola urbana. Rev. CEFAC, São Paulo, v. 8, n. 4, p. 429-440, 2006.

BEZERRA, M. G.; KASSOUF, A. L. Análise dos fatores que afetam o desempenho escolar nas escolas das áreas urbanas e rurais do Brasil. XLIV Congresso do Sober, Fortaleza, 2006.

BRASIL. Lei no 10880/2004 Programa Nacional de Apoio ao Transporte do Escolar - PNATE e o Programa de Apoio aos Sistemas de Ensino para Atendimento à Educação de Jovens e Adultos. Brasília, DF, 2004.

BRASIL. Lei n 9394/1996 Diretrizes e Bases da Educação. Brasília, DF, 1996.

BRASIL. Ministério da Educação. Resolução n 3/2007 Programa Caminho da Escola. Brasília, DF, 2007.

CAIADO, K. R. M.; GONÇALVES, T. G. G. L. O transporte escolar público para alunos do campo com necessidades educacionais especiais. Rev. Teoria e Prática da Educação, v. 17, p. 119-130, 2014.

CARVALHES, D. Gestão Escolar e Acadêmica: Glossário. Disponível em: <https://gestaoescolar. wordpress.com/glossario/>. Acessado em 29 de junho de 2017.

CARVALHO, W. L.; CRUZ, R. O. M.; CÂMARA, M. T.; ARAGÃO, J. J. G. Rural school transportation in emerging countries: The Brazilian case. Research in Transportation Economics, v. 29, p. 401- 
CARVALHO, W. L.; LEITE, P. S.; NASCIMENTO, H. P. Evolução do transporte escolar rural brasileiro no modo rodoviário. Anais do XXIX Congresso Nacional de Pesquisa em Transporte, ANPET, Ouro Preto, p. 2201-2212, 2015.

CARVALHO, W. L.; YAMASHITA, Y. Uma análise sobre o custo do transporte escolar rural aquaviário no Brasil. Anais do XXIX Congresso Nacional de Pesquisa em Transporte, ANPET, Ouro Preto, p. 2274-2285, 2015.

CAVALCANTE, C. H. L.; JUNIOR, P. A. S. Fatores que influenciam o desempenho escolar: a percepção dos estudantes do curso Técnico em Contabilidade do IFRS. Instituto Federal de Educação, Ciência e Tecnologia do Rio Grande do Sul, Campus Porto Alegre. Revista Liberato, Novo Hamburgo, v. 14, n. 21, p. 91-112, 2013.

COSTA, R. R. A.; ANDRADE, A. P. V.; ARAÚJO, A. G.; DIAS, G. F. Transporte escolar rural: Um estudo estratégico sobre a influência doa indicadores de qualidade no desempenho da educação no ensino fundamental no RN. XXXVIII Encontro do ANPAD, Rio de Janeiro, 2014.

CRUZ, R. O. M.; CÂMARA, M. T.; ARAGÃO, J. J. G.; YAMASHITA, Y. Outsourcing rural school transportation: A Brazilian handbook for practice at the municipal level. Research in Transportation Economics, v. 29, p. 312-318, 2010.

CUNHA, C. G. S. Avaliação de políticas públicas e programas governamentais: tendências recentes e experiências no Brasil. Rio Grande do Sul, 2006.

HINE, J. The provision of home to school transport in Northern Ireland. Research in Transportation Economics, v. 25, p. 29-38, 2009.

IBGE - Instituto Brasileiro de Geografia e Estatística. Disponível em: <https://cidades.ibge.gov.br/ v4/brasil/pe/santa-maria-do-cambuca/panorama>. Acessado em 26 de junho de 2017, 2017.

IBGE - Instituto Brasileiro de Geografia e Estatística. Disponível em: <http://www.ibge.gov.br/ home/estatistica/populacao/censo2010/default.shtm>. Acessado em 26 de junho de 2017, 2010.

KINGHAM, S.; USSHER, S. An assessment of the benefits of the walking school bus in Christchurch, New Zealand. Transportation Research Part A, v. 41, p. 502-510, 2007.

LOPES, E. P. Modelo organizacional para o transporte escolar rural nos estados e municípios brasileiros. Dissertação de Mestrado na Universidade de Brasília, Brasília, 2009.

MACEDO, G. A. Fatores associados ao rendimento escolar de alunos da $5^{\text {a }}$ série (2000) uma abordagem do valor adicionado. XIV Encontro Nacional de Estudos Populacionais, ABEP, Caxambú, 2004.

MARTINS, A.P.A. Análise dos impactos das condições do transporte escolar rural no rendimento escolar dos alunos. Dissertação de Mestrado na Universidade de Brasília, Brasília, 2010.

NASCIMENTO, M. V. L. A.; DOURADO, A. B. F.; ANDRADE, M. O. Avaliação do transporte escolar rural pelos usuários em pequena cidade no agreste de Pernambuco. Anais do XXX Congresso Nacional de Pesquisa em Transporte, ANPET, Rio de Janeiro, p. 2222-2233, 2016.

PERGHER, C. J. Política de transporte escolar rural no Rio Grande do Sul: Configuração de competências e de relações (inter) governamentais na oferta e no financiamento. Tese de Doutorado da Universidade Federal do Rio Grande do Sul, Porto Alegre, 2014. 
PINHEIRO, T. G. B. S. Diagnóstico do transporte escolar rural público no município de Cachoeiro de Itapemirim - ES. Dissertação de Mestrado da Universidade Federal do Espírito Santo, Vitória, 2013.

SANTOS, T. M. M. Transporte escolar rural na perspectiva de gestores e planejadores/ operadores: Subsídios para políticas públicas. Dissertação de Mestrado da Universidade de Brasília, Brasília, 2010.

SCHUH, C.; LOPES, E. R.; FREITAS, V. C. Análise de viabilidade do transporte escolar em município da região central do Rio Grande do Sul. XV Convenção de Contabilidade do Rio Grande do Sul, Bento Gonçalves, 2015.

SILVA, A. R.; YAMASHITA, Y. Modelo de distribuição de recursos para o transporte escolar rural a partir dos princípios da igualdade e da equidade. TRANSPORTES, v. XVIII, n. 3, p. 88-96, 2010.

SONG, S. M.; KIM T. Customer-oriented school bus operations for childcare centers in Korea. Computers \& Industrial Engineering, v. 66, p. 116-124, 2013.

TEIXEIRA, E. C. O papel das políticas públicas no desenvolvimento local e na transformação da realidade. O Papel das Políticas Públicas. AATR - BA, Brasil, 2002. 


\section{AVALIAÇÃO DE PROPRIEDADES MECÂNICAS DE MISTURAS ASFÁLTICAS A QUENTE DOSADAS PELA METODOLOGIA SUPERPAVE}

Matheus Covelo Machado Universidade Federal de Viçosa Viçosa - MG

Heraldo Nunes Pitanga Universidade Federal de Viçosa Viçosa - MG

Taciano Oliveira da Silva Universidade Federal de Viçosa Viçosa - MG

Adriano de Freitas Teixeira Universidade Federal de Viçosa Viçosa - MG Valéria Martins da Costa Pena Universidade Federal de Viçosa Viçosa - MG

Giovani Levi Sant'Anna Universidade Federal de Viçosa Viçosa - MG

RESUMO: Este trabalho teve por objetivo principal analisar o comportamento mecânico de misturas asfálticas a quente dosadas pela metodologia Superpave, empregandose o ligante asfáltico CAP 50/70. A faixa granulométrica selecionada para o estudo foi a "C", destinada à camada de rolamento, segundo a especificação ES 031 (DNIT, 2006a). O teor asfáltico de projeto obtido foi de 3,8\% em relação a massa total da mistura. Para essa mistura, a razão entre as médias dos resultados dos ensaios de módulo de resiliência e de resistência à tração por compressão diametral foi similar ou inferior àquelas identificadas na literatura técnica para misturas asfálticas similares. Comparativamente a misturas asfálticas similares dosadas pelo método Marshall, essa razão foi significativamente diferente, realçando as possíveis incongruências entre esses métodos de dosagem e compactação. Com o presente trabalho, busca-se expandir o conhecimento das propriedades mecânicas de misturas asfálticas a quente dosadas segundo as exigências da metodologia Superpave.

PALAVRAS-CHAVE: Misturas asfálticas a quente. Dosagem Superpave. Propriedades mecânicas..

ABSTRACT: This study aimed to analyze the mechanical behavior of hot mix asphalt, dosed by Superpave methodology, using the asphalt binder CAP 50/70. The $C$ particle size range was selected for the study, used in the surface course according to the specification ES 031 (DNIT, 2006a). The design asphaltic mixture contained $3.8 \%$ asphalt binder, in relation to the total mas of the mixture. For this mix, the ratio between the mean values of the results of tests of resilient modulus and tensile strength by diametrical compression was similar to or lower than those identified in the pertinent literature for 
similar asphalt mixtures, Compared to similar asphalt mixtures dosed by the Marshall method, this ratio was significantly different, highlighting the possible differences between these dosing and compaction methods. With the present study, it is sought to expand the knowledge of the mechanical properties of hot mix asphalt dosed according to the requirements of the Superpave methodology.

KEYWORDS: Hot asphalt mixtures. Superpave method. Mechanical properties.

\section{I INTRODUÇÃO}

O modal rodoviário lidera a matriz de transportes do Brasil, contando, segundo o boletim estatístico da Confederação Nacional dos Transportes (CNT, 2015), com $1.720 .643 \mathrm{~km}$ de rodovias, dos quais $210.619 \mathrm{~km}$ são de rodovias pavimentadas. Mesmo representando pouco mais que $12 \%$ de toda malha rodoviária brasileira, as rodovias pavimentadas suportam grande parte do transporte, tanto de cargas quanto de passageiros.

Independentemente do tipo de pavimento rodoviário (rígido, flexível ou semirígido), tal estrutura deve ser projetada para resistir adequadamente aos esforços gerados pelo tráfego e pelo clima, além de garantir que o rolamento dos veículos se dê com conforto e segurança (Balbo, 2007). A estrutura do pavimento flexível, em particular, a mais amplamente empregada nas rodovias brasileiras, é composta, basicamente, pelas camadas de sub-base, base e revestimento asfáltico, com eventual presença da camada de reforço do subleito.

Por ser a camada externa do pavimento, o revestimento asfáltico sofre mais intensamente as ações do tráfego e das intempéries, justificando o estudo de suas propriedades mecânicas visando a averiguação prévia de seu desempenho sob solicitações similares às solicitações impostas em serviço (Bernucci et al., 2008).

Segundo Nascimento (2008), um dos fatores que influencia o desempenho do pavimento flexível é a correta dosagem experimental da mistura asfáltica constituinte da camada de revestimento. No Brasil, a técnica de dosagem Marshall é bastante utilizada, pois se trata de uma metodologia simples e de baixo custo, na qual se utilizam impactos de um soquete metálico como método de compactação. Contudo, uma técnica mais recente tem representado um avanço nas metodologias de dosagem, que é o sistema Superpave, pois este simula melhor as condições de compactação de campo, considerando variáveis climáticas e de tráfego como parâmetros na escolha dos materiais usados na mistura asfáltica destinada a compor a camada de revestimento asfáltico (Motta et al., 1996).

A necessidade de um novo método de dosagem veio da observação de deformações permanentes prematuras em rodovias americanas de tráfego pesado, durante os anos 80. Tais deformações foram associadas ao excesso de ligante nas misturas dosadas segundo o método Marshall e levavam a acreditar que os corpos de prova compactados com impacto estavam apresentando densidades diferentes das 
misturas asfálticas produzidas em campo (Vasconcelos, 2004).

Dessa forma, foi apresentada pelo Strategic Highway Research Program (SHRP), programa de estudo desenvolvido nos EUA sobre materiais asfálticos, a metodologia Superpave, cuja principal inovação é a forma de compactação da mistura asfáltica. Enquanto no método de dosagem Marshall a compactação é feita por impacto (golpes), no método de dosagem Superpave ela é realizada por amassamento (giros), utilizando-se do Compactador Giratório Superpave (CGS). Dosagens de concreto asfáltico feitas pelas metodologias Marshall e Superpave podem resultar em teores de projeto semelhantes ao se manter a granulometria da mistura dos agregados, entretanto os parâmetros volumétricos e as características mecânicas das misturas compactadas se mostram diferentes, influenciados, fundamentalmente, pela forma de compactação (Marques et al., 2001).

Segundo Nascimento et al. (2006), as dosagens Marshall e Superpave para energias equivalentes fornecem teores de ligante de projeto similares, porém, em termos de propriedades mecânicas tais como o módulo de resiliência (MR) e a resistência à tração por compressão diametral $(\mathrm{RT})$, podem resultar em valores diferentes, pois as estruturas do esqueleto mineral geradas pela compactação por impacto (Marshall) e por amassamento (Superpave) são distintas e interferem no valor dessas propriedades mecânicas. Informações complementares sobre a metodologia Superpave e seu protocolo podem ser encontradas em Bernucci et al. (2008) e em Asphalt Institute (2001).

Dentro dessa perspectiva, considerando-se o caráter ainda incipiente do emprego da metodologia Superpave no Brasil e buscando expandir o conhecimento das propriedades mecânicas de misturas asfálticas a quente dosadas segundo as exigências dessa metodologia, realizou-se, nesse trabalho, um estudo de parâmetros mecânicos derivados dos ensaios de resistência à tração por compressão diametral (RT) e de módulo de resiliência (MR) a fim de contribuir para um melhor entendimento das respostas do material, quando dosado e compactado pela metodologia Superpave.

Adicionalmente, o presente trabalho visa ampliar o banco de dados nacionais pertinentes à dosagem de misturas asfálticas pela referida metodologia, a fim de que a mesma possa gradualmente ser considerada nos centros de pesquisa especializados, nos laboratórios dos cursos de graduação e pós-graduação e, consequentemente, na prática profissional da engenharia rodoviária nacional, contribuindo para a redução das patologias derivadas de eventuais incompatibilidades entre a dosagem de laboratório e o procedimento de execução em campo dessas misturas.

\section{I MATERIAIS E MÉTODOS}

\subsection{Materiais}


Para a realização dos ensaios de laboratório, foram utilizados os seguintes agregados: brita 0, brita 1 e pó de pedra. Esses agregados foram provenientes da pedreira Ervália, localizada no município de Ervália, situado na Zona da Mata Norte do estado de Minas Gerais. A faixa granulométrica adotada neste trabalho foi a $\mathrm{C}$ da especificação de serviço ES 031 (DNIT, 2006a), destinada à camada de rolamento de pavimentos flexíveis. O ligante asfáltico utilizado neste trabalho foi o CAP 50/70, oriundo da empresa Stratura Asfaltos S/A, localizada na cidade de Betim - MG.

\subsection{Métodos}

A Tabela 1 identifica os ensaios realizados sobre os materiais e misturas asfálticas previstos nesse programa experimental de pesquisa, com correspondente indicação da norma adotada. Os correspondentes valores de massa específica máxima medida (Gmm) de cada mistura asfáltica foram determinados segundo o método Rice, regido pela norma D 2041 (ASTM, 2011).

\begin{tabular}{|c|c|c|c|}
\hline \multicolumn{4}{|c|}{ Material } \\
\hline Agregado graúdo & Agregado miúdo & Ligante asfáltico & Mistura asfáltica \\
\hline $\begin{array}{l}\text { Análise granulométrica } \\
\text {-ME } 083 \text { (DNER, 1998a) }\end{array}$ & $\begin{array}{c}\text { Análise } \\
\text { granulométrica - } \\
\text { ME } 083 \text { (DNER, } \\
\text { 1998a) }\end{array}$ & $\begin{array}{c}\text { Penetração - ME } 155 \text { (DNIT, } \\
\text { 2010a) }\end{array}$ & $\begin{array}{l}\text { Massa específica } \\
\text { máxima medida - } \\
\text { D2041 (ASTM, 2011) }\end{array}$ \\
\hline $\begin{array}{l}\text { Abrasão Los Angeles - } \\
\text { ME } 035 \text { (DNER, 1998b) }\end{array}$ & $\begin{array}{c}\text { Massa específica } \\
\text {-ME } 194 \text { (DNER, } \\
1998 d)\end{array}$ & $\begin{array}{l}\text { Ponto de fulgor - ME } 148 \\
\quad \text { (DNER, 1994c) }\end{array}$ & $\begin{array}{l}\text { Resistência à tração } \\
\text { por compressão } \\
\text { diametral - ME } 136 \\
\text { (DNIT, 2010c) }\end{array}$ \\
\hline $\begin{array}{l}\text { Absorção - ME } 081 \\
\text { (DNER, 1998c) }\end{array}$ & & $\begin{array}{l}\text { Ponto de amolecimento - } \\
\text { NBR } 6560 \text { (ABNT, 2008) }\end{array}$ & $\begin{array}{c}\text { Módulo de resiliência } \\
\text { - ME } 135 \text { (DNIT, } \\
2010 \mathrm{~b} \text { ) }\end{array}$ \\
\hline $\begin{array}{l}\text { Adesividade ao ligante } \\
\text { betuminoso - ME 078 } \\
\text { (DNER, 1994b) }\end{array}$ & & $\begin{array}{c}\text { Massa específica e } \\
\text { densidade relativa - ME } 193 \\
\text { (DNER, 1996) }\end{array}$ & $\begin{array}{c}\text { Dosagem Superpave } \\
\text { - AASHTO M } 323 \\
\text { (2013), AASHTO R } \\
35(2014)\end{array}$ \\
\hline $\begin{array}{l}\text { Índice de forma - ME } \\
086 \text { (DNER, 1994a) }\end{array}$ & & & \\
\hline
\end{tabular}

Tabela 1 - Ensaios realizados no programa experimental de pesquisa.

A metodologia de dosagem seguida baseou-se nos procedimentos M 323 (AASHTO, 2013), R 35 (AASHTO, 2014), descritos pela American Association of State Highway and Transportation Officials (AASHTO).

Os corpos de prova foram confeccionados utilizando o ligante à $165^{\circ} \mathrm{C}$ e os agregados à $175^{\circ} \mathrm{C}$, ambos aquecidos em estufas. Após a homogeneização dos materiais, as misturas asfálticas eram encaminhadas para o envelhecimento de curto prazo, onde permaneciam por um período de duas horas à $140^{\circ} \mathrm{C}$, junto com os moldes de compactação. Dando sequência ao procedimento, os moldes de compactação 
com a mistura asfáltica dentro eram levados ao CGS para a aplicação do esforço de compactação. A compactação foi feita à $140^{\circ} \mathrm{C}$ para garantir que o CAP apresentasse a viscosidade proposta pela especificação de serviço ES 031 (DNIT, 2006a). Após a compactação, o corpo de prova é retirado do molde e resfriado à temperatura ambiente em uma superfície plana.

A presente pesquisa considerou, para fins de projeto, a condição de tráfego médio a alto ( $\mathrm{N}$ de $3.10^{6} \mathrm{a} 10.10^{6}$ solicitações do eixo padrão AASHTO), para a qual se definem, conforme Tabela 2, os respectivos números de giros do equipamento CGS pertinentes aos esforços de compactação em Ninicial, Nprojeto e Nmáximo, os dois primeiros para avaliar a compatibilidade da mistura, o último para selecionar o teor de asfalto de projeto. A partir do tráfego considerado, Bernucci et al. (2008) sugerem que o projeto da mistura asfáltica envolveria ensaios de previsão de desempenho a uma temperatura além do projeto volumétrico da mesma, Nível 2 da metodologia Superpave, porém no Laboratório de Asfalto e Misturas do Departamento de Engenharia Civil da Universidade Federal de Viçosa não se dispõe de equipamentos para realizar os ensaios exigidos pelos demais níveis.

\begin{tabular}{cccc}
\hline \multicolumn{3}{c}{ Parâmetros de compactação } & Tráfego \\
$\mathrm{N}_{\text {inicial }}$ & $\mathrm{N}_{\text {projeto }}$ & $\mathrm{N}_{\text {máximo }}$ & Muito leve (local) \\
6 & 50 & 75 & Médio (rodovias colaterais) \\
7 & 75 & 115 & Médio a alto (vias principais, rodovias rurais) \\
8 & 100 & 160 & Alto volume de tráfego (interestaduais, muito pesado) \\
9 & 125 & 205 &
\end{tabular}

Tabela 2 - Números de giros do equipamento CGS especificados na norma de dosagem Superpave (Bernucci et al., 2008).

\section{I RESULTADOS E DISCUSSÃO}

\subsection{Caracterização dos agregados}

As respectivas granulometrias dos agregados empregados na composição das misturas asfálticas consideradas na dosagem Superpave estão apresentadas na Figura 1 e na Tabela 3, a qual também reúne os demais índices físicos característicos desses materiais. Os agregados apresentaram propriedades adequadas para a utilização em misturas asfálticas do tipo concreto asfáltico, em conformidade com a especificação de serviço ES 031 (DNIT, 2006a). 


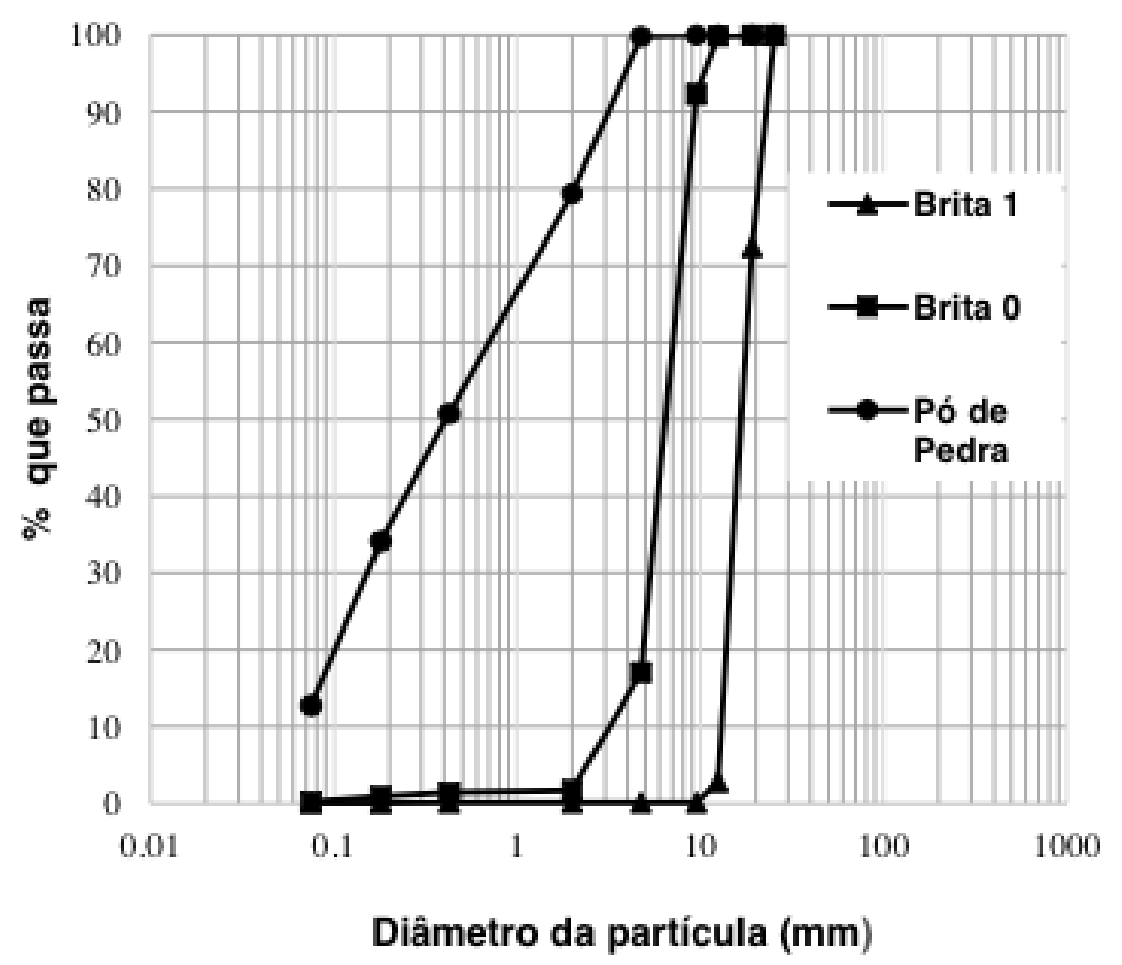

Figura 1 - Curvas granulométricas dos agregados minerais empregados na pesquisa.

\begin{tabular}{cccc}
\hline Índice físico & \multicolumn{3}{c}{ Magnitude do índice físico } \\
& Brita 0 & Brita 1 & Pó de pedra \\
\hline Abrasão Los Angeles (\%) & 44,9 & 44,9 & - \\
Absorção (\%) & 0,65 & 0,68 & - \\
Adesividade ao ligante betuminoso & Satisfatória & Satisfatória & - \\
Índice de forma (\%) & 0,68 & 0,68 & - \\
Massa específica real $\left(\mathrm{g} / \mathrm{cm}^{3}\right)$ & 2,816 & 2,818 & 2,782 \\
Massa específica aparente $\left(\mathrm{g} / \mathrm{cm}^{3}\right)$ & 2,771 & 2,775 & - \\
\hline
\end{tabular}

Tabela 3 - Índices físicos dos agregados minerais empregados na pesquisa.

\subsection{Caracterização do ligante asfáltico}

As características físicas do ligante asfáltico empregado na pesquisa estão reunidas na Tabela 4. Nota-se que todos os resultados obtidos estão em conformidade com a especificação de material EM 095 (DNIT, 2006b) para o CAP 50/70.

\begin{tabular}{cc}
\hline Índice físico & Magnitude do índice físico \\
\hline Penetração $(\mathrm{dmm})$ & 51 \\
Ponto de fulgor $\left({ }^{\circ} \mathrm{C}\right)$ & 343 \\
Ponto de amolecimento $\left({ }^{\circ} \mathrm{C}\right)$ & 51 \\
Massa específica real $\left(\mathrm{g} / \mathrm{cm}^{3}\right)$ & 1,001 \\
Densidade relativa & 1,004 \\
\hline
\end{tabular}

Tabela 4 - Índices físicos do ligante asfáltico empregado na pesquisa. 
3.3 Caracterização das composições de agregados minerais das misturas tentativas

Atendendo às exigências da metodologia Superpave, as três composições granulométricas tentativas de agregados minerais empregadas na dosagem são apresentadas na Figura 2, em conjunto com os limites da faixa $C$ da especificação ES 031 (DNIT, 2006a) e com as restrições estabelecidas por essa metodologia (pontos de controle).

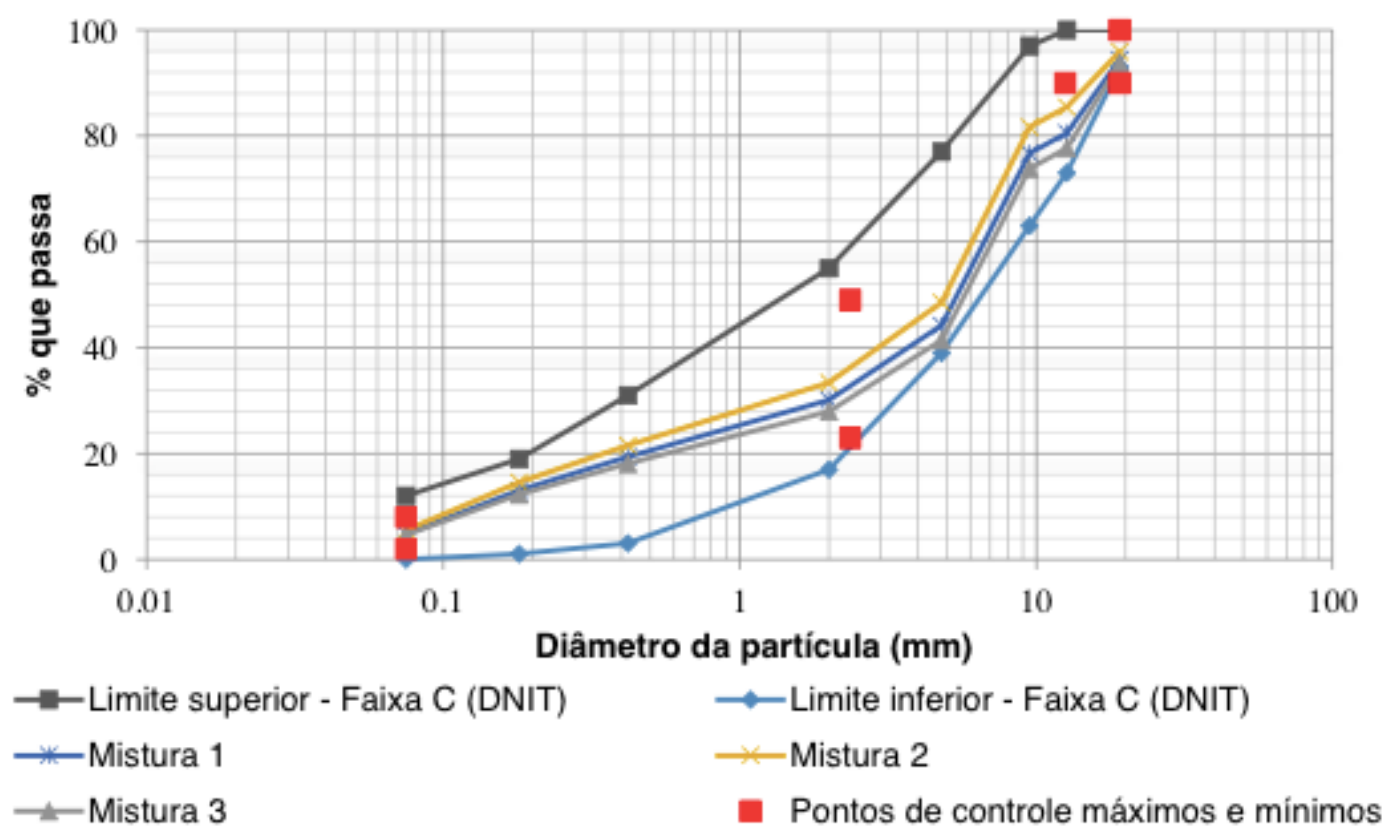

Figura 2 - Curvas granulométricas das misturas de agregados minerais tentativas empregadas na dosagem Superpave e dos limites da faixa C do DNIT.

As percentagens dos agregados minerais em cada uma dessas composições e os correspondentes valores de massas específicas real (Gsa), aparente (Gsb), efetiva (Gse) e máxima medida (Gmm) são apresentados na Tabela 5, ressaltando-se que os três primeiros índices são pertinentes à mistura dos agregados (sem ligante), e o último é pertinente à mistura asfáltica (agregados e ligante).

\begin{tabular}{|c|c|c|c|}
\hline \multirow{2}{*}{ Agregado } & Mistura 1 & Mistura 2 & Mistura 3 \\
\hline & \multicolumn{3}{|c|}{$\%$ na mistura de agregados } \\
\hline Brita 0 & 43 & 44 & 43 \\
\hline Brita 1 & 20 & 15 & 23 \\
\hline Pó de pedra & 37 & 41 & 34 \\
\hline Massas específicas & Mistura 1 & Mistura 2 & Mistura 3 \\
\hline Gsa $\left(\mathrm{g} / \mathrm{cm}^{3}\right)$ & 2,804 & 2,804 & 2,805 \\
\hline $\mathrm{Gsb}\left(\mathrm{g} / \mathrm{cm}^{3}\right)$ & 2,768 & 2,768 & 2,768 \\
\hline Gse $\left(\mathrm{g} / \mathrm{cm}^{3}\right)$ & 2,786 & 2,785 & 2,786 \\
\hline $\mathrm{Gmm}\left(\mathrm{g} / \mathrm{cm}^{3}\right)$ & 2,586 & 2,596 & 2,579 \\
\hline
\end{tabular}




\subsection{Resultados das dosagens tentativas}

Para as composições granulométricas tentativas adotadas no programa experimental, a metodologia de dosagem Superpave indicou os valores de percentagem estimada de ligante ( $\mathrm{Pl}$, est) apresentados na Tabela 6, os quais foram adotados na preparação das amostras compactadas no Compactador Giratório Superpave (CGS). Para o número de giros de projeto $\left(\mathrm{N}_{\text {projeto }}\right)$, os parâmetros volumétricos de interesse (VAM, RBV, \%Gmm a $N_{\text {iniciall, }} \% G m m$ a $N_{\text {máximo }}, P / A$ ) foram quantificados, conforme apresentado nessa mesma Tabela.

\begin{tabular}{ccccccc}
\hline $\begin{array}{c}\text { Mistura } \\
\text { tentativa }\end{array}$ & $\begin{array}{c}\text { Percentagem } \\
\text { estimada de } \\
\text { ligante (\%) }\end{array}$ & $\begin{array}{c}\text { VAM } \\
(\%)\end{array}$ & $\begin{array}{c}\text { RBV } \\
(\%)\end{array}$ & $\% G m m$ a N inicial & \%Gmm a N máximo & P/A \\
\hline 1 & 3,7 & 13,5 & 70,3 & 88,8 & 97,0 & 1,34 \\
2 & 3,8 & 13,2 & 69,8 & 89,7 & 97,0 & 1,48 \\
3 & 3,8 & 14,4 & 72,2 & 87,3 & 97,4 & 1,20 \\
\hline
\end{tabular}

Tabela 6 - Percentagens estimadas de ligante para as misturas tentativas e correspondentes valores dos parâmetros volumétricos de interesse segundo a metodologia Superpave.

Os parâmetros volumétricos apresentados na Tabela 6 devem respeitar as exigências da metodologia Superpave descritas na Tabela 7, que, para o tráfego admitido nesse trabalho e o Tamanho Máximo Nominal (TMN =19,0 mm) do agregado, são VAM > 13\%, RBV entre 65\% e 75\%, \%Gmm a $\mathrm{N}_{\text {inicial }}<89 \%, \% G m m$ a $\mathrm{N}_{\text {máximo }}<98 \%$ e P/A (relação pó/asfalto ou pó/betume efetivo) entre 0,6 e 1,2.

À luz dos resultados obtidos, constata-se que a mistura 1 não atende ao requisito da relação pó/asfalto, pois se mostrou superior ao limite de 1,2. Já a mistura 2, além de também apresentar resultado superior a 1,2 para a relação pó/asfalto, não respeitou o limite máximo do requisito \% $\mathrm{Gmm}$ a $\mathrm{N}_{\text {inicial }}$ Os parâmetros volumétricos da mistura 3 estão de acordo com a especificação, possibilitando, portanto, sua utilização como mistura granulométrica de projeto. Com isso, foram confeccionados dois corpos de prova para quatro teores de ligante diferentes $(3,8 \%, 3,8 \% \pm 0,5 \%$ e $3,8 \%+1,0 \%)$, obtendo-se os resultados apresentados na Tabela 8. 


\begin{tabular}{|c|c|c|c|c|c|c|c|c|c|c|c|}
\hline \multirow{3}{*}{$\begin{array}{c}\text { Tráfego N } \\
\text { AASHTO } \\
\times 10^{6}\end{array}$} & \multicolumn{3}{|c|}{$\begin{array}{l}\text { Densidade relativa requerida } \\
\qquad(\% \mathrm{Gmm})\end{array}$} & \multicolumn{6}{|c|}{$\begin{array}{l}\text { Vazios no Agregado Mineral (VAM), \% } \\
\text { mínima }\end{array}$} & \multirow{3}{*}{$\begin{array}{c}\text { Relação } \\
\text { Betume- } \\
\text { Vazios } \\
\text { (RBV), } \\
\text { em \% }\end{array}$} & \multirow{3}{*}{$\begin{array}{c}\text { Relação } \\
\text { Pó- } \\
\text { Asfalto } \\
\text { (P/A), } \\
\text { em \% }\end{array}$} \\
\hline & \multirow[b]{2}{*}{$N_{\text {inicial }}$} & \multirow[b]{2}{*}{$\mathrm{N}_{\text {projeto }}$} & \multirow[b]{2}{*}{$\mathrm{N}_{\text {máximo }}$} & \multicolumn{6}{|c|}{$\begin{array}{l}\text { Tamanho Máximo Nominal (TMN), } \\
\text { em mm }\end{array}$} & & \\
\hline & & & & 37,5 & 25,0 & 19,0 & 12,5 & 9,5 & 4,75 & & \\
\hline$<0,3$ & $\leq 91,5$ & 96,0 & $\leq 98,0$ & 11,0 & 12,0 & 13,0 & 14,0 & 15,0 & 16,0 & $70-80$ & $0,6-1,2$ \\
\hline 0,3 a 3 & $\leq 90,5$ & 96,0 & $\leq 98,0$ & 11,0 & 12,0 & 13,0 & 14,0 & 15,0 & 16,0 & $65-78$ & $0,6-1,2$ \\
\hline 3 a 10 & $\leq 89,0$ & 96,0 & $\leq 98,0$ & 11,0 & 12,0 & 13,0 & 14,0 & 15,0 & 16,0 & $65-75$ & $0,6-1,2$ \\
\hline 10 a 30 & $\leq 89,0$ & 96,0 & $\leq 98,0$ & 11,0 & 12,0 & 13,0 & 14,0 & 15,0 & 16,0 & $65-75$ & $0,6-1,2$ \\
\hline$>30$ & $\leq 89,0$ & 96,0 & $\leq 98,0$ & 11,0 & 12,0 & 13,0 & 14,0 & 15,0 & 16,0 & $65-75$ & $0,6-1,2$ \\
\hline
\end{tabular}

Tabela 7 - Requisitos volumétricos do método Superpave (Bernucci et al., 2008).

\begin{tabular}{cccccccc}
\hline $\begin{array}{c}\text { Teor de } \\
\text { ligante } \\
(\%)\end{array}$ & $\begin{array}{c}\% G m m \text { a } \\
\mathrm{N}_{\text {inicial }}(\mathrm{N}=8)\end{array}$ & $\begin{array}{c}\% \mathrm{Gmm} \\
\mathrm{a} \mathrm{N}_{\text {projeto }} \\
(\mathrm{N}=100)\end{array}$ & $\begin{array}{c}\% \mathrm{Gmm} \\
\mathrm{a} \mathrm{N}_{\text {máximo }} \\
(\mathrm{N}=160)\end{array}$ & $\mathrm{Vv}(\%)$ & VAM (\%) & RBV (\%) & $\begin{array}{c}\text { Massa } \\
\text { específica } \\
\left(\mathrm{g} / \mathrm{cm}^{3}\right)\end{array}$ \\
\hline 3,3 & 87,65 & 95,69 & 96,84 & 4,31 & 13,17 & 67,30 & 2,485 \\
3,8 & 87,74 & 96,05 & 97,21 & 3,95 & 13,20 & 70,04 & 2,497 \\
4,3 & 89,15 & 97,66 & 98,91 & 2,34 & 12,91 & 81,87 & 2,519 \\
4,8 & 89,48 & 98,88 & 100,00 & 1,12 & 12,96 & 91,37 & 2,530 \\
\hline
\end{tabular}

Tabela 8 - Resumo dos parâmetros volumétricos da mistura granulométrica de projeto compactada no número de giros correspondente a Nprojeto.

As curvas de variação das propriedades volumétricas de interesse em função do teor de ligante, para a compactação no número de giros $\mathrm{N}_{\text {projeto }}$, são apresentadas na Figura 3.

Analisando os resultados, percebeu-se que a mistura asfáltica com teor de ligante asfáltico de 3,8\% apresentou $\mathrm{Vv}$ de 3,95\%, muito próximo, portanto, ao volume de vazios alvo de $4 \%$ prescrito pela metodologia Superpave.

Além disso, o resultado de $13,2 \%$ de VAM está de acordo com a especificação dessa metodologia para esse parâmetro volumétrico, conforme Tabela 7, que exige uma porcentagem maior que $13 \%$. O parâmetro RBV apresentou resultado igual a $70,04 \%$, que se encontra dentro do intervalo de $65 \%$ a $75 \%$ também prescrito pela metodologia de dosagem para a categoria de tráfego admitida nesse trabalho.

Os resultados em relação aos parâmetros de densidade relativa requerida \%Gmm a $\mathrm{N}_{\text {inicial }}$ e \% $\mathrm{Gmm}$ a $\mathrm{N}_{\text {máximo }}$ também atenderam aos requisitos Superpave presentes na Tabela 7 ( $87,74 \%$ e $97,21 \%$, respectivamente). 


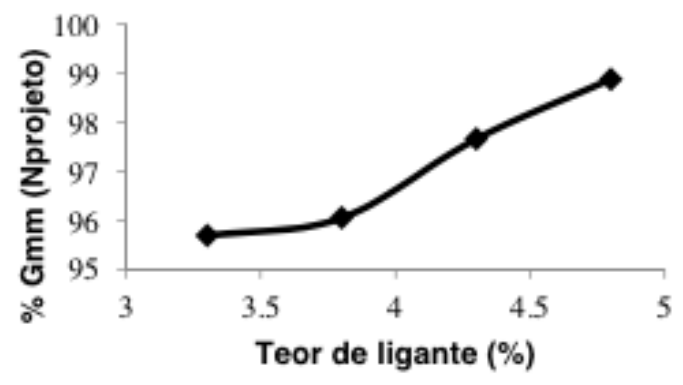

(a)

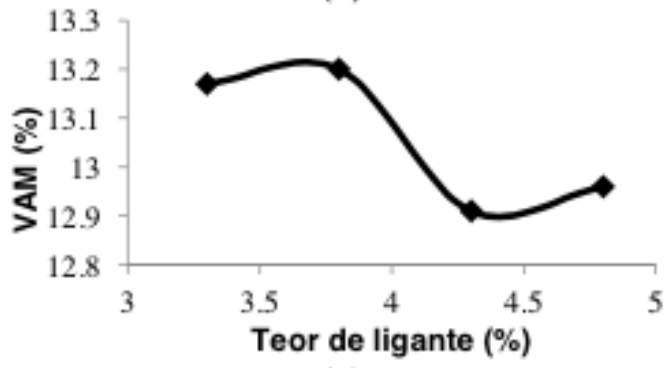

(c)

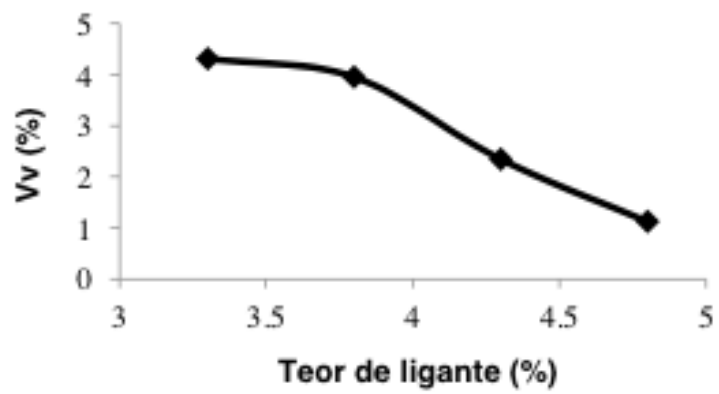

(b)

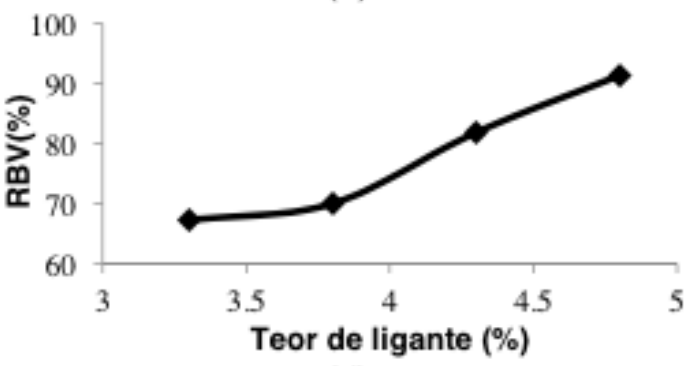

(d)

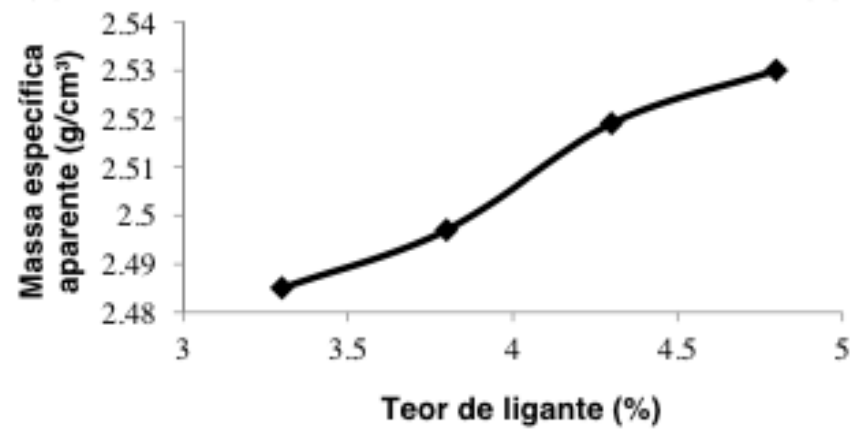

(e)

Figura 3 - Curvas de variação dos parâmetros volumétricos de interesse da dosagem Superpave em função do teor de ligante, para a compactação no Nprojeto: (a) \%Gmm; (b) Vv; (c) VAM; (d) RBV; (e) Massa específica aparente.

Após essa análise, a mistura granulométrica 3, com teor de ligante asfáltico de $3,8 \%$, foi adotada como a mistura asfáltica de projeto. Na Tabela 9, encontra-se o resumo dos valores das propriedades volumétricas da mistura de projeto, juntamente com os critérios extraídos da Tabela 7 para a categoria de tráfego admitida nesse trabalho.

\begin{tabular}{|c|c|c|}
\hline Propriedade da mistura & Resultado & Critério \\
\hline Vv & $3,95 \%$ & $4 \%$ \\
\hline VAM & $13,20 \%$ & $\geq 13 \%$ \\
\hline RBV & $70,04 \%$ & $65 \%$ a $75 \%$ \\
\hline Relação Pó-Asfalto (P/A) & 1,20 & 0,6 a 1,2 \\
\hline$\% G m m$ a $\mathrm{N}_{\text {inicial }}(\mathrm{N}=8)$ & $87,74 \%$ & $<89 \%$ \\
\hline$\% G m m$ a $N_{\text {máximo }}(N=160)$ & $97,21 \%$ & $<98 \%$ \\
\hline
\end{tabular}

Tabela 9 - Propriedades volumétricas da mistura de projeto e correspondentes critérios limites estabelecidos pela metodologia Superpave para a categoria de tráfego adotada. 


\subsection{Resultados dos ensaios mecânicos sobre a mistura de projeto}

\subsubsection{Resistência à tração por compressão diametral (RT)}

A Tabela 10 apresenta os resultados dos ensaios de resistência à tração por compressão diametral (RT) realizados sobre corpos de prova da mistura asfáltica de projeto. Segundo a especificação de serviço ES 031 (DNIT, 2006a), misturas asfálticas usinadas a quente, dimensionadas para a camada de rolamento, devem obter resistência à tração por compressão diametral estática, ensaiadas a $25^{\circ} \mathrm{C}$, superior a 0,65 MPa, o que foi atendido pela mistura asfáltica de projeto compactada no $\mathrm{N}_{\text {projeto }}=100$, para a qual obteve-se a média de 1,20 MPa.

\begin{tabular}{ccccccc}
\hline $\begin{array}{c}\text { Corpo de } \\
\text { prova }\end{array}$ & $\begin{array}{c}\text { Carga de } \\
\text { ruptura } \\
(\mathrm{kgf})\end{array}$ & $\begin{array}{c}\text { Diâmetro } \\
(\mathrm{mm})\end{array}$ & $\begin{array}{c}\text { Altura } \\
(\mathrm{mm})\end{array}$ & $\begin{array}{c}\text { Resistência à tração } \\
\text { por compressão } \\
\text { diametral (MPa) }\end{array}$ & $\begin{array}{c}\text { Resistência à tração } \\
\text { por compressão } \\
\text { diametral média } \\
(\mathrm{MPa})\end{array}$ & $\begin{array}{c}\text { Desvio } \\
\text { padrão } \\
\text { médio } \\
(\mathrm{MPa})\end{array}$ \\
\hline 1 & 1212 & 99,91 & 62,40 & 1,24 & 1,20 & 0,04 \\
2 & 1123 & 99,91 & 62,64 & 1,14 & & \\
3 & 1233 & 100,03 & 63,81 & 1,23 & & \\
\hline
\end{tabular}

Tabela 10 - Resultados dos ensaios de resistência à tração por compressão diametral estática (RT) sobre corpos de prova da mistura asfáltica de projeto.

\subsubsection{Módulo de resiliência (MR)}

A Tabela 11 apresenta os resultados dos ensaios para determinação do módulo de resiliência (MR) da mistura asfáltica de projeto, compactada no $N_{\text {projeto }}=100$ giros e também ensaiada a $25^{\circ} \mathrm{C}$.

\begin{tabular}{cccc}
\hline $\begin{array}{c}\text { Corpo } \\
\text { de prova }\end{array}$ & $\begin{array}{c}\text { Módulo de } \\
\text { resiliência } \\
(\mathrm{MPa})\end{array}$ & $\begin{array}{c}\text { Módulo de } \\
\text { resiliência } \\
\text { médio } \\
(\mathrm{MPa})\end{array}$ & $\begin{array}{c}\text { Desvio } \\
\text { padrão } \\
\text { médio } \\
(\mathrm{MPa})\end{array}$ \\
\hline 1 & 3668 & & \\
2 & 3570 & 3733 & 152 \\
3 & 3960 & & \\
\hline
\end{tabular}

Tabela 11 - Resultados dos ensaios de módulo de resiliência sobre corpos de prova da mistura asfáltica de projeto.

Para fins comparativos, apresentam-se, na Tabela 12, os resultados de propriedades mecânicas de revestimentos asfálticos derivados de ensaios similares aos contemplados nesse trabalho, também baseados na dosagem Superpave de misturas asfálticas e destinados à faixa granulométrica C. E a fim de estender essa comparação dos resultados de propriedades mecânicas de revestimentos asfálticos, a Tabela 13 apresenta resultados de pesquisas que utilizaram a metodologia de dosagem Marshall e destinados também à faixa granulométrica C. Além das propriedades mecânicas 
de interesse, a saber, módulo de resiliência $(\mathrm{MR})$ e resistência à tração estática por compressão diametral (RT), foram indicados os correspondentes valores da relação MR/RT.

Segundo Bernucci et al. (2008), a razão MR/RT tem sido considerada pela literatura técnica como um indicador da vida de fadiga de misturas asfálticas compactadas, visto que tal índice aglutina, simultaneamente, dados de rigidez e de resistência do material, sendo preferível, de um lado, uma menor magnitude dessa razão, devido à necessidade estrutural de se projetar camadas de revestimento asfáltico que tenham baixa rigidez, visando evitar a elevada absorção de tensões que levem ao trincamento prematuro do revestimento, e, de outro lado, uma elevada resistência à tração, visto que uma maior resistência à tração na ruptura é, geralmente, também associada a uma maior resistência à fadiga. Leite et al. (2000) e Pinheiro et al. (2003) estimam que misturas com razão MR/RT da ordem de 3000, tal como a da presente pesquisa, apresentam um bom comportamento estrutural sob a ação das solicitações dinâmicas devidas ao tráfego e intempéricas devidas ao clima, ou seja, tendem a ser, simultaneamente, adequadamente flexíveis e resistentes aos esforços de tração gerados por tais solicitações. Nesse cenário, para uma mesma RT, uma menor relação MR/RT pode ser particularmente vantajosa, visto que permite o dimensionamento de revestimentos asfálticos menos espessos para uma mesma vida de fadiga. Salientase, porém, segundo Vasconcelos (2004), que o parâmetro MR/RT não deve eliminar a necessidade de estudo da vida de fadiga de misturas asfálticas, uma vez que o ensaio de fadiga considera diferentes níveis de tensão.

\begin{tabular}{|c|c|c|c|}
\hline Mistura/Autor & $\begin{array}{l}\text { Módulo de re- } \\
\text { siliência - MR } \\
\text { (MPa) }\end{array}$ & $\begin{array}{c}\text { Resistência à tração } \\
\text { por compressão dia- } \\
\text { metral - RT (MPa) }\end{array}$ & $\mathrm{MR} / \mathrm{RT}$ \\
\hline \multirow{3}{*}{$\begin{array}{c}\text { Concreto asfáltico - CAP } \\
\text { 50/60 - Vasconcelos } \\
\text { (2004) }\end{array}$} & 6003 & 1,72 & 3490 \\
\hline & 6421 & 1,47 & 4368 \\
\hline & 4181 & 1,43 & 2924 \\
\hline $\begin{array}{l}\text { Concreto asfáltico - CAP } \\
50 / 70 \text { - Araújo et al. (2008) }\end{array}$ & 2982 & 0,88 & 3389 \\
\hline $\begin{array}{c}\text { Concreto asfáltico - CAP } \\
\text { 50/70 - Borges et al. } \\
(2016)\end{array}$ & 4496 & 1,16 & 3875 \\
\hline $\begin{array}{l}\text { Concreto asfáltico - CAP } \\
\text { 50/70 - Bruxel (2015) }\end{array}$ & 3584 & 1,15 & 3117 \\
\hline $\begin{array}{c}\text { Concreto asfáltico - CAP } \\
\text { 50/70 - Pinheiro et al. } \\
\text { (2014) }\end{array}$ & 3988 & 1,16 & 3438 \\
\hline $\begin{array}{l}\text { Concreto asfáltico - CAP } \\
50 / 70 \text { - Presente pesquisa }\end{array}$ & 3733 & 1,20 & 3111 \\
\hline
\end{tabular}

Tabela 12 - Comparativo entre os resultados dessa pesquisa e os obtidos na literatura técnica para a faixa C do DNIT e para ligantes asfálticos similares. 


\begin{tabular}{cccc}
\hline Mistura/Autor & $\begin{array}{c}\text { Módulo de resiliência - MR } \\
\text { (MPa) }\end{array}$ & $\begin{array}{c}\text { Resistência à tração por } \\
\text { compressão diametral - } \\
\text { RT (MPa) }\end{array}$ & MR/RT \\
\hline $\begin{array}{c}\text { Concreto asfáltico - } \\
\text { CAP 50/70 - Borges } \\
\text { et al. (2016) }\end{array}$ & 4073 & 0,91 & 4475 \\
$\begin{array}{c}\text { Concreto asfáltico - } \\
\text { CAP 50/70 - Tinajeros } \\
\text { et al. (2016) }\end{array}$ & 2656 & 1,11 & 2393 \\
$\begin{array}{c}\text { Concreto asfáltico - } \\
\text { CAP 50/70 - Prudente } \\
(2015)\end{array}$ & 5723 & & 5399 \\
\hline
\end{tabular}

Tabela 13 - Resultados de outras pesquisas obtidos na literatura técnica para a faixa C do DNIT e para ligantes asfálticos similares, utilizando a dosagem Marshall.

Pode-se notar que a mistura asfáltica projetada nesse trabalho apresentou um comportamento satisfatório em relação ao que é recomendado na literatura em termos de RT, MR e a razão MR/RT. Comparando as misturas asfálticas projetadas utilizando a metodologia de dosagem Superpave com as misturas produzidas a partir do método Marshall, observou-se que a relação MR/RT possui diferenças significativas na ordem de grandeza, além de que há uma maior disparidade nos resultados fornecidos pelo método de dosagem Marshall.

\section{I CONSIDERAÇÕES FINAIS}

Esse artigo visou contribuir com a ampliação do banco de dados técnico-científicos nacionais pertinentes à aplicação da metodologia de dosagem Superpave, ainda tímida em nosso país, buscando estimular o desenvolvimento de novas pesquisas que contemplem o emprego do referido método e, consequentemente, que fomentem a perspectiva de sua inserção crescente no âmbito da prática da Engenharia Rodoviária nacional. Sua motivação decorreu da constatação, em campo, da incidência de patologias precoces em rodovias dosadas segundo a metodologia Marshall, o que realça a importância técnica de se considerar, na dosagem de misturas asfálticas constituintes da camada de revestimento asfáltico dessas rodovias, uma metodologia que seja mais representativa das condições executivas em campo, sobretudo da compactação dessas misturas. Para as particularidades dessa pesquisa, os resultados dos ensaios mecânicos realizados sobre a mistura asfáltica de projeto são indicativos, com base na literatura técnica correspondente a misturas e ensaios similares, de um desempenho estrutural satisfatório em termos de resistência aos mecanismos de trincamento térmico e/ou por fadiga, o que, porém, não exclui a necessidade de realização de ensaios de fadiga para tais misturas. 


\section{REFERÊNCIAS}

AASHTO M 323 (2013). Specification for Superpave Volumetric Mix Design. American Association of State Highway and Transportation Officials, USA.

\section{AASHTO R 35 (2014). Practice for Superpave Volumetric Design for Asphalt}

Mixtures. American Association of State Highway and Transportation Officials, USA.

ASTM D2041 (2011). Standard test method for theoretical maximum specific gravity and density of bituminous paving mixtures. American Society for Testing and Materials, USA.

Araújo Júnior, P. C., A. C. Vale, J. B. Soares e M. D. T. Casagrande (2008). Análise Laboratorial do Cimento Asfáltico de Petróleo - CAP 30/45 - em Misturas Asfálticas. Anais do $19^{\circ}$ Encontro do Asfalto, Rio de Janeiro.

Asphalt Institute (2001). Superpave Mix Design. Superpave Series N² (SP-2), USA.

ABNT (2008). NBR 6560. Materiais betuminosos - determinação do ponto de amolecimento método do anel e bola. Associação Brasileira de Normas Técnicas, Rio de Janeiro.

Balbo, J. T. (2007). Pavimentação asfáltica: materiais, projeto e restauração. Editora Oficina de textos, São Paulo.

Bernucci, L. B., L. M. G. Motta, J. A. P. Ceratti e J. B. Soares (2008). Pavimentação asfáltica: formação básica para engenheiros. ABEDA, Rio de Janeiro.

Borges, P. R., G. S. Pereira, T. O. Silva, H. N. Pitanga, G. L. Sant'Anna, C. A. T. Carmo e G. L. O. Marques (2016). Comportamento mecânico de misturas asfálticas a quente dosadas pela metodologia Marshall e compactadas no compactador Marshall e no CGS (Compactador Giratório Superpave). Anais do XXX ANPET - Congresso de Pesquisa e Ensino em Transportes, Rio de Janeiro.

Bruxel, D. F. (2015). Estudo do comportamento viscoelástico de concretos asfálticos convencionais e modificados através de ensaios de laboratório e de análise de desempenho. Dissertação (Mestrado) - Universidade Federal do Santa Maria, Santa Maria, 129p.

CNT (2015). Boletim Estatístico - CNT - Março, 2015. Disponível em: <http://www.cnt.org.br/ Paginas/Boletins_Detalhes.aspx?b=3>. Acesso em 20 de maio de 2015.

DNER - ME 086 (1994a). Agregados - determinação do índice de forma: método de ensaio. Departamento Nacional de Estradas de Rodagem, Rio de Janeiro.

DNER - ME 078 (1994b). Agregado graúdo - adesividade a ligante betuminoso: método de ensaio. Departamento Nacional de Estradas de Rodagem, São Paulo.

DNER - ME 148 (1994c). Material betuminoso - determinação dos pontos de fulgor e de combustão: método de ensaio. Departamento Nacional de Estradas de Rodagem, Rio de Janeiro.

DNER - ME 193 (1996). Materiais betuminosos líquidos e semi-sólidos - determinação da densidade: método de ensaio. Departamento Nacional de Estradas de Rodagem, Rio de Janeiro.

DNER - ME 083 (1998a). Agregados - análise granulométrica: método de ensaio. Departamento Nacional de Estradas de Rodagem, Rio de Janeiro.

DNER - ME 035 (1998b). Agregados - determinação da abrasão "Los Angeles": método de ensaio. Departamento Nacional de Estradas de Rodagem, São Paulo. 
DNER - ME 081 (1998c). Agregados - determinação da absorção e da densidade de agregado graúdo: método de ensaio. Departamento Nacional de Estradas de Rodagem, Rio de Janeiro.

DNER - ME 194 (1998d). Agregados - determinação da massa específica de agregados miúdos por meio do frasco de Chapman: método de ensaio. Departamento Nacional de Estradas de Rodagem, Rio de Janeiro.

DNIT - EM 095 (2006b). Cimento asfáltico de petróleo - Especificação de material. Departamento Nacional de Infraestrutura de Transportes, Rio de Janeiro.

DNIT - ES 031 (2006a). Pavimentos flexíveis - Concreto asfáltico: especificação de serviço. Departamento Nacional de Infraestrutura de Transportes, Rio de Janeiro.

DNIT - ME 155 (2010a). Material asfáltico - Determinação da penetração: método de ensaio. Departamento Nacional de Infraestrutura de Transportes, Rio de Janeiro.

DNIT - ME 135 (2010b). Pavimentação asfáltica - Misturas asfálticas - Determinação do módulo de resiliência: método de ensaio. Departamento Nacional de Infraestrutura de Transportes, Rio de Janeiro.

DNIT - ME 136 (2010c). Pavimentação asfáltica - Misturas asfálticas - Determinação da resistência à tração por compressão diametral: método de ensaio. Departamento Nacional de Infraestrutura de Transportes Rio de Janeiro.

Leite, L. F. M., L. M. G. Motta, L. B. Bernucci e J. B. Soares (2000). Mechanical behavior of asphalt rubber mixes prepared in laboratory. Proceedings, Asphalt Rubber: the pavement material of the $21^{\text {st }}$ century. Vilamoura, p. 309-318.

Marques, G. L. O., L. M. G. Motta e L. M. Leite (2001). Exemplos de Dosagem Superpave no Brasil. Anais da $33^{\mathrm{a}}$ Reunião Anual de Pavimentação, Florianópolis.

Motta, L. M. G., I. Tonial, L. M. F. Leite e R.S. Constantino (1996). Princípios do Projeto e Análise Superpave de Misturas Asfálticas. Tradução comentada, IBP.

Nascimento, L., L. Leite, E. F. Campos, G. Marques e L. Motta (2006). Uso da tomografia computadorizada e de imagens digitais para o estudo de misturas asfálticas. Anais do $18^{\circ}$ Encontro do Asfalto, Rio de Janeiro.

Nascimento, L. A. (2008). Nova abordagem da dosagem de misturas asfálticas densas com uso do compactador giratório e foco na deformação permanente. Dissertação (Mestrado) Universidade Federal do Rio de Janeiro, Rio de Janeiro, 204p.

Pinheiro, G. S., R. L. Oliveira, F. P. Rossato, D. S. Pereira e L.P. Specht (2014). Análise comparativa dos parâmetros de RT e MR para misturas com diferentes ligantes asfálticos a diferentes temperaturas. Anais do XXVI Congresso Regional de Iniciação Científica e Tecnológica em Engenharia - CRICTE 2014, Alegrete, p. 1-4.

Pinheiro, J. H. M., J. B. Soares e L. F. M. Leite (2003). Caracterização de misturas asfálticas com borracha produzidas pelos processos úmido e seco. Anais do XVII ANPET - Congresso de Pesquisa e Ensino em Transportes, Rio de Janeiro, p.116-129.

Prudente, C. Q. A. (2015). Estudo laboratorial de misturas asfálticas a quente utilizadas em Goiás. Dissertação (Mestrado) - Universidade Federal de Goiás, Goiânia, 113 f.

Tinajeros, R. A. P., T. O. Silva, H. N. Pitanga, D. C. Lima e G. L. O. Marques (2016). Estudo do comportamento mecânico de misturas asfálticas a quente produzidas com ligantes convencional e modificado por polímero SBS. Anais do XXX ANPET - Congresso de Pesquisa e Ensino em 
Transportes, Rio de Janeiro.

Vasconcelos, K. L. (2004). Comportamento mecânico de misturas asfálticas a quente dosadas pelas metodologias Marshall e Superpave com diferentes granulometrias. Dissertação (Mestrado), Universidade Federal do Ceará, Fortaleza, 132 p. 


\section{CARACTERÍSTICAS DE VULNERABILIDADE EM IDOSOS E OBESOS NAS TRAVESSIAS DE PEDESTRE}

Frederico Souza Gualberto

UFMG - Departamento de Engenharia de Transportes e Geotecnia: Núcleo de Transportes - NUCLETRANS: Belo Horizonte, MG

(fredgualberto@gmail.com) Janaína Amorim Dias

UFMG - Departamento de Engenharia de Transportes e Geotecnia: Núcleo de Transportes - NUCLETRANS: Belo Horizonte, MG (janaina. mobilidade@gmail.com)

Heloísa Maria Barbosa

UFMG - Departamento de Engenharia de Transportes e Geotecnia: Núcleo de Transportes - NUCLETRANS: Belo Horizonte, MG

(helobarb55@gmail.com)

Marcelo Franco Porto UFMG - Departamento de Engenharia de Transportes e Geotecnia: Núcleo de Transportes - NUCLETRANS:

Belo Horizonte, MG(marcelo@etg.ufmg.br)

Marconi Gomes da Silva SPORTIF - Clínica do exercício e do Esporte/ Diretor da Sociedade Mineira de Medicina do Exercício e do Esporte / Membro do Comitê de Cardiologia do

Esporte da Sociedade Mineira de Cardiologia

(sportifmarconi@gmail.com)

RESUMO: O objetivo principal deste artigo é ponderar e compreender as características dos pedestres em travessias de vias urbanas e ressaltar as diferenças entre os pedestres obesos e idosos, frente aos demais pedestres.
A partir da análise de vídeos coletados, 902 pedestres foram observados e resultam em $1,28 \mathrm{~m} / \mathrm{s}$ como velocidade média da amostra. Para os idosos e obesos, essa velocidade foi de 1,07 e $1,20 \mathrm{~m} / \mathrm{s}$ respectivamente. Foram apresentadas as diferenças destes grupos (idosos e obesos) em função de outras características como sexo, idade e largura da via. Com os dados de velocidade de pedestres, foi possível utilizar um modelo de previsão de velocidades para criar três cenários (2017/2022/2030) com o envelhecimento estimado da população (IBGE), bem como o aumento projetado do número de obesos (Ministério da Saúde). As velocidades preditas foram comparadas, indicando pequena variação $(0,01 \mathrm{~m} / \mathrm{s}$ de 2017 para 2022 e $0,02 \mathrm{~m} / \mathrm{s}$ de 2017 para 2030).

PALAVRAS-CHAVE: comportamento de pedestres; velocidade de caminhada; vulnerabilidade de pedestres, travessias urbanas; idosos e obesos em travessias; pedestres idosos e deficientes, modelo de previsão de velocidades.

ABSTRACT: This article's main objective is to deliberate and understand the characteristics of pedestrians at urban roads crossings and to highlight the differences between obese and elderly pedestrians, compared to other pedestrians. Based on an analysis of collected 
videos, 902 pedestrians were observed indicating $1.28 \mathrm{~m} / \mathrm{s}$ as average walking speed of the sample. For the elderly and obese of the sample, this average speed was 1.07 and $1.20 \mathrm{~m} / \mathrm{s}$ respectively. Differences of these groups (elderly and obese) were presented according to other characteristics such as sex, age and extension of the crossing. With the pedestrian speed data, it was possible to use a speed forecasting model to create three scenarios (2017/2022/2030) with the estimated population aging (IBGE), as well as the projected increase in the number of obese people (Ministry of Health). The predicted speeds were compared, indicating small variation $(0.01 \mathrm{~m} / \mathrm{s}$ from 2017 to 2022 and $0.02 \mathrm{~m} / \mathrm{s}$ from 2017 to 2030).

KEYWORDS: pedestrian behaviour; walking speed (gait speed); vulnerability of pedestrians; urban crossings; elderly and obese at crossings; elderly and disabled pedestrian; speed prediction model.

\section{I INTRODUÇÃO}

Os pedestres obesos e idosos possuem um maior nível de vulnerabilidade em situações cotidianas, entre elas, o atravessamento de ruas. A OMS (Organização Mundial da Saúde) indica que anualmente mais de 270.000 pedestres morrem nas vias públicas de todo o mundo. Esses constituem $22 \%$ de todas as mortes no trânsito e, em alguns países, essa proporção chega a 66\% (WHO, 2013). De acordo com a Pesquisa Nacional de Saúde, de 2013, as projeções populacionais do Brasil apontam o avanço do envelhecimento da população. Um dos indicadores que mostram esse fenômeno é a esperança de vida ao nascer, que era 71,2 anos em 2003 e passou para 74,9 anos em 2013 (INSTITUTO BRASILEIRO DE GEOGRAFIA E ESTATISTICA, 2013). No Brasil, de acordo com o IBGE (2015), a partir de dados publicados em Agosto de 2015 , o total de obesos corresponde a $20,8 \%$ da população. Esse número, quando analisado em conjunto com outros fatores, como o envelhecimento da população, torna ainda mais alarmante a situação dos considerados mais propensos a acidentes viários. Aliado a esses dados, nota-se o aumento do uso do automóvel no Brasil nos últimos anos. Segundo o Departamento Nacional de Trânsito (DENATRAN), o número de emplacamentos mensais cresceu no País entre 2000 e 2013. No fim do ano 2000, a média mensal de emplacamentos era de aproximadamente 100.000 veículos e em 2013, essa média era de cerca de 300.000 veículos. Entre as razões para a falta de segurança em uma travessia, destacam-se a sinalização estatigráfica (vertical e horizontal) inadequada ou insuficiente, a alta velocidade praticada pelos veículos e a programação semafórica, que muitas vezes promove um tempo pequeno para a travessia adequada dos pedestres, priorizando o fluxo de veículos, em detrimento da segurança àquele que caminha. Além disso, observa-se que a deterioração de calçadas e travessias também contribuem para a redução da segurança do pedestre. Todos esses fatores de falta de seguridade são notados e agem de forma distinta nas pessoas diferentes. 
O trabalho tem como objetivo ponderar e compreender as características dos pedestres em travessias de vias urbanas, por meio da identificação dos fatores que afetam o seu comportamento referente à velocidade desenvolvida durante o cruzamento de uma via, bem como a avaliação da relevância desses fatores. Além disso, pretende analisar de forma mais incisiva os pedestres idosos e obesos, ressaltando as diferenças destes para os demais pedestres, determinando os pontos principais onde esses são mais afetados pelos fatores de insegurança. Para esse fim, buscou-se realizar pesquisa de campo coletando velocidades de pedestres em travessias (filmagens); examinar os diversos tipos de comportamento observáveis (antes, durante e após a travessia) e associá-los com as características dos pedestres: idade, sexo, mobilidade, gravidez, obesidade, carregamento de peso. Acredita-se que a velocidade desenvolvida pelo pedestre pode demonstrar como os pedestres agem em cada tipo de situação de atravessamento, a partir de suas características pessoais, esclarecendo pontos importantes a respeito da diferença dos caminhantes. Por fim, a partir de estudos anteriores de estimativa de velocidade dos pedestres, foi possível demonstrar, através de simulações, a maior vulnerabilidade dos idosos e obesos frente ao atravessamento de vias.

\section{I FATORES DE VULNERABILIDADE EM TRAVESSIAS DE VIAS URBANAS}

O conceito de obesidade está relacionado a um conjunto de fatores, dentre eles, destacam-se os fatores genéticos, ambientais, psicológicos, emocionais, o sedentarismo, a mudança de hábitos alimentares influenciados pela situação social, econômica e cultural. Essa multiplicidade de fatores talvez seja o principal determinante da grande dificuldade encontrada para o controle desse problema de saúde pública. Dados do Ministério da Saúde demonstram que, pela primeira vez, o percentual de pessoas com excesso de peso supera mais da metade da população brasileira. A pesquisa VIGITEL 2014 (Vigilância de Fatores de Risco e Proteção para Doenças Crônicas por Inquérito Telefônico) mostra que 52,5\% da população (acima de 18 anos) está acima do peso ideal, e destes, 17,9\% são obesos. Dados do VIGITEL ainda mais recentes, de 2016 , mostram que $53,8 \%$ da população brasileira está acima do peso e 18,9\% estão obesas. Em 2006, o índice que representava o excesso de peso era de $43 \%$ e de obesidade, cerca de $11,8 \%$. Nos dados VIGITEL de 2014 , constatou-se que $49 \%$ da população brasileira está insuficientemente ativa e $15 \%$ foi considerada inativa. Ou seja, 64\% da população brasileira não realizava exercícios físicos na intensidade e volume recomendados pela Organização Mundial de Saúde (OMS). Em 2016 esse número mostrou uma discreta queda, passando para 62,4\%. Ou seja, mesmo apresentando uma pequena melhora no percentual da população que se exercita em seu tempo livre, ainda assim notam-se níveis crescentes de obesidade e excesso de peso na população brasileira. Trata-se de uma condição que vem se repetindo em muitos outros países. 
O índice de massa corporal, mais conhecido pela sigla IMC, é um índice adotado pela OMS que vem sendo usado para o diagnóstico do sobrepeso e da obesidade. Embora seja um método que pode apresentar algumas distorções, tendo em vista que a massa de gordura (massa gorda) é contabilizada juntamente com a massa muscular (massa magra), o IMC pode ser facilmente calculado a partir de dois simples dados: peso e altura.

$$
I M C=p \div h^{2} \text { (metros) }
$$

Onde:

p é a massa (comumente conhecida por peso) da pessoa avaliada, em quilos (kg)

h é a altura da pessoa avaliada, em metros (m)

Os resultados indicarão:

Peso normal $=$ entre 18,50 e $24,99 \mathrm{~kg} / \mathrm{m}^{2}$

Sobrepeso = entre 25 e 29,99 kg/m²

Obesidade grau I = entre 30 e $34,99 \mathrm{~kg} / \mathrm{m}^{2}$

Obesidade grau II = entre 35 e $39,99 \mathrm{~kg} / \mathrm{m}^{2}$

Obesidade grau III (obesidade mórbida) = maior que $40 \mathrm{~kg} / \mathrm{m}^{2}$

O IMC é um indicador indireto do estado de saúde. De acordo com Carneiro, Silva e Vieira (2009), a obesidade é um problema de saúde pública cada vez mais impactante nas sociedades modernas, sobretudo ocidentais, com relevantes implicações na qualidade de vida e no desenvolvimento de comorbidades, provocando distúrbios no aparelho locomotor, com implicações na velocidade de caminhada. $\mathrm{O}$ excesso de peso provoca uma menor amplitude dos movimentos, falta de ar, fadiga precoce, diminuição da absorção dos impactos e degradação da condição das articulações (FAINTUCH et al. 2005). Todos esses fatores acabam por limitar a biomecânica da deambulação. Dessa maneira, a obesidade, ao comprometer a velocidade da marcha, o equilíbrio e a capacidade de reação, torna-se um fator predisponente a uma maior vulnerabilidade do pedestre nessa condição.

Os dados do IBGE (2015) indicam que entre 2005 e 2015, a proporção de pessoas com 60 anos ou mais, na população do país, passou de 9,8\% para 14,3\%. Dentre as consequências mais graves do envelhecimento, destacam-se os seus efeitos sobre o sistema neuromusculoesquelético (RYALL, SCHERTZER \& LYNCH, 2008). Lauretani et al. (2005) apontam que na velhice observa-se diminuição progressiva da massa e da força muscular o que afeta diretamente a mobilidade física e pode desencadear um processo de incapacidade funcional. A incapacidade funcional pode ser definida como a dificuldade de realizar tarefas que fazem parte do cotidiano do ser humano e que são indispensáveis para uma vida independente na comunidade (YANG e GEORGE, 2005). 
O comprometimento da capacidade funcional do idoso tem implicações importantes para a família, a comunidade, o sistema de saúde e a vida do próprio idoso, uma vez que a incapacidade ocasiona maior vulnerabilidade e dependência, contribuindo para a diminuição do bem estar e da qualidade de vida (ALVES e RODRIGUES, 2005; VERAS, 2009). A perda muscular, também denominada sarcopenia, é um dos elementos da definição da síndrome de fragilidade do idoso e está associada a risco para quedas, fraturas, incapacidade, dependência, hospitalização recorrente e morte (FRIED et al., 2001). Cruz et al. (2010) indicam que entre os critérios de diagnóstico dessa doença está o baixo desempenho físico, diminuindo a velocidade de marcha (caminhada). A correlação entre idade e velocidade de marcha é bem estabelecida, com redução progressiva ao longo das décadas. Esse comportamento está relacionado às alterações da senescência, como a maior tendência à inatividade, redução da massa muscular, redução do número e função das unidades motoras e aumento da latência de execução das contrações fásicas da musculatura dos membros inferiores e do tempo de reação (OBERG et al., 1993; BOHANNON et al., 1996). O estudo de Novaes et al. (2011) mostrou, utilizando metodologia simples e de baixo custo, que a velocidade de marcha (VM) em teste de 10 metros declina com a idade e que indivíduos com idade igual ou superior a 70 anos apresentam reduções significativas da velocidade quando comparados aos indivíduos com idades entre 40 e 59 anos, independente do gênero. Entretanto, não foi encontrada diferença significativa na velocidade de marcha entre as faixas etárias de 60-69 anos e maior ou igual a 70 anos em ambos os gêneros. Segundo os dados desse estudo, os indivíduos com idade acima de 70 anos apresentaram VM significativamente inferior aos indivíduos entre 40 e 49 anos e entre 50 e 59 anos tanto nos homens $(1,09 \pm 0,18 \mathrm{~m} / \mathrm{s}, 1,35 \pm 0,11 \mathrm{~m} / \mathrm{s}$ e $1,34 \pm 0,22 \mathrm{~m} / \mathrm{s}$, respectivamente) quanto nas mulheres $(1,02 \pm 0,10 \mathrm{~m} / \mathrm{s}, 1,27 \pm 0,20 \mathrm{~m} / \mathrm{s}$ e $1,27 \pm 0,15 \mathrm{~m} / \mathrm{s}$, respectivamente). Esse declínio na VM, associado ao aumento da idade, já foi observado em estudos prévios que utilizaram análise computadorizada de imagens. (GUALBERTO et al., 2013; MURRAY et al., 1969; ELBLE et al., 1991). A VM tem sido considerada a variável cinemática da marcha clinicamente mais relevante e uma boa preditora do desempenho funcional, condição de saúde cardiovascular e capacidade para realizar atividades de vida diária em indivíduos idosos (HARDY et al., 2007; HOLLMAN et al. 2008; ASHER, L. et al., 2012).

O Highway Capacity Manual (HCM) TRB (2000) define pedestre como "um indivíduo movimentando-se a pé" e a OMS define o pedestre como qualquer pessoa andando a pé em pelo menos parte da sua jornada. A segurança nas vias é uma preocupação que o Brasil vem enfrentando, principalmente onde há conflito de veículo e pedestre. Esse último é considerado o mais vulnerável no trânsito, e deve receber uma atenção especial, como prevê o Código de Trânsito Brasileiro "os veículos de maior porte serão sempre responsáveis pela segurança dos menores, os motorizados pelos não motorizados e, juntos, pela incolumidade dos pedestres" (Brasil, 1997). O HCM também recomenda que a velocidade esperada para pedestres seja de 1,2 m/s (TRB, 
2000), assim como FHWA (2003) e Austroads (1988). De acordo com TRB (2000), a velocidade de circulação dos pedestres é fortemente dependente da porcentagem de idosos ( $\geq 65$ anos) existentes na população pedestre. Assim, se essa porcentagem se situar entre os 0 e os $20 \%$, a velocidade de circulação média mantém-se em 1,2 m/s, diminuindo para $1 \mathrm{~m} / \mathrm{s}$ no caso da porcentagem de pedestres idosos ser superior a $20 \%$ (TRB, 2000). Knoblauch et al. (1996) mostram que, para os idosos, a velocidade ideal a ser considerada é $0,91 \mathrm{~m} / \mathrm{s}$ e os fatores que podem influenciar a velocidade de travessia são muito diversos. A velocidade adotada para pedestres nos cálculos de programação semafórica por parte dos principais manuais de tráfego mundiais é de $1,22 \mathrm{~m} / \mathrm{s}$, como citado anteriormente, porém muitas vezes essa velocidade pode ser questionada, principalmente quando são analisadas mais profundamente as travessias de pedestres com maior vulnerabilidade, como exemplo os obesos e idosos, objeto de estudo desse artigo.

\section{I METODOLOGIA}

O artigo busca atingir seus objetivos através de um estudo de caso realizado na cidade de Belo Horizonte, capital do estado de Minas Gerais, no Brasil. A metodologia elaborada para a condução deste estudo compreende sete etapas: (i) definição da área de pesquisa; (ii) seleção de travessias; (iii) levantamento cadastral de locais; (iv) definição dos métodos de obtenção de dados; (v) pesquisa de campo para coleta de dados de velocidade de pedestres; (vi) tabulação dos dados e informações coletadas; e (vii) análise de dados. Algumas dessas etapas serão comentadas a seguir.

\subsection{Seleção de travessias}

Este estudo aborda o comportamento de pedestres enquanto atravessam vias urbanas, bem como sua interação com os veículos e com o ambiente em seu entorno de maneira geral. A área de pesquisa compreende a região central de Belo Horizonte e o entorno de um Polo Gerador de Viagens fora da região central, próximo à Universidade Federal de Minas Gerais - UFMG. Treze travessias sinalizadas com faixa de pedestres foram escolhidas. Elas possuem diferentes configurações geométricas, estruturais e fluxos, sendo 12 dessas na região central da cidade. Seis atributos viários foram observados: função da via, tipo de circulação, número de faixas de tráfego, existência de canteiro central, largura da pista de rolamento e existência de sinalização semafórica, apresentados juntamente com suas respectivas características na Figura 1. 


\subsection{Método de coleta e tabulação de dados}

O método definido para a obtenção da variável velocidade foi a filmagem dos deslocamentos dos pedestres nos locais selecionados. O processo de filmagem no campo deveria ser inconspícuo para os usuários de forma a não afetar o comportamento dos sujeitos pesquisados. Recentemente, métodos similares foram utilizados por Papadimitriou (2009); Lee e Lam (2008); Silva et al. (2014); Marisamynathan e Perumal (2014), e serviram de contribuição e base para o desenvolvimento do método adotado neste trabalho.

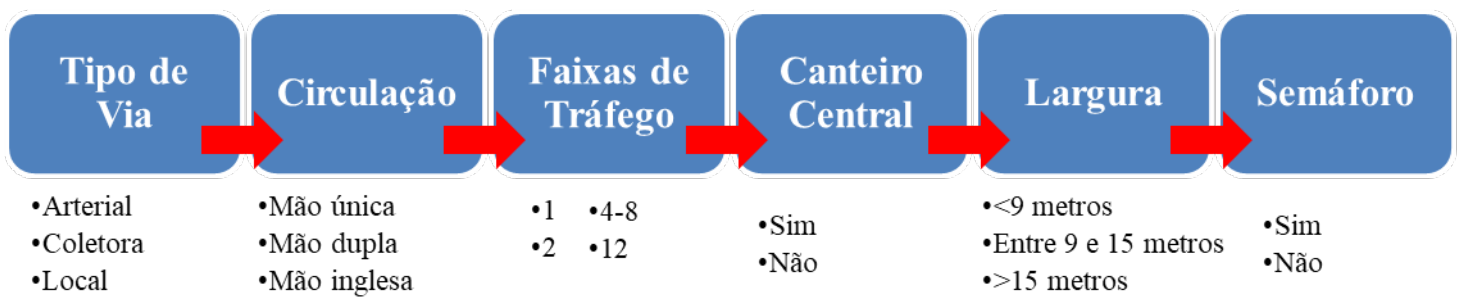

Figura 1: Atributos e respectivas características viárias consideradas (GUALBERTO, 2016)

Os dados foram coletados em boas condições de tempo e clima, sem precipitação e com o pavimento seco, evitando assim a inclusão de novas variáveis indesejadas para esse estudo. As filmagens foram realizadas nos meses de Abril de 2013 e entre Agosto e Novembro de 2014. O período escolhido para essa aquisição de informações foi entre 12:00 e 14:00, uma vez que neste horário existe um grande movimento de pedestres com diferentes características devido ao período de almoço. Cada travessia teve um tempo de gravação específico, com uma câmera CANON EOS 5D Mark II em qualidade full HD, gerando arquivos no formato .mov.

Todas as gravações foram analisadas cuidadosamente por uma equipe de no mínimo duas pessoas, a partir de critérios previamente estabelecidos, com o objetivo de garantir uma boa qualidade na medição. Os principais critérios de seleção da amostra de pedestres foram: realizar a travessia sem se deslocar muito na diagonal; (ii) atravessar no semáforo aberto para si; (iii) não correr durante a travessia. A medição da velocidade das pessoas adotou os seguintes critérios: começo da contagem do tempo a partir do momento que o pedestre saía da calçada em direção à rua e término do tempo quando alcançava a calçada e utilização de cronômetro para a marcação do tempo, a fim de se comparar com o tempo transcorrido no vídeo. Os pedestres cadastrados e tabulados foram 902, escolhidos aleatoriamente entre aqueles que atravessavam as ruas selecionadas. Os locais selecionados podem ser verificados em Gualberto (2016).

$\mathrm{Na}$ tabulação dos dados dos vídeos, o processo consistiu em escolher aleatoriamente pedestres filmados, que realizavam a travessia e atendessem aos critérios descritos na metodologia. Uma vez escolhido um pedestre, o vídeo era pausado 
no exato momento em que esse começava a travessia e reiniciado para medição do tempo, contando com o auxílio de um cronômetro. O tempo de travessia foi medido tanto pelo cronômetro, quanto pela barra de tempo do vídeo e depois comparadas às medições. O valor apontado pelo cronômetro foi o utilizado na tabulação, pois o dado possuía duas casas decimais. O valor medido pelo vídeo, sem qualquer casa decimal, serviu apenas como comparação. Caso os valores fossem discrepantes, a medida era realizada de novo. Uma vez que as travessias já haviam sido medidas, os valores das larguras foram inseridos em uma planilha que contava com o tempo de cada pedestre para atravessar a via. A partir da divisão da largura de cada travessia, em metros, pelo tempo de atravessamento, em segundos, obteve-se a velocidade de marcha de cada pedestre $(\mathrm{m} / \mathrm{s})$. O tamanho da amostra final foi de 902 casos.

\subsection{Variáveis e características de pedestres}

Conforme antecipado na introdução, a velocidade de caminhada durante a travessia das vias foi a principal variável definida para caracterizar o comportamento do pedestre, associada às características físicas como idade, sexo, obesidade e deficiência e outras características momentâneas, como o carregamento de peso e a travessia individualmente ou em dupla/grupo. A partir dos fatores/características extraídos, das análises dos vídeos e das configurações das vias selecionadas foi possível dividi-los em dois grupos: os fatores relativos às características dos pedestres e os fatores relacionados às características viárias.

A análise visual dos vídeos permitiu identificar os pedestres segundo as características sugeridas. Esta atividade foi executada pelos revisores dos vídeos, que estimaram a idade e classificaram as pessoas de acordo com o sexo, carregamento de peso, deficiência aparente, gravidez, obesidade e caminhar em grupo ou individualmente. A qualidade das filmagens digitais permitiu uma boa visualização da imagem de cada individuo da amostra, ainda assim, pode haver algum erro em relação à estimativa de idade. Foram consideradas grávidas somente as mulheres que claramente aparentavam estar esperando bebê. Quanto à obesidade, característica detalhada nesse estudo em relação às publicações anteriores (GUALBERTO e BARBOSA, 2016), a observação também foi realizada de maneira apenas visual, sendo considerada obesa a pessoa que possuía visível sobrepeso e muito obesa aquela que claramente estava obesa. A OMS, como indicado na revisão bibliográfica, classifica as pessoas em sobrepeso e obesas, de acordo com o IMC (Índice de Massa Corporal). Devido às limitações de dados e método de coleta deste trabalho, foram consideradas três categorias: não obeso, obeso e muito obeso. Este trabalho também relacionou as características de idade e obesidade, apontando a influência de um fator associado ao outro. 


\section{I CARACTERIZAÇÃO DA AMOSTRA E ANÁLISE DE RESULTADOS}

Esse estudo pretende explorar a vulnerabilidade dos idosos e obesos em relação aos demais pedestres presentes nas ruas. Assim sendo, verifica-se a necessidade de dados gerais permitindo uma análise comparativa. A amostra coletada nos vídeos foi selecionada a partir da população que passava nos locais de estudo. Foram escolhidos aleatoriamente os pedestres para a composição da amostra. Sendo assim, as características físicas dos pedestres seguem o padrão da população do local pesquisado (que circulava na região no momento das gravações). Com a amostra de 902 pessoas para este estudo, garantiu-se um intervalo de confiança de mais de 99\% e margem de erro de 5\%. Dessa forma, a amostra é adequada para representar a população de pedestres das regiões analisadas. A Tabela 1 apresenta as estatísticas básicas para a velocidade de pedestres (média, desvio padrão, percentil 15, percentil 85 , valores máximo e mínimo) de acordo com as variáveis adotadas no presente estudo: sexo, idade, extensão da travessia, mobilidade reduzida, semáforos, obesidade, carregamento de peso e gravidez aparente. A Tabela 1 também aponta 206 casos de obesidade (23\%) e 49 pessoas idosas (5,5\%). Os idosos são considerados os pedestres que foram classificados com faixa etária acima de 65 anos. A velocidade média dos pedestres obesos é mais baixa quando comparada à velocidade média de todo grupo estudado (1,20 x 1,28 m/s). As velocidades do grupo obeso que representam o percentil 85 e 15, são respectivamente, 1,46 m/s e 0,93 m/s. Dessa maneira, considerando $1,22 \mathrm{~m} / \mathrm{s}$ como a velocidade adotada para cálculo de programação semafórica, estimase que mais de $50 \%$ dos obesos estão caminhando em uma velocidade abaixo do valor estipulado para uma travessia, uma vez que a velocidade no percentil 50 do grupo obeso foi de $1,17 \mathrm{~m} / \mathrm{s}$.

No caso da população idosa, as velocidades que representam o percentil 85 e o percentil 15 foram estimadas em 1,22 m/s e 0,82 m/s, respectivamente. Ou seja, considerando percentil 85 da amostra, apenas 15\% dos pedestres idosos terão velocidades acima desse valor, sendo justamente essa a velocidade normalmente instituída na programação semafórica. Ou seja, 85\% da população idosa da amostra estudada encontra-se em nítida situação de vulnerabilidade ao atravessar um via de trânsito por andarem mais lentamente que a velocidade adotada nos principais manuais de tráfego mundiais.

\begin{tabular}{|c|c|c|c|c|c|c|c|c|c|}
\hline \multicolumn{2}{|c|}{ Variável } & \multicolumn{2}{|c|}{$\mathbf{N}$} & \multirow{2}{*}{$\begin{array}{c}\mathbf{V}_{\text {média }} \\
(\mathrm{m} / \mathrm{s})\end{array}$} & \multirow{2}{*}{$\begin{array}{c}\begin{array}{c}\boldsymbol{\sigma} \\
(\mathrm{m} / \mathrm{s})\end{array} \\
0,27\end{array}$} & \multirow{2}{*}{$\begin{array}{c}\begin{array}{c}\mathbf{V}_{15} \\
(\mathrm{~m} / \mathrm{s})\end{array} \\
0,99\end{array}$} & \multirow{2}{*}{$\begin{array}{c}\begin{array}{c}\mathbf{V}_{85} \\
(\mathrm{~m} / \mathrm{s})\end{array} \\
1,53\end{array}$} & \multirow{2}{*}{$\begin{array}{c}\begin{array}{c}\mathbf{V}_{\min } \\
(\mathrm{m} / \mathrm{s})\end{array} \\
0,43\end{array}$} & \multirow{2}{*}{$\begin{array}{r}\mathbf{V}_{\text {max }} \\
(\mathrm{m} / \mathrm{s})\end{array}$} \\
\hline & Feminino & 496 & $(55 \%)$ & & & & & & \\
\hline sexo & Masculino & 406 & $(45 \%)$ & 1,31 & 0,25 & 1,07 & 1,55 & 0,52 & 2,37 \\
\hline
\end{tabular}




\begin{tabular}{llcllllll}
\hline & $<15$ & $\mathbf{1 3}(1,44 \%)$ & 1,28 & 0,28 & 1,07 & 1,48 & 0,89 & 1,98 \\
& $15-18$ & $\mathbf{2 4}(2,66 \%)$ & 1,31 & 0,19 & 1,08 & 1,51 & 0,99 & 1,65 \\
Idade & $18-30$ & $\mathbf{3 6 3}(40,24 \%)$ & 1,34 & 0,25 & 1,11 & 1,59 & 0,82 & 2,37 \\
& $30-45$ & $\mathbf{2 7 3}(30,27 \%)$ & 1,27 & 0,25 & 1,01 & 1,52 & 0,43 & 2,06 \\
& $45-65$ & $\mathbf{1 8 0}(19,96 \%)$ & 1,22 & 0,28 & 0,96 & 1,49 & 0,43 & 2,15 \\
& $>65$ & $\mathbf{4 9}(5,43 \%)$ & 1,07 & 0,23 & 0,82 & 1,22 & 0,47 & 1,84 \\
\hline \multirow{2}{*}{ Extensão da } & $\leq 10 \mathrm{~m}$ & $\mathbf{2 9 4}(32,59 \%)$ & 1,26 & 0,24 & 1,00 & 1,52 & 0,69 & 2,20 \\
travessia & $10-12 \mathrm{~m}$ & $\mathbf{4 7 6}(52,77 \%)$ & 1,30 & 0,28 & 1,06 & 1,55 & 0,43 & 2,37 \\
& $\geq 12 \mathrm{~m}$ & $\mathbf{1 3 2}(14,64 \%)$ & 1,22 & 0,25 & 0,95 & 1,48 & 0,75 & 1,89 \\
\hline Mobilidade & Sim & $\mathbf{2 7}(3 \%)$ & 0,93 & 0,32 & 0,65 & 1,22 & 0,43 & 1,82 \\
reduzida & Não & $\mathbf{8 7 5}(97 \%)$ & 1,29 & 0,25 & 1,04 & 1,54 & 0,43 & 2,37 \\
\hline \multirow{2}{*}{ Semáforo } & Sim & $\mathbf{6 6 1}(73,28 \%)$ & 1,28 & 0,26 & 1,04 & 1,53 & 0,43 & 2,37 \\
& Não & $\mathbf{2 4 1}(26,72 \%)$ & 1,26 & 0,26 & 0,99 & 1,56 & 0,69 & 2,20 \\
\hline \multirow{2}{*}{ Obesidade } & Sim & $\mathbf{2 0 6}(22,84 \%)$ & 1,20 & 0,28 & 0,93 & 1,46 & 0,43 & 2,03 \\
& Não & $\mathbf{6 9 6}(77,16 \%)$ & 1,30 & 0,25 & 1,05 & 1,55 & 0,52 & 2,37 \\
\hline Carregamento & Sim & $\mathbf{1 4 1}(15,63 \%)$ & 1,24 & 0,26 & 1,00 & 1,51 & 0,47 & 2,37 \\
de peso & Não & $\mathbf{7 6 1}(84,37 \%)$ & 1,28 & 0,26 & 1,02 & 1,55 & 0,43 & 2,22 \\
\hline Gravidez & & $\mathbf{4}(0,44 \%)$ & 1,15 & 0,19 & 0,99 & 1,29 & 0,90 & 1,29 \\
\hline Fatores & Sim & $\mathbf{1 0 3 ( 1 1 , 4 2 \% )}$ & 0,99 & 0,16 & 0,85 & 1,18 & 0,52 & 1,55 \\
redutivos & Não & $\mathbf{7 9 9}(88,58 \%)$ & 1,31 & 0,25 & 1,08 & 1,56 & 0,43 & 2,37 \\
\hline Fatores & Sim & $\mathbf{9 3 ( 1 0 , 3 1 \% )}$ & 1,49 & 0,31 & 1,14 & 1,80 & 0,87 & 2,37 \\
aditivos & Não & $\mathbf{8 0 9}(89,69 \%)$ & 1,25 & 0,25 & 1,00 & 1,50 & 0,43 & 2,22 \\
\hline & Total & $\mathbf{9 0 2}(100 \%)$ & $\mathbf{1 , 2 8}$ & $\mathbf{0 , 2 6}$ & $\mathbf{1 , 0 1}$ & $\mathbf{1 , 5 4}$ & $\mathbf{0 , 4 3}$ & $\mathbf{2 , 3 7}$ \\
\hline
\end{tabular}

Tabela 1: Velocidades de pedestres de acordo com as variáveis adotadas

FONTE: (GUALBERTO e BARBOSA, 2016)

A obesidade é um fator pessoal relevante na velocidade de travessia das pessoas. Muitos pedestres com sobrepeso possuem mais dificuldade em realizar uma travessia, especialmente se estes são "pressionados" a desenvolver velocidades maiores para completar o percurso em segurança. No Brasil, de acordo com o IBGE (2015), com base nos dados publicados em Agosto de 2015, o total de obesos corresponde a 20,8\% da população. A Figura 2 apresenta os valores observados em relação à obesidade dos pedestres que realizavam a travessia dos locais selecionados.
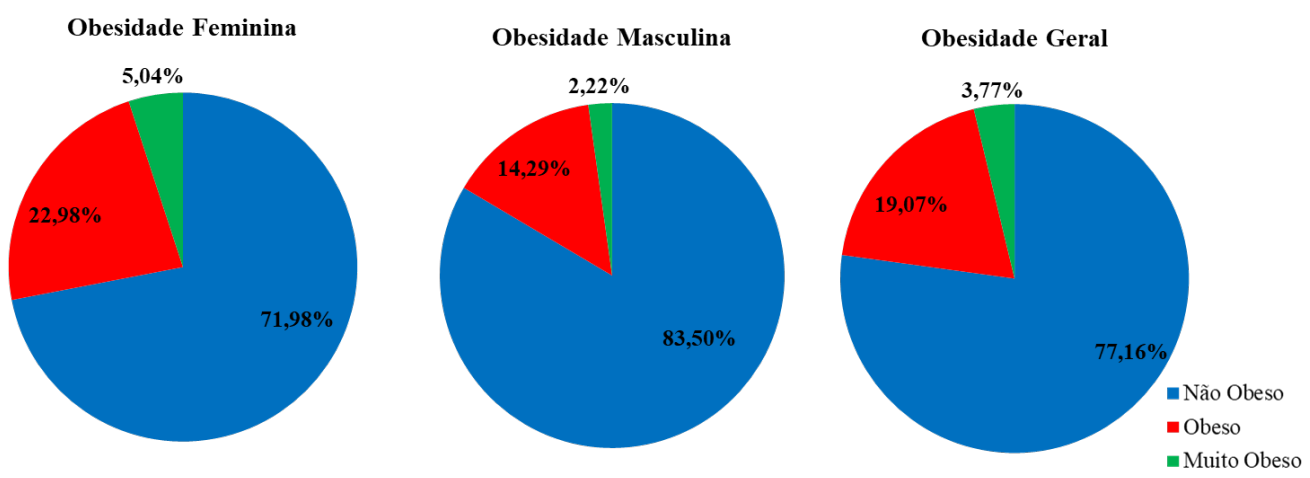

Figura 2 - Obesidade dos pedestres na amostra 
Comparando-se os dados da Figura 2 com a Tabela 2, que resume os dados coletados por este órgão, verifica-se que a amostra resultante se aproxima bastante dos dados fornecidos pelo IBGE. Os dados apresentados na Figura 2 deste trabalho apontam que $23 \%$ da amostra possui obesidade ou muita obesidade, e os dados do IBGE apontam para a população brasileira um valor de 20,8\%. Para os valores femininos e masculinos, a observação indica $28 \%$ e 16,5\% respectivamente, resultados similares aos mensurados pelo IBGE, de $24,4 \%$ e 16,8\%. Essa análise indica que a amostra desta pesquisa segue a tendência dos padrões da população brasileira. Considerando a classificação dos indivíduos da amostra em função da variável obesidade, verifica-se que a velocidade praticada por obesos tende a ser menor, de acordo com os valores médios expostos na Tabela 1.

\begin{tabular}{cccc}
\hline Grupos de Idade & Obesidade Total & Obesidade Masculina & Obesidade Feminina \\
\hline Total & $\mathbf{2 0 , 8} \%$ & $\mathbf{1 6 , 8} \%$ & $\mathbf{2 4 , 4 \%}$ \\
\hline $18-24$ & $10,3 \%$ & $8,6 \%$ & $12,0 \%$ \\
\hline $25-29$ & $15,5 \%$ & $13,6 \%$ & $17,5 \%$ \\
\hline $30-34$ & $18,4 \%$ & $16,7 \%$ & $20,0 \%$ \\
\hline $35-44$ & $23,5 \%$ & $18,8 \%$ & $27,6 \%$ \\
\hline $45-54$ & $25,3 \%$ & $20,2 \%$ & $29,9 \%$ \\
\hline $55-64$ & $28,0 \%$ & $23,0 \%$ & $32,2 \%$ \\
\hline $65-74$ & $24,2 \%$ & $18,9 \%$ & $28,5 \%$ \\
\hline$>74$ & $18,7 \%$ & $11,7 \%$ & $23,8 \%$ \\
\hline
\end{tabular}

Tabela 2 - Dados de obesidade da população brasileira fornecidos pelo IBGE

Fonte: IBGE, Diretoria de Pesquisas, Coordenação de Trabalho e Rendimento, Pesquisa Nacional de Saúde 2013.

Quanto maior a obesidade observada, menor a velocidade média medida. Isso indica, conforme mencionado anteriormente, que a obesidade leva a uma diminuição do ritmo de caminhada. Entre as pessoas consideradas obesas e muito obesas (206 pessoas $=23 \%$, a velocidade média de caminhada está abaixo do padrão $(1,22 \mathrm{~m} / \mathrm{s})$ estabelecido pelos manuais de tráfego no mundo (MUTCD, 2003; ITE, 2013).

A obesidade também é um fator que pode ser associado às faixas de idade dos pedestres observados. Na Tabela 4, pode-se notar que em todas as faixas etárias, os obesos e muito obesos andam mais devagar do que os considerados não obesos.

\begin{tabular}{lrr}
\hline Descrição & \multicolumn{1}{l}{ Percentual } & Velocidade média $(\mathbf{m} / \mathbf{s})$ \\
\hline Não obeso & & $\mathbf{1 , 3 0}$ \\
\hline$<15$ & $1,87 \%$ & 1,28 \\
\hline $15-18$ & $3,16 \%$ & 1,32 \\
\hline $18-30$ & $43,68 \%$ & 1,36 \\
\hline $30-45$ & $28,30 \%$ & 1,28 \\
\hline $45-65$ & $17,82 \%$ & 1,23 \\
\hline$>65$ & $5,17 \%$ & 1,11 \\
\hline
\end{tabular}




\begin{tabular}{lrl}
\hline Obeso & & $\mathbf{1 , 2 1}$ \\
\hline $15-18$ & $1,16 \%$ & 1,23 \\
\hline $18-30$ & $30,23 \%$ & 1,24 \\
\hline $30-45$ & $38,37 \%$ & 1,24 \\
\hline $45-65$ & $24,42 \%$ & 1,18 \\
\hline$>65$ & $5,81 \%$ & 0,94 \\
\hline Muito obeso & & $\mathbf{1 , 1 5}$ \\
\hline $18-30$ & $20,59 \%$ & 1,10 \\
\hline $30-45$ & $29,41 \%$ & 1,19 \\
\hline $45-65$ & $41,18 \%$ & 1,20 \\
\hline$>65$ & $8,82 \%$ & 0,95 \\
\hline Total Geral & & $\mathbf{1 , 2 8}$ \\
\hline
\end{tabular}

Tabela 3 - Veloc. médias e percentual de pedestres não obesos, obesos e muito obesos por faixa etária

A partir do exposto, nota-se que os idosos da amostra, percentualmente, têm uma maior propensão à obesidade e ao mesmo tempo são os mais afetados quando se compara a velocidade média dos idosos não obesos com os idosos obesos. Enquanto um idoso não obeso anda a 1,11 m/s, aqueles obesos andam a 0,94 m/s, ou seja, uma diferença de 0,17 m/s. Por outro lado, para os adultos (30-45 anos), essa mesma diferença é de $0,10 \mathrm{~m} / \mathrm{s}$. Isso significa que, de maneira geral, o aumento do peso nos idosos tem uma influência maior do que nos adultos. A obesidade, como indicado previamente, tem maior incidência sob a população feminina. Em todas as faixas etárias da amostra, as mulheres estão com percentuais de obesidade superiores aos dos homens. Isso aumenta a vulnerabilidade das mesmas, uma vez que esse trabalho infere que a obesidade é um fator de risco nas travessias de vias urbanas.

\section{I UTILIZAÇÃO DO MODELO DE PREVISÃO DE VELOCIDADES}

Com base no modelo de previsão de velocidades criado por Gualberto (2016) é possível predizer a velocidade média de caminhada dos pedestres, de acordo com os dados de entrada de suas características. Para esse artigo foi criado um cenário atual com base nos dados populacionais observados pelo IBGE (2015) e Ministério da Saúde (2016). Esses órgãos apontaram a porcentagem de cidadãos por faixa etária e a proporção de obesos no contexto experimental. As demais características (dos pedestres e da via) foram escolhidas a partir da ocorrência das mesmas na coleta de dados apresentada na Tabela 1. Essas características foram mantidas nas projeções futuras, evitando-se inserir variáveis diferentes na comparação.

Utilizando-se dos dados do IBGE (2015) e da pesquisa do Ministério da Saúde (2016), realizada pela VIGITEL, foi-se projetado cenários populacionais futuros para os anos de 2022 e 2030. A escolha de 5 anos para o primeiro cenário foi determinada pelos autores, visando uma atuação mais prática e recente de planejamento urbano. O ano de 2030 foi escolhido com base nas informações do IBGE, que garante um grau 
de confiança alto em suas projeções até esse ano (>90\%). Com essas informações, foi possível realizar uma comparação das velocidades de travessia de pedestres entre o cenário atual e esses cenários futuros. Os dados dessa comparação são apresentados na Tabela 5.

\begin{tabular}{|c|c|c|c|}
\hline \begin{tabular}{|lll} 
Variável Ano & Ano \\
\end{tabular} & 2017 & 2022 & 2030 \\
\hline Idade & $\begin{array}{l}<15=8,5 \% \\
15-18=13 \% \\
18-30=23,5 \% \\
30-45=26 \% \\
45-65=21 \% \\
>65 \quad=8 \%\end{array}$ & $\begin{array}{l}<15=7 \% \\
15-18=13 \% \\
18-30=22 \% \\
30-45=27 \% \\
45-65=21 \% \\
>65 \quad=10 \%\end{array}$ & $\begin{array}{l}<15=5 \% \\
15-18=13 \% \\
18-30=22 \% \\
30-45=26 \% \\
45-65=20 \% \\
>65 \quad=14 \%\end{array}$ \\
\hline Obesidade & $19 \%$ & $23 \%$ & $26 \%$ \\
\hline Velocidade Média & $\begin{array}{l}1,3226 \mathrm{~m} / \mathrm{s} \\
4,76 \mathrm{~km} / \mathrm{h}\end{array}$ & $\begin{array}{l}1,3157 \mathrm{~m} / \mathrm{s} \\
4,74 \mathrm{~km} / \mathrm{h}\end{array}$ & $\begin{array}{l}1,3053 \mathrm{~m} / \mathrm{s} \\
4,70 \mathrm{~km} / \mathrm{h}\end{array}$ \\
\hline
\end{tabular}

Tabela 4: Velocidades preditas de pedestres nos cenários criados

Os dados para gravidez, deficiência, travessia em grupo, carregamento de peso e sexo foram mantidos inalterados nos três cenários. A extensão da travessia foi de 8 metros, por ser considerada uma largura média entre os tipos possíveis. Além disso, a travessia possui semáforo em todas as situações. Preservando-se as características dos locais analisados, foi possível ter uma ideia correta da influência somente do aumento da obesidade e do envelhecimento da população sobre a velocidade média dos pedestres.

Os resultados indicam uma pequena variação na velocidade. De 2017 para 2022 haveria uma redução de $0,01 \mathrm{~m} / \mathrm{s}(0,02 \mathrm{~km} / \mathrm{h})$ e de 2017 para 2030, redução de $0,02 \mathrm{~m} / \mathrm{s}(0,06 \mathrm{~km} / \mathrm{h})$. Apesar de aparentemente a redução de velocidade global ser considerada pequena, análises mais aprofundadas podem sugerir que determinados grupos etários sejam mais afetados pelo aumento da obesidade, conforme já mencionado anteriormente nesse trabalho.

\section{I CONCLUSÕES}

O artigo teve como principal objetivo ponderar e compreender as características dos pedestres em travessias de vias urbanas. Os idosos e obesos foram destacados em uma análise particular perante aos demais pedestres. A revisão bibliográfica contou com diversos artigos da área de saúde, demonstrando a grande influência e relação do setor médico com a engenharia de tráfego. Um dos tratamentos para a obesidade é a caminhada. Caso os ambientes urbanos não sejam adequados para as pessoas com sobrepeso e obesas se locomoverem, eles estarão sujeitos a um ciclo que pode levar à morbidez como estilo de vida. As análises dos dados indicaram uma velocidade média da amostra de $1,28 \mathrm{~m} / \mathrm{s}$ e uma distribuição normal dos dados. No entanto, a velocidade média de 1,07 m/s e 1,20 m/s obtidos para pedestres idosos e obesos, respectivamente, são menores, até mesmo, que o valor da velocidade de 1,22 m/s, 
usada como uma base para a temporização do sinal de tráfego em muitas cidades de todo o mundo.

Com os dados de velocidade de pedestres, foi possível utilizar um modelo de previsão de velocidades para criar três cenários (2017/2022/2030) com o envelhecimento estimado da população (IBGE), bem como o aumento projetado do número de obesos (Ministério da Saúde). As velocidades preditas foram comparadas, indicando pequena variação (0,01 m/s de 2017 para 2022 e 0,02 m/s de 2017 para 2030). Essa pequena variação pode se tornar um grande problema de tráfego ao se inserir esses valores nas bases de programação semafórica.

As limitações encontradas durante o desenvolvimento do estudo foram, conforme apontado na metodologia, a observação realizada de maneira apenas visual, acarretando uma limitação de dados, sendo considerada obesa a pessoa que possuía visível sobrepeso e muito obesa aquela que claramente estava obesa. A OMS, como indicado na revisão bibliográfica, classifica as pessoas em sobrepeso e obesas, de acordo com o IMC (Índice de massa corporal). Nesse mesmo sentido, a análise da idade dos pedestres também era feita exclusivamente de maneira visual, podendo conter alguns dados não correspondentes com a realidade. Essas limitações indicam um caminho a seguir para o desenvolvimento de trabalhos futuros. Podemse realizar entrevistas em conjunto com a coleta de dados de velocidade, permitindo maior credibilidade às informações de IMC e de idade. Os dados médicos, tais como a incidência de sarcopenia na população, também podem ser utilizados para aumentar os parâmetros de criação de cenários de previsão de velocidade. Outro fator a ser considerado em trabalhos futuros é a programação semafórica, que pode ser modificada e afetada por cenários onde a proporção de idosos e obesos é maior que o padrão/proporção considerado atualmente. Os cenários criados, em conjunto com dados de classificação da população de determinados locais ou travessias, servem de subsídio para estipulação de programações semafóricas mais adequadas à circulação de idosos e obesos, dependendo da proporção destes no local analisado, garantindo maior conforto e segurança para todas as pessoas que realizam travessias urbanas.

\section{AGRADECIMENTOS}

Os autores agradecem ao Conselho Nacional de Desenvolv. Científico e Tecnológico - CNPq e à Fundação de Amparo à Pesquisa de Minas Gerais - FAPEMIG pela concessão de auxílio para realização dessa pesquisa.

\section{REFERÊNCIAS BIBLIOGRÁFICAS}

Alves LS, Rodrigues RN (2005). Determinantes da autopercepção de saúde entre idosos do município de São Paulo, Brasil. Rev Panam Salud Publica; 17(5-6):333-341.

Asher, L. et al (2012). Most older pedestrians are unable to cross the road in time: A cross- 
sectional study. Age and Ageing, v. 41, n. 5, p. 690-694.

AUSTROADS (1995). Guide to Traffic Engineering Practice. Part 13 - Pedest. Sidney: Standards Australia.

Bohannon RW, Andrews AW, Thomas MW (1996). Walking speed: reference values and correlates for older adults. J Orthop Sports Phys Ther. 24(2):86-90.

Brasil (1997) Lei ${ }^{\circ} 9.503$ de 23 de setembro de 1997. Institui o Código de Trânsito Brasileiro (CTB). Diário Oficial da República Federativa do Brasil, Brasília, DF, 24 de setembro de 1997, p. 21201.

Brasil (2010). Instituto Brasileiro de Geografia e Estatística (IBGE). Censo demográfico 2010: população estimada 2015. Disponível em: <http://cidades.ibge.gov.br/xtras/perfil. php?lang $=\&$ codmun $=310620>$.

Carneiro J. A., Silva, M.S., \& Vieira, M. F (2009). Efeitos do Método Pilates e do Treinamento com pesos na cinemática da marcha de mulheres obesas. Brazilian Journal of Biomechanics, 18, 3343.

Cruz-Jentoft AJ, Landi F, Topinková E, Michel JP (2010). Understanding sarcopenia as a geriatric syndrome. Curr Opin Clin Metab Care; 13(1):1-7.

Dalton et al. (2003). Waist circumference, waist-rip ratio and body mass index and their correlation with cardiovascular disease risk factors in Australian adults. Journal of Internal Medicine, 254, 555-563.

Elble RJ, et al. (1991). Stride-dependent changes in gait of older people. J Neurol. 238(1):1-5.

Faintuch, S, A., et al. (2005). Gait Cinematic Analysis in Morbidly Obese Patients. Obesity Surg, $15,1238-1242$.

FHWA (2003) Manual on Uniform Traffic Control Devices for Streets and Highways. Federal Highway. Edição 2003. Washington: Federal Highway Administration.

Fried LP, Tangen CM, Walston J, Newman AB, Hirsch C, Gottdiener J, Seeman T, Tracy R, Kop WJ, Burke G, McBurnie MA (2001). Frailty in older adults: Evidence for Phenotype. J Gerontol; 56(3):164-156

Gualberto, F.; Barbosa, H. M.; Amorin, J. A.; Thebit, M (2013) Velocidade de pedestres em área hospitalar - um estudo exploratório. Anais do XXVII Congresso de Pesq. e Ensino em Transp., ANPET, Belém; v.1 p. 12.

Gualberto, $F$ (2016). Estudo dos fatores que influenciam o comportamento de pedestres em travessias de vias urbanas. 2016. 162 f. Dissertação (Mest. em Eng. de Transportes) - Esc. de Eng, UFMG, Belo Horizonte.

Gualberto, F.; Barbosa, H. M. (2016) Estudo dos fatores que influenciam o comportamento de pedestres em travessias de vias urbanas. Anais do XXX Cong. de Pesq. e Ens. em Transp., ANPET, R. de Jan; v.1 p. 12.

Hardy SE, Perera S, Roumani YF, Chandler JM, Studenski SA (2007). Improvement in usual gait speed predicts better survival in older adults. J Am Geriatr Soc. 55(11):1727-34.

Hollman $\mathrm{JH}$, et al. (2008). Minimum detectable change in gait velocity during acute rehabilitation following hip fracture. J Geriatr Phys Ther. 31(2):53-6.

INSTITUTO BRASILEIRO DE GEOGRAFIA E ESTATISTICA (2015). Pesq. Nac. De Saúde 2013: 
Ciclos De Vida. Brasil e grandes regiões / IBGE, Coord. de Trabalho e Rend. - Rio de Janeiro : IBGE, 2015. 92 p.

International Association for the Study of Obesity - IASO (2012); About Obesity. Disponivel em: http:// www.worldobesity.org/data/

Knoblauch, R. L.; M. T. Pietrucha e M. Nitzburg (1996) Field Studies of Pedestrian Walking Speed and Start-Up Time. Transportation Research Record: Journal of the Transportation Research Board, n.1538, p. 27-38.

Lauretani R, Jorge MHPM, Gotlieb SLD (2005). Perfil epidemiológico da morbi-mortalidade masculina. Cien Saude Colet; 10(1):35-46.

Lee, J. Y. S.; Lam, W. H. K (2008). Simulating pedestrian movements at signalized crosswalks in Hong Kong. Transportation Research Part A: Policy and Practice, v. 42, n. 10, p. 1314-1325.

Marisamynathan; Perumal, V (2014) Study on pedestrian crossing behavior at signalized intersections. Journal of Traffic and Transportation Engineering (English Edition), v. 1, n. 2, p. 103110.

Ministério da Saúde (2016). Vigitel Brasil 2016. Saúde Suplementar: vigilância de fatores de risco e proteção para doenças crônicas por inquérito telefônico. Brasília, 2016.

Murray MP, Kory RC, Clarkson BH (1969). Walking patterns in healthy old men. J Gerontol. 24(2):169-78.

Novaes, RD, Miranda, AS, Dourado, VZ (2011). Velocidade usual da marcha em brasileiros de meia idade e idosos. Rev Bras Fisioter; 15(2):117-22.

Oberg T, Karsznia A, Oberg K (1993). Basic gait parameters: reference data for normal subjects,10-79 years of age. J Rehabil Res Dev. 30(2):210-23.

Papadimitriou, E.; Yannis, G.; Golias, J (2009) A critical assessment of pedestrian behaviour models. Transportation Research Part F: Traffic Psychology and Behaviour, v. 12, n. 3, p. 242-255.

Ryall JG, Schertzer JD, Lynch GS (2008). Cellular and molecular mechanisms underlying agerelated skeletal muscle wasting and weakness. Biogerontology; 9(4):213-228.

Silva, A. M. C. B.; Da Cunha, J. R. R.; Da Silva, J. P. C (2014) Estimation of pedestrian walking speeds on footways. Proceedings of the Institution of Civil Engineers. Municipal engineer, v. 167, n. 1, p. 32-43.

TRB (2000) Highway Capacity Manual - Transportation Research Board. National Research Council. Washington, D.C: The National Academies.

WHO (2013) World Healthy Organization. Pedestrian safety: a road safety manual for decisionmakers and practitioners. Genebra, Suíça: World Health Organization.

Yang Y, George, LK (2005). Functional disability, disability transitions, and depressive symptoms in late life. Aging Health; 17(3):263-292.

Veras R (2009). Envelhecimento populacional contemporâneo: demandas, desafios e inovações. Rev Saude Publica; 43(3):548-554. 


\section{CAPÍTULO 11}

\section{DESASTRES NATURAIS: SELEÇÃO E LOCALIZAÇÃO ESPACIAL DE ABRIGOS PARA FLAGELADOS}

Manuela Marques Lalane Nappi

Universidade Federal de Santa Catarina, Programa de Pós-Graduação em Arquitetura e Urbanismo - PósARQ

Florianópolis - Santa Catarina

João Carlos Souza

Universidade Federal de Santa Catarina,

Programa de Pós-Graduação em Arquitetura e Urbanismo - PósARQ

Florianópolis - Santa Catarina

RESUMO: A ocorrência de desastres naturais ou antrópicos vem evidenciando um tratamento logístico especial, designado de logística humanitária. Sabe-se que existem grandes desafios na implementação de processos logísticos sistematizados, especialmente aqueles relacionados à infraestrutura e localização de centrais de assistência humanitária e coordenação de processos, incluindo-se os abrigos temporários. Tem-se como objetivo deste trabalho a divulgação do desenvolvimento de um modelo multicritério de decisão, com foco nos princípios da logística humanitária, para a seleção e localização espacial de abrigos temporários comunitários ou coletivos - o ShelterPro. Trata-se de um software de plataforma intuitiva, ou seja, uma ferramenta de fácil compreensão e usabilidade. Acredita-se que essa ferramenta possa ser útil no nível estratégico ou operacional das decisões logísticas.

PALAVRAS-CHAVE: Arquitetura. Desastres Naturais. Abrigos Temporários. Modelo Multicritério de Decisão.

ABSTRACT: The occurrence of either natural or man-made disasters is demanding a special logistical treatment, known as humanitarian logistics. There are major challenges in the implementation of systematized logistics processes, especially those related to the infrastructure and location of humanitarian assistance centers and process coordination, including temporary shelters. The objective of this work is the dissemination of a multicriteria decision model, focusing on the principles of humanitarian logistics, developed for the selection and spatial location of community or collective temporary shelters - entitled ShelterPro. This is an intuitive software, i.e., a tool that is easy to understand and use. It is verified that this tool can be useful at the strategic or operational level of logistical decisions.

KEYWORDS: Architecture. Natural disasters. Temporary Shelters. Multi-criteria Decision Model. 


\section{I INTRODUÇÃO}

A comunidade internacional reconhece que a magnitude, o número de pessoas afetadas, bem como a recorrência de desastres naturais, ou não, vem aumentando (Nappi \& Souza, 2015). Imediatamente após a ocorrência de um desastre, a prioridade se concentra na localização de vítimas, prestação de cuidados médicos para as pessoas lesionadas, fornecimento de água, comida e abrigo aos sobreviventes. Para Fernandes (2010) a ocorrência de desastres tem evidenciado um tratamento logístico especial, que vem sendo designado como logística humanitária. Segundo Apte (2009) foi após o tsunami no Oceano Índico, em 2004, que aumentaram os esforços humanitários, chamando atenção para a logística humanitária e despertando o interesse de acadêmicos e profissionais. Pesquisas nesta área avaliam que o uso de conceitos logísticos contribui significativamente para o sucesso de uma operação. Nesse sentido são apontados grandes desafios na implementação de processos logísticos sistematizados, destacando-se os aspectos relacionados à infraestrutura, localização de centrais de assistência e coordenação de processos (Fernandes, 2010).

A logística humanitária é considerada um ramo especial da logística com desafios específicos, como incertezas de demanda, tempo crítico e vulnerabilidade de infraestrutura (Nogueira et al., 2008). A cadeia da logística humanitária pode ser considerada como uma cadeia de suprimentos que abrange todo o ciclo de vida de um desastre. O ciclo completo da gestão de desastres inclui quatro etapas - preparar, responder, recuperar e mitigar (Thomas, 2007). Elevados níveis de incerteza quanto ao momento e local do próximo desastre requerem o pré-posicionamento. Planejar a pré-disposição de bens e suprimentos, onde se incluem os abrigos temporários, bem como a evacuação da população afetada, é tarefa fundamental.

O foco deste trabalho está voltado para os abrigos temporários, especificamente os abrigos comunitários ou coletivos (abrigos provisórios em espaços internos), para os quais são utilizadas infraestruturas existentes como escolas, ginásios poliesportivos, recintos onde são realizadas feiras, etc. A essas instalações podem ser-Ihes atribuídos os recursos necessários para que sejam transformadas em abrigos temporários. Para tanto, fez-se necessário a realização de um estudo sobre a possibilidade de escolher lugares apropriados, objetivo prévio e necessário para o desenvolvimento do software apresentado neste trabalho.

Segundo Nappi \& Souza (2014), pode-se dizer que são muitos os desafios enfrentados no desenvolvimento de métodos de gestão e na seleção de indicadores de desempenho para abrigos temporários. Acredita-se, no entanto, que a complexidade da logística humanitária pode ser amenizada com o auxílio de pesquisas voltadas ao entendimento dos desafios desse campo. Sendo uma dessas complexidades a seleção e localização de instalações que promovam a resposta humanitária, bem como o estabelecimento de critérios que permitam a avaliação do seu desempenho. Para tanto, os autores desenvolveram um sistema de medidas de desempenho para abrigos 
temporários que resultou num modelo para seleção e localização desses abrigos a partir de uma metodologia multicritério (Nappi, 2016). Esse modelo, denominado ShelterPro, buscou servir de base para o aprimoramento de operações e coordenação de processos em uma situação de emergência, tendo-se como objetivo deste trabalho demonstrar a sua aplicabilidade.

O desenvolvimento da ferramenta multicritério de apoio à decisão para seleção e localização de abrigos temporários foi possível a partir da mensuração das necessidades de usuários e gestores. Essas necessidades foram levantadas na literatura e junto a especialistas da área, identificando-se elementos primários de avaliação de abrigos temporários. Acredita-se que a utilização do ShelterPro permitirá a avaliação prévia do desempenho das edificações adotadas como abrigos temporários, bem como a criação de bases de dados para consulta e tomada de decisão em situações emergenciais. Além disso, os relatórios gerados a partir do software apontam a necessidade de promoverem-se adaptações, melhoramentos ou seleção de novos equipamentos para melhorar o desempenho de abrigos temporários em função de diferentes cenários que possam se apresentar.

\section{I GESTÃO DE DESASTRES}

Considera-se como desastre natural um fenômeno natural que provoca, direta ou indiretamente, danos extensos à propriedade e/ou faz um grande número de vítimas. De acordo com a Instrução Normativa n. 1, de 24 de agosto de 2012, do Ministério da Integração Nacional, que estabelece os critérios para a decretação de situação de emergência ou estado de calamidade pública em municípios e estados, desastre é:

\footnotetext{
[...] resultado de eventos adversos, naturais ou provocados pelo homem sobre um cenário vulnerável, causando grave perturbação ao funcionamento de uma comunidade ou sociedade envolvendo extensivas perdas e danos humanos, materiais, econômicos ou ambientais, que excede a sua capacidade de lidar com o problema usando meios próprios (BRASIL, 2012, p. 1).
}

Cardona et al. (2003) consideram que um desastre é uma situação ou um processo social desencadeado após a manifestação de um fenômeno de origem natural, tecnológica ou provocada pelo homem que, ao encontrar condições de vulnerabilidade em uma população, causa significativas alterações nas suas condições normais. Essas alterações podem representar perda de vida e saúde, destruição ou perdas de bens da coletividade e prejuízos ambientais, razões pelas quais os desastres requerem respostas imediatas das autoridades e da população para atender aos afetados e reestabelecer a normalidade e o seu bem-estar. Para Kunz, Reiner e Gold (2014), a preparação para desastres tem sido reconhecida como um elemento central na redução do impacto de desastres no mundo.

Com base em ampla literatura (Kovács e Spens 2007; Kovács e Tatham, 2009; Vitoriano et al., 2011; Gralla, Goentzel e Fine, 2014; Chandes e Paché, 2010; etc.), 
pode-se afirmar que a implementação de processos de preparação para desastres tem sido cada vez mais abordada com a finalidade de acelerar a assistência de socorro e aumentar a sua eficácia, reduzindo o impacto dos desastres. Esta fase preventiva de gestão de desastres, segundo Wassenhove (2006), pode ser definida como o conjunto de atividades a serem realizadas pela população, governo e organizações de ajuda antes de um desastre, tendo como objetivo a redução de seus potenciais efeitos de devastação.

Segundo a Política Nacional de Defesa Civil (Brasil, 2007) as ações que visam a redução de desastres compreendem quatro fases ou aspectos globais: a prevenção de desastres, a preparação para emergência e desastres, a resposta aos desastres e a reconstrução. Conforme Oliveira (2009):

a) a primeira fase é a prevenção. Esta fase engloba o conjunto de ações cujo objetivo é evitar que o desastre se concretize ou diminuir a intensidade de suas consequências;

b) a segunda fase é representada pela preparação. Ela reúne o conjunto de ações que visam aprimorar a capacidade da comunidade diante de um desastre (incluindo indivíduos, organizações governamentais e não governamentais);

c) a fase de resposta diz respeito ao conjunto de ações que tem como objetivo socorrer e auxiliar a população atingida, reduzindo danos e prejuízos e garantindo o funcionamento de sistemas essenciais da comunidade;

d) a última fase é a reconstrução. Ela abrange o conjunto de ações destinadas à reconstrução de uma comunidade atingida, propiciando a retomada da condição de normalidade e procurando minimizar novos desastres.

Fernandes (2010) destaca a importância de orientar e preparar a população, a fim de que ela saiba o que fazer e como fazer diante de uma emergência. Desta forma, as ações que tenham sido implementadas poderão encontrar respaldo na comunidade, chegando-se a uma resposta eficiente.

\section{I LOGÍSTICA HUMANITÁRIA}

Apte (2009) define logística humanitária como um ramo especial da logística que gerencia a cadeia de abastecimento de suprimentos críticos e serviços. Esse ramo apresenta desafios específicos, como os picos de demanda, a incerteza dos suprimentos, janelas de tempo crítico em face à vulnerabilidade de infraestruturas e o grande alcance e dimensão das operações.

Segundo Thomas (2007, p. 3 e 7, tradução nossa):

a Logística humanitária se refere aos processos e sistemas envolvidos na mobilização de pessoas, recursos e conhecimento para ajudar pessoas vulneráveis, afetadas por desastres naturais e emergências complexas. Ela engloba uma série de atividades, incluindo a aquisição, o transporte, a localização e acompanhamento, o desembaraço aduaneiro, o transporte local, a armazenagem e a entrega da última milha. [...] Os profissionais da logística devem obter os produtos certos, no 
Fernandes (2010) cita que o principal objetivo da logística é vencer o tempo e a distância na movimentação de bens e na prestação de serviços de forma eficiente e eficaz. Segundo a autora, o setor de serviços e até mesmo a indústria têm implementado este conceito que pode constituir um diferencial competitivo na medida em que faz a entrega do produto certo, no local certo, na quantidade certa, no momento desejado e a um custo adequado. Na revisão de literatura realizada por Overstreet, et al. (2011), os autores chegaram à conclusão de que as maiores incógnitas no campo de logística humanitária são a hora, o local e a gravidade de um desastre. Dentre os fatores que mais influenciam a eficiência e eficácia da resposta logística, destacam-se a quantidade, o tipo e a usabilidade de infraestrutura e equipamentos, sendo que a maior parte da literatura sobre logística humanitária está focada na fase de preparação ou planejamento.

Embora os canais de assistência constituam um dos canais mais dinâmicos e complexos, Fernandes (2010) afirma que pouca atenção Ihe é conferida por pesquisas ou organizações governamentais. A autora atenta para o fato da importância que é dada à fase de resposta a um evento em detrimento das demais fases que compõe o ciclo do desastre. Cita-se como exemplo o Tsunami do Oceano Índico ocorrido em 2004, quando numerosos aviões de suprimentos precisaram ser desviados em função da obstrução de aeroportos, atrasando a distribuição dos suprimentos e forçando agências de assistência a localizarem depósitos, além de terem de acomodar pessoas em abrigos. A observação desse comportamento leva à conclusão de que a complexidade logística só é compreendida após a ocorrência de um desastre de grande magnitude.

Ainda que existam diversas interpretações do que é ou poderia ser considerado como uma ação humanitária, há quatro princípios amplamente aceitos - humanidade, neutralidade, imparcialidade e independência - que devem estar presentes para constituir uma operação humanitária. Estes princípios foram desenvolvidos por Henry Dunant após a batalha de Solferino (1859), inicialmente para proteger os direitos dos soldados. Em 1864 eles passaram a integrar a Convenção de Genebra e, em 1875 foram a semente do desenvolvimento da Cruz Vermelha:

a) humanidade implica que o sofrimento humano deve ser aliviado aonde for encontrado. É a razão pela qual as organizações humanitárias são implantadas. Um desafio constitui-se em identificar e acessar grupos carentes. Cita-se como exemplo a crise de alimentos de 2002, na África do Sul, quando as agências de ajuda humanitária demoraram a descobrir que havia grupos relativamente remotos do leste de Moçambique atingidos pela crise. As informações sobre eles não estavam disponíveis por serem de difícil acesso e manterem pouco contato com as autoridades nacionais (Tomasini e Wassenhove, 2009). O Conselho da União Europeia (2007) acrescenta, ainda com base no princípio da humanidade, que se deve dar particular atenção às 
camadas mais vulneráveis da população. Além disso, afirma que a dignidade de todas as vítimas precisa ser respeitada e protegida.

b) neutralidade implica que o alívio deve ser providenciado sem preconceito ou influência política, religiosa, etc. Manter a neutralidade pode ser a condição mais desafiante e cara para as agências de ajuda humanitária (Tomasini e Wassenhove, 2009). Segundo este princípio, a ajuda humanitária não deve beneficiar nenhuma parte, seja num conflito armado ou noutro litígio qualquer (Conselho da União Europeia, 2007).

c) imparcialidade implica que a assistência deve ser prestada sem discriminação e com prioridade para as necessidades mais urgentes. A imparcialidade nas operações pode ser avaliada com mais precisão em relação à não discriminação entre os grupos e à proporcionalidade em relação às suas necessidades (Tomasini e Wassenhove, 2009). O Conselho da União Europeia (2007) reforça que este princípio implica que a ajuda humanitária seja prestada somente com base na necessidade, sem discriminação entre as populações afetadas.

d) independência implica que deve haver autonomia dos objetivos humanitários em relação aos objetivos políticos, econômicos, militares, etc. Este princípio, segundo o Conselho da União Europeia (2007), tem como objetivo garantir que a finalidade única da ajuda humanitária seja o de amenizar e prevenir o sofrimento das pessoas atingidas por crises humanitárias.

Apte (2009) distingue as decisões logísticas em três níveis: estratégico, tático e operacional. As decisões tomadas no nível estratégico, como pesquisas e desenvolvimento de capacidades logísticas, abastecimento de suprimentos, determinação de políticas de distribuição e acumulação de infraestrutura, têm impacto de longa duração. No nível operacional o objetivo é obter o alívio rápido para a população afetada. Esta fase implica, por exemplo, a evacuação da população afetada por um desastre. Decisões táticas fazem a ponte entre os níveis estratégico e operacional. O objetivo primário deste nível é a gestão em tempo real da cadeia de abastecimento, como o estoque ideal, o roteamento, a distribuição e a programação da entrega de suprimentos, sabendo-se que tudo deve ser feito o mais rápido possível. Nesse sentido, ferramentas analíticas podem ser úteis na otimização em todos os níveis. Modelos a nível estratégico, por exemplo, podem auxiliar na alocação de recursos e na localização de instalações. No nível tático, podem auxiliar na gestão de inventário, distribuição e programação e no nível operacional, podem colaborar na evacuação, na redução do tempo e distribuição da "última milha". O problema de distribuição da última milha diz respeito ao estudo da distribuição da parte final da cadeia de abastecimento; refere-se à entrega de suprimentos nas áreas afetadas (locais de demanda), a partir de centros de distribuição locais e temporários. É importante ressaltar que os três princípios da logística humanitária - humanidade, neutralidade e imparcialidade devem estar presentes durantes as fases estratégicas, táticas e operacionais das ações humanitárias. A logística humanitária, portanto, se propõe a utilizar efetivamente 
os conceitos logísticos adaptando-os às peculiaridades da cadeia de assistência humanitária.

\subsection{O Planejamento de Abrigos Temporários}

O direito ao abrigo é implícito na Declaração Universal dos Direitos Humanos e em outros documentos elaborados por organizações multilaterais como a ONU, sendo que o acesso ao abrigo básico e contextualmente apropriado é uma necessidade humana essencial. Os padrões para este abrigo podem variar dependendo do contexto cultural, da situação, do clima e de outros fatores, pois até mesmo a forma física dos lugares representa uma linguagem espacial muito importante, podendo adquirir diversos significados na interpretação individual.

O abrigo pode ser definido como um lugar físico destinado a prestar asilo, amparo, alojamento e resguardo para pessoas diante da ameaça, iminência ou ocorrência de um fenômeno destrutivo. Para a constituição de abrigos comunitários ou coletivos (abrigos provisórios em espaços internos) utilizam-se infraestruturas existentes como escolas, ginásios poliesportivos, recintos onde são realizadas feiras, etc. A ação consiste em adequar essas instalações, dotando-as dos recursos necessários para que sejam transformadas em abrigos temporários e garantam melhores condições de vida para a população afetada. Faz-se necessário, para tanto, que se realize um estudo sobre as possibilidades de escolher lugares adequados em diferentes pontos (UNICEF, 2008).

Para Apte (2009), o planejamento de abrigos é uma questão crítica, sendo necessário identificar a sua localização e capacidade. Ela afirma, ainda, que é sabido no meio acadêmico que não há uma única metodologia, banco de dados ou software para solucionar a maioria dos problemas de logística humanitária. Conforme afirmam Nappi \& Souza (2015), a falta de critérios com respeito ao planejamento e implementação de abrigos temporários pode conduzir a fatores imprevisíveis, influenciando na qualidade de uma operação logística como um todo. Muitas vezes essa decisão é tomada após a ocorrência de um evento catastrófico, quando não há tempo suficiente para a reflexão sobre normas essenciais que devem reger a escolha e a constituição de abrigos temporários ou emergenciais (Omidvar, Baradaran-Shoraka e Nojavan, 2013). Kar e Hodgson (2008) afirmam que o foco dos estudos de evacuação realizados até o momento não tem despendido atenção à adequação dos locais de abrigo e/ou à identificação de possíveis instalações. Os autores afirmam, ainda, que tanto fatores físicos como sociais são importantes na adequação de um abrigo, mas nenhum estudo formal avaliou e especificou critérios para a sua constituição.

Conforme foi abordado neste item, para a concepção de um espaço - neste caso o espaço do abrigo - é necessário conviver com a necessidade de se pensar no desempenho de lugares. A identificação de aspectos frágeis ou o fortalecimento dos requisitos mínimos que devem ser atendidos no projeto de abrigos temporários, considerando-se as especificidades sociais e ambientais das populações afetadas, 
pode promover melhorias que minimizarão o sofrimento da população afetada e garantirão os provimentos mínimos vitais e sociais.

\subsection{Localização de Abrigos Temporários}

Conforme afirma Apte (2009) a logística humanitária é caótica por si só e extremamente complexa. Uma das complexidades, segundo a autora, é a localização de instalações para promover a resposta ou o alívio. Locais ideais de armazéns e centros de distribuição de suprimentos de emergência e serviços, além de uma localização ótima de centros de ajuda para a evacuação, são alguns dos desafios de qualquer ajuda humanitária ou instância de respostas a desastres. Há necessidade, portanto, de pesquisas em diversos aspectos desses assuntos vitais e os modelos existentes precisam ser melhorados e ampliados. Muitas vezes, a seleção de um sítio para abrigo temporário envolve apenas critérios básicos, como a propriedade da terra e a área por habitante. Critérios estes que não garantem a seleção de um sítio minimamente apropriado. Nesse sentido, podem-se citar outros critérios mais abrangentes como a identificação de informações culturais, econômicas, geográficas, políticas e sociais. A não apreciação desses aspectos pode gerar uma situação em que as pessoas não aceitem o sítio selecionado (Omidvar, Baradaran-Shoraka e Nojavan, 2013).

Para Saadatseresht, Mansourian e Aleai (2009) as trajetórias ótimas são determinadas pela eleição de rotas curtas, satisfazendo restrições de trânsito e segurança. Ao se referirem a trajetórias de veículos para distribuição de suprimentos, Campbell, Vandenbussche e Hermann (2008) afirmam que existem muitas ferramentas para solucionar problemas de trajetórias, sendo que a maioria delas está centrada na minimização da distância total percorrida, na perspectiva do custo total. Segundo os autores, depois de um desastre, o tempo de chegada de suprimentos de socorro nas comunidades afetadas influencia claramente a taxa de sobrevivência dos cidadãos e a minimização de seu sofrimento. Nas rotas criadas pela otimização baseada na distância total, algumas comunidades podem ser servidas muito mais tarde, a fim de minimizar os custos totais, contrariando princípios básicos da logística humanitária (Campbell, Vandenbussche e Hermann, 2008).

Vê-se, portanto, que no campo da gestão de desastres naturais é essencial considerar-se diferentes abordagens e objetivos. Por constituir uma importante tarefa, a tomada de decisão necessita do apoio de métodos sistemáticos de decisão, os quais devem ser alimentados com atributos que abranjam um leque variado de aspectos sociais, ambientais e econômicos. Ao abordarem problemas de decisão cujos objetivos requerem uma visão global e abrangente, os métodos multicritérios podem mostrar-se eficazes na gestão de desastres, já que incorporam fatores qualitativos e quantitativos. Por considerar-se que modelos multicritérios se adequam melhor ao contexto deste trabalho, na sequencia serão desenvolvidos aspectos desse modelo específico (Nappi 


\section{I MÉTODO DE PESQUISA}

Na gestão do risco de desastres naturais faz-se necessário considerar uma gama variada de assuntos como aqueles relacionados "a aspectos sociais, econômicos, ambientais, qualidade de vida, ao desenvolvimento sustentável e, principalmente, à preservação da vida" (Fernandes, 2010 p.69). Para a autora, os modelos multicritérios objetivam auxiliar na tomada de decisão, em especial nos problemas onde não há uma solução ótima, cabendo ao decisor selecionar ou classificar uma e / ou diversas alternativas. Dentre as possíveis perspectivas de análise por múltiplos critérios, está a identificação dos atributos que são relevantes para a decisão do problema (Nappi \& Souza, 2015).

Alguns métodos multicritérios são aplicáveis à avaliação de critérios de natureza qualitativa enquanto outros são adequados para critérios quantitativos. Mas há situações em que ambos os critérios, qualitativo e quantitativo, se apresentam juntos. Nesses casos, há um modelo denominado Analytic Hierarchic Process (AHP) que pode ser utilizado para a construção de uma estrutura de avaliação sistêmica integrando todos os critérios e permitindo a realização de testes de consistência (Chou, Hsub e Chen, 2008).

Neste trabalho, a aplicação do método AHP teve como objetivo a proposição de um sistema de medição de desempenho de abrigos temporários comunitários ou coletivos para a seleção eficaz e eficiente desses equipamentos. Para tanto, fez-se necessária a proposição de um modelo de decisão com base no sistema de medição resultante. Esse modelo pode auxiliar na localização de novos equipamentos, com dimensões e outras características compatíveis ao estabelecimento de abrigos para situações emergenciais, contemplando as necessidades da população em risco. Também pode proporcionar, aos arquitetos, parâmetros para o projeto de novos equipamentos, em especial os ginásios de esportes, salões paroquiais, escolas, etc., a fim de que funcionem temporariamente como abrigos emergenciais.

O trabalho que precedeu e embasou o sistema de medidas de desempenho para abrigos temporários desenvolvido, levantou 9 possíveis critérios - com seus respectivos subcritérios - e os aspectos relevantes a serem considerados em cada um deles. Esse levantamento conformou a etapa de definição dos elementos primários de avaliação e abrigos temporários comunitários ou coletivos, compondo critérios, subcritérios e seus respectivos indicadores de desempenho que, em seguida, foram hierarquizados e lapidados. Para tanto, foram convidados especialistas com experiência na área de estudo que apontaram quais aspectos levantados consideravam importantes para a constituição de abrigos temporários comunitários ou coletivos. Ao mesmo tempo em que foram lapidados os indicadores de desempenho, procedeu-se à síntese de prioridades 
da hierarquia desenvolvida a partir de matrizes de comparações paritárias. Os dados obtidos foram sintetizados e priorizados com auxílio de matemática computacional, especificamente do software Expert Choice. Concluída a etapa de estabelecimento de prioridades e avaliada a coerência global da hierarquia estabelecida, deu-se início ao desenvolvimento do modelo multicritério de decisão com base no sistema de medição de desempenho resultante, que recebeu o nome de ShelterPro.

A verificação da aplicabilidade do sistema de medição de desempenho se deu a partir da verificação da consistência das avaliações de especialistas. Já a verificação da aplicabilidade do modelo de decisão foi efetuada através da simulação de situações de emergência. Todos os especialistas participantes, num total de 24 , foram contatados por telefone e receberam, por e-mail, uma carta de apresentação da pesquisa. Os questionários foram elaborados no Google Forms, um aplicativo gratuito do Google, sendo disponibilizado aos participantes o link para o seu preenchimento online. Este estudo, portanto, está centrado nas preferências de especialistas em logística, bem como na revisão de documentos publicados por organizações de ajuda humanitária e de outras literaturas específicas.

\section{I APRESENTAÇÃO DO SOFTWARE SHELTERPRO}

O modelo multicritério para seleção de abrigos temporários comunitários ou coletivos, desenvolvido a partir do sistema de medição de desempenho supracitado, foi denominado ShelterPro. O programa foi desenvolvido na linguagem Java, que tem como principal característica a portabilidade, ou seja, o programa desenvolvido nesta tecnologia é independente de plataforma ou sistema operacional, portanto não há problemas de compatibilidade entre sistemas como Windows, Mac OS, Linux, etc. Outra vantagem da linguagem Java é o fato dela ser uma das mais utilizadas e difundidas atualmente, garantindo assim a facilidade e baixo custo de manutenção futura por muitos anos. Além da linguagem Java, o programa utiliza um banco de dados SQLite embarcado na aplicação, gerando acesso rápido e armazenamento seguro de dados. Por fim, para a parte de geolocalização e mapas foi utilizada a biblioteca do GoogleMaps que garante a localização de qualquer endereço mundial sem onerar na rapidez e tamanho do programa, visto que ele se utiliza da Internet para busca e carregamento dos mapas.

O cadastro de abrigos no software ShelterPro permite a composição de uma base de dados para consulta de possíveis equipamentos para a instituição de abrigos temporários (Figura 1). Ao serem cadastrados, os abrigos são automaticamente priorizados e seus dados podem ser acessados e editados conforme necessidade. 


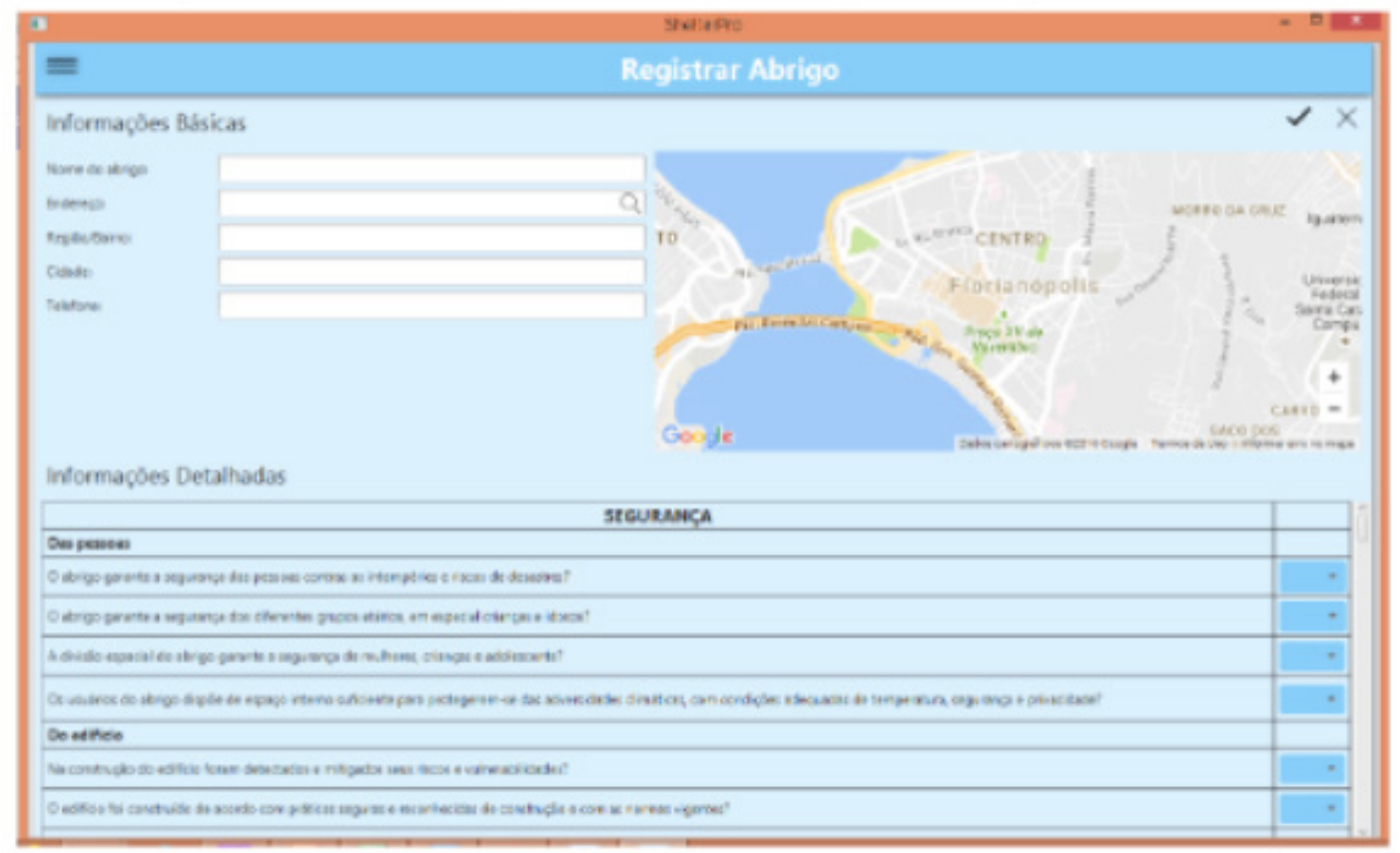

Figura 1: Tela oferecida pelo software para o registro de abrigos temporários

Cadastrados os equipamentos com potencial para constituírem abrigos temporários comunitários ou coletivos, é possível listá-los na forma de um ranking, cuja pontuação considera apenas aqueles indicadores que não estão diretamente relacionados a um evento específico. Diz-se isso em função do cadastro de um evento incluir informações sobre o número de pessoas afetadas (que possibilita o cálculo do número de famílias a serem abrigadas) e a sua localização. Quando há o cadastro de um evento, os abrigos são priorizados de tal maneira que todas as alternativas que atendem a esse parâmetro recebem a pontuação máxima, enquanto os demais recebem pesos proporcionais a sua capacidade. O critério de avaliação "Localização", no entanto, em seu subcritério "Distribuição Ótima", possui um indicador relacionado à distância máxima a ser percorrida pela população em risco até o abrigo temporário. Para que esse indicador seja considerado na priorização dos abrigos, é necessário que seja cadastrado um evento, bem como seja indicada a sua localização no mapa.

Na ocorrência de um evento, portanto, deve-se cadastrá-lo no software ShelterPro, informando dados como o nome, a data de ocorrência, o local, o raio de sua abrangência e a quantidade de pessoas atingidas, por exemplo. O software ShelterPro permite o registro e localiza o evento no mapa de acordo com o raio de abrangência informado. Concluído o registro do evento, o software apresenta a lista de abrigos cadastrados, iniciando por aquele que mais se adequa à situação apresentada. São considerados para a conformação deste ranking todos os critérios de avaliação cadastrados e seus respectivos pesos. Os abrigos cadastrados podem ser observados em um mapa, conforme mostra a Figura 2, facilitando a identificação de possíveis abrigos em áreas próximas a um evento. 


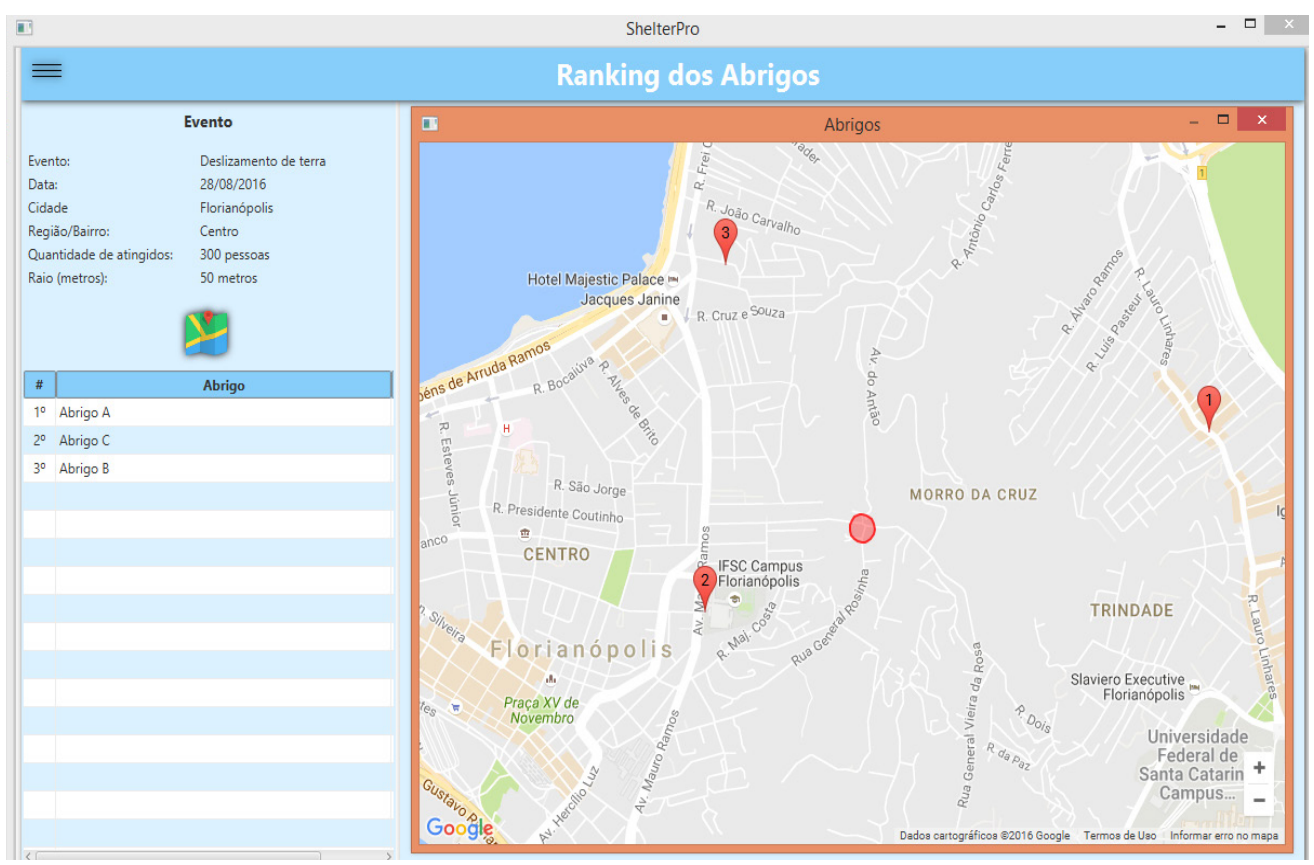

Figura 2: Tela oferecida pelo software com a indicação de um evento e com a localização de abrigos temporários cadastrados

Apresentado o ranking dos abrigos, o decisor deve verificar a capacidade ideal de cada um deles, a fim de saber quantos precisarão ser ativados. De maneira geral, um mesmo abrigo pode apresentar capacidades diferentes de acordo com o critério analisado. Sendo assim, torna-se necessário que o decisor opte por aqueles critérios quantitativos mais importantes para cada situação apresentada ou, ainda, que os adeque, otimizando aqueles aspectos que indicam uma capacidade menor.

É possível, ainda, obter-se um relatório em PDF com os dados cadastrados e com dados quantitativos calculados pelo software. Nesse relatório também são apontadas as possíveis melhorias para que o abrigo atinja um melhor desempenho. Isso se dá em função daqueles indicadores que foram avaliados como insuficientes ou ausentes no equipamento cadastrado. Ou seja, o relatório proporciona, aos decisores, parâmetros para a adequação desses equipamentos aos requisitos validados pelos especialistas consultados nesta pesquisa.

Faz-se importante destacar que o software ShelterPro foi desenvolvido para ser uma ferramenta fácil e intuitiva de apoio à decisão. Essa ferramenta multicritério tem como objetivo facilitar o trabalho de decisores em uma situação emergencial, propondo a ativação de determinados equipamentos para constituírem abrigos temporários comunitários ou coletivos, que se adequem, da melhor maneira possível, à situação apresentada e à população afetada. Ao mesmo tempo, esta ferramenta pode auxiliar na melhoria de equipamentos existentes, demonstrando aspectos que precisam ser observados e/ou melhorados. 


\section{I CONSIDERAÇÕES FINAIS}

A ocorrência de desastres naturais ou antrópicos, no Brasil e no mundo, vem evidenciando um tratamento logístico especial, designado de logística humanitária. Foram citados, neste trabalho, grandes desafios na implementação de processos logísticos sistematizados, especialmente aqueles relacionados à infraestrutura e localização de centrais de assistência e coordenação de processos, incluindo-se aqui os abrigos temporários.

O sistema de medição de desempenho para a avaliação de abrigos temporários apresentado neste trabalho pode auxiliar administradores de organizações de assistência humanitária na tomada de decisão, bem como na melhoria do desempenho logístico dessas organizações. O modelo multicritério de decisão originado desse sistema, além de permitir a análise individual de cada abrigo, constitui uma ferramenta multicritério de apoio à decisão para a seleção e localização de abrigos temporários. Essa ferramenta poderá ser útil no nível estratégico ou operacional das decisões logísticas.

No nível estratégico relaciona-se à acumulação de infraestruturas, neste caso especificamente de abrigos temporários, auxiliando na determinação da quantidade de abrigos necessária diante de possíveis cenários de desastres. Consequentemente, será possível apontar a necessidade de novas estruturas para a constituição de abrigos, bem como as modificações e adaptações necessárias para que essas estruturas atinjam um desempenho melhor. No nível operacional, o modelo multicritério de apoio à decisão poderá ser útil para a distribuição da população afetada entre os abrigos selecionados e instituídos.

Como sugestão para futuros trabalhos, seria interessante acrescentar ao software desenvolvido - o ShelterPro - parâmetros relacionados à distribuição ótima da população atingida e ao seu transporte, fazendo-se necessário, para tanto, o desenvolvimento de pesquisas e métodos de quantificação desses parâmetros.

\section{AGRADECIMENTOS}

O presente trabalho foi apresentado e publicado originalmente nos Anais do XXXI Congresso de Pesquisa e Ensino em Transportes - 2017 e foi realizado com apoio da Coordenação de Aperfeiçoamento de Pessoal de Nível Superior - Brasil (CAPES) Código de Financiamento 001.

\section{REFERÊNCIAS}

APTE, Aruna. Humanitarian Logistics: A New Field of Research and Action. 1. ed. Hanover: Now Publishers Inc., 2009. 102 p. v. 3. 
BRASIL. Ministério da Integração Nacional. Instrução Normativa n. 1, de 24 de agosto de 2012. Diário Oficial da União. Seção 1, n. 169, quinta-feira, 30 de agosto de 2012. Disponível em: <http:// www.cnm.org.br/portal/images/stories/Links/09062014_Instrucao_normativa_de_01_de_agosto_ de_2012.pdf>. Acesso em: 28 nov. 2013.

BRASIL. Ministério da Integração Nacional. Política Nacional de Defesa Civil. Brasília: Secretaria Nacional de Defesa Civil, 2007. 82 p. Disponível em: <http://www.ceped.ufsc.br/sites/default/files/ projetos/PoliticaNac._DF.pdf>. Acesso em: 10 set. 2013.

CAMPBELL, Ann Melissa; VANDENBUSSCHE, Dieter; HERMANN, William. Routing for Relief Efforts. Transportation Science, v. 42, n. 2, p. 127-145, mar. 2008. Disponível em: <http://dx.doi. org/10.1287/trsc.1070.0209. >. Acesso em: 03 abr. 2014.

CARDONA, Omar Darío et al. La Noción de Riesgo desde la Perspectiva de los Desastres: Marco Conceptual para su Gestión Integral. Manizales: BID/IDEA Programa de Indicadores Para La Gestión de Riesgos, Universidad Nacional de Colombia, 2003. 40 p. Disponível em: <http://idea.unalmzl.edu. co>. Acesso em: 03 set. 2014.

CHANDES, Jérôme; PACHÉ, Gilles. Investigating Humanitarian Logistics Issues: from Operations Management to Strategic Action. Journal of Manufacturing Technology Management, v. 21, n. 3, p. 320-340, 2010. Disponível em: <https://doi.org/10.1108/17410381011024313>. Acesso em: 21 set. 2014.

CHOU, Tsung-YuC; HSUB, Chia-Lun; CHEN, Mei-Chyi. A Fuzzy Multi-Criteria Decision Model for International Tourist Hotels Location Selection. International Journal of Hospitality Management, v. 27, n. 2, p. 293-301, jun. 2008. Disponível em: <https://doi.org/10.1016/j.ijhm.2007.07.029>. Acesso em: 18 set. 2012.

CONSELHO DA UNIÃO EUROPEIA. Declaração conjunta do Conselho e dos Representantes dos Governos dos Estados-Membros reunidos no Conselho, do Parlamento Europeu e da Comissão Europeia. O Consenso Europeu em Matéria de Ajuda Humanitária. Bruxelas: Jornal Oficial da União Europeia, 2007. 14 p. Disponível em: <https://europa.eu/european-union/sites/europaeu/files/ docs/body/joint_statement_and_common_approach_2012_pt.pdf>. Acesso em: 03 jan. 2014.

FERNANDES, Christiane Wenck Nogueira. O Enfoque da Logística Humanitária na Localização de uma Central de Inteligência e Suporte para Situações Emergenciais e no Desenvolvimento de uma Rede Dinâmica . 2010. 273 p. Tese (Doutorado em Engenharia de Produção) - Programa de Pós-Graduação em Engenharia de Produção, Universidade Federal de Santa Catarina, Florianópolis, 2010.

GRALLA, Erica; GOENTZEL, Jarrod; FINE, Charles. Assessing Trade-Offs among Multiple Objectives for Humanitarian Aid Delivery Using Expert Preferences. Production And Operations Management, v. 23, n. 6, p. 978-989, ago. 2013. Disponível em: <https://doi.org/10.1111/poms.12110>. Acesso em: 23 fev. 2014.

KAR, Bandana; HODGSON, Michael E. A GIS-Based Model to Determine Site Suitability of Emergency Evacuation Shelters. Transactions in GIS, v. 12, n. 2, p. 227-248, maio. 2008. Disponível em: <https://doi.org/10.1111/j.1467-9671.2008.01097.x>. Acesso em: 11 mar. 2012.

KOVÁCS, Gyöngyi; SPENS, Karen M. Humanitarian Logistics in Disaster Relief Operations. International Journal of Physical Distribution \& Logistics Management, v. 37, n. 2, p. 99-114, 2007. 
KOVÁCS, Gyöngyi; TATHAM, Peter. Humanitarian Logistics Performance in the Light of Gender. International Journal Of Productivity And Performance Management, v. 58, n. 2, p. 174-187, 2009. Disponível em: <https://doi.org/10.1108/17410400910928752>. Acesso em: 11 mar. 2014.

KUNZ, Nathan; REINER, Gerald; GOLD, Stefan. Investing in Disaster Management Capabilities versus Pre-Positioning Inventory: A New Approach to Disaster Preparedness. International Journal of Production Economics, v. 157, p. 261-272, nov. 2014. Disponível em: <https://doi. org/10.1016/j.ijpe.2013.11.002>. Acesso em: 22 mai. 2015.

NAPPI, Manuela Marques Lalane. Modelo Multicritério de Decisão com Foco na Logística Humanitária a partir de Medidas de Desempenho para Abrigos Temporários. 2016. 213 p. Tese (Doutorado em Arquitetura e Urbanismo) - Programa de Pós-Graduação em Arquitetura e Urbanismo, Universidade Federal de Santa Catarina, Florianópolis, 2016.

NAPPI, Manuela Marques Lalane; SOUZA, João Carlos. Disaster Management: Hierarchical Structuring Criteria for Selection and Location of Temporary Shelters. Natural Hazards, v. 75, n. 3, p. 2421-2436, set. 2014. Disponível em: <https://doi.org/10.1007/s11069-014-1437-4>. Acesso em: 22 mai. 2015.

NAPPI, Manuela Marques Lalane; SOUZA, João Carlos. Logística Humanitaria: Indicadores de Sostenabilidad para Alojamientos Temporales. Noticreto, Colômbia, n. 122, p. 12-15, dez. 2014.

NOGUEIRA, Christiane Wenck et al. A Logística Humanitária e Medidas de Desempenho: a Perspectiva da Cadeia de Assistência Humanitária. In: Congresso de Pesquisa e Ensino em Transportes, XXII, 2008, Fortaleza. Rio de Janeiro: Panorama Nacional da Pesquisa em Transportes, ANPET, 2008. p. 1-12. Disponível em: <https://www.researchgate.net/publication/265976620_A_ LOGISTICA_HUMANITARIA_E_MEDIDAS_DE_DESEMPENHO_A_PERSPECTIVA_DA_CADEIA_ DE_ASSISTENCIA_HUMANITARIA>. Acesso em: 10 set. 2012.

OLIVEIRA, Marcos de. Livro Texto do Projeto Gerenciamento de Desastres: Sistema de Comando de Operações. Florianópolis: Ministério da Integração Nacional, Secretaria Nacional de Defesa Civil, Universidade Federal de Santa Catarina, Centro Universitário de Estudos e Pesquisas Sobre Desastres, 2009. 74 p. Disponível em: <http://www.ceped.ufsc.br/wp-content/uploads/2014/09/Manualde-Gerenciamento-de-Desastres.pdf>. Acesso em: 05 jul. 2014.

OMIDVAR, Babak; BARADARAN-SHORAKA, Mohammad; NOJAVAN, Mehdi. Temporary Site Selection and Decision-Making Methods: A Case Study of Tehran, Iran. Disasters, v. 37, n. 3, p. 536-553, maio. 2013. Disponível em: <https://doi.org/10.1111/disa.12007>. Acesso em: 05 jul. 2014.

OVERSTREET, Robert E. et al. Research in Humanitarian Logistics. Journal of Humanitarian Logistics and Supply Chain Management, v. 1, n. 2, p. 114-131, jan. 2011. Disponível em: <https://doi. org/10.1108/20426741111158421>. Acesso em: 11 mar. 2014.

SAADATSERESHT, Mohammad; MANSOURIAN, Ali; ALEAI, Mohammad. Evacuation Planning Using Multiobjective Evolutionary Optimization Approach. European Journal of Operational Research, v. 198, n. 1, p. 305-314, out. 2009. Disponível em: <https://doi.org/10.1016/j. ejor.2008.07.032>. Acesso em: 11 mar. 2014.

THOMAS, Anisya. Humanitarian Logistics: Enabling Disaster Response. [S.I.]: The Fritz Institute, 
2007. 17 p. Disponível em: <http://www.fritzinstitute.org/pdfs/whitepaper/enablingdisasterresponse. pdf>. Acesso em: 20 dez. 2012.

TOMASINI, Rolando; WASSENHOVE, Luk Van. Humanitarian Logistic. New York: Palgrave Macmillan, 2009. $178 \mathrm{p}$.

UNICEF. Organización de las Naciones Unidas. Albergues en Escuela, ¿Cuándo?, ¿Cómo?, ¿Por Qué?. Ginebra: Fondo de Las Naciones Unidas Para La Infancia, 2008. 70 p. Disponível em: <http:// www.eird.org/cd/toolkit08/material//nicio/escuela_albergue/escuela-albergue.pdf>. Acesso em: 11 maio 2012.

VITORIANO, Begoña et al. A Multi-Criteria Optimization Model for Humanitarian Aid Distribution. Journal of Global Optimization, v. 51, n. 2, p. 189-208, out. 2011. Disponível em: <https://link.springer. com/article/10.1007/s10898-010-9603-z>. Acesso em: 20 dez. 2012.

WASSENHOVE, Luk Van. Blackett Memorial Lecturew Humanitarian aid logistics: supply chain management in high gear. Journal of the Operational Research Society, v. 57, n. 5, p. 475-489, 2006. Disponível em: <ttps://www.nulearningforlife.org/wp-content/uploads/2014/10/VanWassenhove_2005. pdf > Acesso em: 14 dez. 2015. 
SOBRE OS ORGANIZADORES

JOÃO DALLAMUTA: Professor assistente da Universidade Tecnológica Federal do Paraná (UTFPR). Graduação em Engenharia de Telecomunicações pela UFPR. MBA em Gestão pela FAE Business School, Mestre pela UEL. Trabalha com Gestão da Inovação, Empreendedorismo e Inteligência de Mercado.

RENNAN OTAVIO KANASHIRO - Professor na Universidade Norte do Paraná (Unopar). Graduação e Mestrado em Engenharia Mecânica pela UTFPR. Trabalha com temas: Identificação de Sistemas, Problema Inverso e Otimização. 
Agência Brasileira do ISBN

ISBN 978-85-7247-352-1

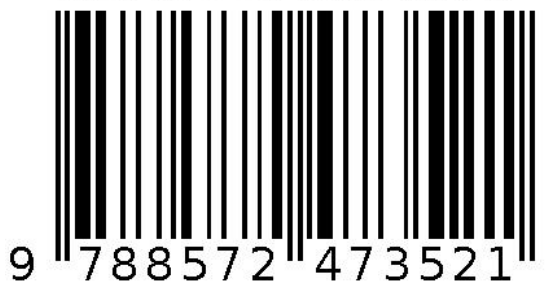

